\title{
Drilling, Completion, Stimulation, and Testing of BDM/CNGD Well 3997, Lee District, Calhoun County, West Virginia
}

\author{
Final Report
}

\author{
William K. Overbey, Jr. \\ Richard S. Carden \\ S. Phillip Salamy \\ C. David Locke \\ Harry R. Johnson
}

Work Performed Under Contract No.: DE-AC21-89MC25115

\author{
For \\ U.S. Department of Energy \\ Office of Fossil Energy \\ Morgantown Energy Technology Center \\ P.O. Box 880 \\ Morgantown, West Virginia 26507-0880 \\ By
BDM Engineering Services Company
7915 Jones Branch Drive
McLean, Virginia 22102
}

March 1992 


\begin{abstract}
This report discusses the detailed field operations in drilling, casing, completing, and stimulating the Hunter Bennett \# 3997 well located in Lee District, Calhoun County West Virginia. The project was designed and managed by BDM in cooperation with CNG Development Company. The well was spudded on November 9, 1990, and drilling was completed on December 14, 1990. The well was drilled on an average asmuth of 312 degrees with a total horizontal displacement of 2459 feet. The well was turned to a 90 degree inclination from the vertical over a measured course length of 1216 feet. Approximately 1381 feet of the well had an inclination higher than 86 degrees, while 2179 feet had an inclination greater than 62 degrees. The well was partitioned into five zones for stimulation purposes. Each zone is a little more than 300 feet long. The well was stimulated with ritrogen gas in zones one and two. Early production results are encouraging. The BDM/CNGD horizontal well averaged 147 mcfd over the first week of production and, in week five, began to produce oil at a rate of about $2 \mathrm{bbl} / \mathrm{day}$.
\end{abstract}


FINAL REPORT OF

DRILLING, COMPLETION, STIMULATION, AND TESTING OF BDM/CNGD WELL \#3997

LEE DISTRICT, CALHOUN COUNTY,

WEST VIRGINIA

\section{TABLE OF CONTENTS}

Page

1.0 EXECUTIVE SUMMARY

2.0 INTRODUCTION

3.0 LEASE ACQUISITION AND LOCATION DEVELOPMENT

4.0 DRILLING PLAN SUMMARY

5.0 DRILLING OPERATIONS

5.1 Vertical Hole To $3253^{\prime}$

5.2 Build Section

5.3 Horizontal Section

6.0 LOGGING OPERATIONS

6.1 Mud Logging

6.2 Shallow Hole and Free Fall Logging

6.3 Horizontal Section Logging

7.0 CASING OPERATIONS

8.0 MOTOR PERFORMANCE AND BOTTOM HOLE ASSEMBLIES

9.0 STEERING TOOL OPERATIONS

10.0 DISCUSSION AND ANALYSIS OF DRILLING OPERATIONS 
11.1 Introduction 26

11.2 Casing Design 26

11.3 Inflation of Casing Packers 29

11.4 Cementing 30

$\begin{array}{ll}12.0 \text { STIMULATION OPERATIONS } & 31\end{array}$

12.1 Introduction 31

12.2 Stimulation Plan 31

12.2.1 Stimulation Fluid, Rate and Pressure Design 35

12.3 Stimulation of Zone \#1 37

12.4 Stimulation of Zone \#2 40

12.5 Analysis of Stimulation Operations 42

13.0 WELL TESTING OPERATIONS 42

13.1 Production Testing 45

14.0 ANALYSIS OF COMPLETION, STIMULATION, AND TESTING 48

15.0 WELL COST ANALYSIS $\quad 49$

16.0 SUMMARY AND CONC!-USIONS 49

17.0 REFERENCES 53

$\begin{array}{ll}18.0 & \text { APPENDICES } \\ & 54\end{array}$ 
LIST OF ILLUSTRATIONS

FIGURE

Page

Figure 3.1 Relationship of the Planned Wellbore

Trajectory to Structure on Top on the Fifth Interval

Figure 5.1

Planned vs. Actual Drilling Time

Figure 5.2

Plan View of Well Trajectory

Figure 5.3

Vertical View of Planned vs. Actual Horizontal Well

Figure 6.1

Location of Gas Shows As a Function of Measured Depth Along the Inclined and Horizontal Wellbore

Figure 11.1 Wellbore Configuration of BDM/CNGD HB\#3997

Figure 11.2 Horizontal Well Profile and Gas Shows

Figure 11.3 FO Cementer Isolation Packer with Sleeve Positioner and Circulation Valve

Figure 12.1 Plot of Pressure Versus Time for Zone \#1 Frac

Figure 12.2 Plot of Pressure Versus Time for Zone \#2. Frac

Figure 13.1 Plot of Pressure Pulse Test on Zone \#1

Figure 13.2 Seven Day Pressure Buildup Curve for Zone \#2 


\section{LIST OF TABLES}

Page

Table 5.1 Survey Data for Hunter Bennett \#3997

Table 12.1 Zone Configuration and Production Analysis of Horizontal Well BDM/CNGD HB\#3997

Table 12.2 Completion Configuration and Stimulations Planned

Table 13.1 Zone Testing After Stimulation of HB \#3997

Table 15.1 Cost Data Analysis of Hunter Bennett \#3997 


\subsection{EXECUTIVE SUMMARY}

The Consolidated Natural Gas Development Company Hunter Bennett \#3997 well was spudded on November 9,1990, and drilling was completed at a total measured depth of 5013 feet on December 14th, 1990. The well was drilled on an average azimuth of $312^{\circ}$, with a total horizontal displacement of 2459 feet. The well was turned to a 90 degree inclination over a measured course length of 1216 feet. This included a tangent section 175 feet long when the wellbore had reached an inclination of 46 degrees. Approximately 1381 feet of the well had an inclination higher than 86 degrees (horizontal), while 2179 feet of the well had an inclination greater than $6 ?$ degrees.

The inclined welltiore encountered 27 gas shows after the inclination was greater than 60 degrees. Most of the shows were in the 20 to $30 \mathrm{mcf} /$ day range, however, the largest show had a calculated flow rate of $275 \mathrm{mcf} / \mathrm{day}$.

A $121 / 4$ " hole was drilled to within 75 feet of the kickoff point and 9 5/8" casing set. Directional drilling was initiated at 2160 feet. A bent housing motor set at 1.75 degrees was projected to build angle at $9 \% 100^{\prime}$ but built at $11 /{ }^{\circ} 100^{\prime}$. This made a tangent section of 175 feet necessary to hit the target interval at the right position. The second bent housing motor also built at 11 to 12 degrees/100 feet requiring some maneuvering of the drilling direction to arrive within the target interval when the inclination had reached 90 degrees. It required 108 hours of drilling over an 8 day period to turn the well to 90 degrees. The average rate of penetration was 11 feet per hour during angle building.

Steering tool operations were quite acceptable on this well. Eventhough, three steering tool failures caused delays in drilling operations. The failures that occurred were two wire line connector failures and one probe failure, but the impact to overall drilling operations was not as severe as it has been on previous wells.

Logging operations on the well suffered a delay due to failure of the density logging tool, but otherwise, they were very smooth. Both free fall and drillstring logging operations were completed within 29 hours. Prior 
wells required 48 or more hours to complete logging. A detailed study of the logs and comparison with the mud log is required to establish the utility and economics of the logs run and their desirability in future horizontal drilling operations. However, the video log was not run to reduce costs.

Directional drilling operations on this well were conducted almost entirely in siltstones or interbedded siltstones and shales which slowed the rate of penetration considerably. However, the well was completed on schedule within 25 working days as planned.

Six (6) external casing packers (ECP's) and eleven port collars (PC's) were installed with the 5-1/2", K-55, 17.5lb/ft casing which was cemented through the inclined section to prevent any future water problems in the producing zones. The ECP's and PC's were used to create five separate zones averaging about 360 feet in length.

Gas shows were encountered in four out of five zones and the zones were rank ordered based on natural open flow production. An analysis of reservoir properties, budget constraints and technical risk concluded that Zones 1 and 2 should be stimulated and evaluated before any additional work was conducted on the well under the DOE contract.

BDMESC stimulated the two zones with 1,500 mcf of nitrogen gas and then conducted pressure build-up tests on Zone \#2 and open flow potential tests on 3,4 , and 5 . After eight hours open flow testing the well was producing $280 \mathrm{mcfd}$ natural gas and 2 bbls/day of oil.

When placed in production three months after testing, the well averaged $147 \mathrm{mcfd}$, against 52 psig line pressure, for the first seven days of production. The well began producing oil during the fifth week and is currently producing $2 \mathrm{bbl} / \mathrm{day}$ of oil along with the gas.

\subsection{INTRODUCTION}

The Department of Energy (DOE) has for a number of years been conducting a program to test emerging technology as methods of improving or enhancing the recovery of natural gas resources at more 
economic rates. The Morgantown Energy Technology Center has for more than twenty years, been exploring the concept of horizontal drilling as an advanced technology concept designed to improve gas and oil recovery efficiency.

The first successful air-drilled horizontal well was designed and drilled by BDM International for DOE in 1986 (Reference 1) in Wayne County, West Virginia, in conjunction with a small industry partner. BDM Engineering Services Company (BDMESC), a subsidiary of BDM International, was awarded a second competitive contract in 1989 to continue to explore the economics of drilling, completing and producing horizontal wells in tight, resource rich, Devonian shales of the Appalachian basin.

BDMESC proposed a cost sharing agreement with CNG Development Company (CNGD) whereby they provide leases for drilling, share in the well costs, and serve as operator for drilling and production operations. BDMESC conducted geologic studies, selected the drill sites to be approved by CNGD and DOE, designed the well, and supervised drilling and completion operations.

\subsection{LEASE ACQUISITION AND LOCATION DEVELOPMENT}

The site acquired for drilling was one of three areas examined in considerable detail so that a recommendation to drill could be made. One area was located in Boone County, while two other areas were located in Calhoun County. The Sandridge area was selected by the METC project office as the area meoting project requirements. The specific site was selected from among three potential sites recommended to DOE in a topical report "Selection of Geographic Area and Specific Site for Drilling a Horizontal Well in Cooperation with CNG Development Company".

The location required the acquisition of three leases in a production unit. Two of the leases were owned by CNGD while the third was owned by Prime Energy. Drilling of the well was delayed by four months while problems with the drilling unit were solved. The one hundred sixty five (165) acre drilling unit is shown in figure 3.1. Structure contours on top of the target interval and the orientation of the projected wellbore 


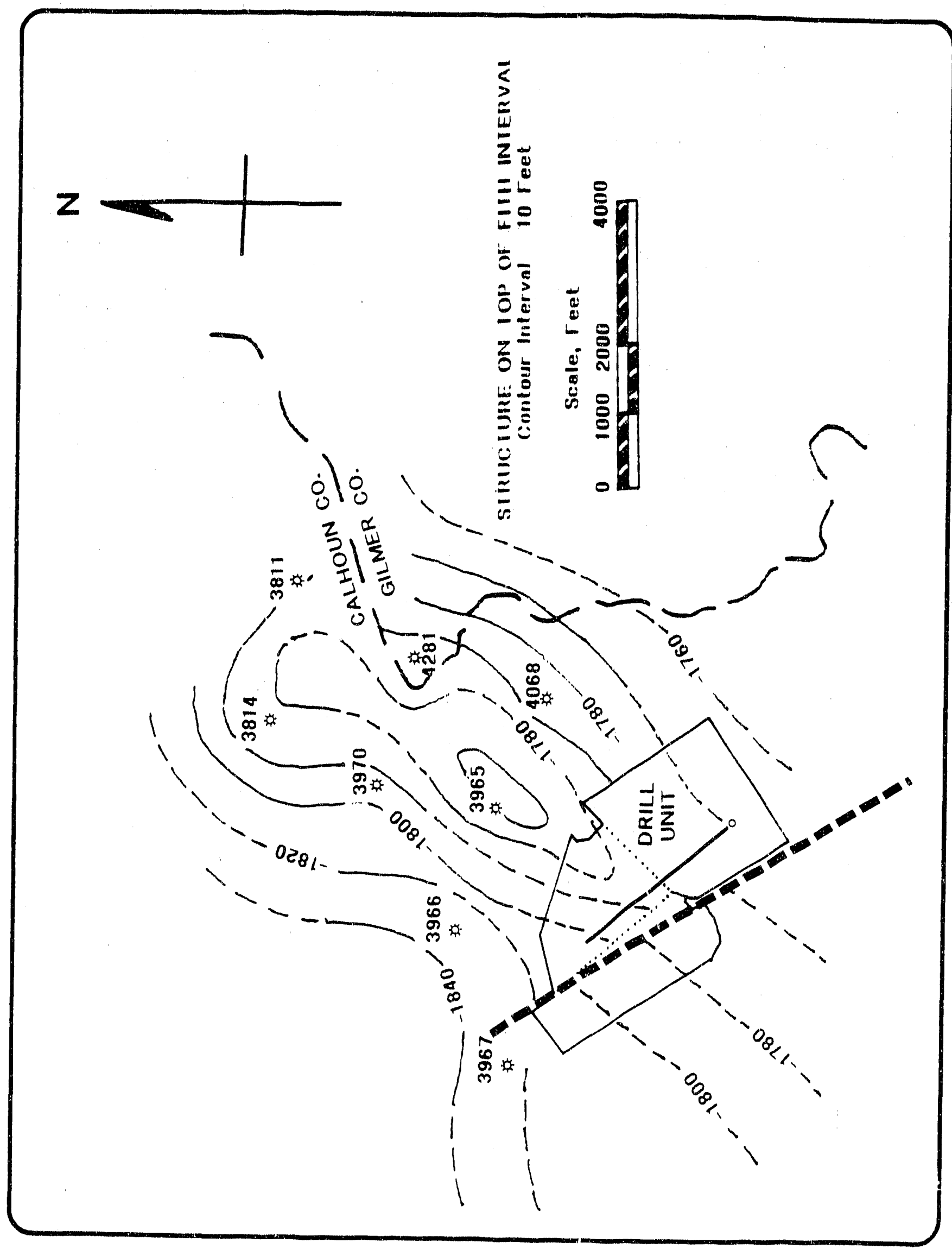

Fig. 3.1 Relationship of the Planned Wellbore Trajectory to Structure 
trajectory is also depicted. Problems encountered included development of a pooling agreement for each of the three leases, and selection of equal fifty five (55) acre sections of the three leases for the drilling unit, and obtaining agreement from joint venture partners on one of the leases.

The location presented in Figure 3.1 was designed to cross a production fairway which appeared to be oriented $N 12^{\circ} \mathrm{E}$ and was determined by three strong producing wells in the area $(3965,3814$, and 3811 ) which have projected reserves of 295 to $450 \mathrm{mmcf}$ of gas. The location was oriented $\mathrm{N} 40^{\circ} \mathrm{W}$ to allow crossing the fairway at nearly right angles $\left(60^{\circ}\right)$. Based on examination of shallower structure and analysis of hydraulic fracturing data, a strike slip fault system was projected to be crossing the area in the near vicinity of the planned well as shown in Figure 3.1, thus the projected area was believed to be one of potential significant faulting and fracturing to aid in development of production.

\subsection{DRILLING PLAN SUMMARY}

The drilling plan for the fiunter Bennett \#1-3997 called for drilling a 17 1/2" hole to approximately $250^{\prime}$ and running $133 / 8^{\prime \prime}$ casing. A 12 $1 / 4^{\prime \prime}$ hole would be drilled to $50^{\prime}$ below the base of the Big Injun formation estimated to be 2110'. A string of $95.8^{n}$ casing would be run to isolate water bearing formations and would be drilled out with an 8 3/4" bit. Approximately 50 to 60 feet of hole would be drilled to the kick off point so the steering tool would be in the open hole.

The well would be kicked off and build inclination at a constant rate to the target interval. The target interval was the 5th shale at a true vertical depth of $2846^{\prime}$ to $2911^{\prime}$ (65' thick). Being horizontal anywhere within the target interval would be acceptable. The drilling prognosis called for being $88^{\circ}$ at TVD of $2896^{\prime}$ with a required build rate of $7.84^{\circ} / 100^{\prime}$. Then, 2000' of horizontal section would be drilled keeping the wellbore within the target interval. Holding or mild rotary building and dropping assemblies would be used to drill the horizontal section and keep the wellbore within the target interval. 
The planned azimuth of the well was $320^{\circ}$; however, the large lease allowed for considerable drift in the horizontal section. The azimuth of the horizontal section would not be a major concern.

After reaching TD, the well would be logged with free fall and drill pipe conveyed open hole logs and a video camera. A string ci 5 1/2" casing would be run with external packers and port collars to isolate zones.

\subsection{DRILLING OPERATIONS}

Drilling operations were conducted at the site between November 9 , 1990 and December 11, 1990. Operations were suspended between November 14, 1990 and November 23, 1990 for the Thanksgiving holidays. Twenty four days were spent on location, which was the same as the estimated time of drilling. A plot of the actual and planned depth versus days can be seen in Figure 5.1.

The vertical portion of the well to the kick off point took two days less time to drill than had been anticipated because no problems were encountered. Total time was five days. The build section required eight days to drill compared to a planned six days. Penetration rates were lower than anticipated and a reaming run was required. The horizontal section was planned for seven days and actually took eight days to complete. Drilling time was increased because strong formation tendencies necessitated more frequent surveying and changes in the rotary assemblies. Logging and running casing required three days of rig time and four days had been estimated. The video log had been cancelled due to budget constraints. Drilling from the kick off point to the end of the drilling operation took two days longer than had been anticipated.

\subsection{Vertical Hole to $2165^{\prime}$}

The vertical portion of the well to the kick off point was drilled on a footage basis by Burdette Drilling. The well was spudded at 11:00 am on November 9, 1990. Twenty inch conductor casing was set at five feet below ground level. A $171 / 2^{n}$ surface hcle was drilled to $279^{\prime}$ through the fresh water zones. 


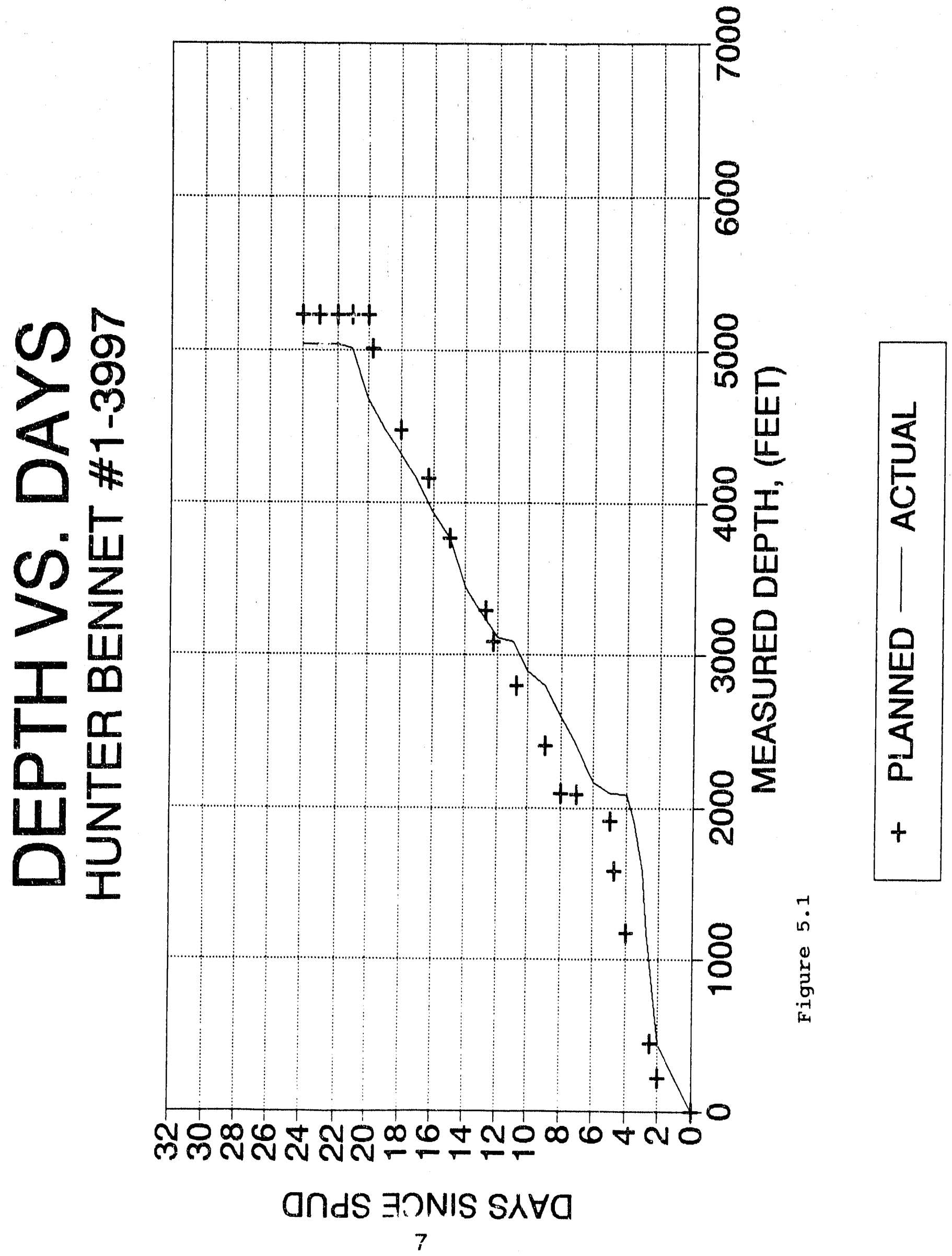


Six joints of $133 / 8^{n}, 37 \# / \mathrm{ft}$, A500 casing was run and set at $258.50^{\prime} \mathrm{GL}$ to isolate fresh water zones as required by the state of West Virginia. The casing was cemented to the surface with 204 sacks of Class "A" containing $2 \% \mathrm{CaCl}_{2}$. The cement was mixed at $15.6 \mathrm{ppg}$ with a yield of $1.18 \mathrm{ft} 3 /$ sack. Good cement was circulated to the surface.

The $121 / 4^{\prime \prime}$ intermediate hole was drilled to a depth of 2091' which was five feet below the base of the Big Injun formation. No unanticipated problems were encountered.

A string of $95 / 8^{\prime \prime}, 37 \# / f t, M 44$, ST\&C casing was run and set at 2096' GL. The casing was cemented with 540 sacks of leading cement containing $2 \% \mathrm{Gel}, 3 \% \mathrm{CaCl}_{2}$ and 0.25 \#/sack cell flake followed by 100 sacks of tailing cement with $3 \% \mathrm{CaCl}_{2}$ and $0.25 \#$ /sack cell flake. The lead cement was mixed at $14.8 \mathrm{ppg}$ and the tail cement was mixed at 15.7 ppg. Thirty barrels of good cement were circulated to the surface. The casing tally can be found in Appendix A. At this time, the rig was shut down until after Thanksgiving.

Operations resumed at 7:00 am on November 23, 1990. The casing shoe was drilled out and the hole dried up. Drilling continued with an $83 / 4^{\prime \prime}$ bit to the kick off point of $2165^{\prime}$.

\subsection{Build Section from $2165^{\prime}$ to $3280^{\prime}$}

The bottom-hole assembly was pulled from the hole and the drill collars were laid down. A Baker adjustable bent housing motor was picked up and the bend set at 2 degrees. The Baker motors arrived on location with an $85 / 8^{\prime \prime}$ stabilizer below the bend. The plan was to run the motors without a stabilizer but the stabilizers could not be removed in the field. With the stabilizer on the motor, the build rate would be less predictable and it would not be possible to drill and $81 / 2^{\prime \prime}$ hole. If a gauge problem is encountered, the build section will have to be reamed so that another $83 / 4^{\prime \prime}$ bit can be run rather than reducing hole size to $81 / 2$ ".

Two non-magnetic drill collars were placed on top of the motor and the bottom-hole assembly was tripped in the hole. The bottom- 
hole assembly data in Appendix B. Three 14/32" jets had been placed in the bit to increase steering tool life.

Well Nav's steering tool was run through a side entry sub to orient the motor. The first motor run drilled from 2165' to 2598'. The average penetration rate was 10.3 feet per hour. Initially, the motor was run with one $1050 \mathrm{scfm}$ compressor. Two compressors made the motor run much too rough and the tool face orientation would jump around. At a depth of approximately 4200', the second compressor was put back on the hole because the penetration rate had slowed.

The motor was building inclination at an average rate of $10.1^{\circ} / 100^{\circ}$. A short tangent section was planned at 55 to $60^{\circ}$ to compensate for the higher build rates. Unfortunately, the motor quit drilling at a measured depth of 2598'. The motor could not be made to drill and it would stick on bottom. The hole was not cleaning properly. The estimated inclination at this depth was $46^{\circ}$.

Examination of the bottom-hole assembly indicated that the problem was caused by hole cleaning. The penetration rate had been very low for the last few hours of the motor run (2' per hour). Not enough cuttings were being generated to absorb the oil being injected into the drill pipe for motor lubrication and the hole was wet. A rotary assembly would have to be run to clean and dry out the well. Therefore, it was decided to drill the tangent section at this point.

Bottom-hole assembly \#2 (30' building assembly) was run to ream the build curve and drill the tangent section. The well reamed easily and the assembly drilled from 2598' to $2773^{\prime}$. The assembly dropped inclination at a rate of $0.45^{\circ} / 100$. The average penetration rate for the rotary assembly was 24.1 feet per hour.

The end of the tangent section was based upon finishing the build section with an average build rate of $9.5^{\circ} / 100^{\prime}$. Based upon the observed build rate of the first motor run, the bend in the second motor should be set at 1.75 degrees to achieve a build rate of $9.5 \% 100$. Aiso, a softer formation bit was run to improve penetration rates. Three 16/32" jets were placed in the bit. The pressure while drilling with two 
compressors was 370 to 390 psi which is too high for continued operation of the compressor system. The large jets were placed in the bit to bring the pressure down to 300 psi.

The second motor run (bottom-hole assembly \#3) drilled from $2773^{\prime}$ to 3117 '. It was pulled because it quit drilling. The oil injection rate was limited to approximately one gal per hour for this motor run because of the previously experienced hole cleaning problems. The reduction in oil did not hurt the motor. The average penetration rate for the notor run was 8.65 feet per hour.

The build rate for the second motor run turned out to be greater than that of the first motor run. The indicated build rate was over $12^{\circ} / 100^{\prime}$. At that rate, the well would be horizontal above the target interval so the motor was turned first left and then right to adjust the TVD. Unfortunately, the motor dropped inclination slightly while being turned to the left and the well never did get back to an azimuth of $320^{\circ}$ because more time was spent building inclination rather than turning the well to the right. More Jetails can be found in the Daily Log of Operations in Appendix $\mathrm{H}$.

At 3117', the motor quit drilling. The assembly was pulled from the hole and examined. The bit was $1 / 4^{\text {n }}$ under gauge and the stabilizer on the motor was taking the bit weight.

Bottom-hole assembly \#4 was run to ream the hole out since drilling could not continue with an $81 / 2^{n}$ bit. This time the wellbore reamed hard. The bit stopped reaming at $3081^{\prime}$ and acted like it was trying to sidetrack the hole. With considerable effort, the directional driller was able to get the bit into the old hole. Reaming continued to bottom but there was a tight spot at $3081^{\prime}$ for a couple trips after the reaming run.

The third motor run (bottom-hole assembly \#5) finished the build section. The third motor run used the same motor as used on the second run but with a 1.75 degree bend. The motor drilled from $3117^{\prime}$ to $3280^{\prime}$ where the inclination was estimated to be $88^{\circ}$ on bottom. 
The average penetration rate for the motor was 13.6 feet per hour. The average build rate for this run was $10.3 \% 100^{\prime}$ even thought the tool face was positioned $45^{\circ}$ right for most of the motor run. When the motor was pulled, it was estimated that the inclination on bottom was $88^{\circ}$ and the azimuth was $317^{\circ}$. The last survey at $3231^{\prime}$ showed an inclination of $83.6^{\circ}$ and an azimuth of $312^{\circ}$.

\subsection{Horizontal Section from $3280^{\prime}$ to $5013^{\prime}$}

The horizontal section was drilled from $3280^{\prime}$ to $5013^{\prime}$ with bottom-hole assembly \#'s 6 thru 10 . The final motor run only required slight reaming because the hole size was reduced to $81 / 2^{n}$. The first rotary assembly run (bottom-hole assembly \#6) was similar to bottomhole assembly \#2 which had been used to drill the tangent section. That assembly dropped inclination at a rate of $0.45 \% 100$; therefore, bottomhole assembly \#6 was modified slightly to keep it from dropping as much inclination. The button cutters and an eight foot pony collar was added between the reamers. It was assumed that the assembly would still drop slightly.

The first survey at $3326^{\prime}$ showed an inclination of $89.25^{\circ}$ and should have been an indication of the starting point for this assembly. The second survey taken at $3420^{\prime}$ had an inclination of $90.25^{\circ}$. The assembly had built $1.06 \% 100^{\prime}$ which was unexpected and could have been attributed to follow thru. Another survey was taken at 3514' after drilling three more joints $\left(90^{\prime}\right)$. This time the inclination was $95^{\circ}$ and the assembly had build 5.05\%100'. The survey instrument had been changed from a 90 degree compass to a 120 degree compass on this survey so we were not sure that all the inclination change was due to the bottom-hole assembly. Some of the change could have been due to the difference in the compass units but not all of it. The assembly was obviously building much too fast. With the survey instrument 30 feet off bottom, the wellbore could easily be inclined $96.5^{\circ}$ of bottom.

Also, the projected azimuth at the end of the motor run was $317^{\circ}$. The tool face had been positioned at $45^{\circ}$ right for the last part of the motor run and the surveys with the steering tool showed right hand turn for the last few surveys. The first singleshot survey after the motor 
run indicated that the well had turned left to $306^{\circ}$. It is highly unlikely the well turned to the left while drilling with the motor. At no time was any left hand torque put in the drill string while drilling with the motor. All of the turn would have had to occur in the 46' drilled by the rotary assembly which would yield a dogleg severity of over 20\%1100'. The azimuth difference is probably due to using two types of survey instrument, a singleshot versus a steering tool. As the azimuth direction was not critical in the target interval, no remedial action was contemplated to correct the azimuth. A multishot survey was planned at the end of the horizontal to check the accuracy of the survey data.

Since the wellkore was near the top of the target interval, dropping assembly would have to be run. Bottom-hole assembly \#7 was run to drop inclination. It is the same assembly that was run in the Hardy HW\#1 well that dropped at an average rate of $2.5 \% 100$. A survey was taken at $3727^{\prime}$ and showed the inclination to be $95.5^{\circ}$ which was higher than expected. However, if the inclination had been over $96^{\circ}$ on bottom, the assembly was starting to drop. Another three joints (93') were drilled and a survey run at $3820^{\prime}$. The inclination was $95.75^{\circ}$ which showed that the short pendulum was still building inclination. The rotary assemblies were going to have to fight some strong formation tendencies.

The wellbore was now above the target interval top of $2846^{\prime}$ TVD so the inclination would have to be dropped back down to less than $85^{\circ}$ to drill through the target interval at 2911' TVD. A 30 foot pendulum assembly was run to drop the inclination. Bottom-ho, 3 assembly \#8 was run in the hole at 3846'. The first survey was taken at 3927' and showed a drop rate of $2.10^{\circ} / 100^{\prime}$. The second survey taken at $4136^{\prime}$ showed a drop rate of $2.39 \% 100^{\prime}$ which is low for a 30 foot pendulum in a horizontal well. Drilling continued until the projected survey on bottom was $84^{\circ}$ which was a depth of 4335'. The wellbore should now be back within the target interval. A little less than 600 feet of the wellbore was above the target TVD of $2846^{\prime}$.

Next, a short packed hole assembly was run to try and maintain an inclination of $84^{\circ}$ through the target interval. Bottom-hole assembly \#9 was run in the hole and drilled to $4665^{\prime}$. This assembly was more stiff than the previous assemblies and had to be reamed to bottom from 
$3500^{\prime}$ requiring twelve hours rig time. The first survey was taken at $4410^{\prime}$ to get a starting point for evaluating the assembly. The inclination was $84^{\circ}$ which was as predicted. The next survey at $4534^{\prime}$ was $85^{\circ}$ which indicated that the assembly was building $0.81 \% 100$. It was assumed that the packed assembly would drop slightly. With the packed assembly building inclination, the wellbore would not drop all the way through the horizontal interval and a dropping assembly would have to be run to finish the well. Bottom-hole assembly \#9 was pulled from the hole at $4665^{\prime}$ when it would no longer fall into the hole. An assembly that would drop close to $2 \% 100^{\prime}$ would be required to drill through the target TVD of $2911^{\prime}$.

In order to reduce the amount of bottom-hole assembly drag, a slick assembly was run to finish drilling the horizontal section. It was assumed that the assembly would drop inclination a little slower than the 30 foot pendulum and would produce less hole drag. Bottom-hole assembly \#10 was run in the hole at $4665^{\prime}$ and drilled to $5013^{\prime}$ where it would no longer fall into the well. Drag calculations suggested that casing could not be run past this depth so drilling was terminated. No surveys were taken in this interval since a multishot survey was to be run at the end of the well.

While circulating to clean the hole after reaching TD, the drill string twisted off on the 15th drill collar down. The failure was in a box. Fishing tools were ordered and the fish was retrieved with an overshot. The top of the fish was at $40^{\circ}$ and there was no problem running the overshot or latching on to the fish. After retrieving the fish, a multishot survey was to be run. Unfortunately, Well Nav did not have the right equipment on location and the multishot survey had to be cancelled. The necessary inclination angle unit had been sent back to Casper, because Well Nav did not tell the directional drilling contractor that he should keep the angle unit on location.

Table 5.1 is a record of the survey data. Note that the last two surveys at $4665^{\prime}$ and $5013^{\prime}$ are estimated surveys. A plot of the planned versus actual wellbore path can be found in Figures 5.2 and 5.3. 


\section{Table 5.1 - Survey Data for Bennett \#3997}

BENNET $1-3997$ DOE/BDMESC/CNGD

HORIZONTAL WELL

PAGE

\begin{tabular}{|c|c|c|c|c|c|c|c|c|}
\hline MEASURED & DRIFT & DRIFT & COURSE & TRUE & $R E C T A$ & $N G \cup L A R$ & VERTICAL & DOGLEG \\
\hline DEPTH & ANOLE & AZIMUTH & LENGTH & VERTICAL & $C O O R O$ & INATES & SECTION & SEVERITY \\
\hline FEET & DEGREES & DEGREES & FEET & UEPTH & NORTH & EAST & FEET & DEQ $/ 100^{\prime}$ \\
\hline 0.00 & 0.00 & 249.00 & 0.00 & 0.00 & 0.00 & 0.00 & 0.00 & 0.00 \\
\hline 1000.00 & 0.00 & 249.00 & 1000.00 & 1000.00 & -0.00 & -0.00 & 0.00 & 0.00 \\
\hline 2000.00 & 0.00 & 249.00 & 1000.00 & 2000.00 & -0.00 & -0.00 & 0.00 & 0.00 \\
\hline 2160.00 & 2.00 & 249.00 & 160.00 & 2159.97 & -1.00 & -2.61 & 0.91 & 1.25 \\
\hline 2222.00 & 5.40 & 313.00 & 62.00 & 2221.83 & -0.28 & .6 .33 & 3.86 & 7.85 \\
\hline 2284.00 & 11.80 & 317.00 & 62.00 & 2283.10 & 6.27 & -12.88 & 13.09 & 10.36 \\
\hline 2346.00 & 18.50 & 315.00 & 62.00 & 2342.91 & 17.92 & -24.13 & 29.24 & 10.84 \\
\hline 2408.00 & 26.00 & 313.00 & 62.00 & 2400.25 & 34.22 & -41.01 & 52.57 & 12.16 \\
\hline 2439.00 & 29.60 & 313.00 & 31.00 & 2427.67 & 44.08 & -51.58 & 66.92 & 11.61 \\
\hline 2470.00 & 33.00 & 314.00 & 31.00 & 2454.16 & 55.16 & .63 .26 & 82.92 & 11.09 \\
\hline 2532.00 & 39.60 & 317.00 & 62.00 & 2504.10 & 81.32 & -88.97 & 119.49 & 11.02 \\
\hline 2625.00 & 46.25 & 327.00 & 93.00 & 2572.16 & 131.14 & -127.89 & 182.67 & 10.22 \\
\hline 2687.00 & 46.00 & 325.00 & 62.00 & 2615.13 & 168.19 & -152.88 & 227.11 & 2.36 \\
\hline 2737.00 & 45.75 & 325.00 & 50.00 & 2649.94 & 197.59 & -173.47 & 2.62 .87 & 0.50 \\
\hline 2779.00 & 46.50 & 322.00 & 42.00 & 2679.05 & 221.93 & -191.48 & 293.08 & 5.45 \\
\hline 2842.00 & 52.40 & 324.00 & 63.00 & 2719.99 & 260.14 & -220.27 & 340.87 & 9.67 \\
\hline 2904.00 & 60.10 & 325.00 & 62.00 & 2754.41 & 302.08 & -250.18 & 392.22 & 12.49 \\
\hline 2966.00 & 66.40 & 323.00 & 62.00 & 2782.30 & 346.84 & -282.71 & 447.42 & 10.56 \\
\hline 2997.00 & 64.60 & 320.00 & 31.00 & 2795.15 & 368.92 & -300.27 & 475.61 & 10.55 \\
\hline 3028.00 & 63.00 & 317.00 & 31.00 & 2808.84 & 389.74 & -318.69 & 503.41 & 10.10 \\
\hline 3055.00 & 65.50 & 314.00 & 27.00 & 2820.57 & 407.09 & -335.74 & 527.65 & 13.63 \\
\hline 3091.00 & 68.70 & 310.00 & 36.00 & 2834.58 & 429.27 & -360.37 & 560.48 & 13.55 \\
\hline 3153.00 & 75.40 & 308.00 & 62.00 & 2853.67 & 466.37 & .406 .18 & 618.34 & 11.23 \\
\hline 3185.00 & 79.00 & 309.00 & 32.00 & 2860.76 & 485.79 & -430.60 & 648.92 & 11.66 \\
\hline 3216.00 & 81.90 & 310.00 & 31.00 & 2865.90 & 505.23 & -454.18 & 678.97 & 9.88 \\
\hline 3231.00 & 83.60 & 312.00 & 15.00 & 2867.80 & 514.99 & -465.41 & 693.67 & 17.42 \\
\hline 3326.00 & 89.25 & 306.00 & 95.00 & 2873.72 & 574.61 & .539 .04 & 786.66 & 8.66 \\
\hline 3420.00 & 90.25 & 304.00 & 94.00 & 2874.13 & 628.52 & .616 .03 & 877.45 & 2.38 \\
\hline 3514.00 & 95.00 & 306.00 & 94.00 & 2869.82 & 682.36 & -692.92 & 968.12 & 5.48 \\
\hline 3727.00 & 95.50 & 302.00 & 213.00 & 2850.33 & 800.95 & -868.73 & 1171.97 & 1.88 \\
\hline 3820.00 & 95.75 & 302.00 & 93.00 & 2841.22 & 849.99 & -947.22 & 1259.99 & 0.27 \\
\hline 392.7 .00 & 93.50 & 307.00 & 107.00 & 2832.59 & 910.38 & .1035 .08 & 1362.73 & 5.11 \\
\hline 4136.00 & 88.50 & 308.00 & 209.00 & 2828.94 & 1037.55 & -1200.81 & 1566.67 & 2.44 \\
\hline 4410.00 & 84.00 & 308.00 & 274.00 & 2846.86 & 1205.83 & .1416 .21 & 1834.04 & 1.64 \\
\hline 4534.00 & 85.00 & 309.00 & 124.00 & 2858.75 & 1282.67 & .1512 .80 & 1954.99 & 1.14 \\
\hline 4665.00 & 86.06 & 309.00 & 131.00 & 2868.95 & 1364.86 & .1614 .30 & 2083.19 & $0.81 *$ \\
\hline 00 & . & 09.00 & 348.00 & 2913.86 & 1581.89 & .1882 .32 & 2421.73 & 2.00 \\
\hline
\end{tabular}

* Estimated surveys. No surveys were actually raken at these depths.

vertical section azimuth is 320 degrees. 


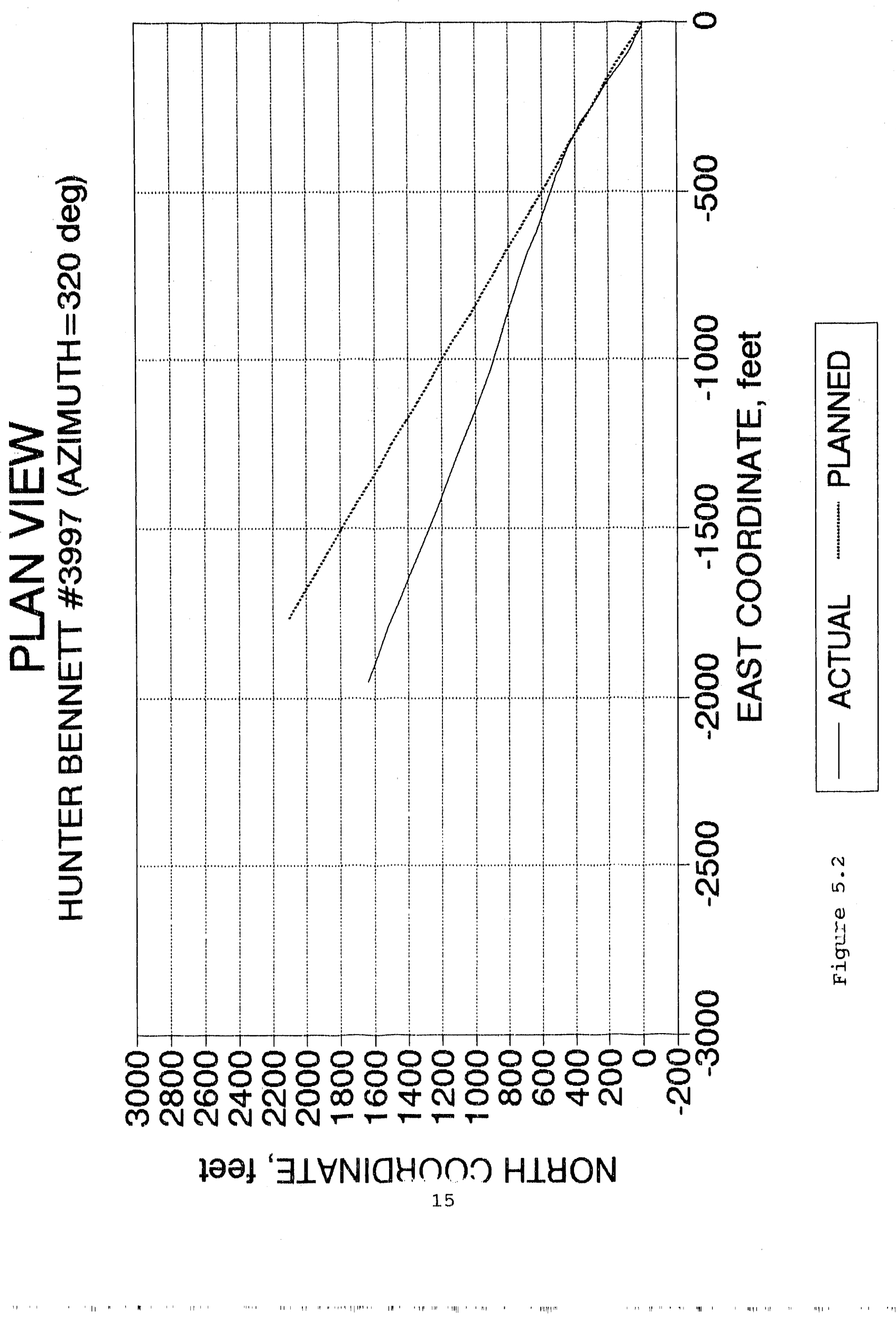




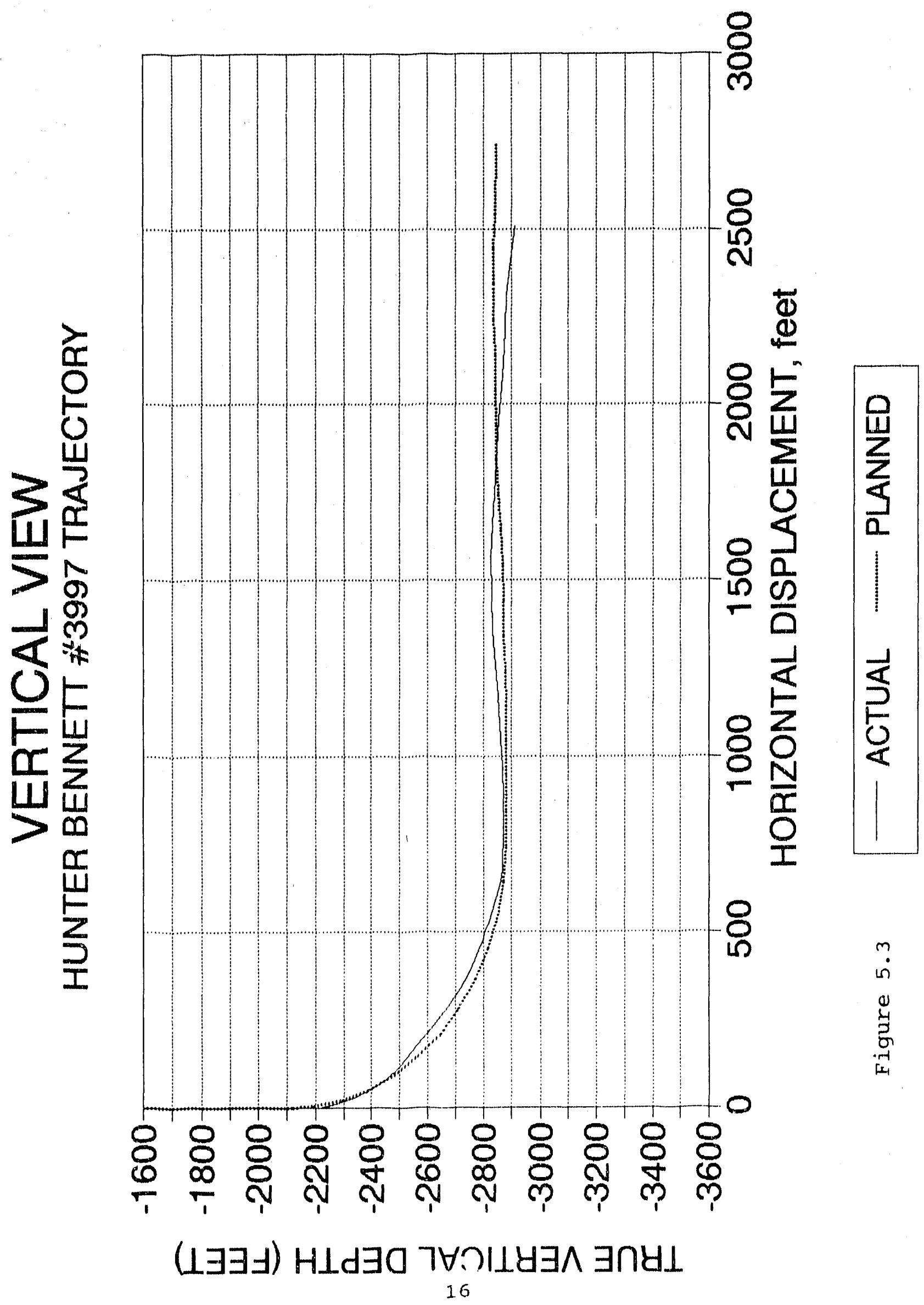




\subsection{LOGGING OPERATIONS}

Logging of this well was planned to provide information useful in determining where gas shows were located and how the well should be completed. Hydrocarbon mud logging was conducted during drilling operations to provide the primary information on gas shows, and information on lithology via drilling time logs. Geophysical logs were run to ald in determining points where external casing packers shuuld be placed in the drill string. A video was planned for the well but was not run .

\subsection{Mud Logging}

Mud logging of the well was initiated at a depth of 1700 feet. This depth was selected because we wanted to be sure that we obtained a good sample description of the rocks through the Big Lime and Big Injun sections for correlation of our projected tops in the area. The top of the Big Lime was determined to be 25 feet lower than expected. This put us on guard to watch the tops of the Big Injun and the Berea Sandstone. These units also came in low which prompted us to revise the target top to a lower depth. Sample studies of a drilling horizontal well are indispensible to the geologist and drilling engineer who have to make sure that the target formation will be penetrated.

Mud logging was accomplished by capturing a portion of the air stream and sending it through a gas chromatograph correlation to determine the various components. The system was calibrated at the beginning of operations so that calculations could be made to estimate the volume of gas encountered by the drill bit. Appendix $E$ lists gas shows and the measured depths where they were encountered. Figure 6.1 shows the location and intensity of gas shows along the length of the inclined borehole.

\subsection{Shallow Hole and Free Fall Logs}

Plans were originally made to obtain a correlation gamma ray log to more accurately determine the tops of the Big Lime and Big Injun 
(udd 000 L) SMOHS S

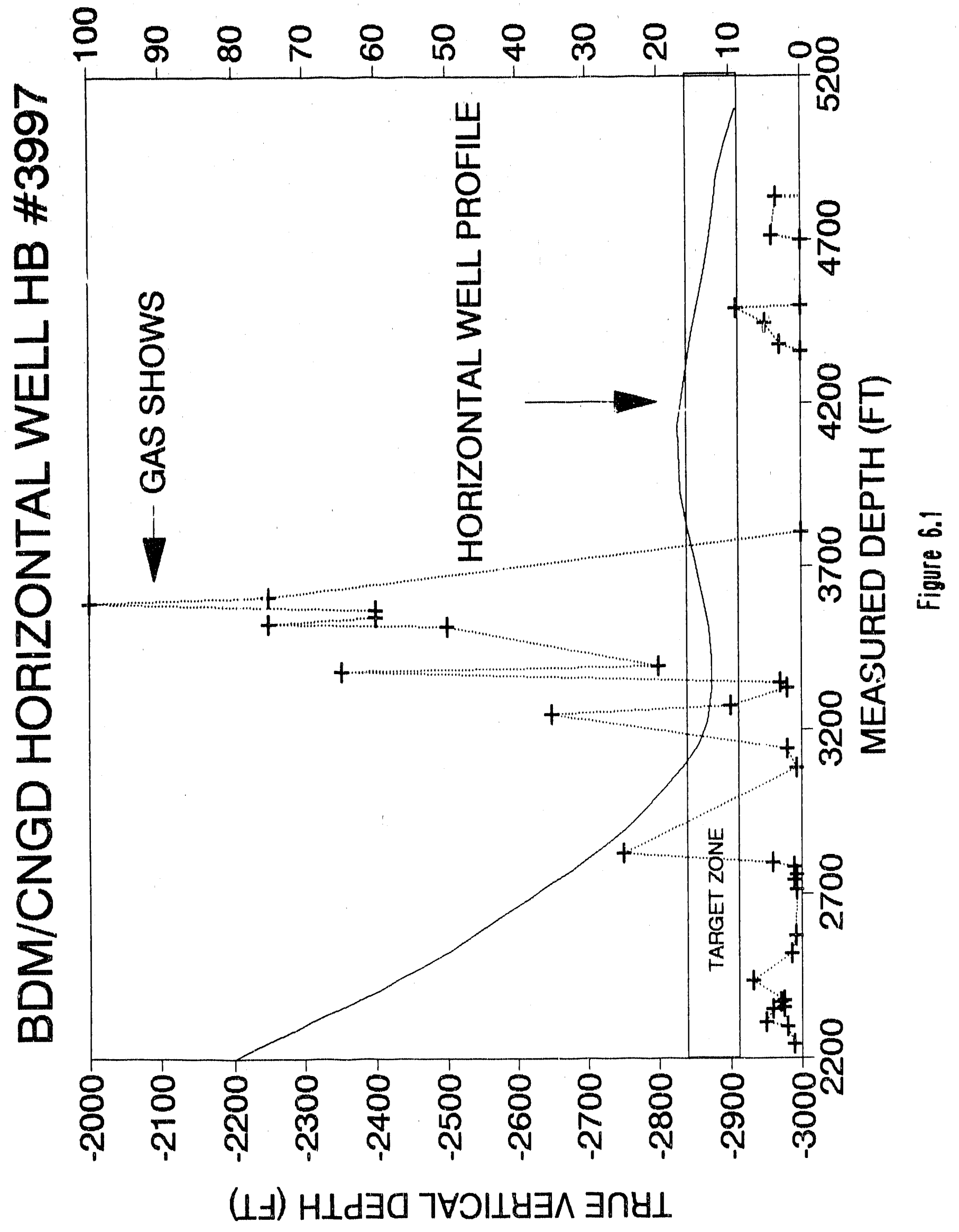


formations and thus the kick off point for directional drilling operations, however in an effort to reduce costs and because of confidence in the sample log tops, the shallow hole logs were run with the free fall logs. Free fall logs were run to a depth of 2969 feet which is an inclination of approxiniately 66 degrees. Gamma ray, compensated density, caliper, and temperature logs were run in the open hole section from 2969 to 2090 feet where the $95 / 8$ " casing is set.

\subsection{Horizontal Section Logging}

The inclined and horizontal sections of the wellbore were logged by attaching the logging sonde to the front end of the drill string and pushing the tools through the open wellbore. The drill pipe was pushed in with 62 foot increments of drill pipe (double stand). Drill pipe conveyed logs were run from $2969^{\prime}$ to $4981^{\prime}$. Schlumberger1 did not want to tag bottom with the logging tools, because of the potential for damaging the tools, thus total drilled depth was not reached.

Shortly after starting the logging run, the density log failed and the drill string had to be tripped out of the hole to change the logging tool. Other than the tool failure, the logging operations went as planned. The logs run were gamma ray, temperature, and compensated density.

No video camera log was run. Drilling costs were over budget because of the extra motor hours due to the slow penetration rates. The video log was cancelled to save money.

\subsection{CASING OPERATIONS}

Upon completion of logging operations, the drill pipe was laid down and casing operations started. While the drill pipe was being laid down, geologists and engineers from BDMESC and CNGD studied the geophysical logs and the mud logs to determine how the well should be completed. It was generally agreed among the parties that completion originally planned would be modified and that most of the well would be completed open hole. This required the purchase of additional port collars (2) and

1 Use of company name does not imply endorsement. 
external casing packers (2). It was also decided to increase the weight of the casing from $15.5 \mathrm{lbs} / \mathrm{ft}$. to $17 \mathrm{lbs} / \mathrm{ft}$ to provide a safety margin during stimulation operations.

One hundred eleven (111) joints of $51 / 2^{n}, 17 \# / \mathrm{ft}, J-55$, ST\&C casing were run in the hole and set at $4755^{\prime} \mathrm{KB}$. The casing contained six external casing packers and nine port collars. The casing tally and setting depth of the packers and port collars are presented in Appendix A-3.

The casing was not run to TD because drag calculations indicated that the casing would probably not go to 5013'. The depth of $4755^{\prime}$ was selected based upon the mud log and open hole logs. Also, drag calculations showed that there would be no problem getting the casing to this depth. The hook load while running the last joint was 5000 lbs. Jamming the casing in the hole could possibly damage the external casing packers in the top part of the string leading to later problems cementing the well. The bottom part of the well was then treated as an open hole completion.

The casing was landed in the wellhead slips with 40,000 lbs tension and the rig prepared for completion operations.

\subsection{MOTOR PERFORMANCE AND BOTTOM-HOLE ASSEMBLIES}

Two motors were used to drill the angle build section of the well. Both motors were Baker motors with an adjustable bent housing. Each motor had an $85 / 8^{\prime \prime}$ stabilizer between the bit and the bend. It was not intended to run motors with stabilizers; however, they could not be removed in the field. All the previous experience with build rates were based on slick motors. With a single stabilizer on the motor, it would be difficult to predict build rates.

The first motor was run once while the second motor was run twice for a total of three motor runs. No motor failures were experienced. The first motor run was terminated because of a hole cleaning problem and the second motor run was terminated because of a bit gauge problem. The third motor run finished the build section. 
The first motor run drilled from $2165^{\prime}$ to $2598^{\prime}$ (433') in 42 drilling hours. The average penetration rate was 10.3 feet per hour and varied between 2 and 25 feet per hour depending, upon the hardness of the formation. The bend had been set at 2 degrees and the average dogleg severity produced by the motor was $10.7 \% / 100^{\prime}$.

Three 14/32" jets were placed in the bit to extend steering tool life. Initially, two $1050 \mathrm{scfm}$ (rated capacity) compressors supplied air for the motor but drilling conditions were very rough. The drill string bounced considerably at the surface so one compressor was taken off line. The motor drilled with one compressor to nearly 2400' when the second compressor was added because the penetration rate was slowing down. The motor drilled better after the second compressor was added. The standpipe pressure increased from 210 psi with one compressor to 360 psi with two compressors. The tool face indicator was not as stable with two compressors on the hole.

At 2598', the motor quit drilling and was pulled from the hole. Three hours prior to tripping, the well quit dusting. The penetration rate was very slow at two to three feet per hour in this interval. To lubricate the motor, oil was being injected into the standpipe at a rate of 5 gallons per hour. Apparently, the penetration rate was too slow and not enough cuttings were being generated to absorb the oil and carry it out of the hole. The hole became dirty and the motor would not drill.

Total drilling and circulating time for the motor was 46.5 hours. The motor appeared to be in good condition when checked at the surface. Since this motor had 46.5 hours on it and only half the build section had been drilled, the motor was laid down and not used again. The likelihood of the motor drilling the rest of the build section was remote.

The second motor drilled from 2773' to $3280^{\prime}$ in two separate runs. Motor run \#2 drilled from 2773' to $3117^{\prime}$ (344') in 39.75 hours. The average penetration rate was 8.65 feet per hour. Again, the penetration rate varied significantly depending upon the formation. The motor run was terminated because the motor would not drill. After tripping out of the hole, the bit was found to be $1 / 4^{n}$ under gauge. The stabilizer above the 
bit was taking all the weight and would not allow the weight to be transferred to the bit.

The under gauge hole was reamed and the motor run back in the hole. Motor run \#3 drilled from $3117^{\prime}$ to $3280^{\prime}$ in 12 hours. The average penetration rate was 13.58 feet per hour. The motor was pulled because the build curve section was complete. The motor was still operating when pulled from the hole.

The second motor had the bend set at 1.75 degrees and produced an average dogleg severity of $11.33 \% 1100$. The dogleg severity for the second motor was greater than the first even thought the bend was set 0.25 degrees lower.

The motor was run with two $1050 \mathrm{scfm}$ compressors and the surface pressure ranged from 300 to $350 \mathrm{psi}$. Three 16/32" jets were placed in the bit. The steering tool experienced three failures during motor run \#2. The first two failures were the connector sub between the wireline rope socket and the steering tool. The third failure was in the electronics that transmits the signal to the surface. There were no probe failures. With the higher pressures on the first motor run, no steering tool failures were experienced. Lower pressures were run with the second motor because the previous pressure was too high for the air package.

The oil injection rate for the second motor was limited to around one gallon per hour. No hole cleaning problems were experienced at the reduced oil rate and the motors functioned adequately. Total dilling and circulating time for the second motor was 53 hours with no failures.

Seven rotary assemblies were used to drill the well. Strong formation tendencies in the horizontal section necessitated changing the bottom-hole assembly frequently. Other than in the vertical portion of the well, the first rotary assembly used was bottom-hole assembly \#2 in Appendix B. The assembly consisted of a bit, float sub, six point reamer, non-magnetic drill collar, three point reamer, non-magnetic drill collar, and six drill collars. The assembly is a moderate holding assembly and should have a slight tendency to build inclination. 
Bottom-hole assembly \#2 was run to drill a tangent section and drilled from 2598' to $2773^{\prime}$. Instead of holding inclination or building slightly, the assembly dropped inclination at the rate of $0.45 \% / 100$. Not enough hole was drilled to establish a walk tendency.

Bottom-hole assembly \#4 was the next rotary assembly to be run in the hole. The assembly was only used to ream a motor run and did not drill any hole.

Bottom-hole assembly \#6 was the first rotary assembly run in the horizontal section. The intention was to run a holding assembly that would maintain inclination at $88^{\circ}$. Bottom-hole assembly \#6 is the same as bottom-hole assembly \#4 with two modifications. First, the button cutters in the bottom of the six point reamer were replaced with flat cutters. Then, a pony collar (8.52' in length) was added between the six point and the three point reamer. The changes were made to increase the building tendency of the assembly. Since the assembly had dropped inclination in the tangent section, some additional building tendency would be required to make the assembly hold inclination.

Bottom-hole assembly \#6 drilled from $3280^{\prime}$ to $3544^{\prime}$. Initially, the assembly built inclination at a rate of 1 degree/100' with a 2 degree/100' left walk tendency (see Build and Walk Rates in Appendix C). On the next survey, the assembly built inclination at a rate of $5.05^{\circ} / 100^{\prime}$ indicating some strong formation tendencies. was controlling the rapid angle build. At any rate, the inclination would have to be dropped to stay within the target interval.

The next assembly to be run was bottom-hole assembly \#7 which drilled from 3544' to 3846'. The bottom-hole assembly consisted of a bit, float sub, pony non-magnetic collar, three point reamer, and non-magnetic collar. The same assembly was used in the Hardy HW\#1 well in Putnam County, and dropped inclination at a rate of $2.5^{\circ} / 100^{\prime}$. In this well, the assembly built inclination at a rate of $0.25 \% 100^{\prime}$ but the walk tendency could not be discerned. Obviously, the formation tendencies were substantial and would require a stronger pendulum assembly to counteract the formation. 
A 30 foot pendulum assembly was run to drill from $3846^{\prime}$ to $4335^{\prime}$. The description of bottom-hole assembly \#8 can be found in Appendix B-2. The assembly dropped inclination at a rate of $2.39 \% 100^{\prime}$ and walked $0.50 \% 1100^{\prime}$ to the right. At a projected inclination of $84^{\circ}$ the assembly was pulled from the hole.

Bottom-hole assembly \#9 was run to hold the inclination near $84^{\circ}$. The packed hole assembly consisted of a bit, float sub, six point, pony nonmagnetic collar, three point, and non-magnetic collar. At $84^{\circ}$, the assembly should have dropped inclination; however, with the formations strong build tendency, it should not have dropped inclination very fast. The assembly had to be reamed to bottom from 3500' because it was considerably more stiff than the previous assemblies.

Bottom-hole assembly \#9 drilled from $4335^{\prime}$ to $4665^{\prime}$. It built inclination at a rate of $0.81 \% 100^{\prime}$ and walked to the right. Drilling continued until the projected inclination was $86^{\circ}$ at the bottom. Another pendulum assembly would be required to drop the well through the target interval.

The last assembly to be run (bottom-hole assembly \#10, Appendix B3) was a slick assembly. It drilled from 4665' to 5013'. The slick assembly was selected over the 30 foot pendulum in order to minimize hole drag. The drop rate should have been similar to the pendulum though somewhat less. A drop rate of $2^{\circ} / 100^{\prime}$ would place the end of the wellbore through the bottom of the target. No surveys were run to check the drop rate of the slick assembly. The drop rate was most likely lower than $2^{\circ} / 100^{\prime}$ because the open hole logs did not suggest that the wellbore dropped out of the target interval.

All of the rotary assemblies were run with 20,000 to 25,000 lbs bit weight and $60 \mathrm{rpm}$. The lower bit weight was to keep the drill pipe from buckling in the horizontal and build sections. Drill collars were placed at the top of the build section to provide the weight necessary to keep the drill pipe from buckling in the vertical section of the hole. The collars were also used to help push the pipe into the hole on trips and connections. The placemerit of the collars can be found in the description of the bottomhole assemblies in Appendix B for each of the rotary assemblies. 


\subsection{STEERING TOOL OPERATIONS}

Steering tool operations for this well were considered quite acceptable. There were only three (3) tool failures that resulted in drilling delays. None of the failures were related to the three-axis probes themselves, but to wireline connectors and electronic components. In previous directional drilling operations steering tool failures were a major source of additional costs due to lost time.

\subsection{DISCUSSION AND ANALYSIS OF DRILLING OPERATIONS}

A primary objective of this drilling project was to continue testing new and evolving drilling, steering, and completion technology, and to improve the economics of drilling horizontal wells. This report was prepared to discuss the results of new drilling techniques tested and the performance of current "off the shelf" technology utilized during the operations.

The major success during this drilling operation was the rate of angle build of the downhole motors, and low failure rate of the steering tools. The motors operated very successfully at pressures from 250 to 350 psi with oil l'ibricant injected at rates of 5 gallons per hour. It would appear that lubricant injection could be lowered to rates of 3 to 4 gallons per hour and still be effective.

The one major development that needs to be made is the use of a low mean failure time wireless steering tool that could be used to make surveys with during the horizontal drilling phase of the well. This tool is the logical next step and several companies are currently working on perfection of such a tool.

Mud logging operations have been very successful during each of the previous horizontal well drilling operations. The gas show data presented has been a key piece of data used in designing the final casing completion configuration in each well. To date it is very hard, if not impossible to justify the cost of geophysical logging operations in relation to the amount of useful data acquired. If future drilling budgets need to be 
trimmed, this a potential area that might save $\$ 35,000$ to $\$ 45,000$, in addition to one or two days of rig time $(\$ 10,000)$. However, sample studies to locate the geologic target properly are an absolute requirement.

Video logs would be quite useful, but they are a potential area of additional costs that have to be carefully weighed against the benefits gained. This would be most helpful in proving or assisting with geologic interpretation of the wellbore.

\subsection{Completion Operations}

\subsection{Introduction}

The completion design of the BDM/CNGD/DOE Hunter Bennett \#3997 (HB\#3997) was based largely on the results of the successful completion of the previous DOE-sponsored horizontal wells in Wayne and Putnam Counties, West Virginia.

The HB\#3997 well was successfully completed with a 5-1/2 inch casing liner with five different zones being isolated from each other by inflatable casing packers. Access to each zone was provided by two port collars per zone (except for Zone \#1) which could be opened and closed using special tools. This system allowed testing, production, and stimulation of individual zones or groups of zones as necessary. Figure 11.1 shows each of the five zones in the wellbore schematic. An additional external casing packer (above ECP\#5) was placed for cementing purposes with a port collar behind ECP\#6 to be used during the cement job.

Mud log shows indicated that the best gas "shows" were in Zones 4 and 5 with good gas "shows" in Zorie \#2. Figure 11.2 shows where the zones occur with respect to the true vertical depth (TVD) log of the well.

\subsection{Casing Design}

In order to isolate the five zones for individual stimulation, the well was cased with 5-1/2 inch, 17.0 \#/ft, J-55 LTC R3 casing. Options considered for isolating the individual zones included 


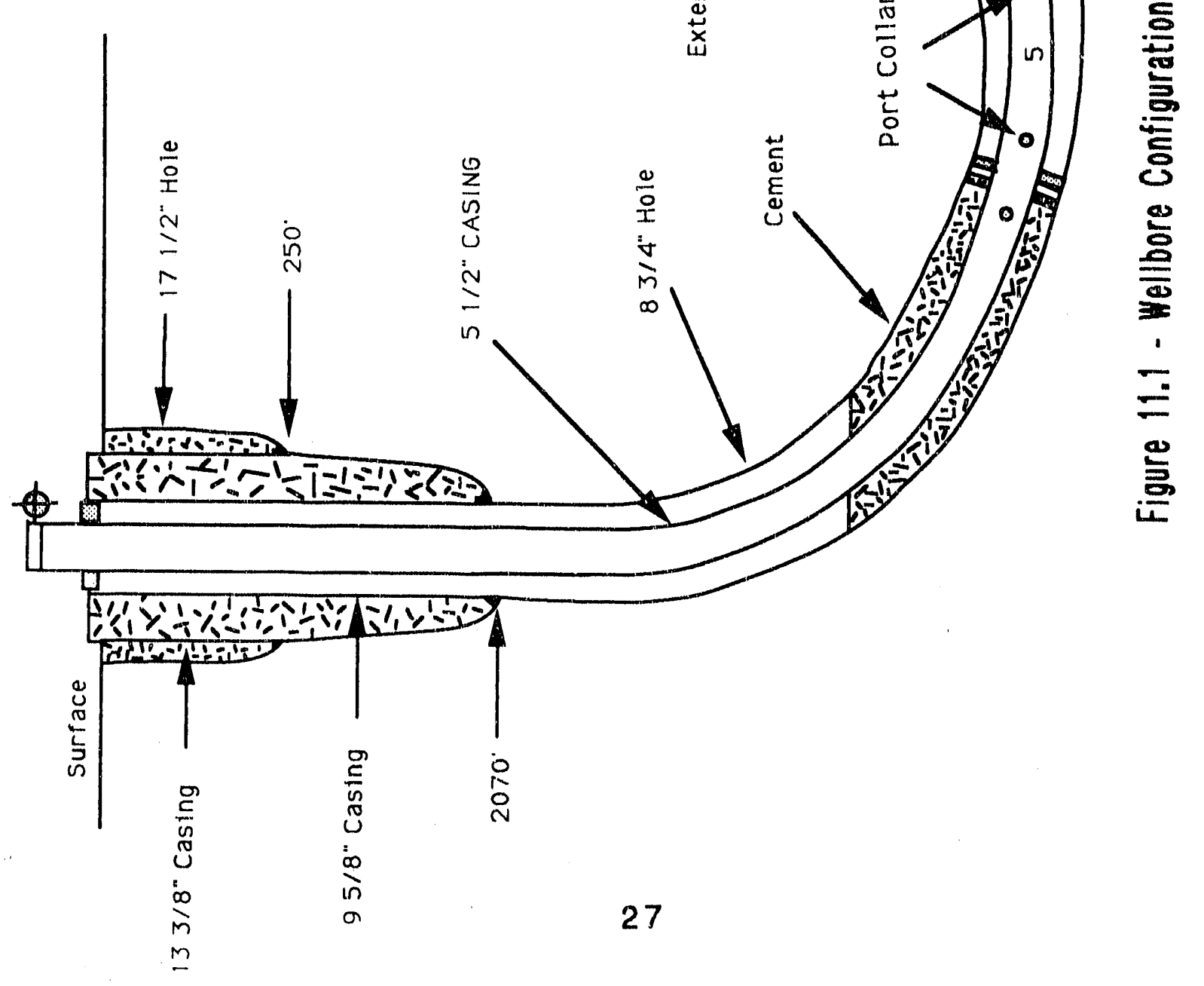


(udd 000 L) SMOHS S $\forall$ D

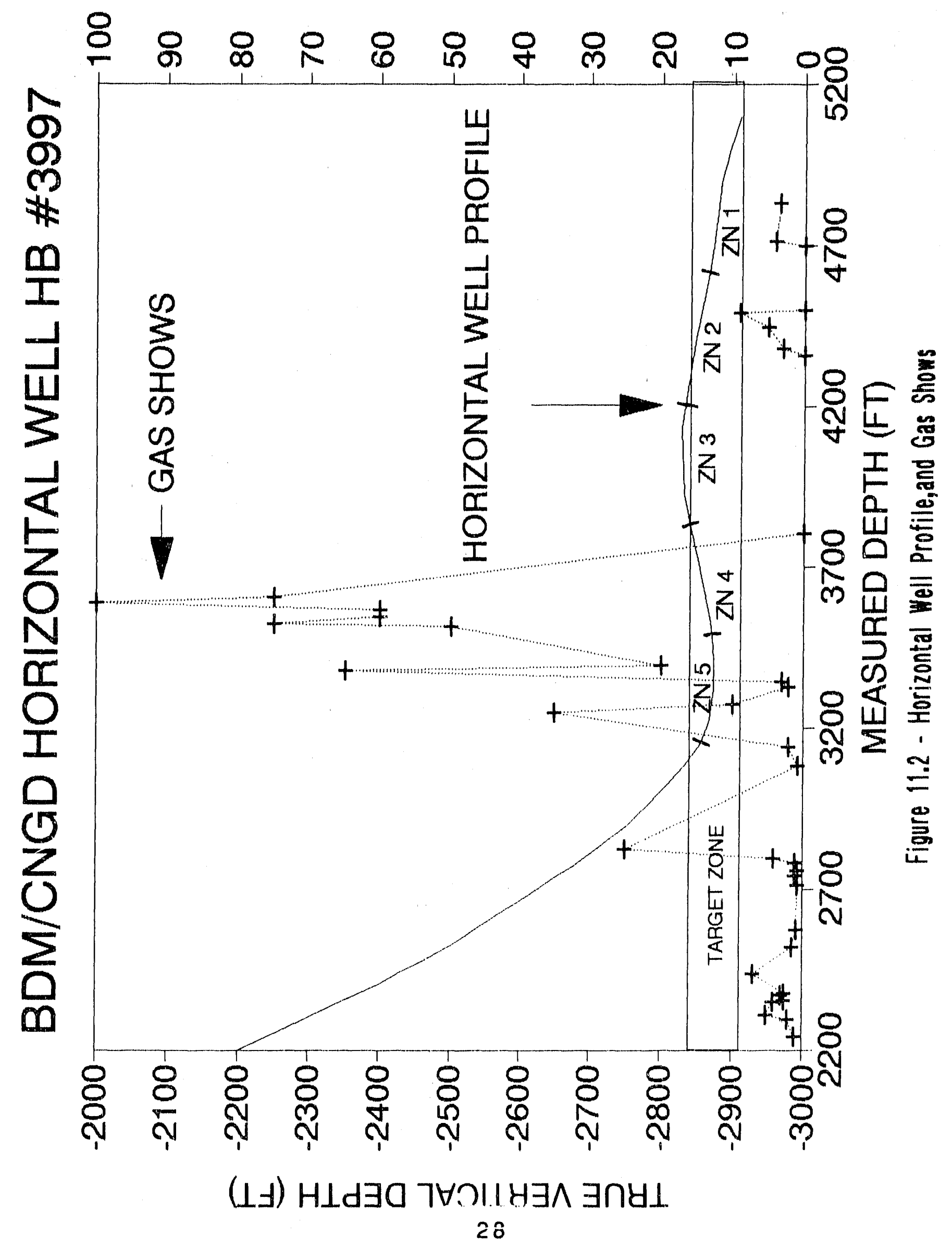


conventional cementing of the casing with perforations to access the individual zones, use of inflatable casing packers in the casing string with port collars to access the zones, a combination of these two techniques. Because of the relatively successful completion of both the BDM/RET\#1 well and the BDM/Hardy \#1 well, the external casing-packer-port collar option was selected for completing the HB\#3997. Six external casing packers were placed in the casing string at measured depths of 4575 , $4179,3826,3474,3160$, and 3109 feet. A total of nine port collars were placed along the horizontal section with two port collars placed in Zones $\# 2$, \#3, \#4 and \#5 and a port collar was placed above the shallowest casing packer (ECP\#6) for use in cementing the casing in that part of the hole. Zone \#1 was left without port collars and without a casing string (le. open hole completion, Figure 11.1).

The size, weight, and grade of the casing, 5-1/2 inch, OD, 17.0 \#/ft, J-55; respectively were designed to meet stimulation requirements. Based on hydraulic fracture treatments $\left(\mathrm{N}_{2}-\mathrm{Frac}\right)$ on nearby vertical wells, the average breakdown pressure and average instantaneous shut-in pressures (ISIP) were estimated at $2400 \mathrm{psi}$ and $900 \mathrm{psi}$ respectively. A minimum amount of friction losses were anticipated since the treatment plan utilized straight nitrogen gas to frac all the zones of interest.

The use of nitrogen gas should eliminate previous problems witnessed in the BDM/Hardy \#1 horizontal well, such as opening/closing of port collars that was attributed to sand remaining after the nitrogenfoam frac. After accounting for the de-rating of strength due to bending stresses subjected to the pipe in the directional hole, it was determined that $17.0 / \mathrm{ft}, J-55$ grade pipe would meet all the design requirements.

\subsection{Inflation Casing Packers}

The procedure selected for inflating the external casing packers (ECP) was to inflate the ECPs from bottom to top using $\mathrm{KCl}$ water and nitrogen. A retrievable bridge plug (RBP) was used to plug the open ended $51 / 2$ " casing in Zone \#1 from the rest of the wellbore. The RBP was set 63 feet below the ECP and then tested to 3000 psi using nitrogen. The nitrogen pressure was released and the RTTS was moved uphole above the ECP, the pipe was then loaded with 3 bbls of 3 percent $\mathrm{KCl}$ water 
which was used to inflate the ECP. Nitrogen was then used to pressurize the $\mathrm{KCl}$ water to Inflate ECP\#1. Pressure increased to $1200 \mathrm{psi}$ then dropped off a little, which indicated that the opening valve pin had sheared and ECP\#1 was being inflated. When the ECP was full, the pressure continued to bulld up and a second pin sheared sealing the inflation port and completing the operation. Nitrogen was pressured to 3000 psi in order to test ECP\#1 and the pressure was held for fifteen minutes to check integrity. During this time, the pressure dropped to 2700 psi indicating a leak in the nitrogen line. Finally the tubing pressure was released and then the RBP was moved up the hole to start inflating and testing ECP\#2.

The RBP was set at 4146 feet. Nitrogen was pumped downhole to pressurize the $\mathrm{KCl}$ water which inflated ECP\#2. This second packer was set at 4179 feet. The same procedures were used for setting and testing the ECP's \#1 and \#2. To save time and nitrogen, the procedure was altered to inflate two ECP's, \#3 and \#4 together. This required a larger charge of $\mathrm{KCl}$ water, but worked fine. Thus ECP's \#5 and \#6 were inflated and tested in the same manner as had ECP's \#3 and \#4.

After inflating and testing all the ECP's the tubing pressure and the RTTS were released. $\mathrm{KCl}$ water was displaced out of the casing using nitrogen and the hole was set for cementing the bulld section above ECP\#6. The opening/closing tool which was part of the tubing assembly. was used to open port \#6 through which the cement would be pumped.

No problems were encountered while inflating and testing the ECP's. When the RBP was initially set and tested, a leak was detected. The RBP was pulled up the hole, reset, and then again tested. The RBP tested to $3,000 \mathrm{ps}$ without any problems. The time consumed in this process was nineteen hours. Only eight hours time was needed to inflate and test the ECP's.

\subsection{Cementing}

Although the basic completion method for this well was essentially open-hole with a liner, one section of the casing was cemented in place. The casing immediately above the uppermost casing 
packer was cemented from approximately 2245 to 3118 feet measured depth with 235 sacks of $50 / 50 \mathrm{POZ}$. The purpose of this cement was to establish a permanent barrier against any water that might enter the wellbore above the productive interval.

The cementing operations were conducted by pumping the cement through a port collar immediately above the uppermost casing packer. Using a cup typo isolation tool in combination with an opening and closing tool (see figure 11.3), the port was opened and the isolation tool positioned so that the tubing ports were opposite the injection ports. The cement was then displaced from the tubing with water and a rubber plug. The port was then closed to allow cleanup of the casing. The cement was overflushed with water and then the casing was acid washed to remove any residual cement that might not have been circulated out.

\subsection{STIMULATION OPERATIONS}

\subsection{Introduction}

Analysis was made of the gas show data to evaluate the need, and potential response to stimulation, on a zone-by-zone basis. The approach that could be taken was constrained by the amount of funds remaining in the contract. There were four candidate zones but funds sufficient to stimulate only two (2) zones. The rational for selection of the two zones for stimulation are next discussed.

\subsection{Stimulation Plan}

A natural gas production flow test was made at the end of drilling operations before cementing the $51 / 2$ "casing, and an 80 mcf daily rate was recorded. The measurement was made with all zones producing. A review of the well bore configuration and production analysis was made as an aid for decision making and the results are presented in table 12.1. This table was prepared after examining figure 6.1 and reviewing data from Appendices $A-2$, and $E$.

Zone 1 was tested after external casing packers (see Figure 11.1) were set by inflation with 2 percent $\mathrm{KCl}$ water. All of the port 


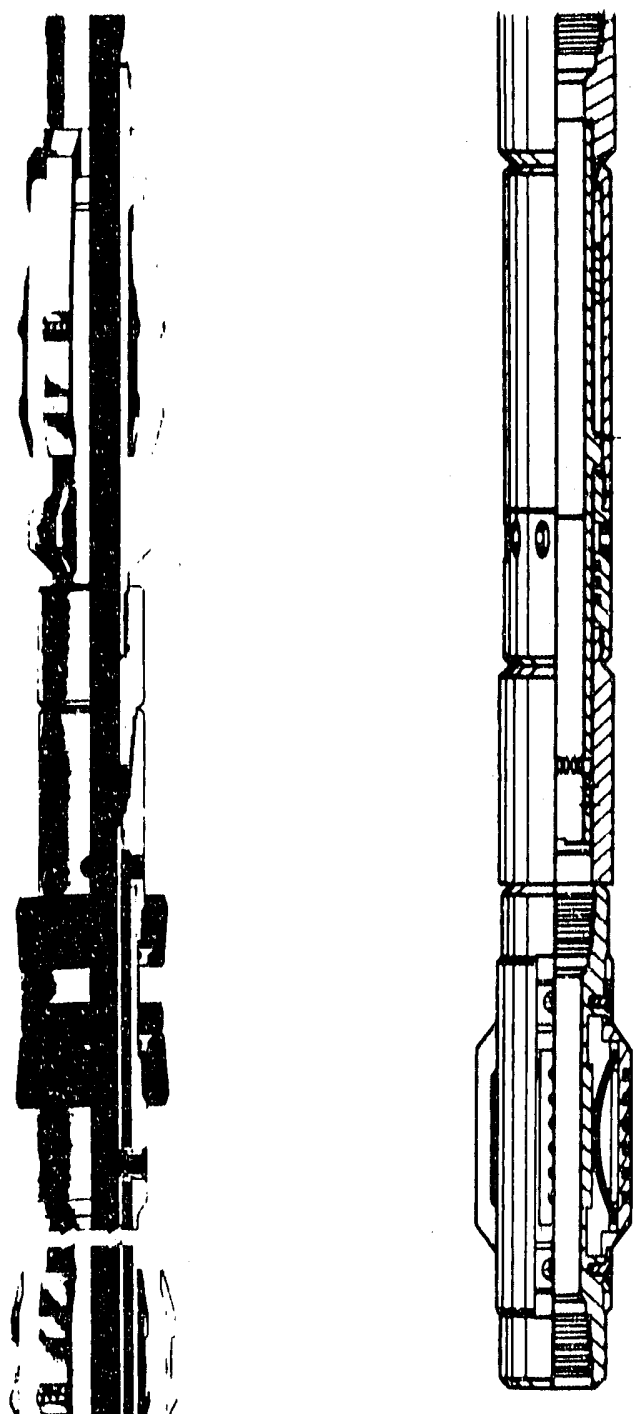

RTTS Circulation

Valve and Drag Block Assembly

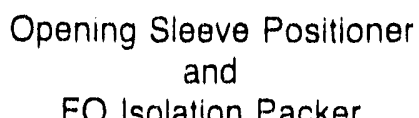

Figure 11.3 - F O Cementer Isolation Packer With Sleeve Positioner and Clrculation Valve 32 
collars were closed except for Zone 1 and the well shut in for ten days prior to testing. Wellhead pressure increased to only six psig over the 10day period. The gas flow from Zone 1 was estimated to be in the range of 2 to 3 Mcid through a $2^{\prime \prime}$ pipe. Zone 1, while having gas shows during drilling, clearly was not connected to the reservoir and needed to be stimulated if it were to produce any significant quantities of natural gas.

Zone 3 is out of the Devonian Shale formation and was not considered to be a candidate for stimulation.

The remaining three candidate intervals, Zones 2, 4, and 5, were estimated to be producing the majority of the 80 Mcfd initial open flow measured after drilling, but prior to cementing the casing. Based on the gas shows during drilling, Zone 4 was estimated to be contributing the majority of the gas, with the remainder being produced from Zones 5 and 2.

Based on the gas shows, BDMESC rank-ordered the potential of each zone with the results presented in Table 12.1. With the budget constrained to only two fractures, BDMESC recommended to the DOE that Zone 2 and Zone 4 be stimulated. Zone 1 was not recornmended because the results of the 10-day shut-in and testing showed that Zone 1 was extremely tight to the point that a fracture may not be initiated and propagated toward a more productive interval.

The BDMESC proposal was designed to stimulate the higher potential intervals on either side of Zone 3, which was not in the formation. Upon review, the DOE concluded that, if the proposed stimulation was carried out as proposed, Zones 1 and 5 may never be stimulated because of the risk of not being able to close the port collars to isolate these zones for stimulation. The more normal approach is to start at the far end of the well and stimulate the well in sequence as one proceeds to the near end of the horizontal section.

Accordingly, Zones 1 and 2 were selected for stimulation under the DOE contract. The highest potential Zones identified in the well 
TABLE 12.1 - ZONE CONFIGURATION AND PRODUCTION ANALYSIS OF HORIZONTAL WELL BDM/CNGD HB \# 3997

\begin{tabular}{|c|c|c|c|c|c|c|c|}
\hline \multirow[b]{2}{*}{ Zone } & \multicolumn{3}{|c|}{ Zone Configuration } & \multicolumn{2}{|c|}{$\frac{\text { Initial Zone }}{\text { Prierities }}$} & \multicolumn{2}{|c|}{$\frac{\text { Stimulation }}{\text { Prierities }}$} \\
\hline & $\begin{array}{l}\text { Bottom } \\
\text { (ft) }\end{array}$ & $\begin{array}{l}\text { Top } \\
\text { (ft) }\end{array}$ & $\begin{array}{l}\text { Length } \\
\text { (ft) }\end{array}$ & $\begin{array}{c}\text { Gas Show } 1 \\
\text { mcfd }\end{array}$ & $\begin{array}{l}\text { Rank } \\
\text { Order }\end{array}$ & $\begin{array}{l}\text { Limited } \\
\text { Budget }\end{array}$ & $\begin{array}{l}\text { Tech. } \\
\text { Bisk }\end{array}$ \\
\hline 1 & 5014 & 4584 & 430 & 159 & 2 & & 1 \\
\hline 2 & 4575 & 4188 & 387 & 128 & 3 & 2 & 2 \\
\hline 3 & 417 & 3835 & 344 & 0 & & & \\
\hline 4 & 386 & 3483 & 343 & 682 & 1 & 1 & \\
\hline 5 & 374 & 3170 & 304 & 108 & 4 & & \\
\hline
\end{tabular}

1) Data from Appendix E. 
(Zones 4 and 5) remain to be stimulated by CNGD if justified by the results of the stimulations conducted under the DOE contract. Table 12.2 presents the salient facts of the stimulation plan.

\subsubsection{Stimulation Fluid, Rate, and Pressure Design}

Based on previous experience with stimulating the Fifth sand in vertical wells in the area of interest, and because of the problems likely to be encountered during clean-up, BDMESC recommended the use of all Nitrogen gas fluid as the stimulating fluid. This recommendation was made in the belief that the well bore had crossed two fracture zones associated with strike-slip faulting and proppant would not be as critical to supporting production as it is in other areas of higher stress regimes.

Many of the vertical wells stimulated in the area were stimulated with one and one half (1.5) million standard cubic feet of nitrogen gas and to gain the benefit of a direct comparison with a single zone frac, BDMESC recommended this volume. Because of the potential for leakoff in the fractures that might be encountered, BDMESC recommended a fairly high injection rate of seventy (70) thuusand standard cubic feet per minute (scfm). The anticipated maximum bottomhole pressure (BHP) was approximately 1100 psi.

Procedures for stimulation and clean-up were as follows:

1. Set $300 \mathrm{bbl}$ steel tank and lay lines for flowback operations.

2. Move in workover rig and install 4000 psi working pressure frac valve on the wellhead. Trip into the hole with closing tool to make sure all port collars are closed.

3. Frac Zone \#1 with $1.5 \mathrm{mmscf}$ of nitrogen at an injection rate of $70 \mathrm{mcf} / \mathrm{m}$ thru the $5.5^{n}$ casing.

4. Open well to flow back through $1 / 4^{\text {" }}$ choke until pressure drops below closure pressure, then open up to flow thru 
TABLE 12.2 - COMPLETION CONFIGURATION OF HB \# 3997

\begin{tabular}{|c|c|c|c|c|c|}
\hline Zone & $\begin{array}{l}\text { Bottom } \\
\text { (ft) }\end{array}$ & $\begin{array}{l}\text { Top } \\
\text { (ft) }\end{array}$ & $\begin{array}{c}\text { Length } \\
(\mathrm{ft})\end{array}$ & PC's at & $\begin{array}{c}\text { Frac Volume } \\
\text { mmscf }\end{array}$ \\
\hline 1 & 5014 & 4584 & 430 & -- & 1.5 \\
\hline 2 & 4575 & 4188 & 387 & $4530^{\prime}, 4273^{\prime}$ & 1.5 \\
\hline 3 & 4179 & 3835 & 344 & $4133^{\prime}, 3876^{\prime}$ & NSP \\
\hline 4 & 3826 & 3483 & 343 & $3780^{\prime}, 3526^{\prime}$ & NSP \\
\hline 5 & 3474 & 3170 & 304 & $3428^{\prime}, 3212^{\prime}$ & NSP \\
\hline
\end{tabular}

NSP- No Stimulation Planned 
1" choke. Flow back into steel pit and measure liquid volume. Flow back until safe to go back in with tools.

5. Trip in with Port Collar (PC) opening and closing tools and a retrievable bridge plug on the tubing. Set bridge plug about 50' below PC \#1. Set bridge plug at 4580'

6. Move back up the hole and open PC \#1 at 4530' with the opening and closing tool. Straddle PC \#1 with the tool and gauge the pressure and measure the production rate through the tubing. Move up the hole to PC \#2 at 4273' and open this port collar. Trip out of the hole with the tubing and the opening and closing tool, making sure to move back down 6' after opening each PC on the way out of the hole.

7. Stimulate zone \#2 with $1.5 \mathrm{mmscf}$ of nitrogen at 70 $\mathrm{scfm} /$ minute down the $5.5^{n}$ casing.

8. Open well and flow back within twenty (20) minutes to produce rapid closure of fracture. Flow back for a period of time (24-36) hours till it is safe to retrieve the bridge plug set down below PC \#1.

9. Test production rate and pressure build up from each zone using an RTTS packer and the isolation tools, record pressure from zone \#1 on the tubing and pressure from zone \#2 on the $5.5^{n}$ annulus.

10. Trip out of the hole with the RTTS packer opening each PC on the way out. Stop long enough to measure pressure and flow rate. Test whole well for production from all five zones.

\subsection{Stimulation of Zone \#1}

Zone number 1 was stimulated on September 16, 1991. All trucks were on location by 8:30 a.m. and rigging up. Frac job started 
pumping at 10:55 a.m. and was completed by 11:27 a.m. The stimulation was initiated slowly with a pumping rate of $20,000 \mathrm{scfm}$ and then was doubled to $40,000 \mathrm{scfm}$ until breakdown occurred. Pumping was shut down for five minutes to watch pressure fall off which is an indication of the leak-off rate of the gas to the formation.

When pumping resumed again, the observed pressure was approximately $100 \mathrm{psig}$ higher than breakdown. Continued to increase injection rate until the pressure reached 3950 psig (maximum pressure reached). Maximum pressure was set at 4000 psig before the job was initiated.

The programmed injection rate of $70,000 \mathrm{scfm}$ was reached at a pressure of $3870 \mathrm{psig}$. Injection rate at the top pressure was 74,700 scfm.

The job proceeded without incident and was completed in 32 minutes. The instantaneous shut-in pressire (ISIP) was 2857 psig. Pressure fall-off readings were taken every five minutes for twenty minutes. the pressure readings were noted as follows:

$$
\begin{array}{r}
5 \text { minutes - } 1751 \text { psig } \\
10 \text { minutes - } 1462 \text { psig } \\
15 \text { minutes - } 1288 \text { psig } \\
20 \text { minutes - } 1185 \text { psig }
\end{array}
$$

Average treating pressure was 3842 psig while the average injection rate was $68,330 \mathrm{scfm}$. A plot of pressure versus time for the frac job is presented in figure 12.1 .

The well was opened to flow back thru chokes and was flowing at a rate of $491 \mathrm{mcfd}$ after 72 hours continuous open flow. On september 27, 1991, the well was flowing at a rate of 210 mcfd 264 hours after initiating flowback. A gas sample was taken on September 24th and the gas still contained 12.4 percent nitrogen. The well was programmed to flow three more days for additional clean up before beginning Build-up and draw down testing. 


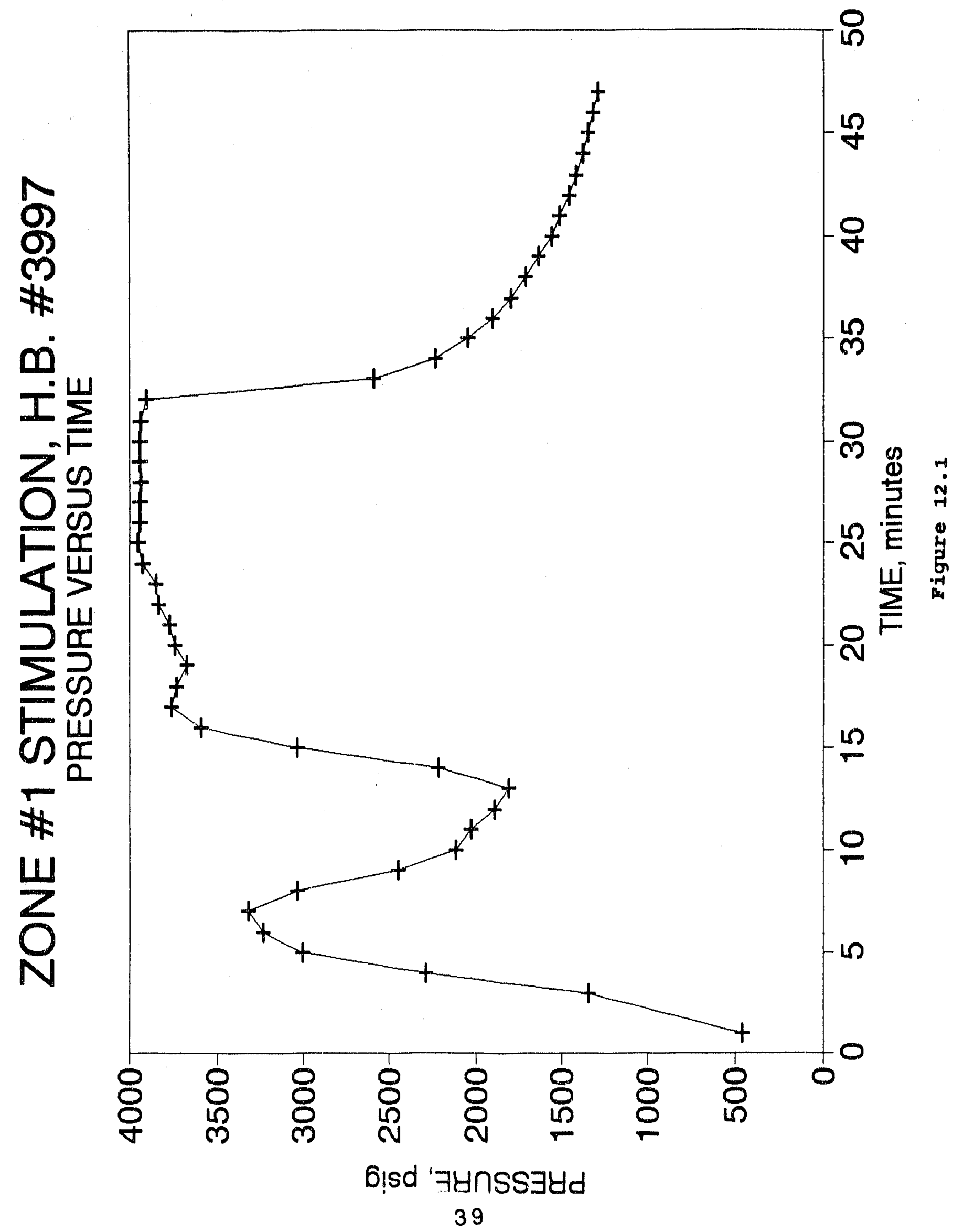




\subsection{Stimulation of Zone \#2}

Before stimulating zone \#2, an external casing packer integrity test was conducted by setting a retrievable bridge plug below the first port collar and opening the port collar and examining the reservoir pressure inside of zone \#2. The pressure recorded in zone \#2 was 450 psig while the pressure recorded in zone \#1 was $550 \mathrm{psig}$. This pressure differential was taken as proof positive that the external casing packer had held during the stimulation of zone \#1 and stimulation of Zone \#2 could proceed. The bridge plug was pressure tested to $3000 \mathrm{psig}$ and was found to be leaking so it was moved down hole about 30 feet and reset again. This time the packer passed the pressure test and the frac job was scheduled for the next day.

On October 9th, 1991 the stimulation of Zone \#2 was initiated at 9:27 a.m.. The pumping job was completed in 22 minutes proceeding a little faster than the job on zone \#1. Formation breakdown occurred at 2996 psig. The average treating pressure was $3608 \mathrm{psig}$, while the maximum pressure reached was $3722 \mathrm{psig}$. The average injection rate was $88,804 \mathrm{scfm}$ while the top injection rate reached was $93,140 \mathrm{scfm}$. Total nitrogen injected was $1,507,000$ scf. A plot of pressure versus time for the frac job is presented in figure 12.2.

By the time that flowback was initiated approximately 20 minutes after the frac job, the pressure had declined to $920 \mathrm{psig}$ so that flowback was initiated thru a 1" choke and opened up to 2 inches within 30 minutes. The rapid decline in pressure was interpreted to mean that a significant fracture system had been created or encountered during the stimulation. The well was left to flow continuously to clean up as rapidly as possible. A gas sample taken on October 14th, five days after the stimulation was determined to have 7 percent nitrogen in the gas indicating a very rapid clean-up of the well. The well was left flowing for an additional two days to insure cleanup before shutting in for a pressure build-up and draw down test. 


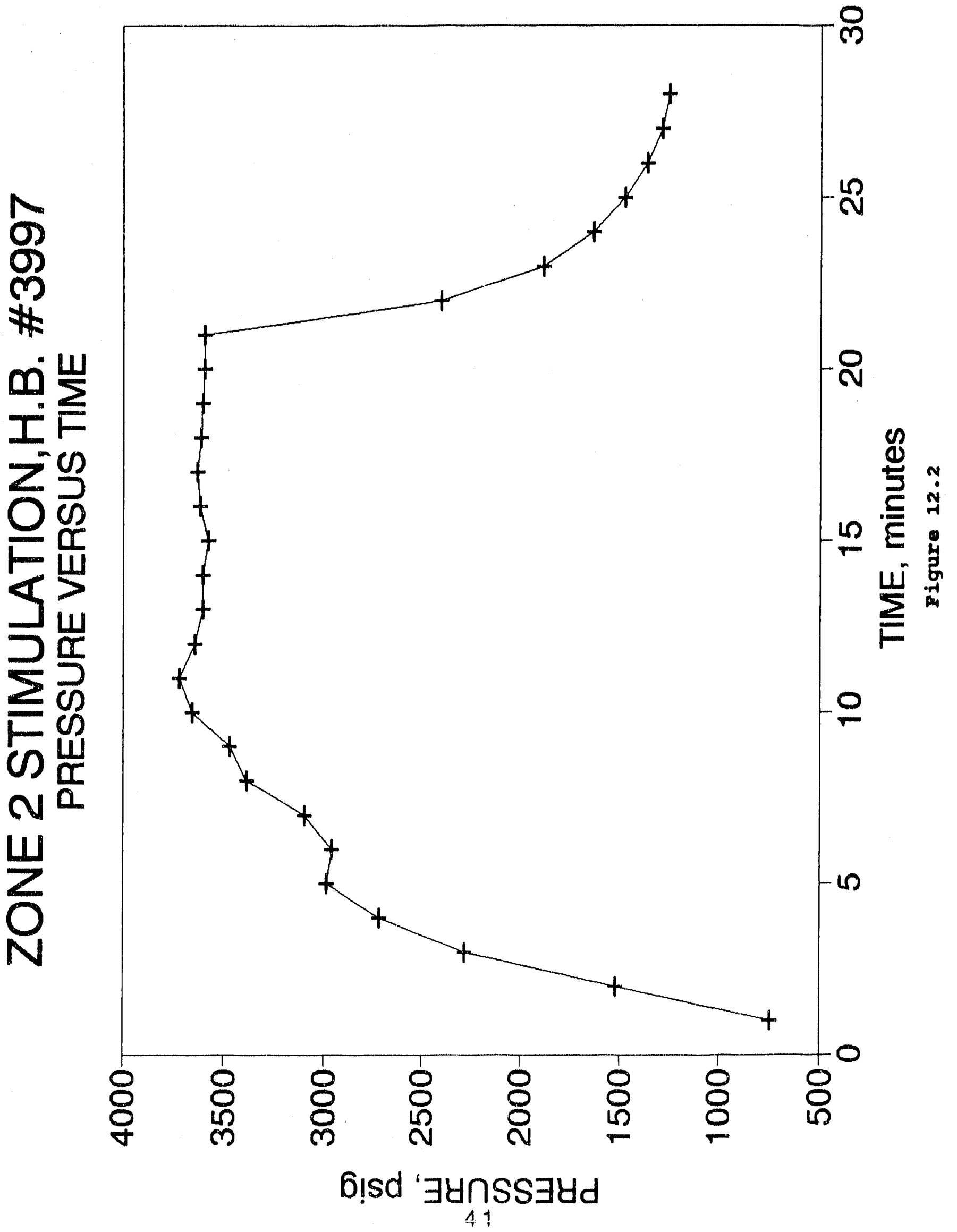




\subsection{Analysis of Stimulation Operations}

The stimulation in zone \#1 was conducted as planned. The breakdown pressure was a little higher than anticipated, but did not present any problems. The higher breakdown pressure and resulting higher average treating pressure prevented BDMESC from getting the planned average injection rate of $70,000 \mathrm{scf} /$ minute as the pressure approached the stated upper limit of 4000 psig for the frac job (see figure 12.1).

The fact that the zone produced significant gas after stimulation is indicative that a vertical fracture of at least 30 to 40 feet vertical in height was generated and propagated through the formation. This is the height that a fracture would have to travel in order to contact the beds that contained hydrocarbons in the front end of the well.

The stimulation of zone \#2 was much smoother than that conducted in zone\#1. All of the design parameters were obtained during the course of the frac job. This was exactly what was expected since a reservoir pressure of 450 psig was detected when the port collars in zone \#2 were opened as opposed to zone \#1 which had a reservoir pressure of only $38 \mathrm{psig}$ after a bulld-up of several months. The average treating pressure of $3600 \mathrm{psig}$ was $200 \mathrm{psig}$ lower than that of zone \#1. The average injection rate of 88,000 was $20,000 \mathrm{scfm}$ higher than the rate for zone \#1.

In summary, the stimulation operations were completed as planned with only minor deviations that presented no real problems in the overall treatments and results.

\subsection{WELL TESTING OPERATIONS}

The initial open flow test of gas production was conducted just before cementing the $51 / 2^{\prime \prime}$ casing in the hole. The gas gauged 80 mcfd 48 hours after reaching T.D. This measurement was made with all of the exposed formations producing. Just before stimulating zone \#1, gas flow was estimated at 2 to 3 mcfpd but was really to low to gauge through 2 " 
pipe. This would indicate that the largest volume of natural gas flow was coming from zones 4,5 , and 2 in the order of importance.

Twenty four hours after stimulation of zone \#1, the gas flow was $520 \mathrm{mcfd}$ and was estimated to carry at least 60 percent nitrogen. Ten days later the gas from zone \#1 was pretty well cleaned up and gauged 200 mofd.

A seven day pressure build-up and drawdown test was agreed to by the well sperator as a means of determining the improved deliverability of zone \#1, and the base case for this end of the reservoir by examining zone \#2 pre-frac conditions. This test also provided an opportunity to determine if the external casing packer had maintained it's integrity during the frac job. DOE requested a pre-frac drawdown test and a post frac pressure build-up on zone \#2.

An RTTS packer was set in the $51 / 2^{n}$ casing to isolate zone \#1 after opening up port collar \#1. The intent was to conduct a pressure bulld -up of zone \#1 on the tubing and a drawdown test on zone \#2 on the annular space. Initially the seal on the RTTS packer seamed to be holding and, within a period of 45 minutes, there was a difference of $25 \mathrm{psig}$ between zone \#1 and \#2. The test was begun approximately 4:00 p.m. on Friday and the well was not checked again until Tuesday, 4 days into the test. At this time it had not been determined that the RTTS packer was leaking and we could not understand why both zones had stabilized at a pressure of 450 psig (\#1-455, \#2-450).

This result was quite disturbing, and it was decided that we needed to determine if the zones were pressure separated and if zone \#2 could be stimulated, or perhaps the packer had falled and zone \#2 was already stimulated. BDMESC decided to conduct a pressure pulse test with the equipment in place as it was configured. Both sides were shut in for a 24 hour build-up, and then one side was flowed for 30 minutes and then shut in for 30 minutes to create the pressure pulses. We estimated that a .1 to .5 psig pressure indication would indicate the pulse had moved through the reservoir. A larger pressure response would likely indicate equipment failure. The results presented in figure 13.1 showed an almost 


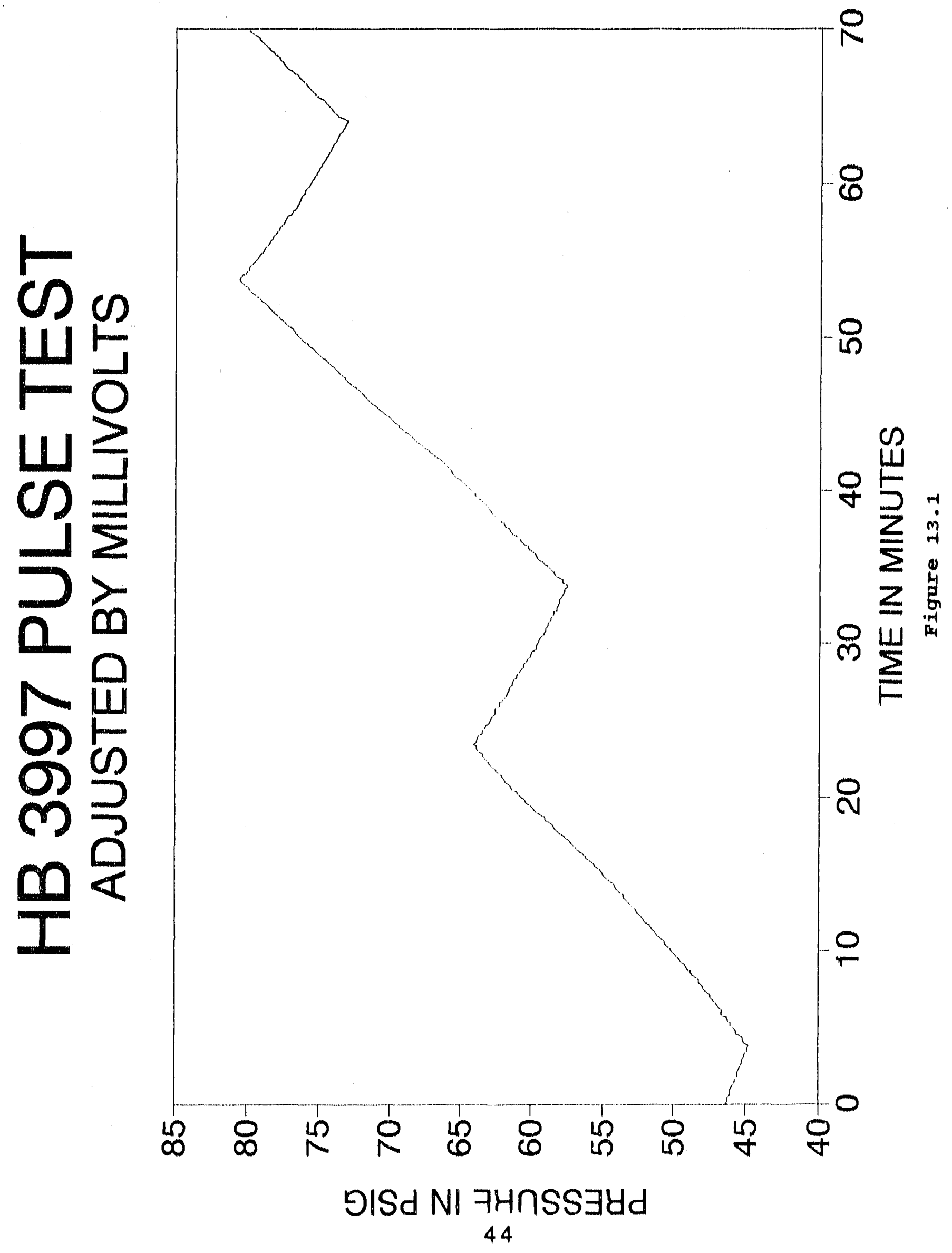


Instantaneous pressure response during the drawdown stage indicating the RTTS packer was not set properly and was leaking. This meant that the stimulation could proceed as planned.

The test equipment was removed from the wellbore and zone \#2 was stimulated (10/9/91). The well flowed back for seven days and then was shut in for a seven day pressure bulld-up test. The results of the test are presented in figure 13.2. Zone \#2 rapidly built up pressure to $375 \mathrm{psig}$ in six hours and had reached stabilized pressures of 560 psig in 148 hours. Prior to stimulation, the formation had only bullt up pressure to $450 \mathrm{psig}$ In more than 6400 hours of shut-in time.

After the pressure build-up test was completed, the tools were tripped out of the hole and as the first port collar was opened in each zone the isolation tool was used to straddle the port thus we were able to measure the initlal open flow production rates for the well. This zone testing after stimulation is presented in Table 13.1.

After well testing was completed, a seating nipple was added and the string of $4100^{\prime}$ of $23 / 8$ " production tubing was run in the well and hooked up to flow thru a separator and the well was ready for production when ever the pipeline should be completed.

\subsection{Production Testing}

The well was place on production on January 17, 1992, three months after stimulation and testing operations were completed in October 1991. After a three month shut-in, the surface pressure recorded on the tubing was $605 \mathrm{psig}$ which is considerably higher than the stabilized pressure of 560 psig recorded for zone \#2 post stimulation. This would tend to indicate some differences in reservoir pressure exist from one end of the well to the other, or a faulty pressure recording device. Evaluation of other wells in the area for reservoir pressure data led to a projection of reservoir pressure expected in the horizontal well area of $580 \mathrm{psig}$. Both numbers are reasonably close to projections which leads us to conclude that the differences in pressures are valid. The front end of the well had gas shows which were more frequent and of larger volumes than the back end of the well which had fewer shows and of lower 

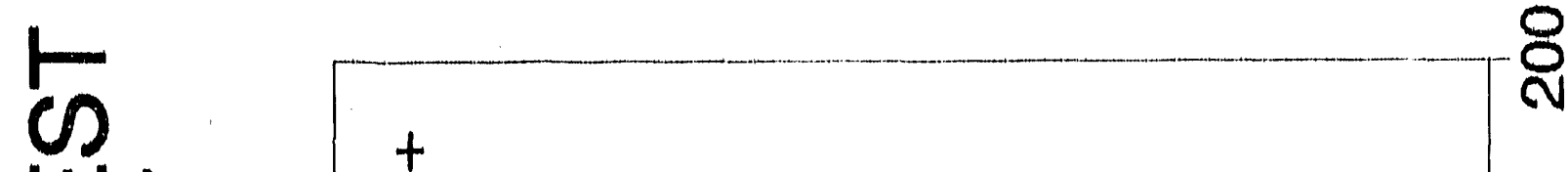

Ш

․

늑

号

$\overline{3}$ Z

뜨

崖邑

N

ᄂ

$z^{N}$

Ш

एᄂ

$\boldsymbol{S}$

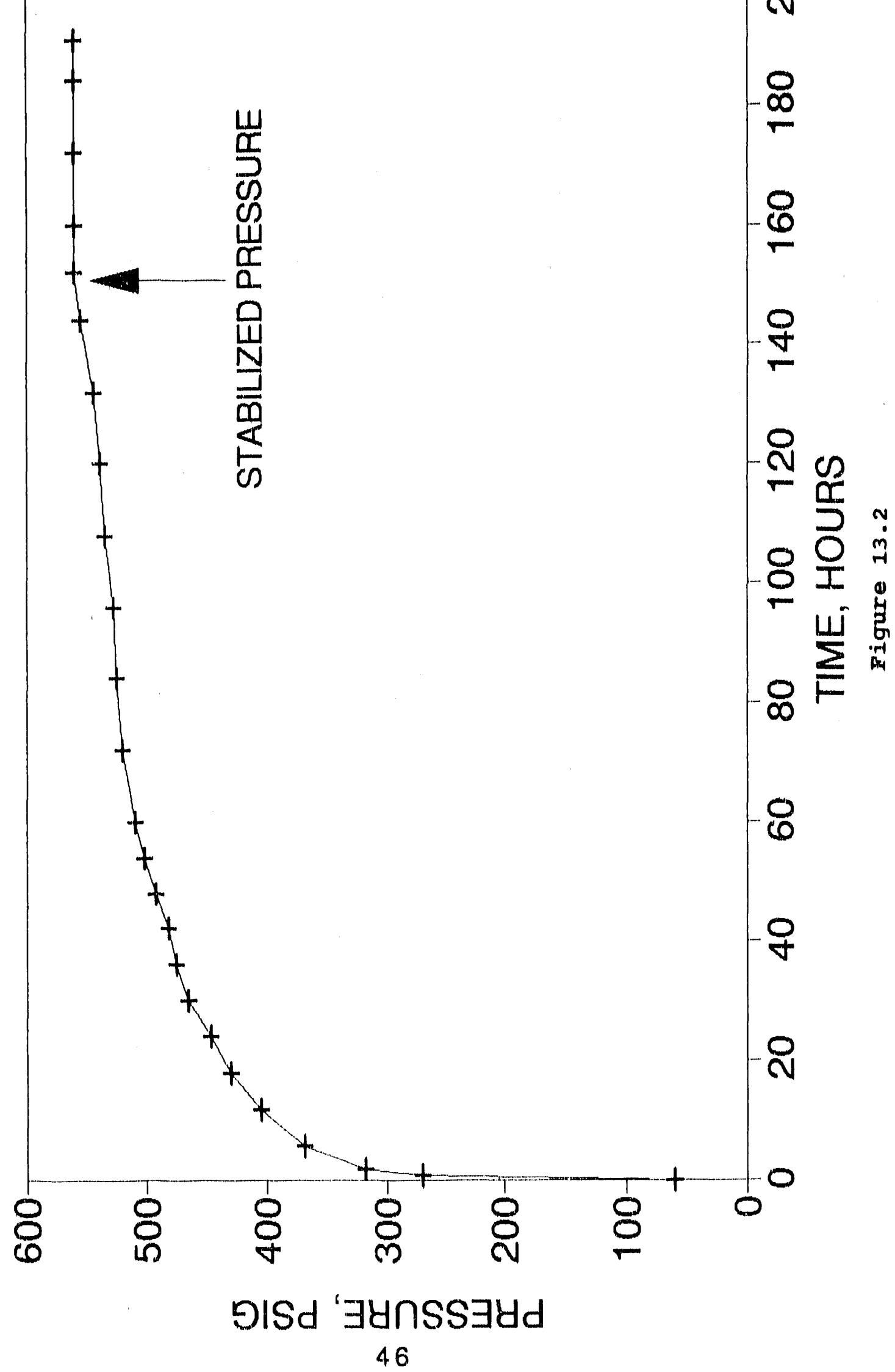


TABLE 13.1 - ZONE TESTING AFTER STIMULATION OF H.B.\#3997

$\begin{array}{lccc}\text { ZONE } & \text { ERAC VOLmmof } & \text { MEASURED OPENFLOWmofd } & \text { CUMM } \\ 1 & 1.5 & 420 & 420 \\ 2 & 1.5 & 183 & 603 \\ 3 & \text { NS } & 90(1) & 693 \\ 4 & \text { NS } & 120_{(2)} & 813 \\ 5 & \text { NS } & 80_{(3)} & 893^{*}\end{array}$

NOTE - NS means not stimulated

(1) - Production from zones $3,4, \& 5$ are esti nated

(2) - Flowing time for zone is 1 hour, gas not measured because of oll flow estimated at 10 bbls per day rate.

(3) - Flowing time is 1 hour, oil estimated at 8 bbl per day rate

* Final open flow rate after 8 hours of testing was 280 mcid and 2 bbls oil/day. 
volumes. The six month shut-in pressure of only 38 psig prior to stimulation also indicates that the reservoir in contact with the wellbore is much tighter. It is also possible that the guide shoe was plugged and no pressure could be recorded.

With 52 psig line pressure, the well produced at an average rate of 147 mcid for the first seven days. The well produced only gas for the first four weoks and then started producing oll at a rate of 2 bbls per day. Production detalls are presented in Appendix $\mathrm{J}$ for the period avallable.

\subsection{ANALYSIS OF COMPLETION, STIMULATION, AND TESTING}

Completion operations were carried off without any problems. The procedure of inflating the farthest ECP first and then traveling back toward the near end of the borehole is a sound procedure. The cementing of a portion of the casing above the ECP's is optional and was used in this case to eliminate potential future water incursion problems.

The similar procedure of stimulating the farthest from the wellhead first (zone \#1) is a conservative but wise procedure. In dealing with completion problems in horizontal holes, problems and remedies are often exaggerated, and more costly to accomplish. Normally the most difficult part of the stimulation operation is the clean up after initial flow back, especially when sand has been injected. However in this case where only nitrogen gas was used, it was only necessary to let the well flow until the nitrogen content was below 4 percent and the well was ready for production.

Well testing after stimulation of zone \#1 was inconclusive because of the failure of the RTTS packer to seat properly and make a pressure seal. Because the tubing and packer are lying on their side within the casing it is much more difficult to judge when a $J$ - ing operation is successful than in a vertical well. The pressure build up test on zone \#2 went fine, however a drawdown test was not conducted because of the time involved, and the period of performance of the contract was expiring within two months. Sufficient data was not obtained to be able to calculate the permeability improvement in the stimulated zones as was performed on the Hardy \#1 well in Putnam County, West Virginia. 


\subsection{WELL COST ANALYSIS}

The BDM/CiNGD well represents the cost improvements that were realized from the lessons learned from the BDM/CABOT well. The cost of drilling and completing the BDM/CNGD well was significantly lower than those of the BDM/CABOT well. Overall improvements in steering tool performance, rates of angle build, reduced logging program, and an improved stimulation fluid (nitrogen) contributed to the reduction in cost. In particular, the reduced cost of opening and closing of port collars during stimulation and clean-up operations represented a significant savings.

Table 15.1 presents the costs associated with each phase of activity on the well. The horizontal well at a cost of $\$ 616,000$ is about three times more costly than the average vertical hole drilled in the area.

Detailed economic analysis of this well will be presented in the final report," Site Selection, Drilling, and Completion of Two Horizontal Wells in the Devonian Shale in West Virginia".

\subsection{SUMMARY AND CONCLUSIONS}

The Hunter Bennett \#3997 was successfully drilled with air as the circulating medium without any major problems. One minor problem with a stiff BHA resulted in a short deviation from the main hole but that was corrected. Drilling tendencies of the formations penetrated produced increased down-drag when the well reached an inclination of 95 degrees instead of holding angle at or near 90 degrees. The continued angle building took the hole above the target zone over a course length of about 350 feet before the right BHA could be employed to bring it back down. BDMESC geologists speculated that inclination of the beds due to faulting produced the drilling tendencies that were so hard to overcome.

Drilling operations were further reduced to approximately twentyfive days on this well, but this may be related to the fact that the well is one thousand feet shorter in measured depth than previous horizontal wells. 
Table 15.1 - Cost Data BDM/CNGD Horizontal Well

DRILLING ACTIVITIES

ITEM DESCRIPTION

BDM/CNGD/DOE

Drilling \& Services

195,600

Directional Driller Services

35,000

Steering Tool \& Directional Tool Rental

13,565

Directional Consultant Engineer - GSM

58,716

Rentals (Reamers, Stabilizers, Other)

Drilling Fluid Additives

Tubulars

12,572

59,074

Cementing

13,691

External Casing Packers \& Port Collars

36,622

Build Location, Reclamation \& Dozer

19,513

Mud Logging

13,968

Field Engineer (Vertical Hole)

2,766

Drill Pipe Inspection

Power Tongs

Permit \& Survey

Neter Setup \& Testing

Miscellaneous (Trucking \& Field Services)

DRILLING SUBTOTAL

477,837

CORING AND LOGGING ACTIVITIES

Coring

Shallow Logging

Deep Logging

5,000

26,594

CORINGLOGGING SUBTOTAL

31,594

STIMULATION ACTIVITIES

Setup \& Testing ECP's \& PC's

28,792

Dozer \& Road Work

1,365

Production Tubing, Tank Rental \& Water Hauling

14,620

Video Camera Runs

Operate ECP's \& PC's Services

15,119

Fishing Equipment

Frac Fluids \& Stimulation Equipment

Perforations

29,144

Field Engineer

0
3,952

1,071

Tool Rental \& Testing

5,500

Pip Disposal/Reclamation

7,094

Clean-Up

406

Trucking \& Miscellaneous

107,063

STIMULATION SUBTOTAL

616,495

GRAND TOTAL HORIZONTAL WELL COST 
These problems can be overcome with current S-O-A drilling technology such as using motor runs to correct the rate of angle build. However, these are expensive and BDMESC elected to stick with the drill plan which called for correction of these problems with rotary BHA's. Again, one of the objectives of this drilling operation was to reduce costs and improve the economics of horizontal wells in the Appalachian area. Failure to come up with a solution early resulted in the loss of about 300 feet of additional horizontal hole because of excessive down-drag.

Rates of penetration during both angle building and horizontal drilling phases need to be improved in future drilling operations to improve the economics of Appalachian basin wells.

It is important to have a well thought out drill plan with a number of alternative actions planned to reduce cost and manage risk. Projecting potential problems in advance of drilling with alternate solution scenarios is good planning.

A test well still needs to be drilled that will compare the results of a cemented and set through completion approach with that of an open hole type completion used in the first three wells drilled by BDMESC for DOE.

After having planned and participated in three (3) horizontal drilling operations in the Appalachian basin, BDMESC believes that statistics for horizontal wells may well be similar to vertical wells in that 95 percent of the vertical wells drilled wili require stimulation, and to date, all horizontal wells drilled in the basin have been stimulated. Of seven horizontal wells drilled since 1986, only one well could have been turned into the line without stimulation. This testifies to the importance of good geologic work in site selection. Site selection continues to be one of the most critical aspects of drilling a horizontal well. The primary utility is to take advantage of reservoir anisotrophy by drilling the well to intersect as many natural fractures as possible. Horizontal wells provide additional exposure of the producing formation to the wellbore, but stimulation is likely to be required in most operations. 
Considerable progress was made to both reduce costs and, at the same time, improve gas production rates as compared with the BDM/Cabot well. As a result, the BDM/CNGD well is projected to be economic at gas prices in excess of about $\$ 2.00 / \mathrm{mcf}$ or greater. The economic analysis is document in the final report to DOE, "Site Selection, Drilling, and Completion of Two Horizontal Wells in the Devonian Shales of West Virginia".

Horizontal well drilling technology is continually improving with the drilling of each well. We project a 10 to 15 percent reduction in investment costs over the next five years with this improving technology. However, continued technology improvements and/or higher well head prices will be required to make horizontal wells economically attractive in the Appalachian area. 


\subsection{REFERENCES}

1. Overbey, W.K. Jr., Salamy, S.P., Locke, C.D., "Recovery Efficiency Test Final Report," U.S. Department of Energy, Contract DE-AC21-85MC22002, Morgantown, West Virginia, February, 1989.

2. Reeves, T.K., Overbey, W.K. Jr., Locke, C.D., Salamy, S.P., "Selection of Area and a Specific Site for Drilling a Horizontal Well in Calhoun County, West Virginia," U.S. Department of Energy, Contract DE-AC21-89MC25115, Morgantown, West Virginia, September, 1990.

3. Overbey, W.K., Carden, R.S., Locke, C.D., Salamy, S.P., "Drilling, Completion, Stimulation, and Testing of Hardy HW\#1 Well, Putnam county, West Virginia," U.S. Department of Energy, Contract DE-AC21-89MC25115, Morgantown, West Virginia, March, 1992.

5. Overbey, W.K., Carden, R.S., Locke, C.D., Salamy, S.P., Reeves. T.K., Johnson, H.R., "Site Selection, Drilling, and Completion of Two Horizontal Wells in the Devonian Shales of West Virginia," U.S. Department of Energy, Contract DE-AC21-89MC25115, Morgantown, West Virginia, March, 1992. 


\section{APPENDICES}

APPENDIX

PAGE

A CASING TALLYS $\quad 55$

9 5/8" Casing Tally 11/14/90 55

5 1/2" Casing Tally 12/01/90 56

B BOTTOM HOLE DRILLING ASSEMBLIES (BHA'S)

C BUILD AND WALK RATE DATA FOR H, BENNETT \#3997 60

D DRILL PIPE TALLY 61

E GAS SHOWS AS DETERMINED FROM HYDROCARBON MUD LOG 62

F DAILY DRILLING REPORT 63

G DAILY COST REPORT 102

H DAILYLOG OF OPERATIONS 122

$1 \quad$ STIMULATION OPERATIONS 138

Stimulation Operations Plan 138

Zone \#1 Stimulation Summary 143

Production Decline From Zone \#1 148

Zone \#1 Build-up, Zone \#2 Drawdown 149

Zone \#2 Stimulation Summary 150

Gas Analyses from Different Zones 154

$\begin{array}{llr}J & 156\end{array}$

Gas Production Rate Decline $\quad 157$

Cumulative Gas Production 158

Oil Production Rate Decline 159

Cumulative Oil Production $\quad 160$ 


\section{APPENDIX A-1}

\section{5/8" CASING TALLY 11/11/90}

\begin{tabular}{rrrrrr}
$\begin{array}{c}\text { JOINT } \\
\text { NUMBER }\end{array}$ & LENGTH & \multicolumn{1}{c}{ TOTAL } & $\begin{array}{r}\text { JOINT } \\
\text { NUMBER }\end{array}$ & LENGTH & TOTAL \\
1 & 43.45 & 43.45 & 26 & 43.65 & 1135.80 \\
2 & 43.75 & 87.20 & 27 & 43.70 & 1179.50 \\
3 & 43.90 & 131.10 & 28 & 43.85 & 1223.35 \\
4 & 43.50 & 174.60 & 25 & 42.15 & 1265.50 \\
5 & 43.60 & 218.20 & 30 & 44.20 & 1309.70 \\
6 & 43.45 & 261.65 & 31 & 43.85 & 1353.55 \\
7 & 43.75 & 305.40 & 32 & 43.65 & 1397.20 \\
8 & 43.80 & 349.20 & 33 & 43.50 & 1440.70 \\
9 & 43.75 & 392.95 & 34 & 44.10 & 1484.80 \\
10 & 43.95 & 436.90 & 35 & 44.25 & 1529.05 \\
11 & 43.70 & 480.60 & 36 & 42.65 & 1571.70 \\
12 & 43.45 & 524.05 & 37 & 43.95 & 1615.65 \\
13 & 43.60 & 567.65 & 38 & 43.60 & 1659.25 \\
14 & 43.15 & 610.80 & 39 & 43.55 & 1702.80 \\
15 & 43.95 & 654.75 & 40 & 43.75 & 1746.55 \\
16 & 43.50 & 698.25 & 41 & 43.35 & 1789.90 \\
17 & 43.95 & 742.20 & 42 & 43.85 & 1833.75 \\
18 & 44.10 & 786.30 & 43 & 43.45 & 1877.20 \\
19 & 43.90 & 830.20 & 44 & 43.60 & 1920.80 \\
20 & 43.45 & 873.65 & 45 & 44.10 & 1964.90 \\
21 & 44.10 & 917.75 & 46 & 43.75 & 2008.65 \\
22 & 43.60 & 961.35 & 47 & 43.80 & 2052.45 \\
23 & 43.50 & 1004.85 & 48 & 43.55 & 2096.00 \\
24 & 43.75 & 1048.60 & & & \\
25 & 43.55 & 1092.15 & & &
\end{tabular}




\section{APPENDIX A-2}

CASING TALLY - 12-11-90

\begin{tabular}{|c|c|c|c|c|c|c|c|c|c|c|}
\hline \multirow{2}{*}{\multicolumn{2}{|c|}{ JOINT }} & & SET & $\mathrm{JC}$ & [NT & & SET & JOINT & & SET \\
\hline & & LENGTH & DEPTH & NUMI & BER & LENGTH & DEPTH & NUMBER & LENG'TH & DEPTH \\
\hline$C$ & $10 E$ & 1.00 & 4755.55 & & 37 & 42.35 & 3160.35 & 85 & 40.55 & 1140.25 \\
\hline & 1 & 42.60 & 4754.55 & $\mathrm{ECP}$ & $\# 6$ & 9.20 & 3118.00 & 86 & 42.70 & 1099.70 \\
\hline & 2 & 42.70 & 4711.95 & & 38 & 36.50 & 3108.80 & 87 & 41.35 & 1057.00 \\
\hline & 3 & 42.60 & 4669.25 & PC & $\# 9$ & 2.95 & 3072.30 & 88 & 42.60 & 1015.65 \\
\hline & 4 & 42.25 & 4626.65 & & 39 & 42.60 & 3069.35 & 89 & 42.65 & 973.05 \\
\hline$E C P$ & $\# 1$ & 9.20 & 4584.40 & & 40 & 42.70 & 3026.75 & 90 & 41.45 & 930.40 \\
\hline & 5 & 42.60 & 4575.20 & & 41 & 42.60 & 2984.05 & 91 & 41.30 & 888.95 \\
\hline PC & \#1 & 2.95 & 4532.60 & & 42 & 42.40 & 2941.45 & 92 & 42.70 & 847.65 \\
\hline & 6 & 42.20 & 4529.65 & & 43 & 42.35 & 2899.05 & 93 & 39.70 & 804.95 \\
\hline & 7 & 42.60 & 4487.45 & & 44 & 41.00 & 2856.70 & 94 & 42.65 & 765.25 \\
\hline & 8 & 42.35 & 4444.85 & & 45 & 42.65 & 2815.70 & 95 & 42.55 & 722.60 \\
\hline & 9 & 42.75 & 4402.50 & & 46 & 42.20 & 2773.05 & 96 & 42.75 & 680.05 \\
\hline & 10 & 42.35 & 4359.75 & & 47 & 38.45 & 2730.85 & 97 & 41.05 & 637.30 \\
\hline & 11 & 41.70 & 4317.40 & & 48 & 42.75 & 2692.40 & 98 & 42.70 & 596.25 \\
\hline PC & $\# 2$ & 2.95 & 4275.70 & & 49 & 42.60 & 2649.65 & 99 & 41.45 & 553.55 \\
\hline & 12 & 42.40 & 2.75 & & 50 & 42.55 & 2607.05 & 100 & 41.95 & 512.10 \\
\hline & 13 & 42.65 & 4230.35 & & 51 & 42.60 & 2564.50 & 101 & 41.70 & 470.15 \\
\hline $\mathrm{ECP}$ & $\# 2$ & 9.20 & 4187.70 & & 52 & 42.45 & 2521.90 & 102 & 41.90 & 428.45 \\
\hline & 14 & 42.45 & 4178.50 & & 53 & 40.80 & 2479.45 & 103 & 41.80 & 386.55 \\
\hline PC & $\# 3$ & 2.95 & 4136.05 & & 54 & 42.60 & 2438.65 & 104 & 41.75 & 344.75 \\
\hline & 15 & 42.60 & 4133.10 & & 55 & 42.75 & 2396.05 & 105 & 41.30 & 303.00 \\
\hline & 16 & 42.70 & 4090.50 & & 56 & 42.50 & 2353.30 & 106 & 41.85 & 261.70 \\
\hline & 17 & 42.60 & 4047.80 & & 57 & 42.65 & 2310.80 & 107 & 42.10 & 219.85 \\
\hline & 18 & 43.15 & 4005.20 & & 58 & 42.30 & 2268.15 & 108 & 42.35 & 177.75 \\
\hline & 19 & 40.95 & 3962.05 & & 59 & 42.75 & .85 & 109 & 42.65 & 135.40 \\
\hline & 20 & 42.60 & 3921.10 & & 60 & 42.70 & 2183.10 & 110 & 40.85 & 92.75 \\
\hline $\mathrm{PC}$ & $\# 4$ & 2.95 & 3878.50 & & 61 & 39.95 & 2140.40 & 111 & 41.90 & 51.90 \\
\hline & 21 & 40.75 & 3875.55 & & 62 & 42.25 & 2100.45 & 112 & 42.65 & 10.00 \\
\hline EC.P & $\# 3$ & 9.20 & 3834.80 & & 63 & 40.80 & 2058.20 & 113 & 41.05 & OUT \\
\hline & 22 & 42.55 & 5.60 & & 64 & & 2017.40 & 114 & 42.55 & OUT \\
\hline PC & $\# 5$ & 2.95 & 3783.05 & & 65 & 42.75 & 1978.30 & 11.5 & 39.20 & OUT \\
\hline & 23 & 42.45 & 3780.10 & & 66 & 42.70 & 1935.55 & 116 & 42.70 & OUT \\
\hline & 24 & 42.70 & 3737.65 & & 67 & 42.60 & .85 & 117 & 42.25 & OUT \\
\hline & 25 & 40.55 & 3694.95 & & 68 & 42.70 & 1850.25 & 118 & 40.65 & OUT \\
\hline & 26 & 40.60 & 3654.40 & & 69 & 39.35 & 1807.55 & 119 & 39.10 & OUT \\
\hline & 27 & 42.60 & .80 & & 70 & 35 & .20 & 120 & 41.95 & OUT \\
\hline & 28 & 42.75 & 3571.20 & & 71 & 35 & 85 & 121 & 42.65 & OUT \\
\hline PC & $\# 6$ & 2.95 & 3528.45 & & 72 & 42.70 & 1686.20 & 122 & 42.55 & OUT \\
\hline & 29 & 42.65 & 5.50 & & 73 & 42.20 & 3.50 & 123 & 42.60 & OUT \\
\hline ECP & $\# 4$ & 9.20 & 3482.85 & & 74 & 42.60 & 1.30 & 124 & 42.65 & OUT \\
\hline & 30 & 42.65 & 3473.65 & & 75 & 42.55 & 8.70 & 125 & 42.80 & OUT \\
\hline PC & $\# 7$ & 2.95 & 3431.00 & & 76 & 42.50 & 1516.15 & 126 & 42.55 & OUT \\
\hline & 31 & 42.10 & 3.05 & & 77 & 42.70 & .65 & 127 & 41.10 & OUT \\
\hline & 32 & 42.75 & 5.95 & & 78 & 38.00 & 0.95 & 128 & 42.65 & OUT \\
\hline & 33 & 42.75 & 3343.20 & & 79 & 42.30 & 1392.95 & 129 & 42.70 & OUT \\
\hline & 34 & 42.7 & 0.45 & & 80 & & 0.65 & 130 & 42.70 & OUT \\
\hline & 35 & 42.70 & 7.75 & & 81 & 41.00 & 1309.30 & 131 & 42.60 & OUT \\
\hline $\mathrm{PC}$ & $\# 8$ & 2.95 & 3215.05 & & 82 & 42.70 & 1268.30 & 1.32 & .2 .15 & OUT \\
\hline & 36 & 42.55 & & & 83 & 42.75 & 5.60 & & & \\
\hline $\mathrm{ECE}$ & $\# 5$ & 9. & 9 & & 84 & 42.60 & 1182.85 & & & \\
\hline
\end{tabular}




\section{APPENDIX B-1}

BHA \#1 - RUN 11-23-90 FROM 2165' TO 2598'

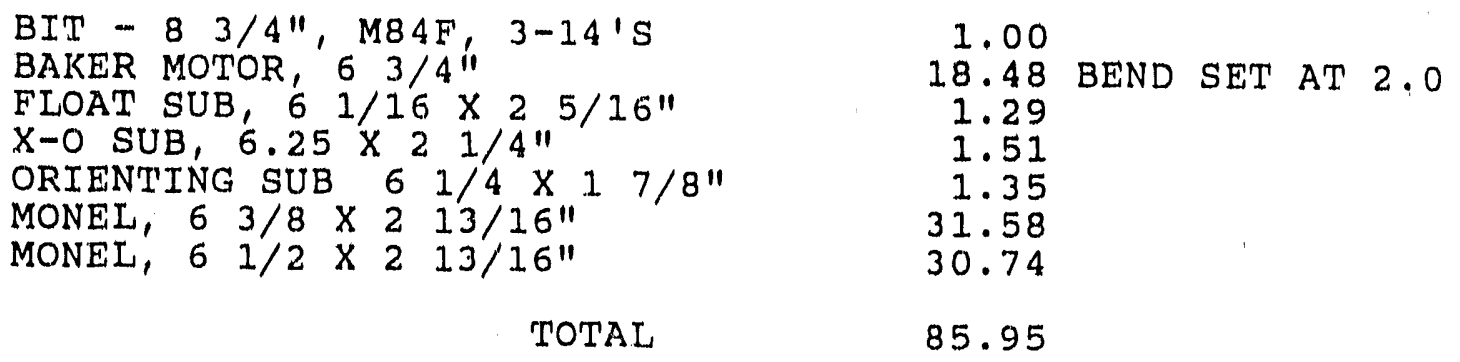

BHA \#2 - RUN 11-26-90 FROM 2598' TO 2773'

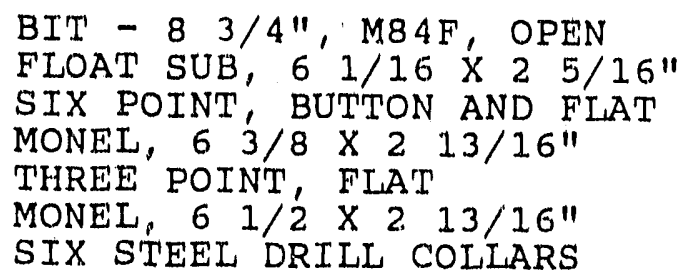

TOTAL 1.00

271.33
1.29

8.35

5.50

30.74

185.34

263.80
$61 / 2 \times 21 / 4^{\prime \prime}$
$61 / 4 \times 21 / 4^{\prime \prime}$
$6 \times 21 / 4^{\prime \prime}$

BHA \#4 - RUN 11-29-90 REAM ONLY

\section{BIT - $83 / 4 ", M 84 F$, open \\ FLOAT SUB, $61 / 16 \times 25 / 16 "$ \\ SIX POINT, BUTTON AND FLAT \\ MONEL, $63 / 8 \times 2$ 13/16" \\ MONEL, $61 / 2 \times 2$ 13/16" \\ SIX STEEL DRILL COLLARS}

1.00

1.29

8.35

31.58

30.74

185.34

$61 / 2 \times 21 / 411$

$6 \times 21 / 411$

T'OTAL

258.30 


\section{APPENDIX B-2}

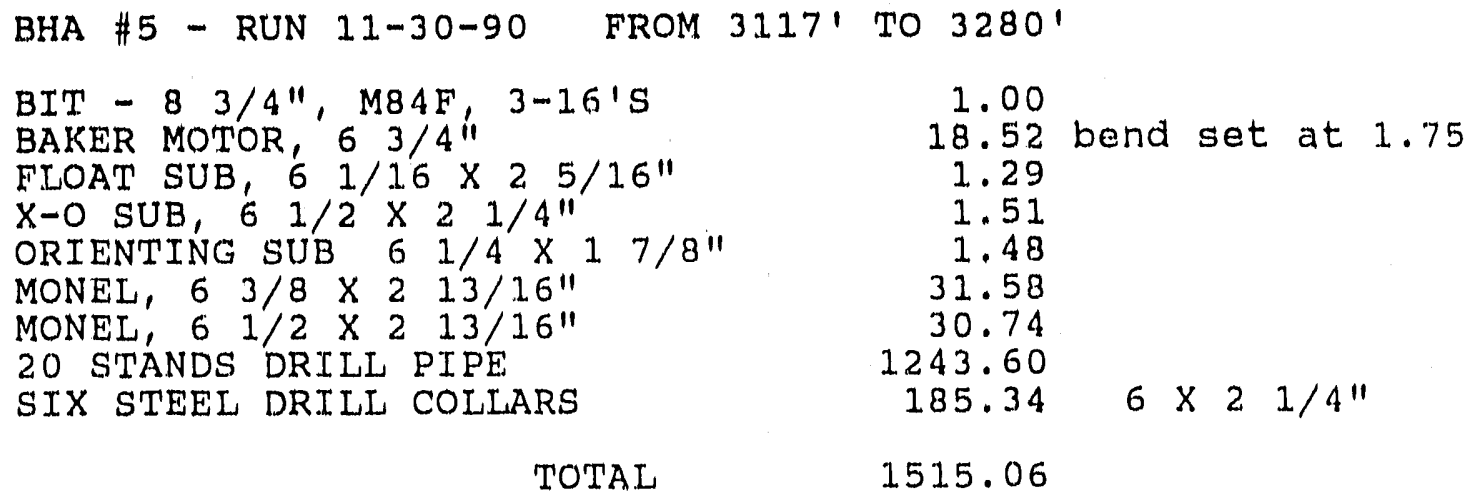

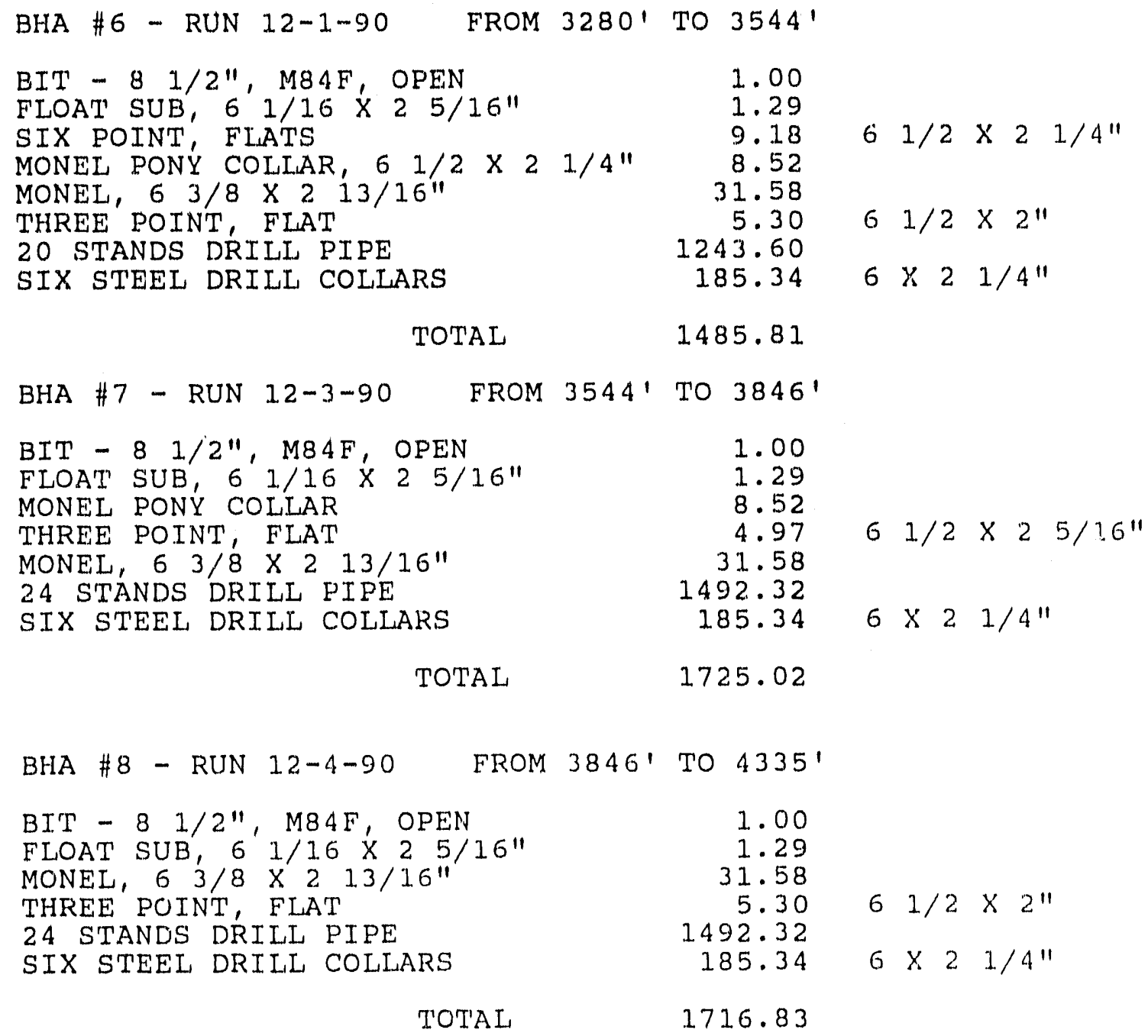




\section{APPENDIX B-3}

BHA \#9 - RUN 12-5-90 FROM 4335' TO $4665^{\prime}$

BIT - $81 / 2^{\prime \prime}, M 84 F^{\prime}, O P E N$

FLOAT SUB, $61 / 16 \times 25 / 16 "$

SIX POINT, FIATSS

PONY MONEL COLLAR

THREE POINT, FLAT

MONEI, $63 / 8 \times 213 / 16 "$

34 STANDS DRILI PIPE

12 STEEL DRILL COLLARS

TOTAL

BHA \#10-RUN 12-8-90 FROM 4665' TO $5013^{\prime}$

BIT - $81 / 2 ", M 84 F$, OPEN

FLOAT SUB, $61 / 16 \times 25 / 16^{\prime \prime}$

MONEI, $63 / 8 \times 213 / 16^{\prime \prime}$

37 STANDS DRILIL PIPE

18 STEEL DRILL COLLARS

TOTAL

1.00

1.29

31.58

2300.66

557.71

2892.24
1.00

1.29

9.18

8.52

4.97

31.58

2114.12

372.21

2542.87

$61 / 2 \times 21 / 4^{11}$

$61 / 2 \times 211$

$6 \times 21 / 41$ 


\section{APPENDIX C}

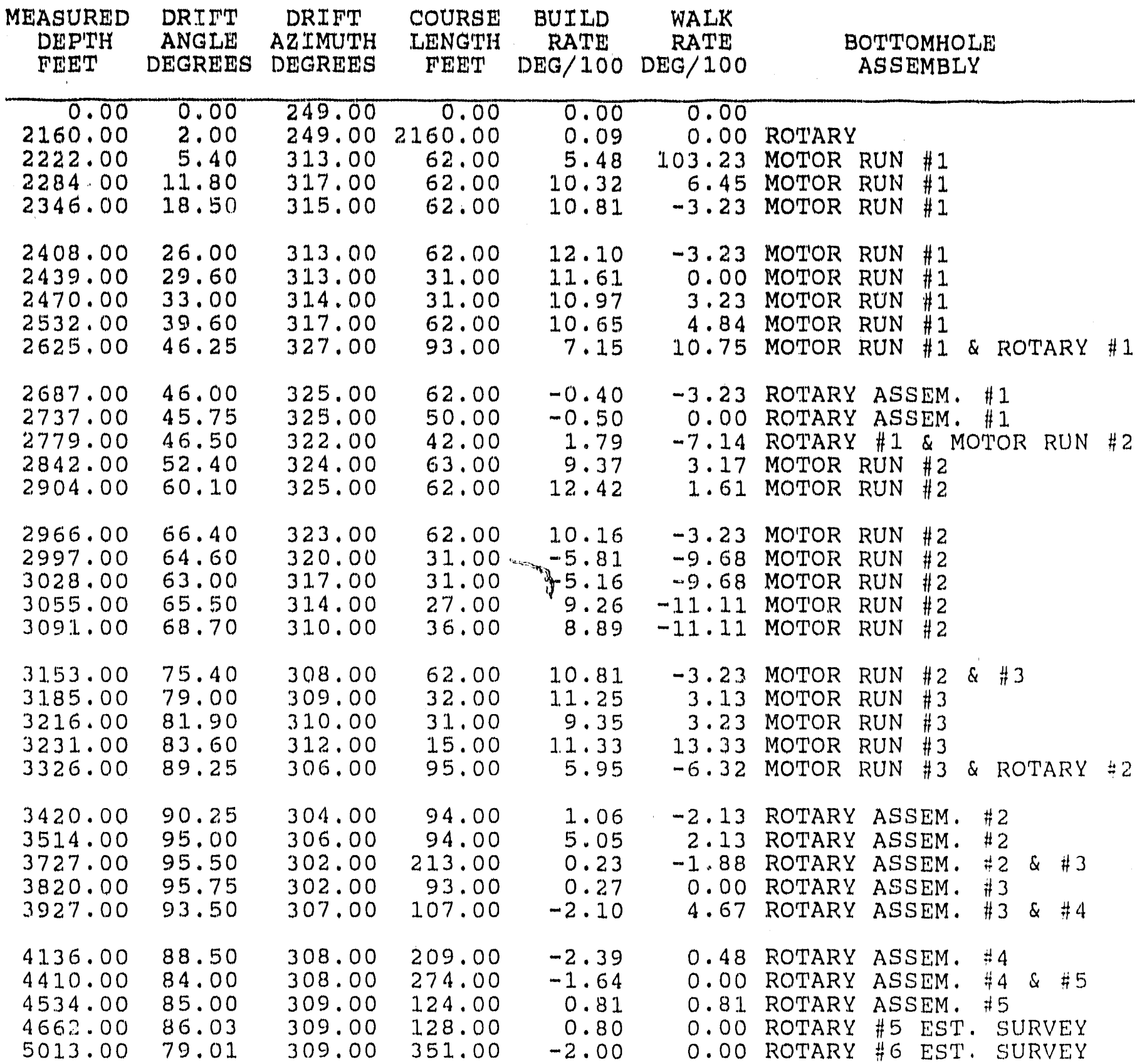




\section{APPENDIX D}

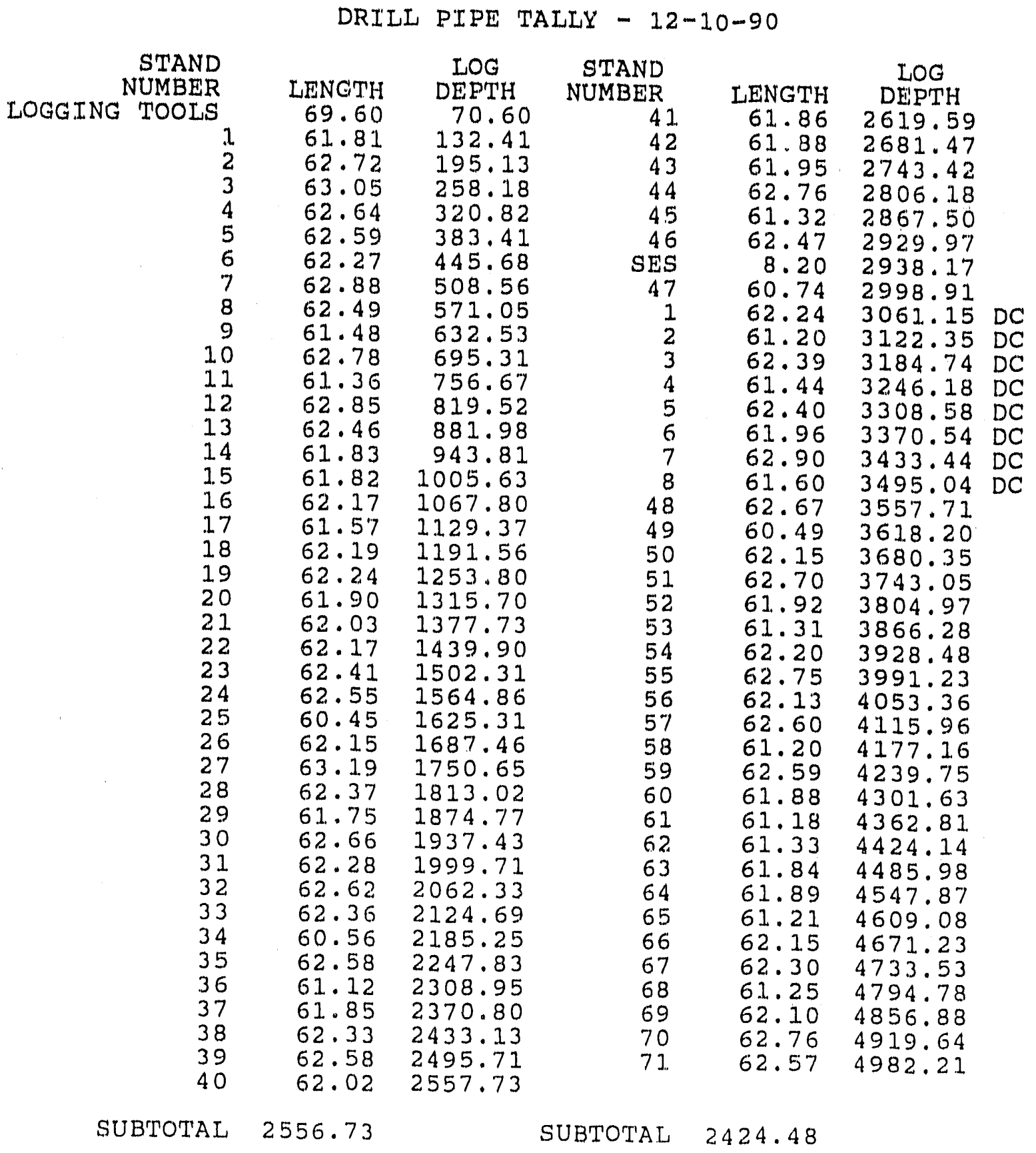




\section{APPENDIXE}

GAS SHOWS WHERE INCLINATION IS GREATER THAN $60^{\circ}$

Measured Depth

Mud Legger Shows, mafpd

\begin{tabular}{lr}
$2941^{\prime}$ & 7.0 \\
$3086^{\prime}$ & 5.2 \\
$3142^{\prime}$ & 8.0 \\
$3252^{\prime}$ & 3.5 \\
$3349^{\prime}$ & 4.0 \\
$3381^{\prime}$ & 70.0 \\
$3398^{\prime}$ & 11.0 \\
$3496^{\prime}$ & 45.0 \\
$3516^{\prime}$ & 40.0 \\
$3525^{\prime}$ & 65.0 \\
$3549^{\prime}$ & 54.0 \\
$3570^{\prime}$ & 42.0 \\
$3573^{\prime}$ & 43.0 \\
$3589^{\prime}$ & 270.0 \\
$3610^{\prime}$ & 75.0 \\
$3659^{\prime}$ & 48.0 \\
$4372^{\prime}$ & 27.0 \\
$4382^{\prime}$ & 29.0 \\
$4447^{\prime}$ & 32.0 \\
$4496^{\prime}$ & 40.0 \\
$4660^{\prime}$ & $33 . \bar{u}$ \\
$4715^{\prime}$ & 34.0 \\
$4802^{\prime}$ & 19.0 \\
$4808^{\prime}$ & 18.0 \\
$4816^{\prime}$ & 18.0 \\
$4834^{\prime}$ & 19.0 \\
$4971^{\prime}$ & 18.0 \\
\hline &
\end{tabular}




\section{APPENDIX F}

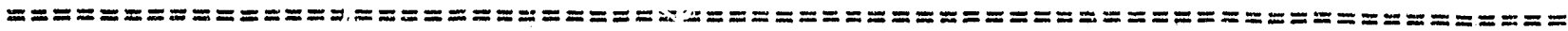
PETROLEUM CONSULTING SERVICES

P.O. BOX 35833

CANTON, OH 44735

( 216 ) $499-3823$

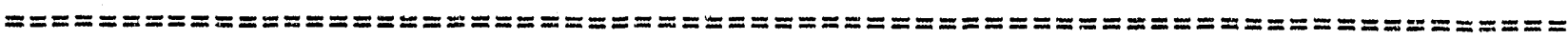

DATE: $11 / 09 / 90$

DAY \# 0

DAILY DRILLING REPORT

PAGE 1 OF 3

WELL:

HUNTER BENNETT 3997

TARGET:

DEVONIAN SHALE

WATERSHED :

CRUMMIS CREEK

QUAD:

DISTRICT :

MILLSTONE( 7.5 )

COUNTY:

LEE

CALHOUN

REPORT TIME 0600 EDST

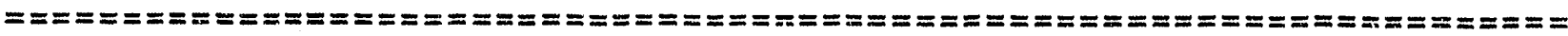
ACTIVITY

MOVE IN, RIG UP DRILLING RIG

MEAS DEPTH

0

FOOTAGE

0

HLU

HLD

ROT WT

TORQUE

RPM

TIME BREAKDOWN AND COMMENTS

\begin{tabular}{lcccc} 
FROM & TO & HRS & ACTIVITY \\
\hline $08: 00$ & $17: 00$ & 9.00 &
\end{tabular}

TOTAL 9.00 HRS

\section{$B H A$ :}




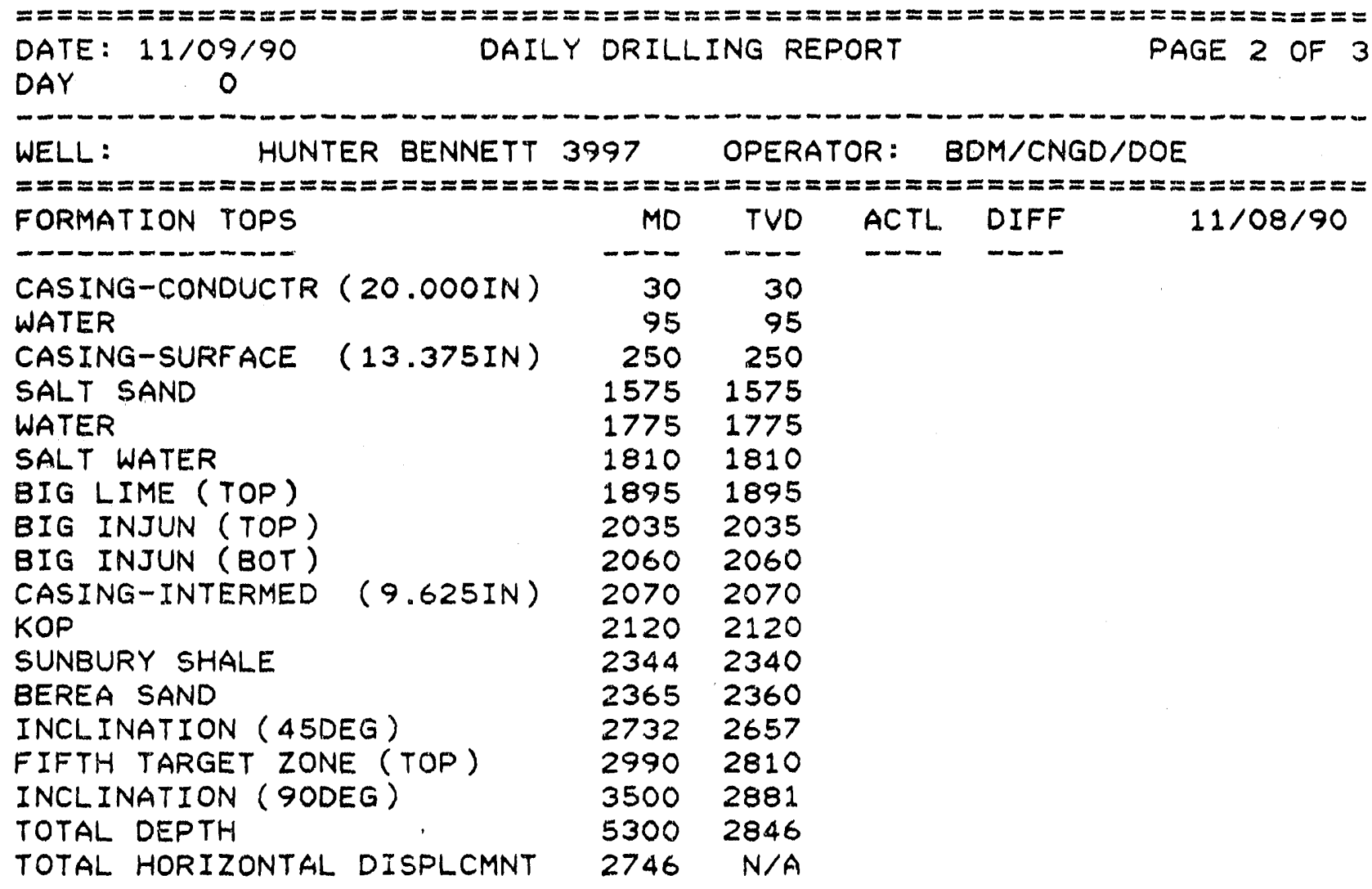

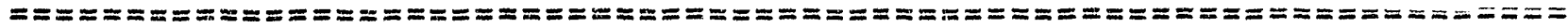




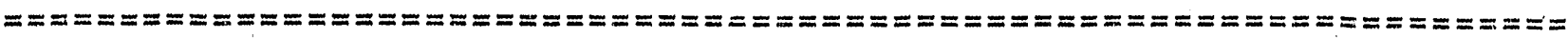
DATE: $11 / 09 / 90$

DAY

\section{WELL:}

HUNTER BENNETT 3997

OPERATOR :

$B D M / C N G D / D O E$

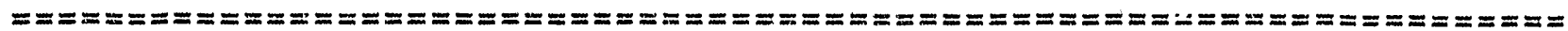

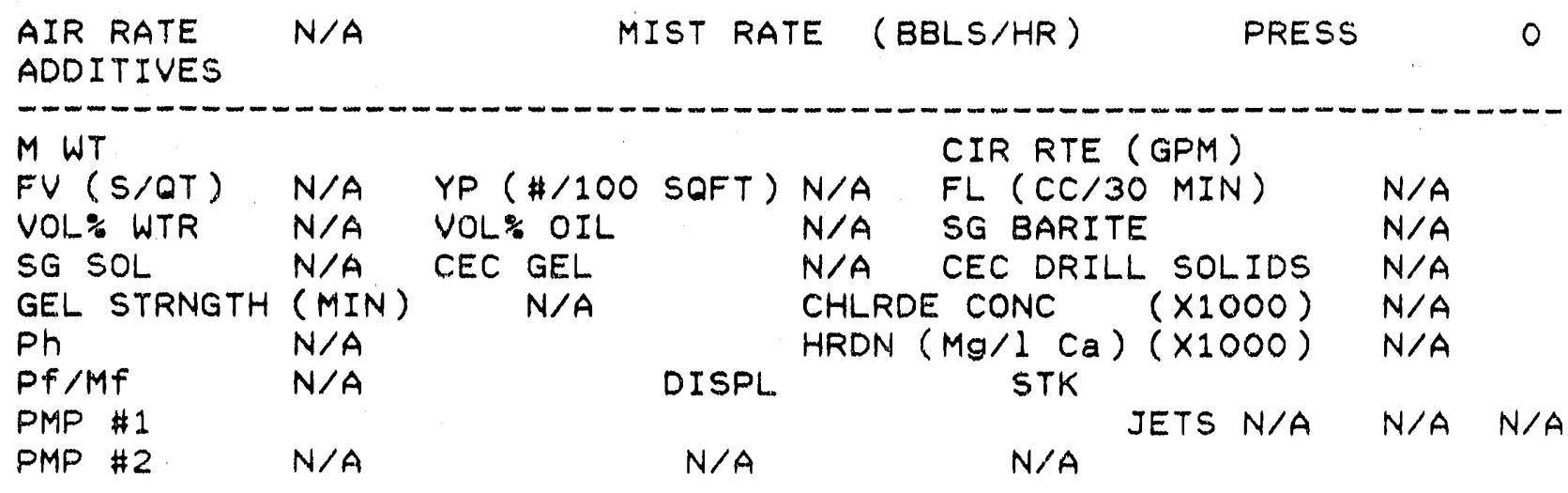

\section{SURVEYS}

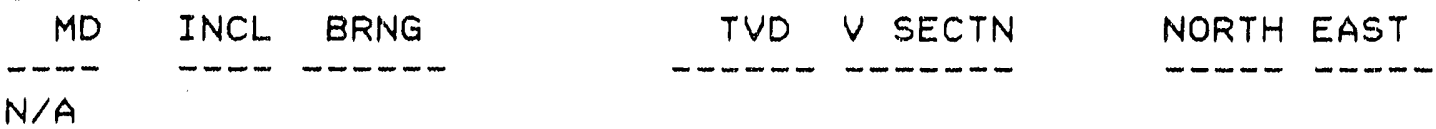




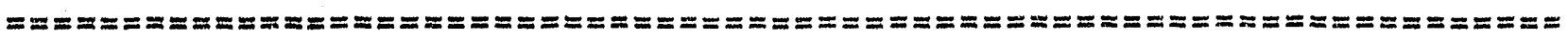
PETROLEUM CONSULTING SERVICES

P.O. BOX 35833

CANTON, OH 44735

( 216 ) $499-3823$

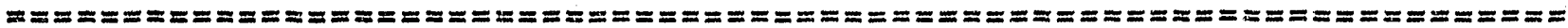

DATE: $11 / 10 / 90$

DAILY DRILLING REPORT

PAGE 1 OF 3

DAY \# 1

REPORT TIME 0600 EDST

$-\sim-m-\cdots-m-$

WELL:

HUNTER BENNETT 3997

TARGET:

DEVONIAN SHALE

WATERSHED:

QUAD:

DISTRICT:

COUNTY:

CRUMMIS CREEK

MILLSTONE( 7.5 )

LEE

CALHOUN

OPERATOR:

CONTRCTR:

RIG \#:

PERMIT \#:

ELEV GL:

ELEV KB:

BDM/CNGD/DOE

BURDETTE

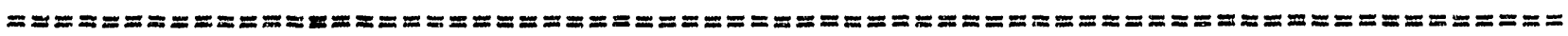
ACTIVITY DRILLING

MEAS DEPTH

TIME BREAKDOWN AND COMMENTS

\begin{tabular}{|c|c|c|c|c|c|}
\hline FROM & TO & HRS & & ACTIVITY & \\
\hline$--m-$ & $-\infty$ & --- & 10 & & \\
\hline $07: 00$ & $09: 00$ & 2.00 & $\begin{array}{l}\text { RIG UP } \\
\text { ORI RATRMSF HIF }\end{array}$ & & \\
\hline $\begin{array}{l}09: 00 \\
11: 00\end{array}$ & $\begin{array}{l}11: 00 \\
12: 00\end{array}$ & $\begin{array}{l}2.00 \\
1.00\end{array}$ & $\begin{array}{l}\text { ORL RAIQMSE HLE } \\
\text { DRL } 24 \text { IN HLE TO }\end{array}$ & $5 F T$, SET $20 I N$ & COND \\
\hline $12: 00$ & $14: 00$ & 2.00 & NU,HU FLO LNE & & \\
\hline $14: 00$ & $15: 00$ & 1.00 & DRLNG w/9IN HMR+ & 17.75 IN RLR & CNE BIT \\
\hline $15: 00$ & $15: 15$ & 0.25 & SER RIG & & \\
\hline $15: 15$ & $23: 45$ & 8.50 & DRLNG $132 \mathrm{FT}$ & & \\
\hline $23: 45$ & $23: 59$ & 0.25 & SER RIG & & \\
\hline $00: 00$ & $06: 00$ & 6.00 & DRLNG $240 F T$ & & \\
\hline
\end{tabular}

TOTAL 23.00 HRS

WATER

$0.50 I N$ FRESH $45 F T$

1.5OIN FRESH 21OFT

BHA: $\quad \operatorname{BIT}(1.00), X 0(2.00), 9 \operatorname{IN~HMR}(4.00), \times 0(2.00), 2-6.875 \times 2.25 D C$ $(59.54), 6-6.0 \times 2.25 \mathrm{DC}(187.59)$ BHA LENGTH 256.13 


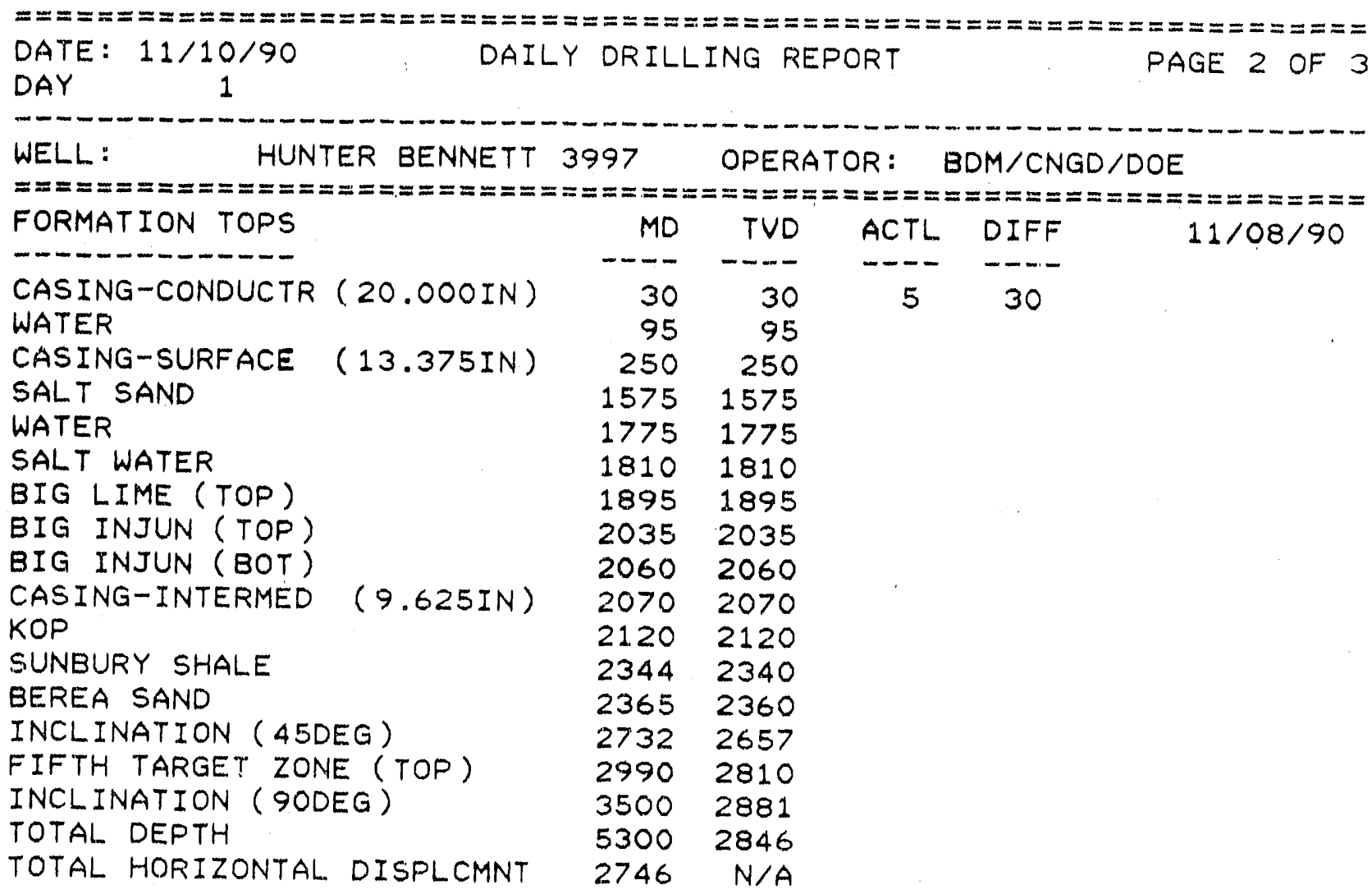

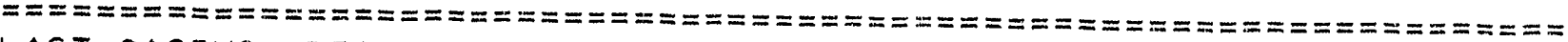

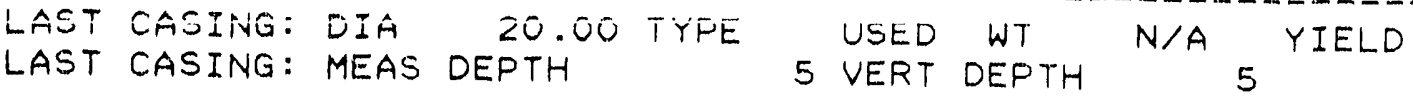




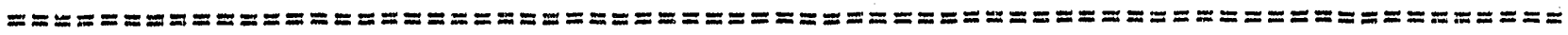
DATE: $11 / 10 / 90$ DAILY DRILLING REPORT

PAGE 3 OF 3 DAY 1

WELL: HUNTER BENNETT 3997 OPERATOR: BDM/CNGD/DOE

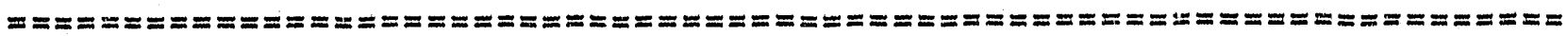

$\begin{array}{lll}\text { AIR RATE } & 3150 \\ \text { ADDITIVES MIST RATE (BBLS/HR) } 8 \text { PRESS }\end{array}$

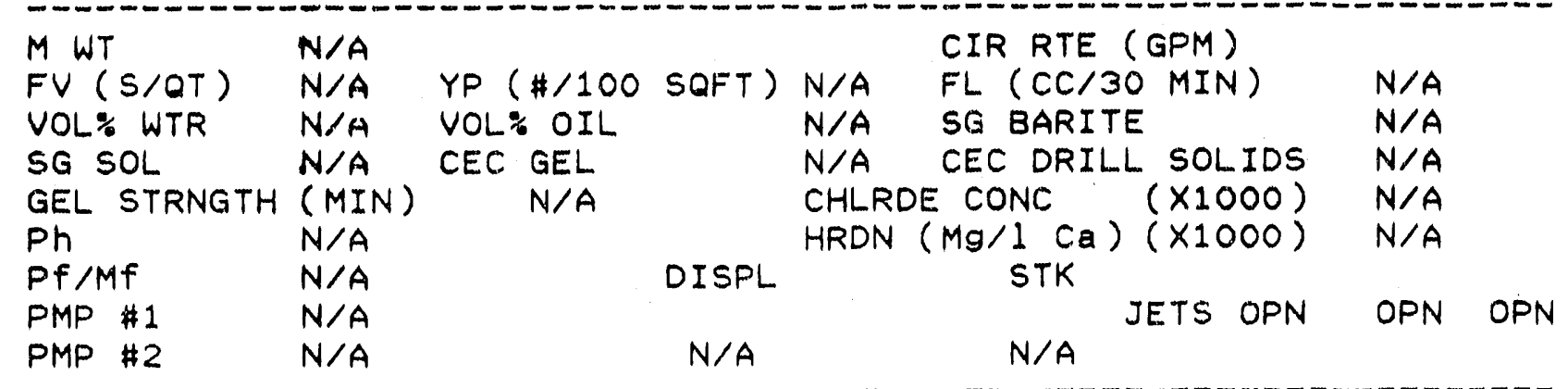

SURVEYS

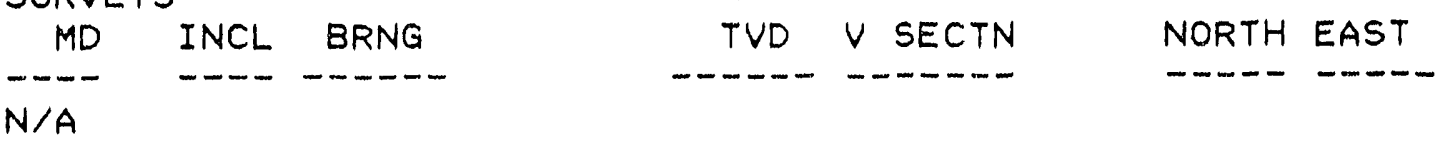

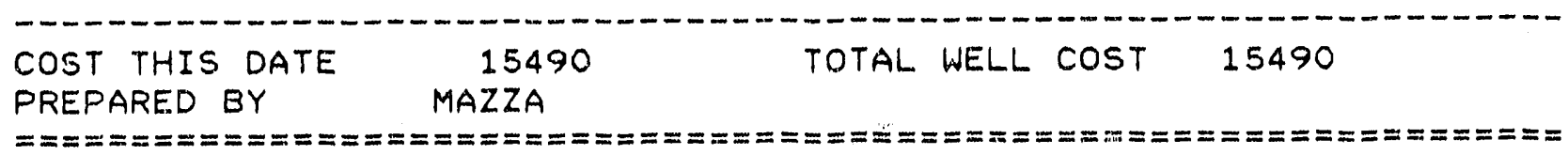




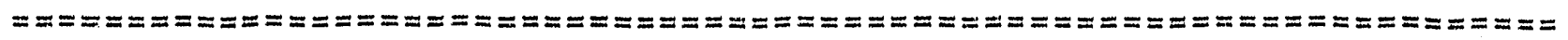
PETROLEUM CONSULTING SERVICES

P.O. BOX 35833

CANTON, OH 44735

( 216 ) $499-3823$

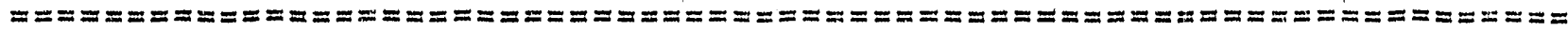
DATE: $11 / 11 / 90$

DAY \# 2 DAILY DRILLING REPORT

PAGE 1 OF 3

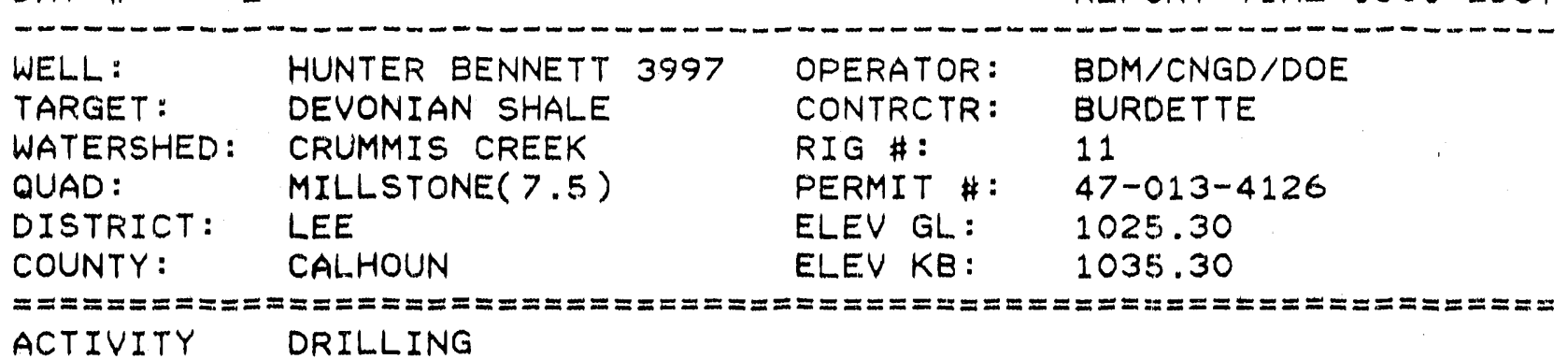
ACTIVITY DRILLING

\begin{tabular}{|c|c|c|c|c|c|c|c|c|c|}
\hline MEAS & DEPTH & 462 & & & & FOOTAGE & & 222 & \\
\hline-- & -- & $-\cdots-1$ & -- & ----- & - & 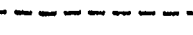 & -- & --- & \\
\hline HLU & 60 & HLD & 60 & ROT WT & 50 & TORQUE & NO & RPM & 60 \\
\hline
\end{tabular}

TIME BREAKDOWN AND COMMENTS

\begin{tabular}{|c|c|c|c|}
\hline FROM & TO & HRS & ACTIVITY \\
\hline--- & --- & $--\infty$ & 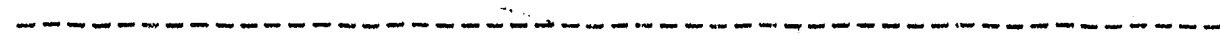 \\
\hline $06: 00$ & $08: 00$ & 2.00 & DRILLING, TD 17.75 IN HLE $0289 \mathrm{FT}(\mathrm{KBM})$ \\
\hline $08: 00$ & $08: 30$ & 0.50 & CLN HLEE \\
\hline $08: 30$ & $10: 30$ & 2.00 & RUN 6JTS $13.375 I N$ 3TPPF A500 LS R3 CSNG, WLD FLT C \\
\hline & & & ON BTM.3CENT,BSKT-LND IN TENS $258.50($ GLM ) \\
\hline $10: 30$ & $14: 15$ & 3.75 & WO SER CO \\
\hline $14: 15$ & $14: 45$ & 0.50 & PMP\&CIRC $2045 \times 5$ CLA W/2\%CaC12,15.6PPg,GOOD RETNS, \\
\hline & & & POB 01445 \\
\hline $14: 45$ & $22: 00$ & 7.25 & WOC \\
\hline $22: 00$ & $23: 00$ & 1.00 & NU AIR HD \\
\hline $23: 00$ & $23: 45$ & 0.75 & TIH W/12.25 ASSY \\
\hline $23: 45$ & $23: 59$ & 0.25 & DRL CMNT-DUSTNG \\
\hline $00: 00$ & $01: 15$ & 1.25 & $"$ \\
\hline $01: 15$ & $02: 45$ & 1.50 & DRLNG-DSTNG, WET Q359FT (0.5IN), FOAM Q6BPH \\
\hline $02: 45$ & $03: 00$ & 0.25 & SURVEY $300 F T$ T $0.50 \mathrm{~d}$ Og (SURE SHOT) \\
\hline $03: 00$ & $06: 00$ & 3.00 & DRLNG-FOAMNG @6BPH 0462 \\
\hline & 4 & 2 & 20 \\
\hline
\end{tabular}

WATER
$0.50 I N$ FRESH 4 4FT
$1.50 I N$ FRESH $210 F T$
$0.50 I N$ FRESH $255 F T$

$B H A: \quad B I T(1.00), X O(1.75), 5 T R \operatorname{RMR}(6.05), X 0(1.60), 2-6.875 \times 2.25 \mathrm{DC}$ $(61.54), X O(1.00), X O(0.75), \operatorname{STR} \operatorname{RMR}(6.60), X 0(1.00), X 0(1.15)$, $12-6.0 \times 2.25 \operatorname{DC}(474.38)$ BHA LENGTH 556.82 


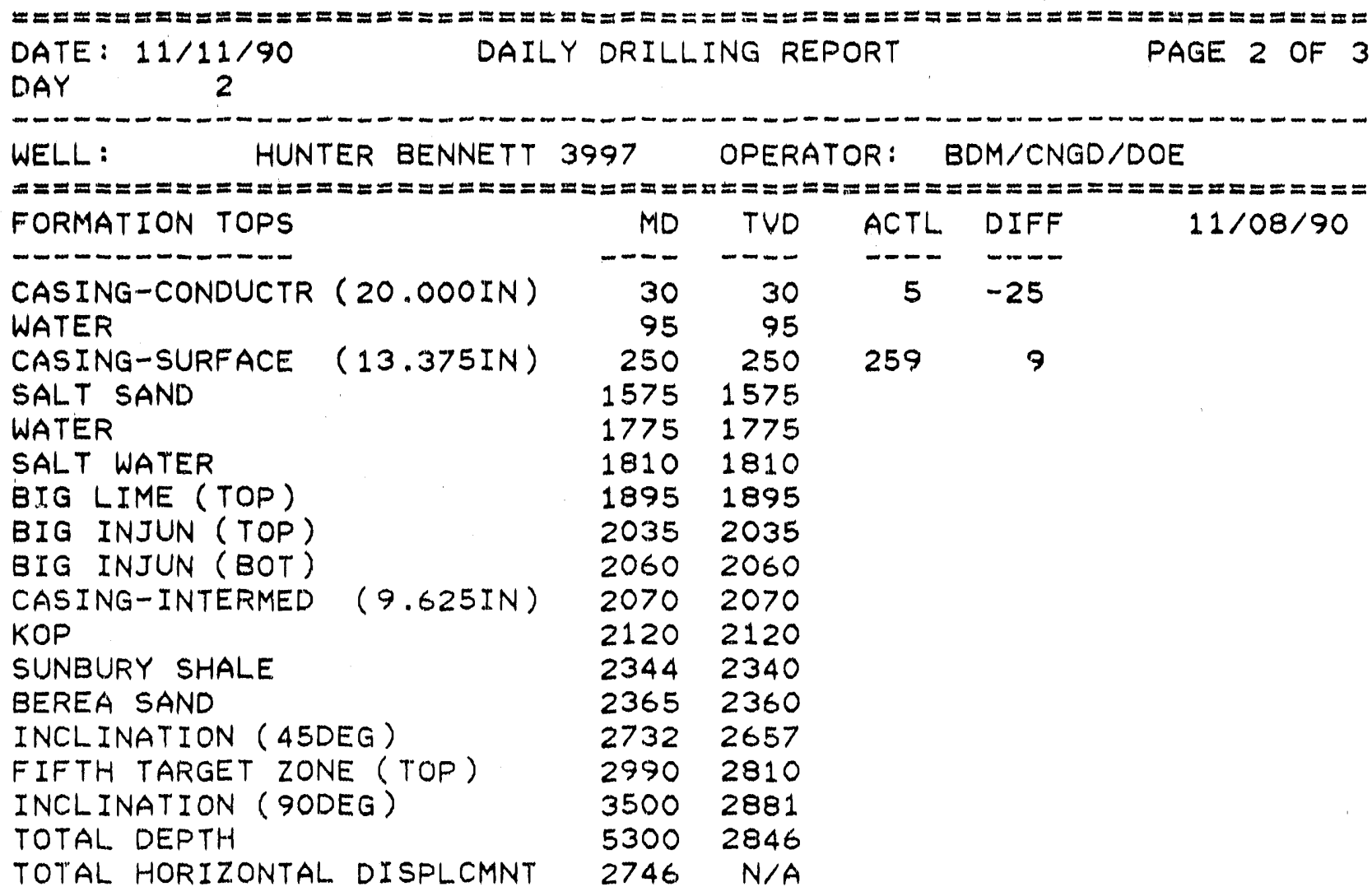

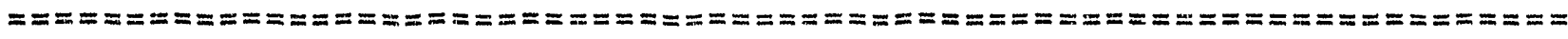
LAST CASING: DIA
13.38 TYPE
A 500 WT
37.00 YIELD $\quad N / A$
LAST CASING: MEAS DEPTH
2.57 VERT DEPTH 257 


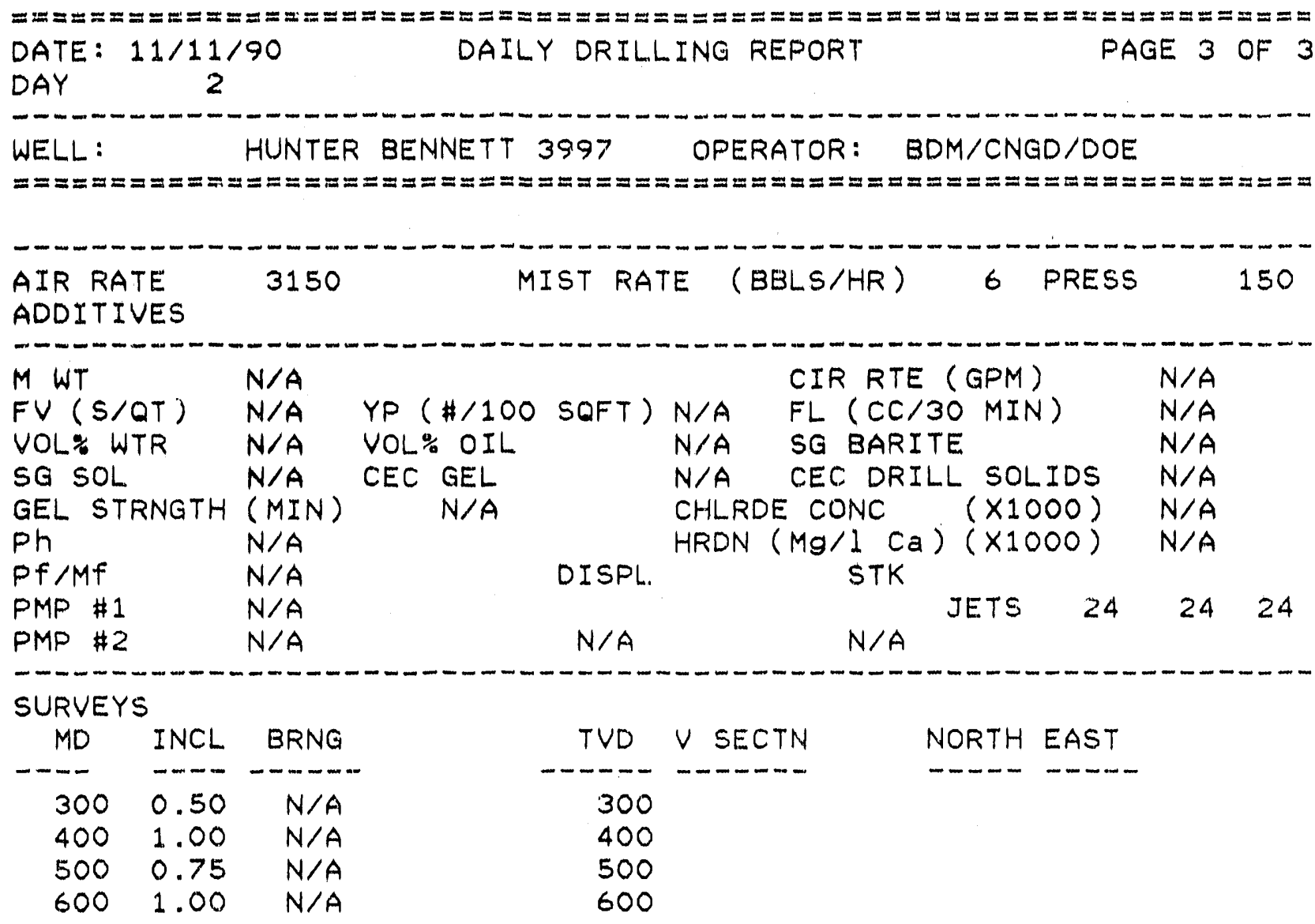

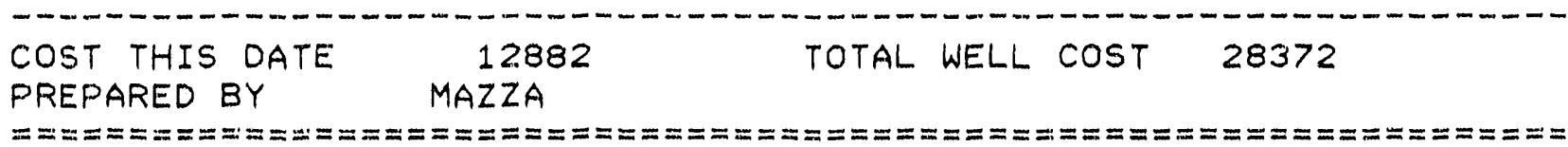




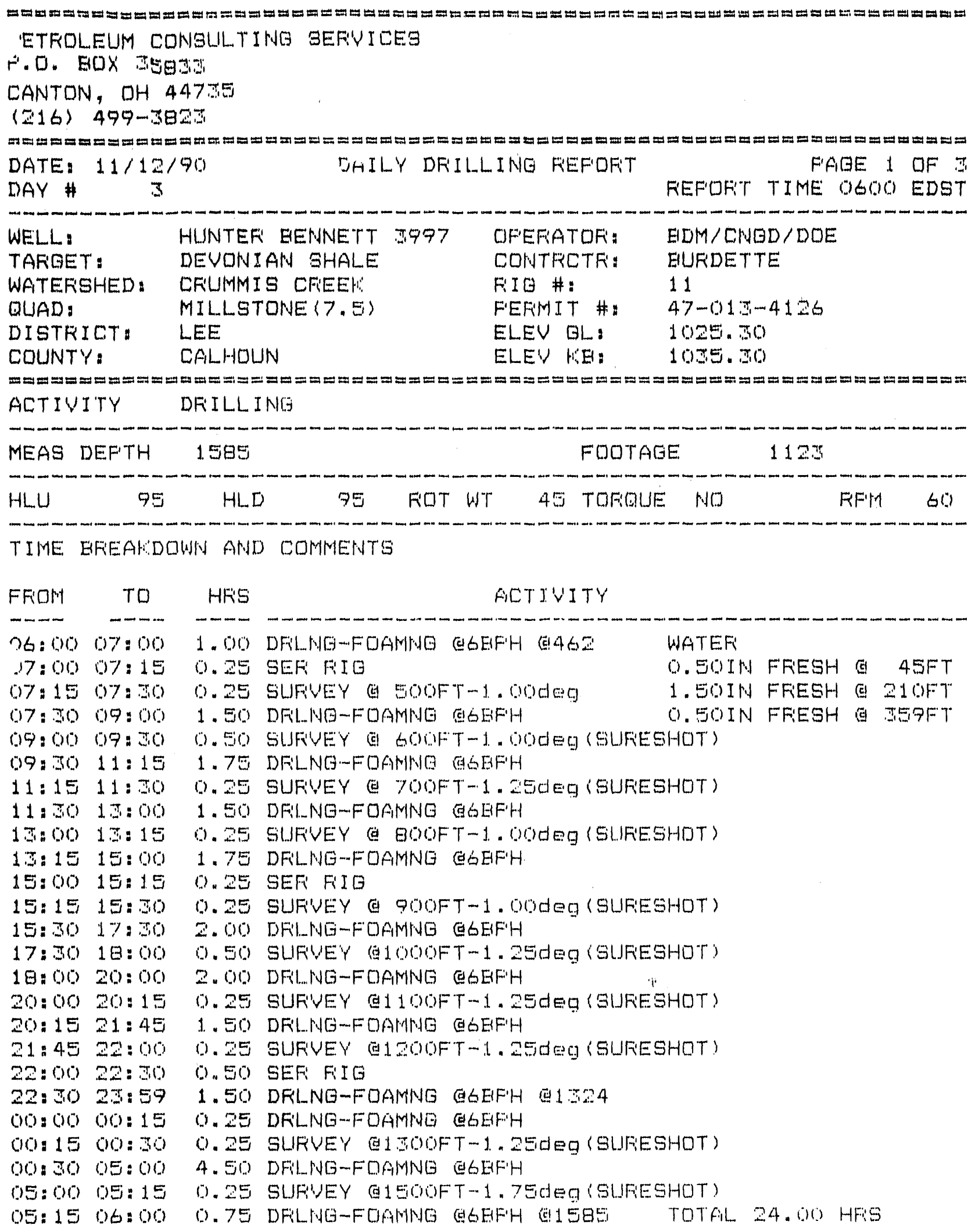

IHA: EIT(1.00), XO(1.75), STF FIMP(6.05), X0(1.60), 2-6.875X2.25 DC $(61.54), \times 0(1.00), \times 0(0.75)$, STF FIMF(6.60), $\times 0(1.00), \times 0(1.15)$, $17-6.0 \times 2.25 D C(530.26)$ EHA LENGTH 611.70 


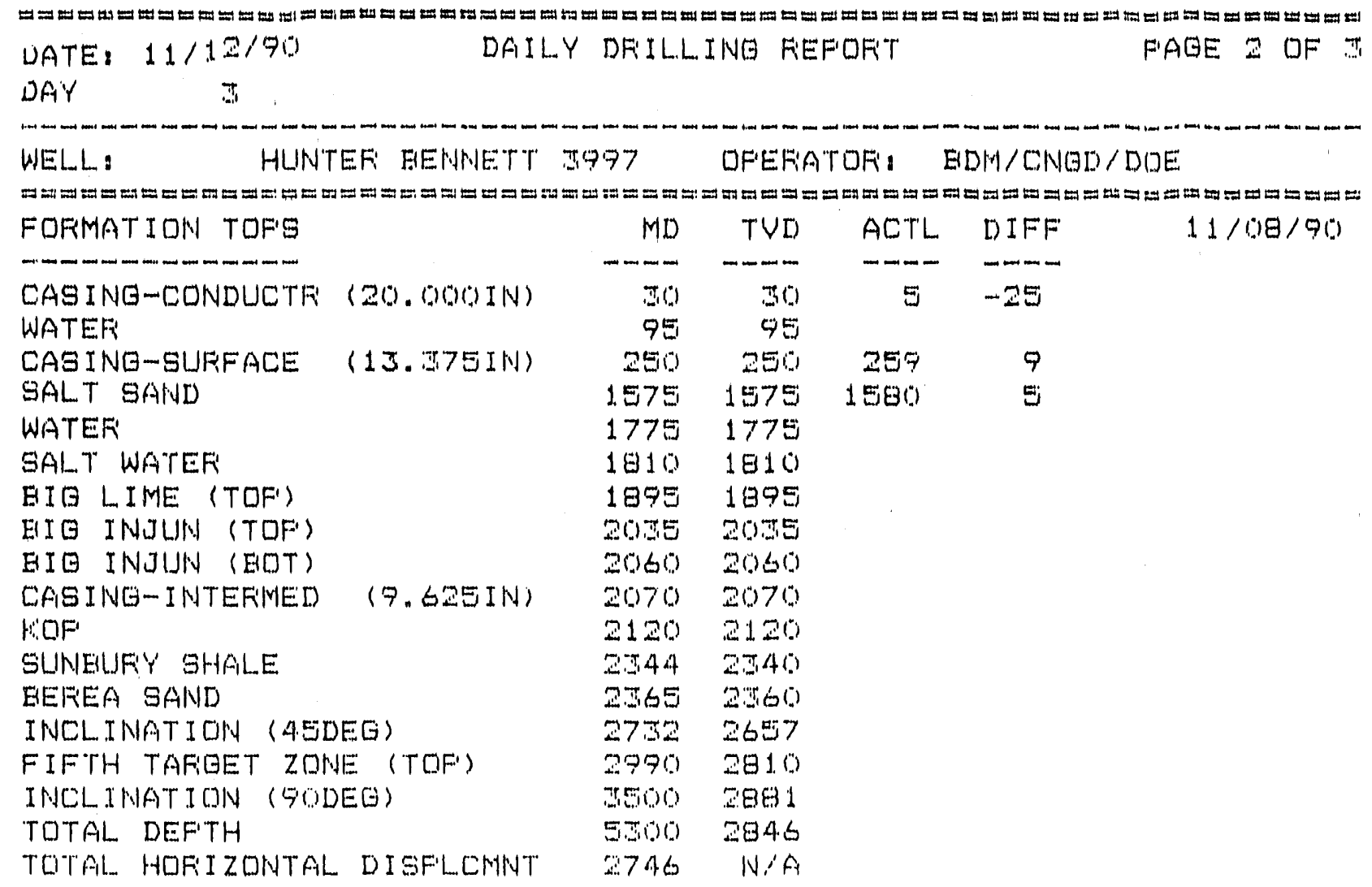

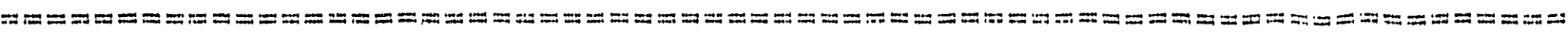
-AST CASING: DIA 1 I. SE TYFE LAST CASING: MEAS DEFTH

I7. OO YIELD NiFi 257
} 


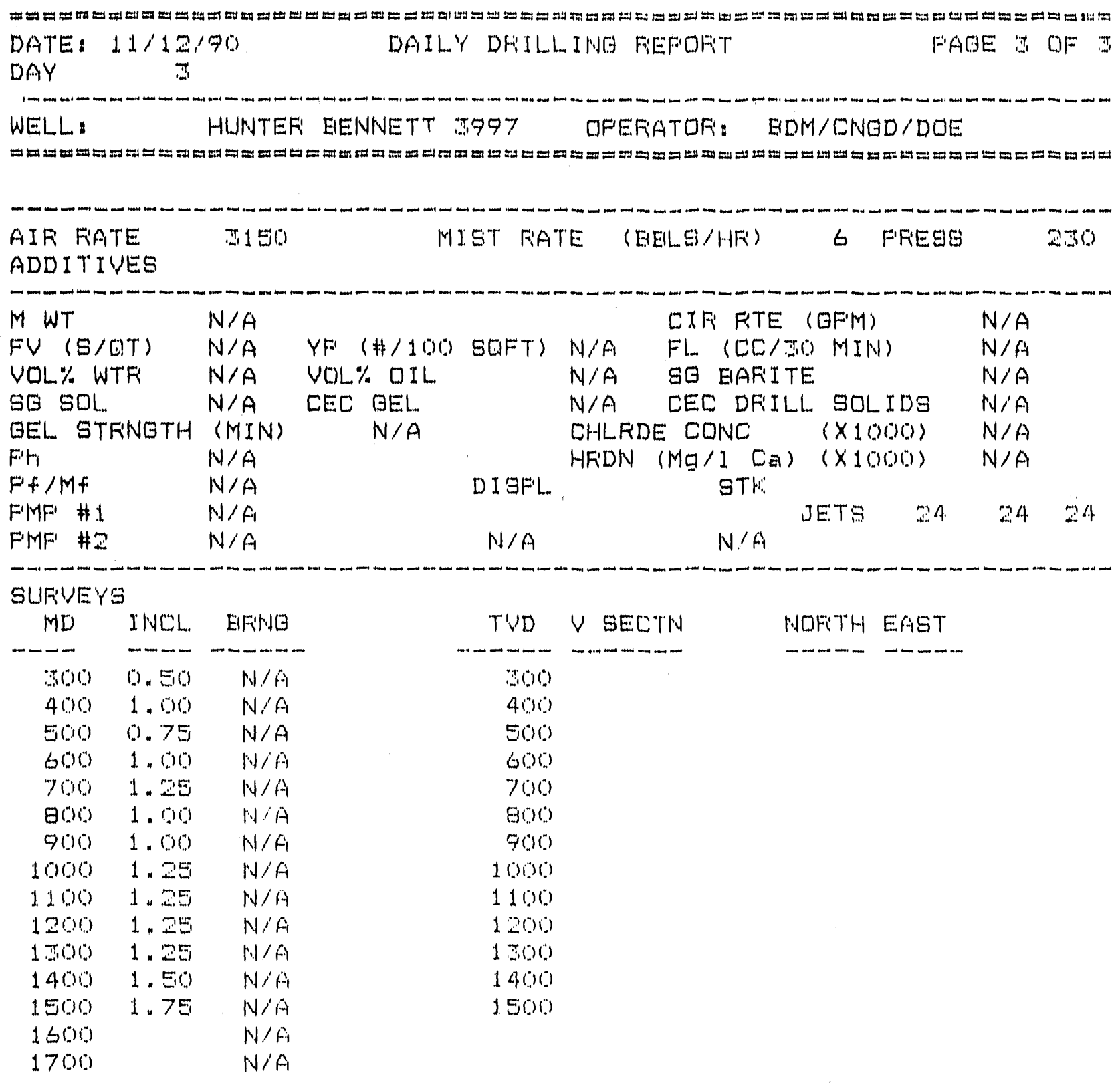

\begin{tabular}{|c|c|c|c|}
\hline $\begin{array}{l}\text { COST THIS DATE } \\
\text { F'FEPAFED EYY }\end{array}$ & $\begin{array}{l}240 B E \\
M A Z Z A\end{array}$ & TOTAL WELL COST & 52405 \\
\hline
\end{tabular}




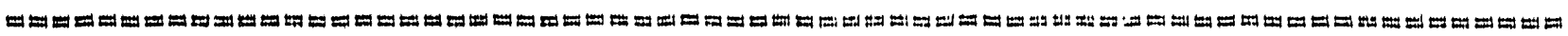
FETROLEUM CONGIJLTING GEFUICEG

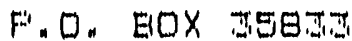

CANTON, UH 447 TS

(216) $499-3 E 2 \pi$

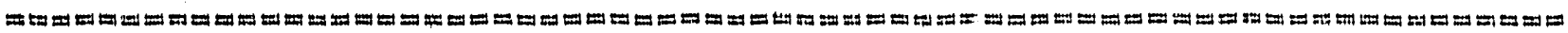
DATE: $11 / 1 \pi / 90^{\circ}$ DAILY' DFILLING FIEOF'T

DAY \# 4

FAOE 1 DF

\begin{tabular}{|c|c|c|c|c|}
\hline WELL A & HUNTEF: EIENNETT & $\$ 997$ & OF"EEFIATDFH: & EDM / CNAGD / DOE: \\
\hline TARGET: & DEVLNIAN SHALE & & CONTFETF: & EUNEDETTE \\
\hline WATERTSHED: & CFILMMIS CFIEEH" & & FIIG \#: & 11 \\
\hline QUUAD: & MILL.STONE (7.5) & & F'EFIVIIT 邦 & $47-(1) 1 \pi-4126$ \\
\hline DISTFICT: & LEE & & ELEV GL & 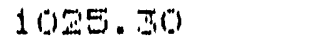 \\
\hline COUNNTY: & CALHOUN & & ELEV HE: & 1015,30 \\
\hline
\end{tabular}

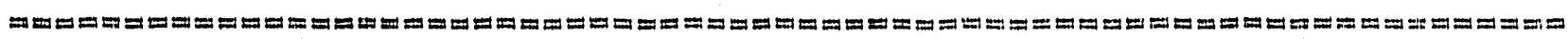
ACTIVITY DFILLING, ANTICIFATE TD WITHIN 1 SFT

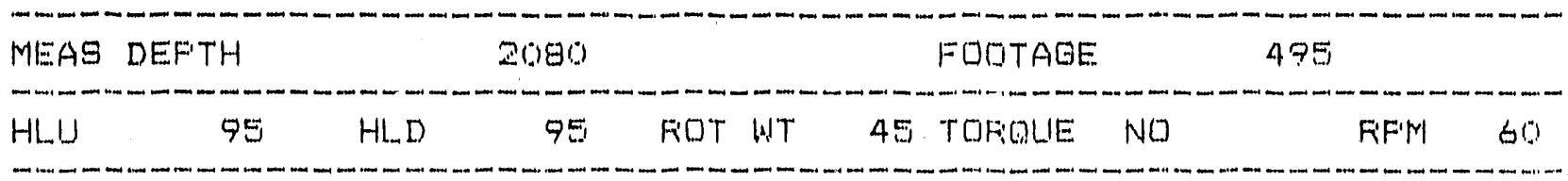

TIME EFIEAKDOWN AND CONMENTS

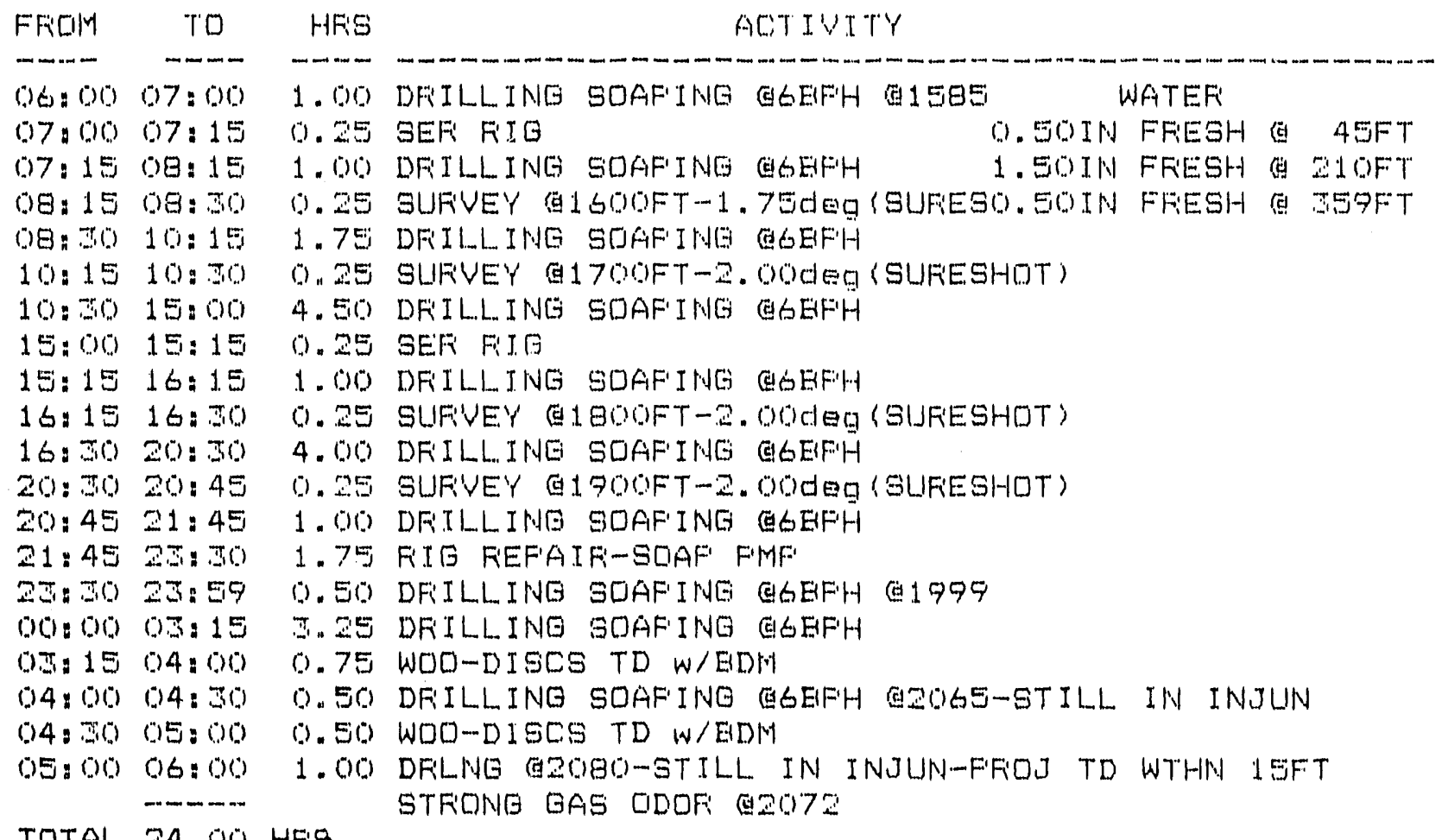

TOTAL 24.00 HFIS

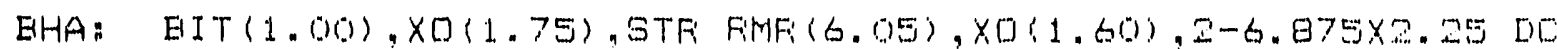

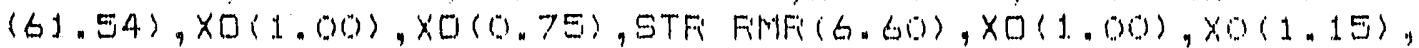
17-6.0X2.25 DC $(5 \pi 0.26) \quad$ EHA LENETH 611.70 


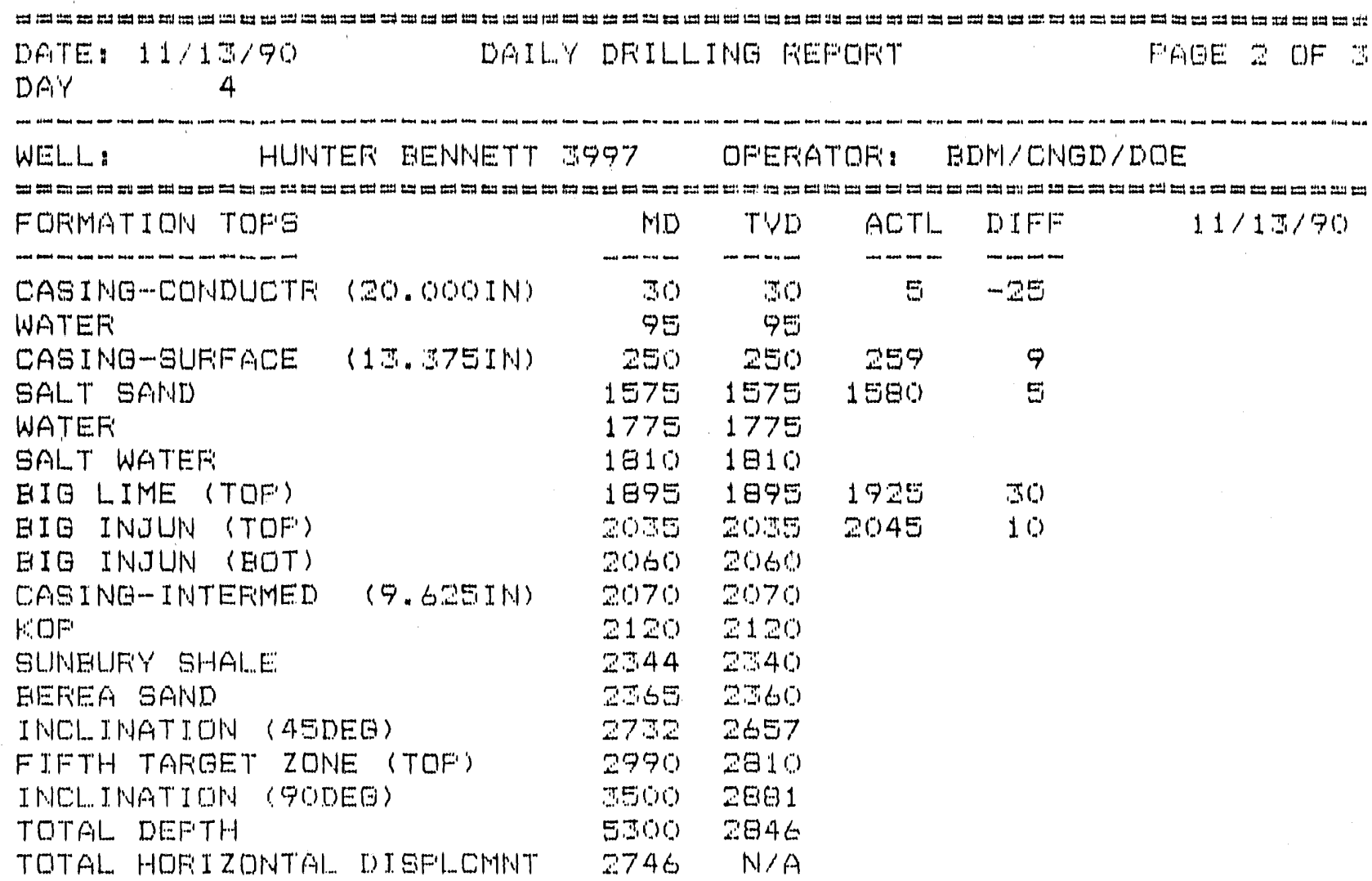

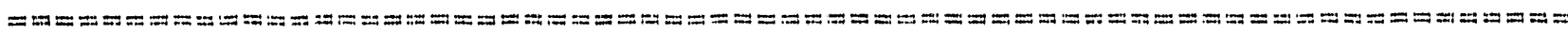
LAST CASINE: DIA 1. JE TYFE A 500 WT 37.00 YIELD WIA LAGT CAGING: MEAG DEFTH
} 


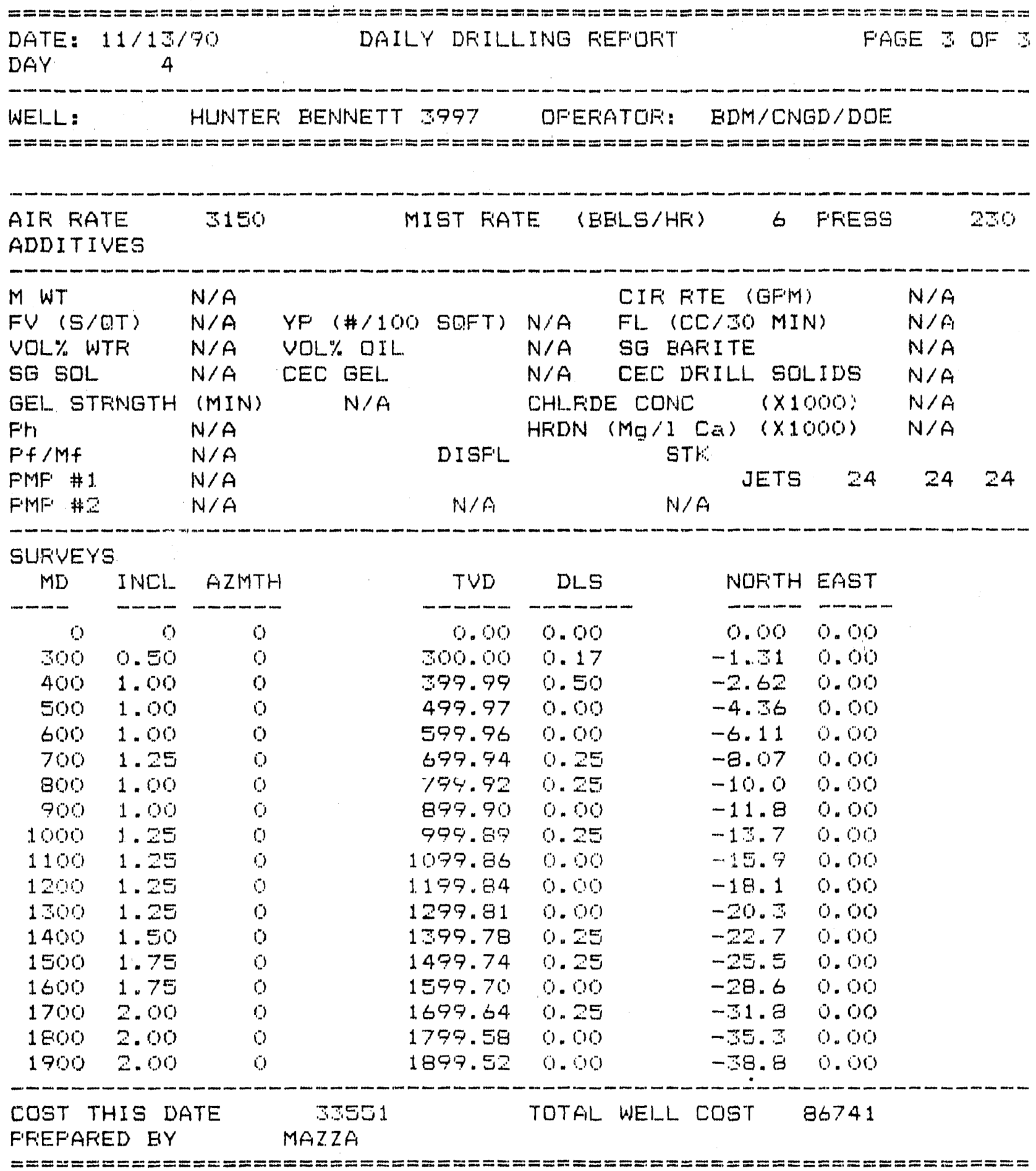




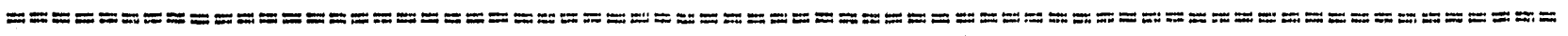
FETFIOLEUM CONSULTING SEFUICES

F.O. BOX 35833

CANTON, OH 44735

(216) $499-3820$

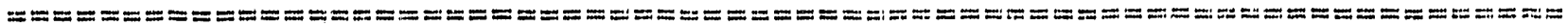

DATE: $11 / 14 / 90$

DAILY DEILLING REFOFT

FAGE 1 OF 3

DAY \# 5

\begin{tabular}{|c|c|c|c|c|}
\hline WELL: & HUNTEE: EENNETT & 3997 & QFEFIATQF': & $E D M / C N G D / D D$ \\
\hline TAFIGET: & DEVINIAN SHALE & & CONTFCTR: & EULFIDETTE \\
\hline WATEFISHED: & CFILNMIS EFIEEF, & & FIIG \#: & 11 \\
\hline QUAD: & MILLSTONE $(7.5)$ & & FERKMIT \#: & $47-012-4126$ \\
\hline DISTFICT: & LEE & & ELEV EL: & 1025.50 \\
\hline COUNTY: & CALHOUN & & ELEV KE: & 1055.30 \\
\hline
\end{tabular}

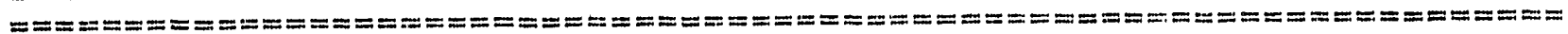
ACTIVITY WOC

MEAS DEFTH 2091 FOQTAGE

TIME BFEAKDOWH AND COMIMENTS

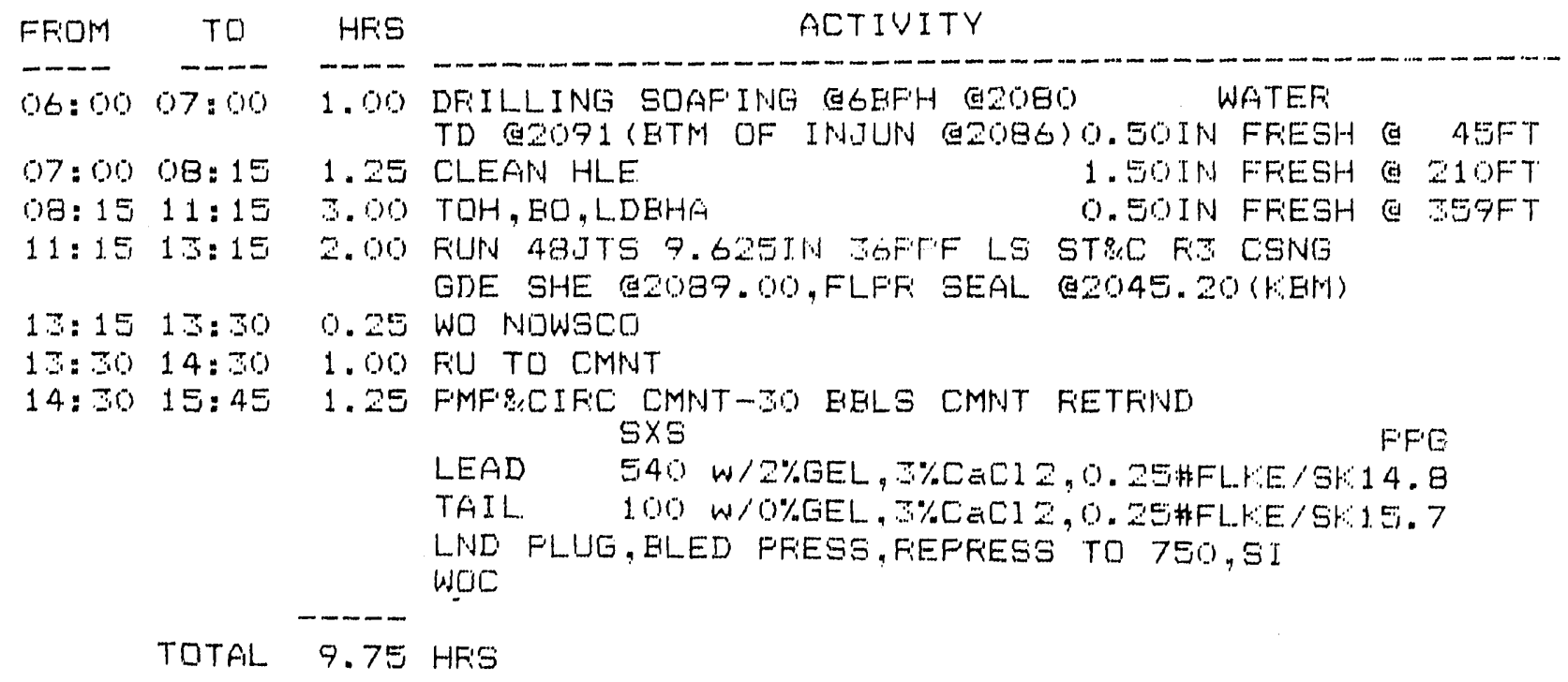

EHA: EIT(1.00),X0(1.75),STF FMF(6.05), $\times 0(1.60), 2-6.375 \times 2.25$ DC $(61.54), \times 0(1.00), \times 0(0.75)$, STF Filf $(6.60), \times 0(1.00), \times 0(1.15)$ $17-6.0 \times 2.25$ DC $(5.0 .26)$ EHA LENGTH $\$ 11.70$ 


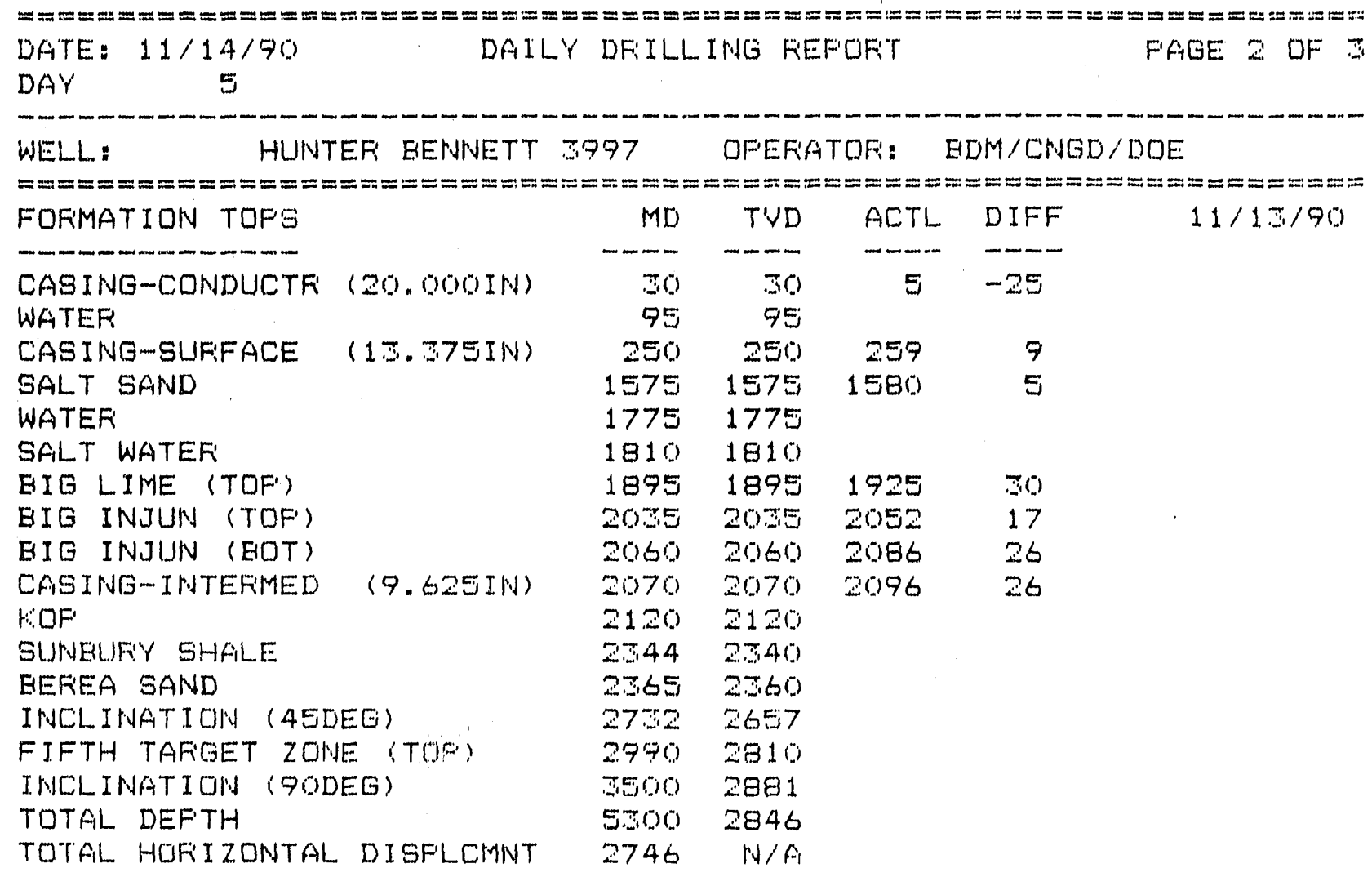

LAST CASING: DIA 9.625 TYFEM44- 1010 WT $37 \%$ VIELD NIA
LAST CASING: MEAS DEFTH DEFTH




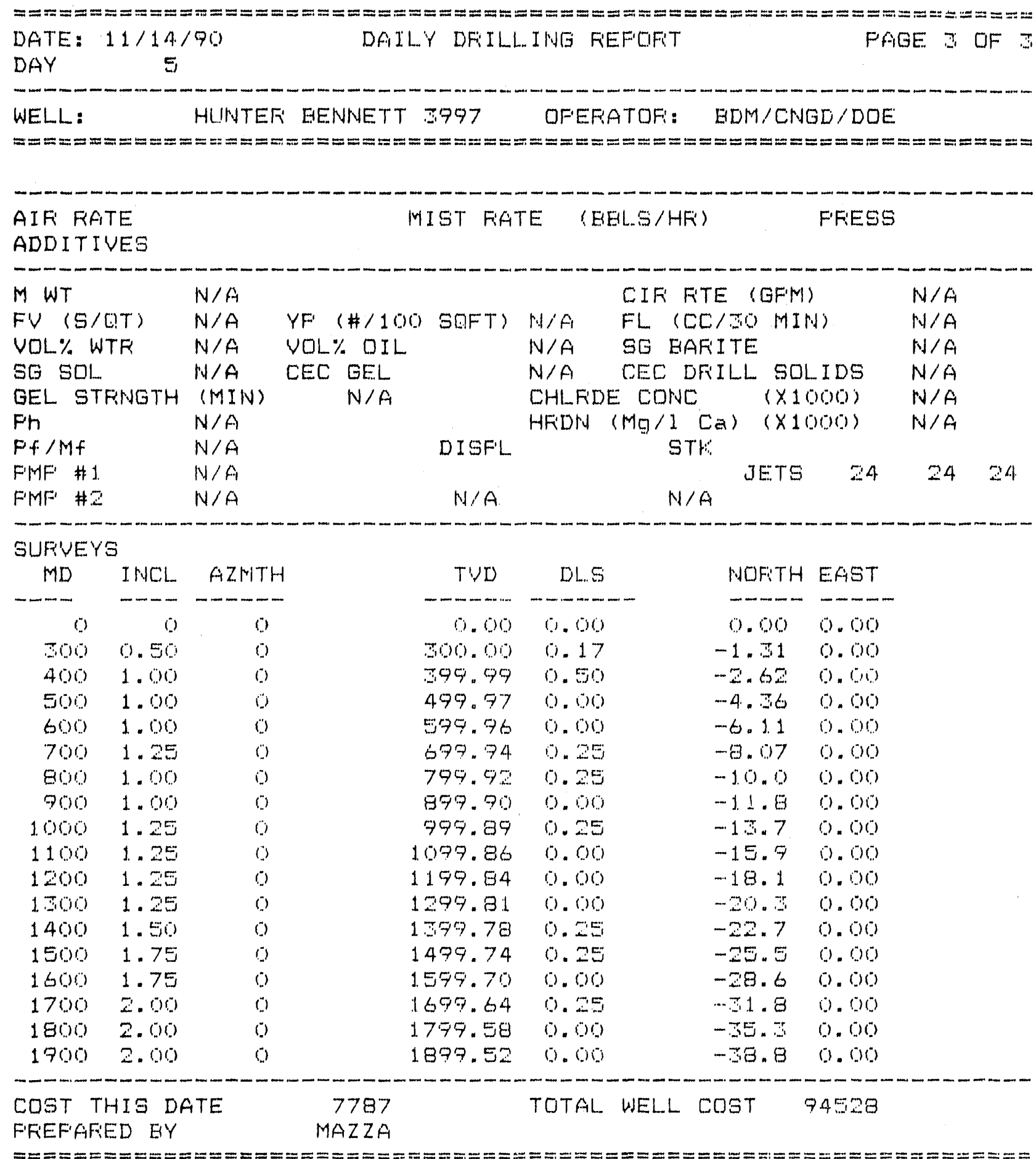


BDM DAILY REPORT

WELI NAME: BDM/DOE CNGD \#3997 DEPTH : 2176 FOOTAGE: 85 FORMATION: POCONO SHALE ROTATING WEIGHT:

BIT RECORD:

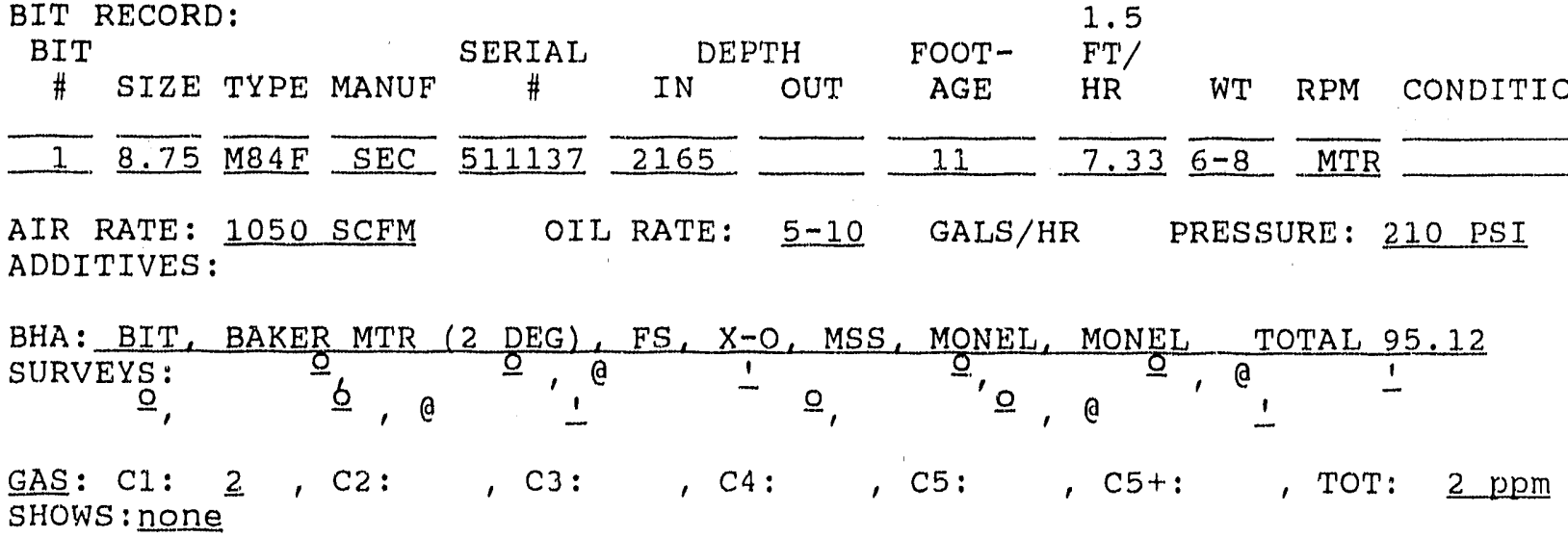

TIME BREAKDOWN AND COMMENTS:

FROM

$6: 00$

$7: 00$

$11: 00$

$12: 30$

$1: 00$

$2: .25$

$2: 30$

$3: 30$

$5: 00$

$8: 00 \quad 10: 00$

10:00 11:00

$11: 00$

$11: 15$

$12: 15$

$1: 15$

$4: 30$
TO

$7: 00$

$11: 00$

$12: 30$

$1: 00$

$2: 15$

$2: 30$

$3: 30$

$5: 00$

$8: 00$

$11: 15$

$12: 1.5$

$1: 1.5$

$4: 30$

$6: 00$ HRS

1 Dry watch.

4 Rig up air compressors, unload reamers, and place drill pipe on the rack for cleaning.

1.5 Drill out shoe joint.

.5 Dry up hole.

1.25

Drill to $2165^{\prime}$

.5 Circulate to clean hole.

1 Trip out of hole to pick up motor.

1.5 Lay down drill collars.

3 Pick up Baker motor.

Test motor. Runs oK. Pick up BHA.

Adjust bend to 2 degrees.
REPORT TIME: 6:00 A.M. DRILLING

HLD:

TORQUE : 2 Wait on steering tool. Had gone back to the shop to work on Well Nav's steering tool equipment.

1 . Check out mule shoe sleeve and stinger. Trip in Hole with the drill pipe from derrick.

.25 Service rig.

1 Finish trip in hole with pipe.

1 Pick up drill pipe of rack to make up for collars.

3.25 Rig up steering tool and wireline. Install side entry sub and float sub. Make up kelly joint.

1.5 orient motor and drill with 6-8,000 lbs wt. Drilling slow but motor is running good. 


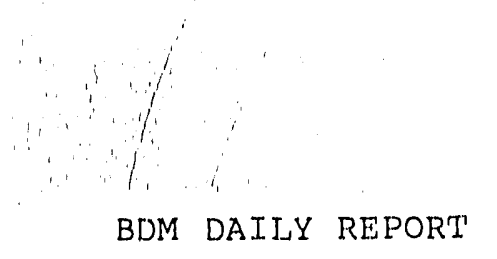

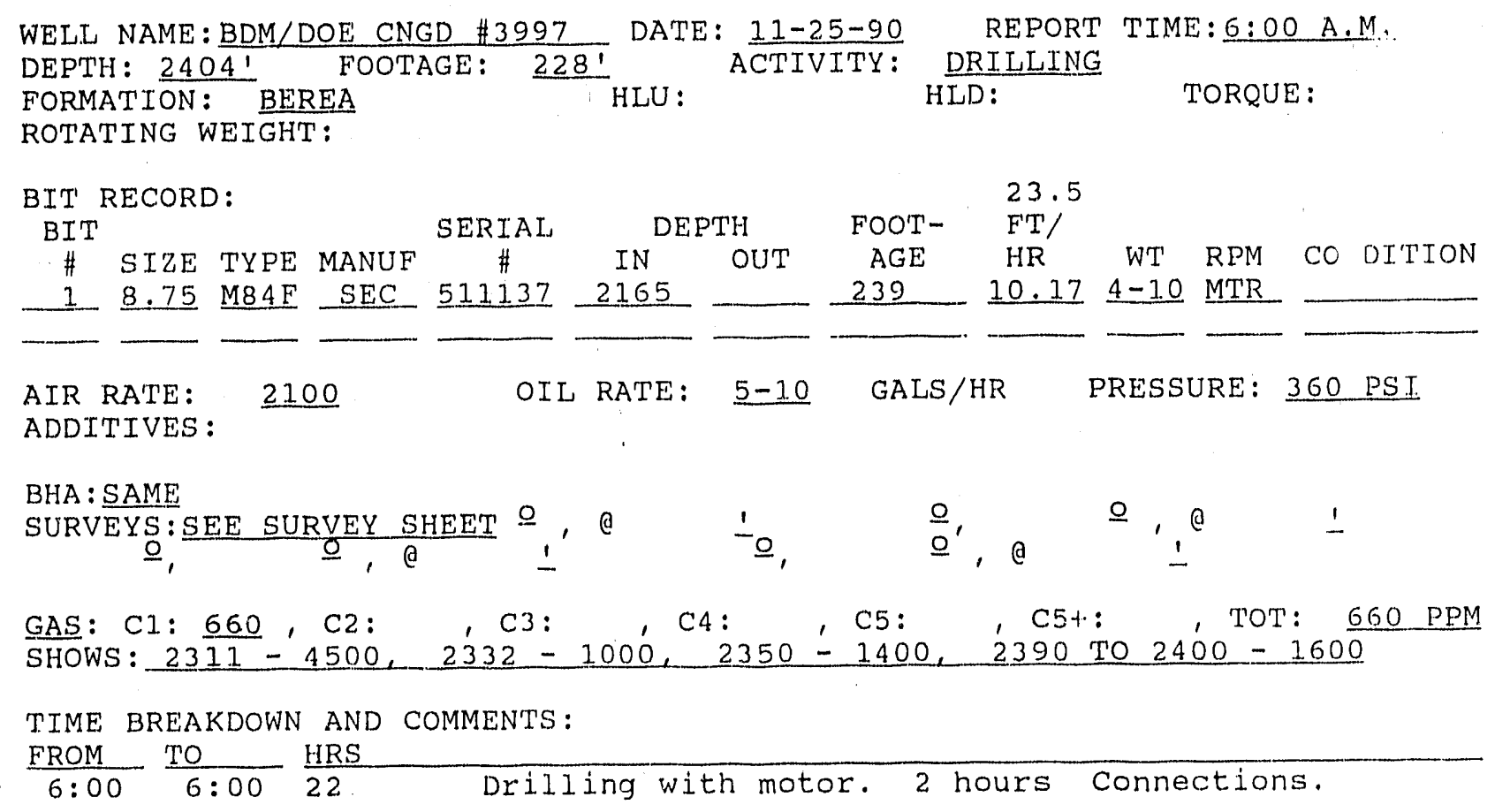


BDM DAILY REPORT

WELL NAME : BDM LDOE CNGD \#3997 DEPTH: $2598^{\prime}$ FOOTAGE: 1941 FORMATION : ROTATING WEIGHT:

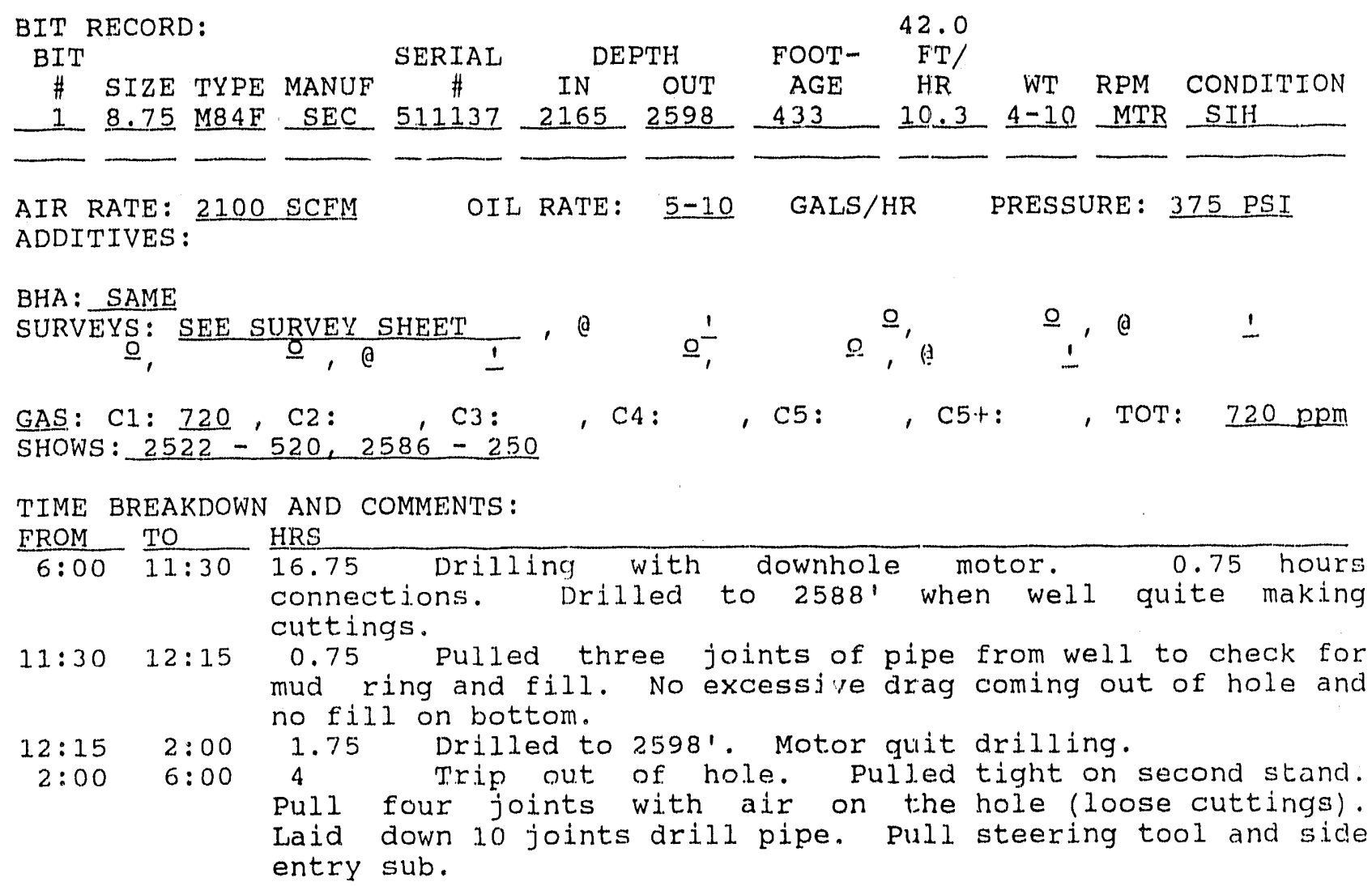

REPOR'T TIME: 6:00 A.M. TRIP OUT OF HOLE HLU: 67,000 HLD: 60,000 TORQUE:

DATE: $\quad 11-26-90$ ACTIVITY : 
BDM DAILY REPORT

WELL NAME: BDM/DOE CNGD \#3997 DEPTH: 27731 FOOTAGE: 1751

DATE: $\quad 11-27-90$ FORMATION : ACTIVITY: HLU :

REPORT TIME: $6: 00$ A.M. ROTATING WEIGHT:

\section{TRIP HLD:} TORQUE :

BIT RECORD:

\begin{tabular}{|c|c|c|c|c|c|c|c|c|c|c|c|}
\hline BIT & & & & SERIAL & & & FOOT - & $\mathrm{FT} /$ & & & \\
\hline$\#$ & SIZE & TYPE & MANUF & \# & IN & OUT & AGE & HR & WT & RPM & CONDITION \\
\hline 1. & 8.75 & M84F & $S E C$ & 511137 & 2165 & 2598 & 433 & 10.3 & $4-10$ & MTR & $2-S E-I$ \\
\hline RI. & 8.75 & $\mathrm{M84F}$ & SEC & 511137 & 2598 & 2773 & 275 & 24.14 & 25 & 50 & $2-S E-I$ \\
\hline
\end{tabular}

AIR RATE: 3150 SCFM MIST RATE: $\underline{0}$ BBLS/HR PRESSURE: 180 PSI ADDITIVES :

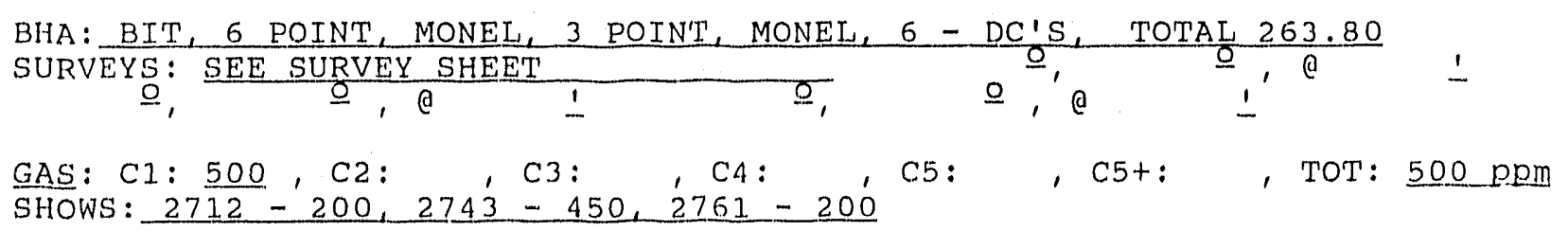

TIME BREAKDOWN AND COMMENTS:

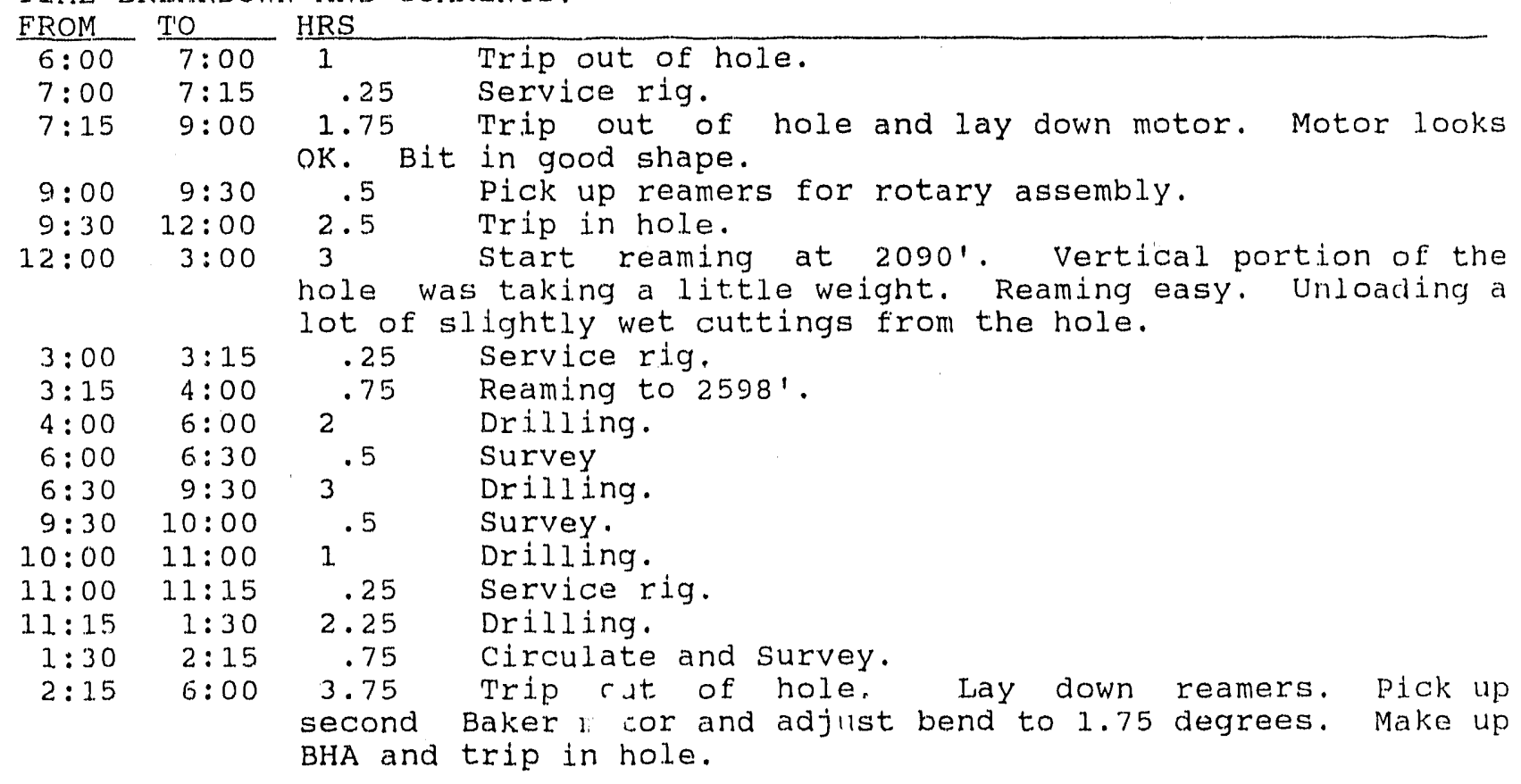


BDM DAILY REPORT

WELL NAME: BDM/DOE CNGD \#3997 DEPTH: 28871 FOOTAGE: 1141 FORMATION: SILT AND SHALE ROTATING WEIGHT:
DATE: $11-28-90$ ACT'IVITY:
REPORT TIME: 6:00 A.M. DRILLING

HLD: 64000 TORQUE:

BIT RECORD:

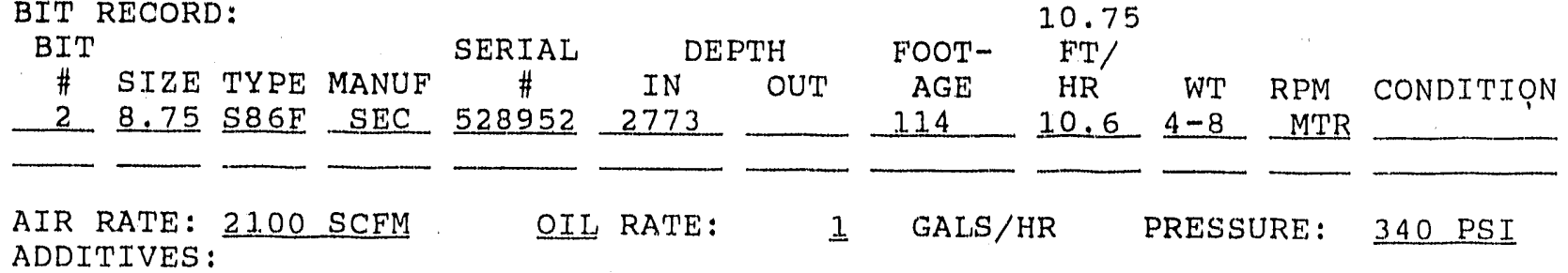

BHA: BIT, BAKER MOTOR (1.75 DEGREE BEND), FS, $x-0$, MSS, MONEL, MONEL, 6-DC'S TOTAL 280.40

SURVEYS: SEE SURVEY SHEET

GAS: C1: $4800, \mathrm{C2}:, \mathrm{C} 3:, \mathrm{C} 4:, \mathrm{C} 5:, \mathrm{C} 5+:$, TOT: 4800 PPM SHOWS : $2829-25,000$

TIME BREAKDOWN AND COMMENTS:

\begin{tabular}{|c|c|c|}
\hline$O M$ & To & RS \\
\hline $6: 00$ & $7: 00$ & $\begin{array}{l}1.00 \text { Trip in hole with Baker motor. Motor set at } 1.75 \\
\text { degrees. }\end{array}$ \\
\hline $7: 00$ & $7: 15$ & Service rig. \\
\hline $7: 1$ & $9: 3$ & tool and start drilling. steering \\
\hline $9: 30$ & $12: 00$ & $\begin{array}{l}2.50 \text { Pull to side entry sub. Remove steering tool. } \\
\text { Connector between cable head and probe failed. Replace same } \\
\text { and run steering tool. Run pipe to bottom. }\end{array}$ \\
\hline $12: 00$ & $5: 00$ & 5.00 Drilling with motor. \\
\hline $5: 00$ & $9: 00$ & $\begin{array}{l}4.00 \text { steering tool falled again. Pull pipe to side } \\
\text { entry sub and pull steering tool. Falled in connector. }\end{array}$ \\
\hline $9: 00$ & $2: 45$ & $\begin{array}{l}\text { Modify connector and run steering tool. Trip to bottom. } \\
5.75 \text { Drilling. Rotating head rubber started leaking } \\
\text { bad. }\end{array}$ \\
\hline $2: 45$ & $6: 00$ & $\begin{array}{l}\text { Pull to side entry sub and pull steering tool. } \\
\text { rotating head rubber. Run steering tool and trip to }\end{array}$ \\
\hline
\end{tabular}


BDM DAILY REPORT

WELI, NAME: BDM/DOE CNGD \#3997

DATE: $11-29-90$

DEPTH: 30981 FOOTAGE: 2111

FORMATION: SILT AND SHALE HLU: ACTIVITY:

ROTATING WEIGHT:

REPORT T.IME: 6:00 A.M. DRILLING HLD:

TORQUE :

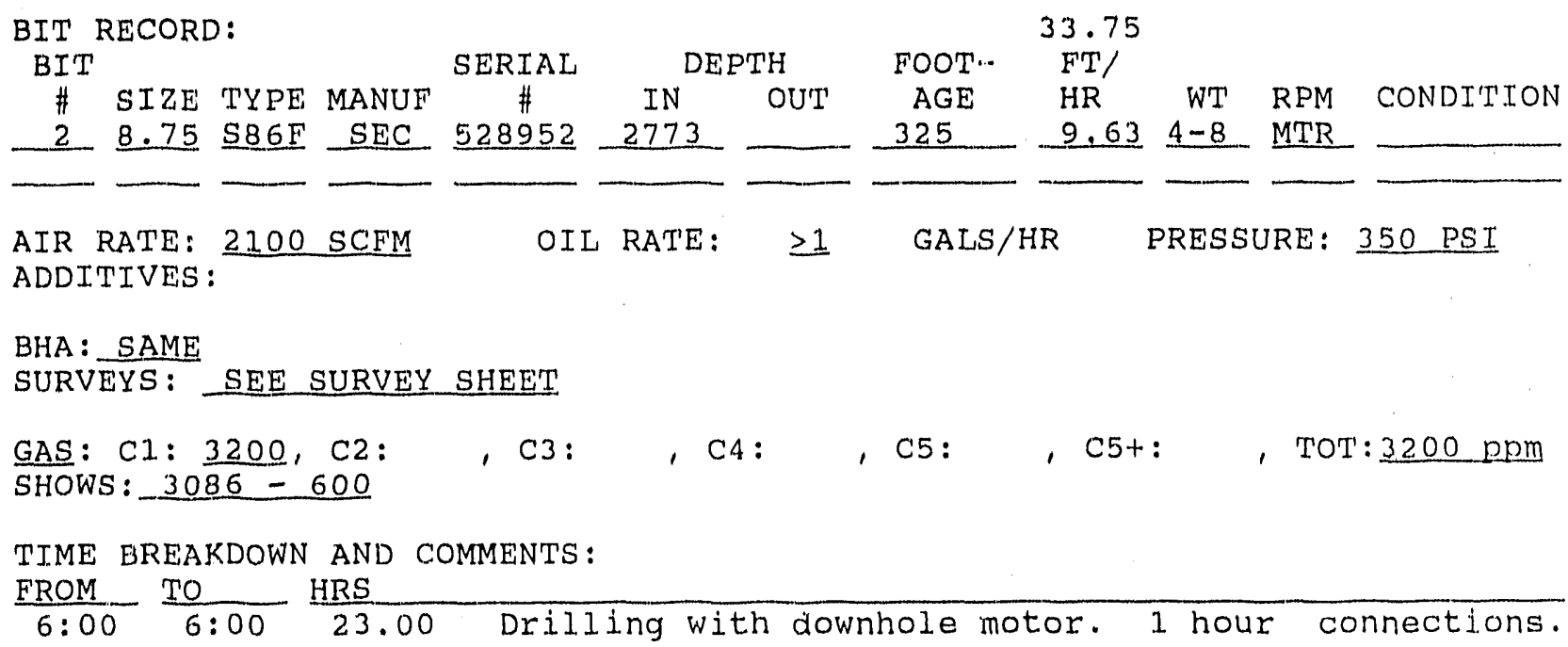


BDM DAILY REPORT

WELL NAME: BDM $\angle D O E$ CNGD \#3997 DEPTH: 3117 FOOTAGE: 191 FORMATION: SILT AND SHALE ROTATING WEIGHT: 75,000
DATE: $11-30-90$ REPORT TIME: 6:00 A.M. ACTIVITY: REAMING

HLU: 100,000 HLD: 64,000 TORQUE:

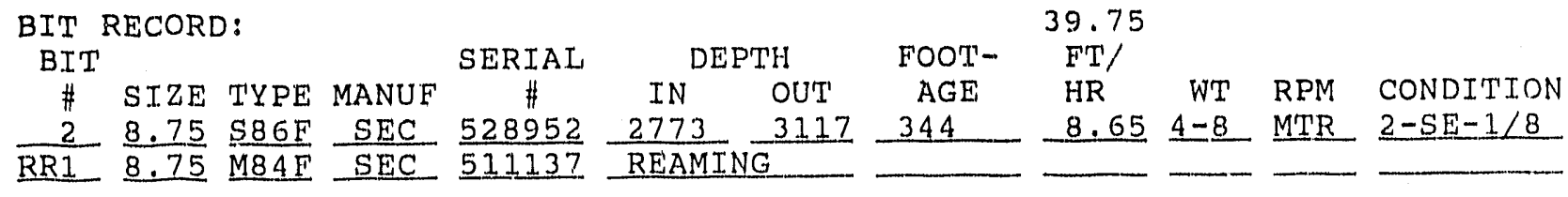

AIR RATE: 3150 MIST RATE: BBLS/HR PRESSURE: 200 PSI

ADDITIVES :

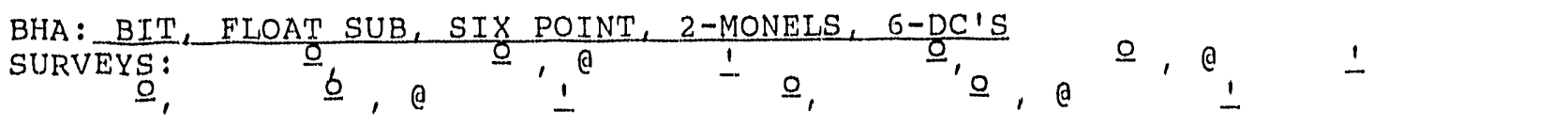

GAS: C1: $1100, C 2: \quad, \mathrm{C} 3:, \mathrm{C} 4:, \mathrm{C} 5:, \mathrm{C} 5+:$, TOT: 4100 ppm SHOWS:

TIME BREAKDOWN AND COMNE..T'S:

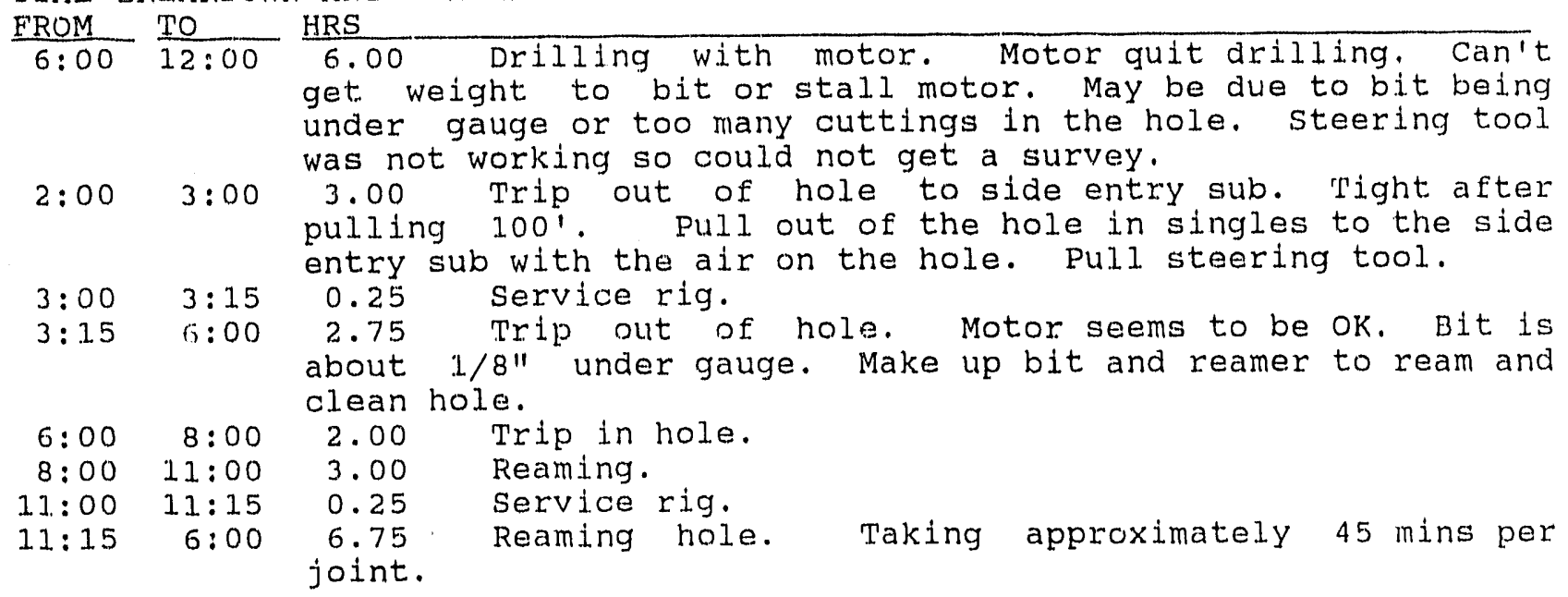


BDM DAILY REPORT

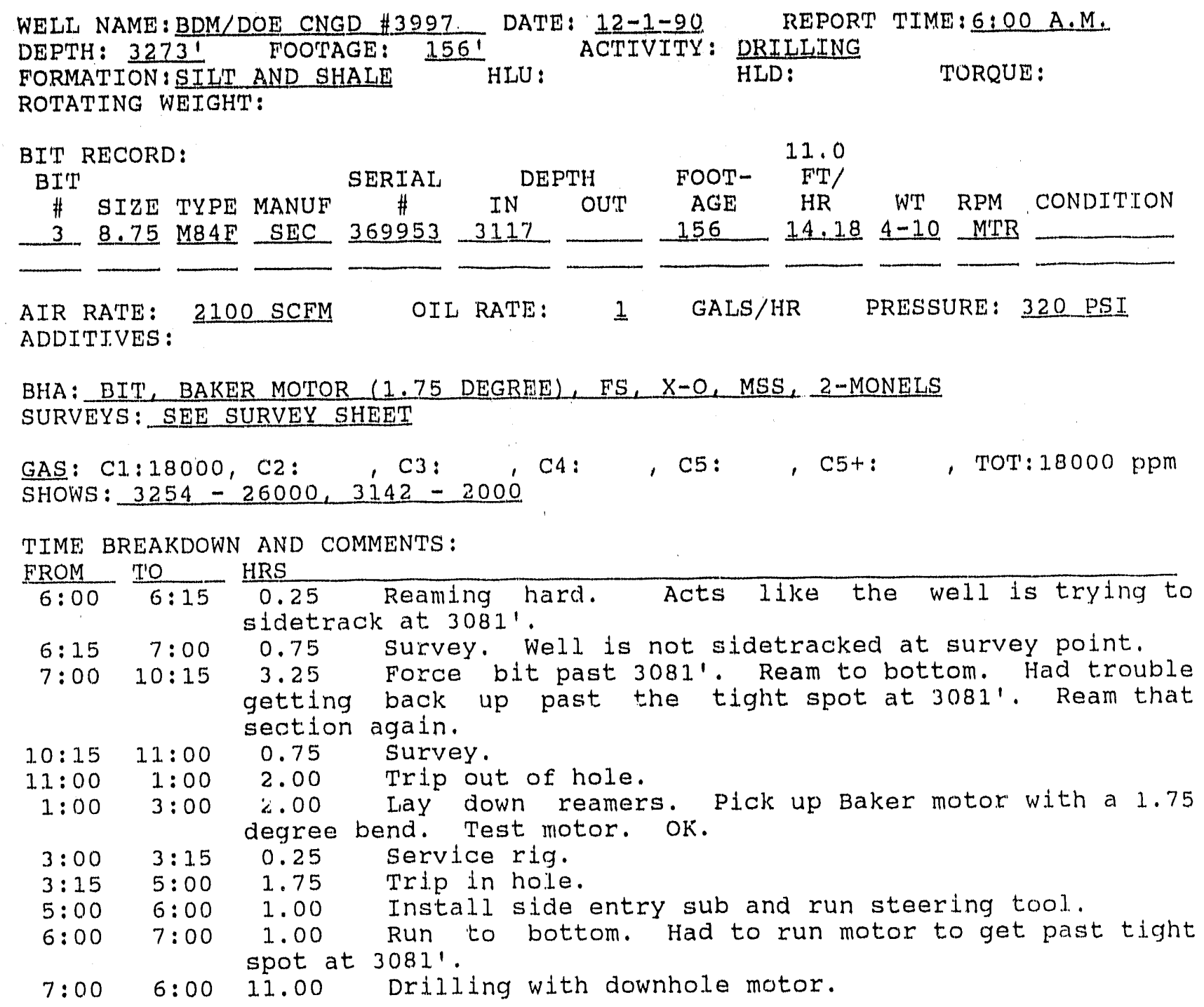


BDM DAILY REPORT

WELI, NAME : BDM/DOE CNGD \#3997

DATE: $\quad 12=2-90$ DEPTH: 34501 FOOTAGE: 1771 ACTIVITY FORMATION: SILT AND SHALE HLU: 100,000 HLD: 50,000 'TORQUE:

ROIATING WEIGHT: 75,000

BIT RECORD:

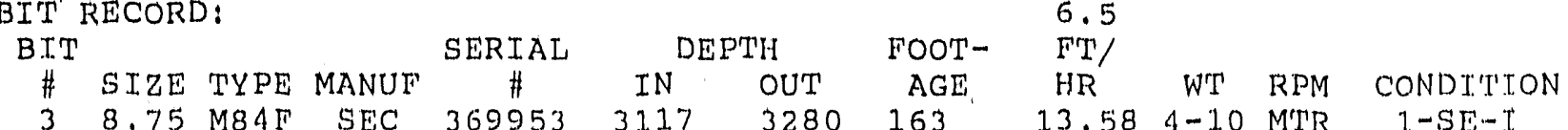

$\frac{3}{4} \frac{8.75}{8.50} \frac{\mathrm{M} 84 \mathrm{~F}}{\mathrm{M} 84 \mathrm{~F}} \frac{\mathrm{SEC}}{\mathrm{SEC}} \frac{369953}{529616} \frac{3117}{3280}=\frac{3280}{170} \frac{163}{26.15} \frac{13-10}{25} \frac{\mathrm{MTR}}{50} 1-\mathrm{SE}-\mathrm{I}$

\section{A.TR RATE: 3150 \\ MIST RATE : \\ BBLS/HR \\ PRESSURE: 200 PSI}

ADDITIVES :

BHA: BIT, FLOAT SUB, 6 PT, PONY MONEL, MONEL, 3 PT, 20 STDS DP, G-DC'S

SURVEYS : - SEE SURVEY SHEET

GAS: C1:30000, C2:, C3:, C4:, C5:, C5t:, ,TOT: 30000 PPM SHOWS: $3349-3000,3372-75,000,3398-20,000$

TIME BREAKDO'NN AND COMMENTS:

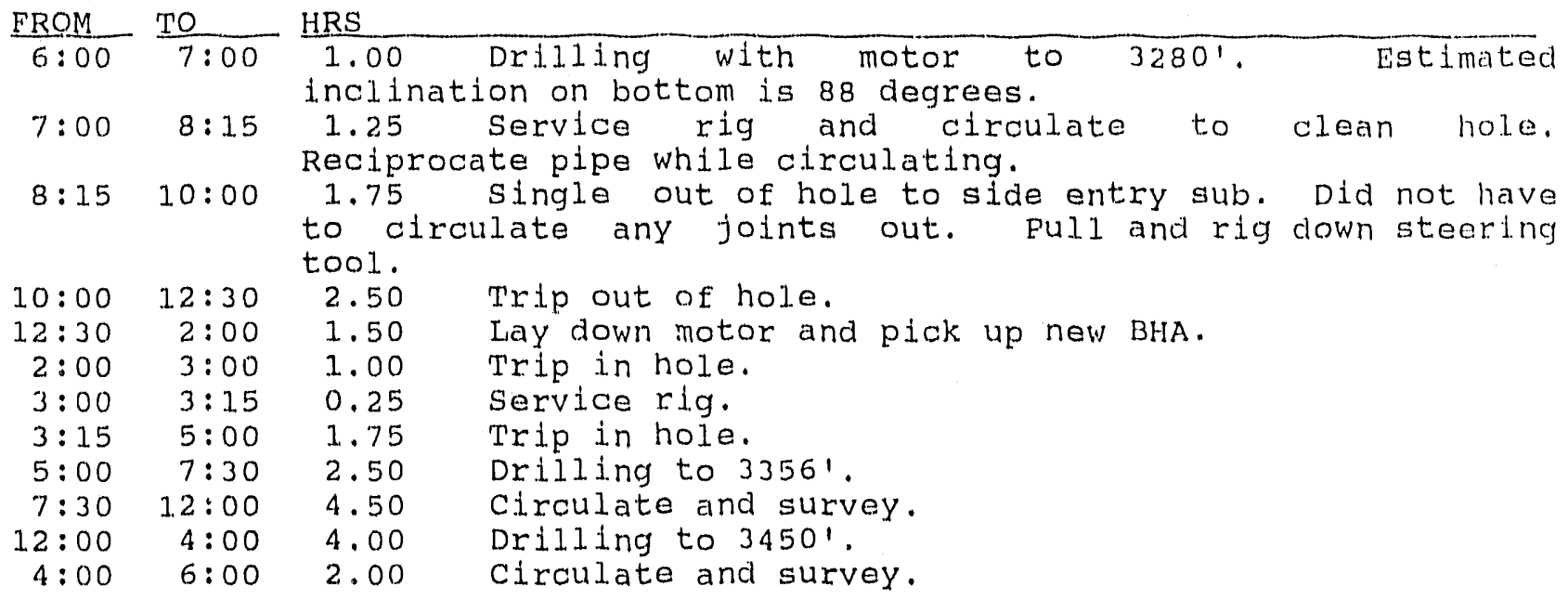


BDM DAILY REPORT

WELL NAME: BDM/DOE CNGD \#3997

DA'IE: $12-3-90$ ACTIIVIT'Y :

DEPTH: 37531 FOOTAGE: 3031 FORMATION: SILT AND SHALE HLU: $\begin{array}{r}\text { ACTIVI } 115,00 \\ \hline\end{array}$

REPORI TIME: 6:00 A.M. ROTATING WEIGH'T: 15,000

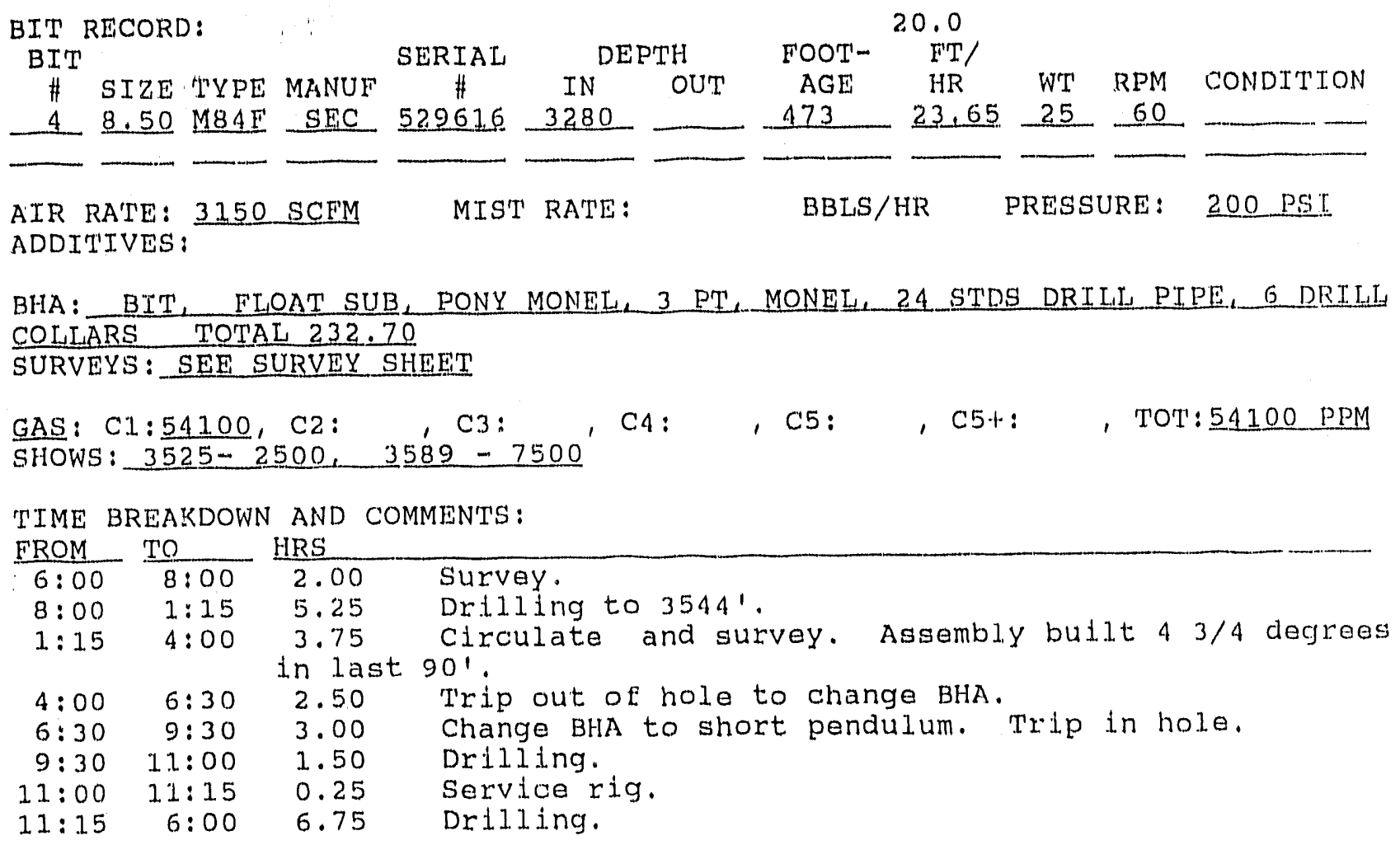


BDM DAILY REPORT

WELL NAME: BDM/DOE CNGD \#3997

DATE: $12-4-90$ REPORT TIME: 6:00 A.M. DEPTH : 3939' FOOTAGE: 186' FORMATION : SILIT AND SHALE ROTATING WEIGHT: ACTIVITY: SURVEY HLU: 115,000 HID: 35,000 TORQUE: $11 / 2$ RD

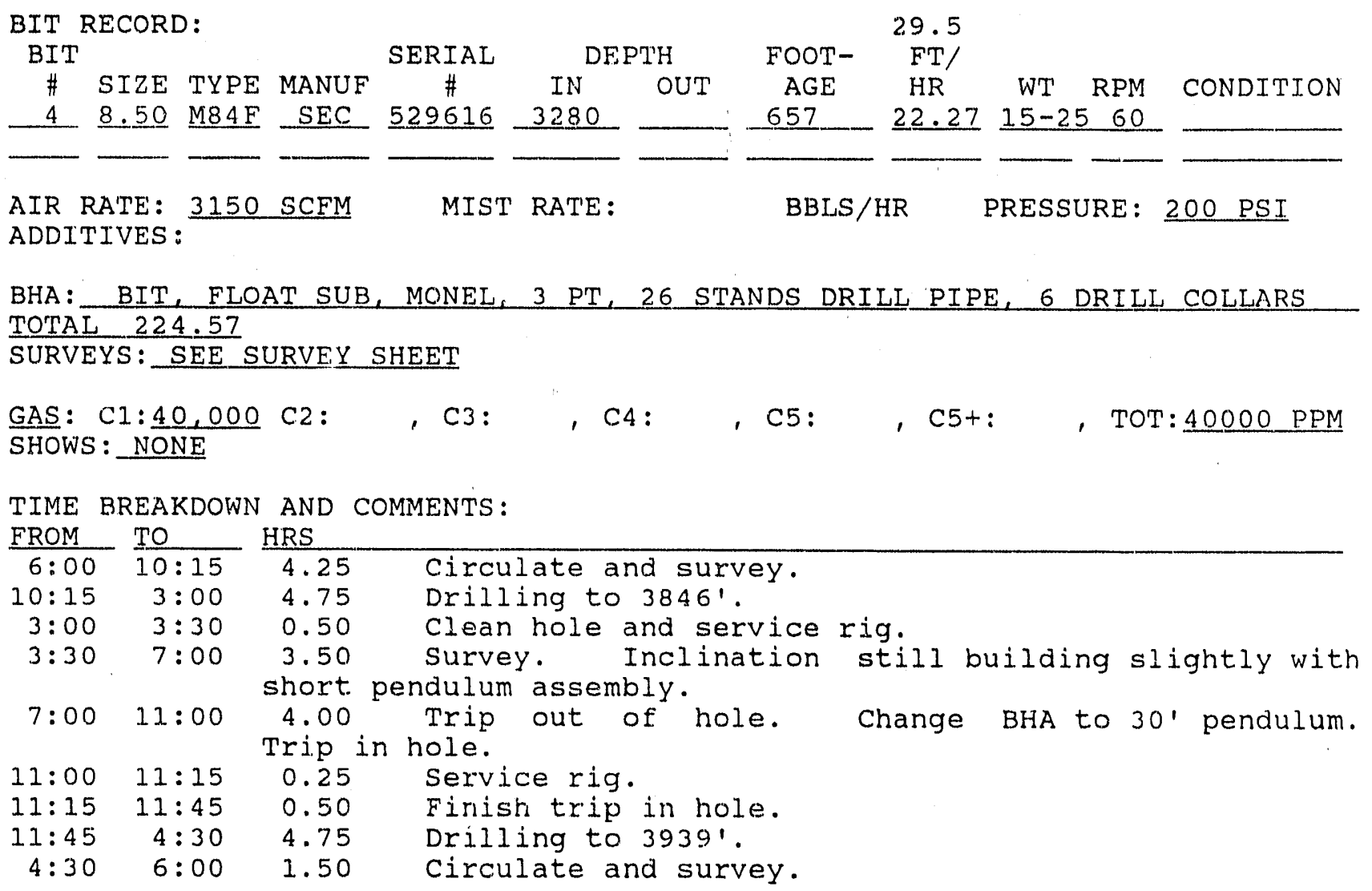




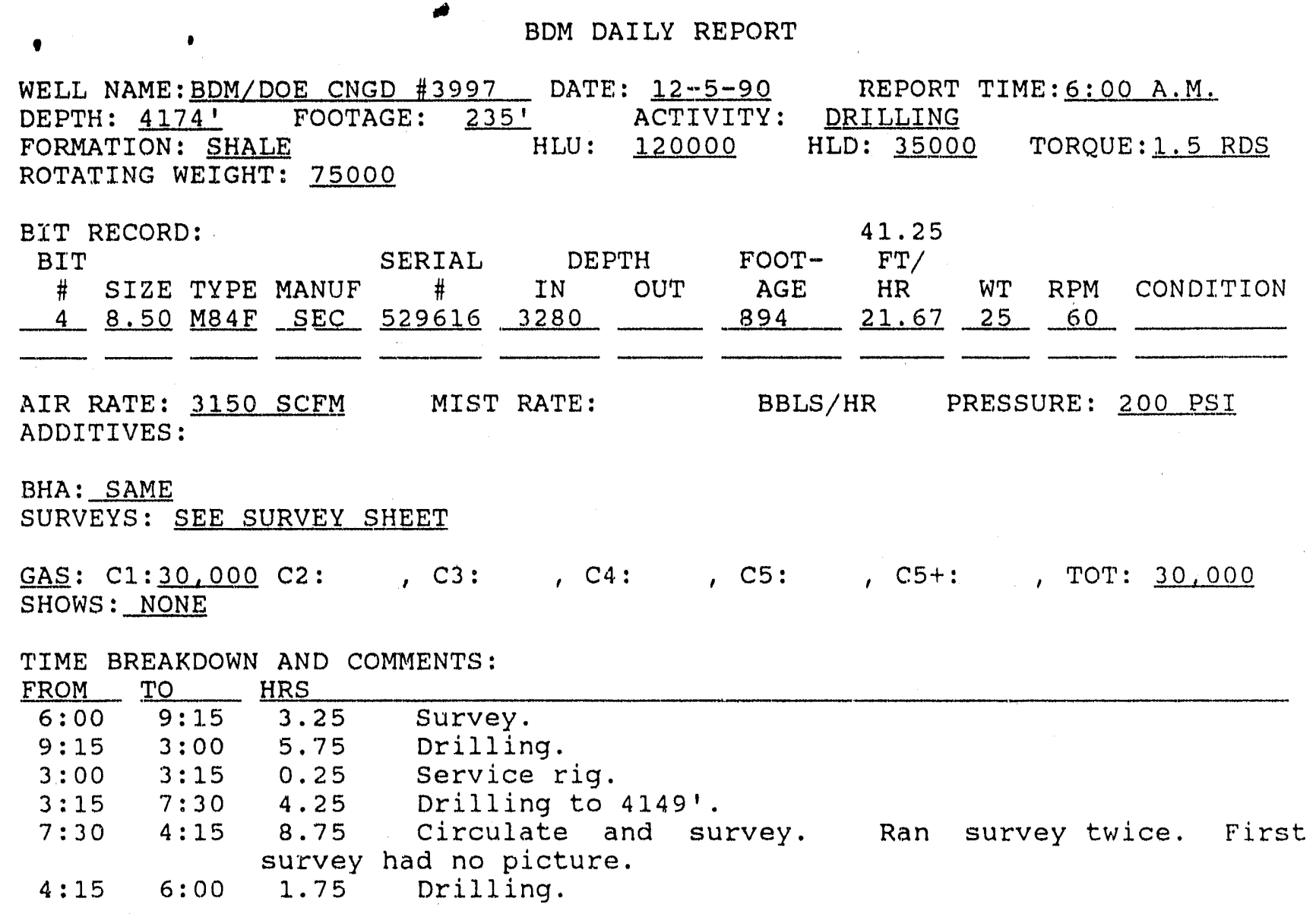


BDM DAILY REPORT

WELL NAME: BDM/DOE CNGD \#3997 DEPTH: 43351 FOOT'AGE: 1611 FORMATION:

ROTATING WEIGHT: 75,000
DATE: $12-6-90$ ACTIVITY HLU : 125,000
REPORT TIME: 6:00 A.M. REAMING TO BOTTOM

HLD: 10,000 TOROUE:

BIT RECORD:
BIT
\# SIZE TYPE MANUF




\section{BDM DAILY REPORT}

WELL NAME: BDM/DOE CNGD \#3997 DEPTH : 45051 FOOTAGE: 1701 FORMATION: ROTATING WEIGHT: 95,000
DATE: $12-7-90$ REPORT TIME: $6: 00$ A.M. ACTIVITY: DRILLING

HLU: 150,000 HLD: 20,000 TORQUE:

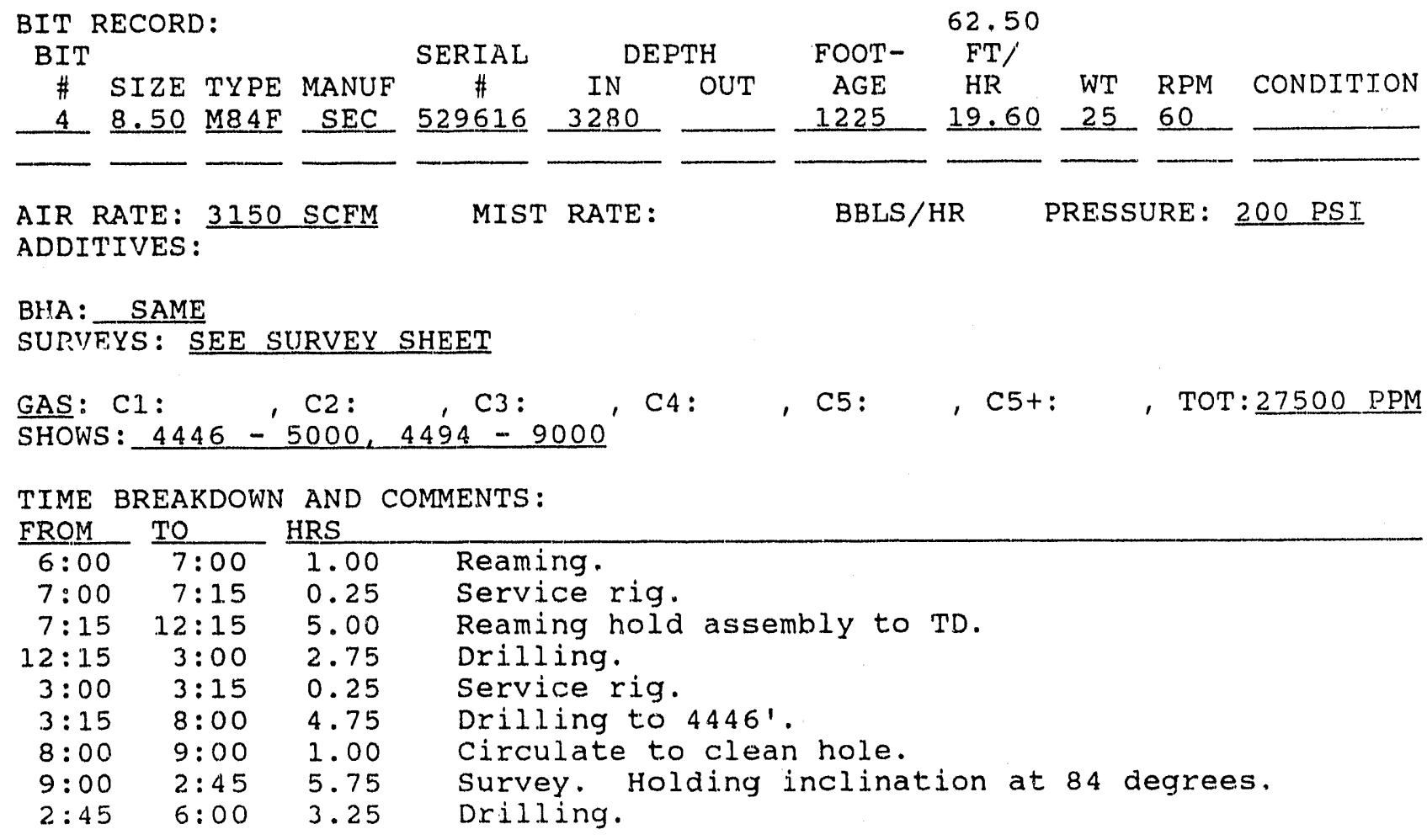


BDM DAIIY REPOR'T

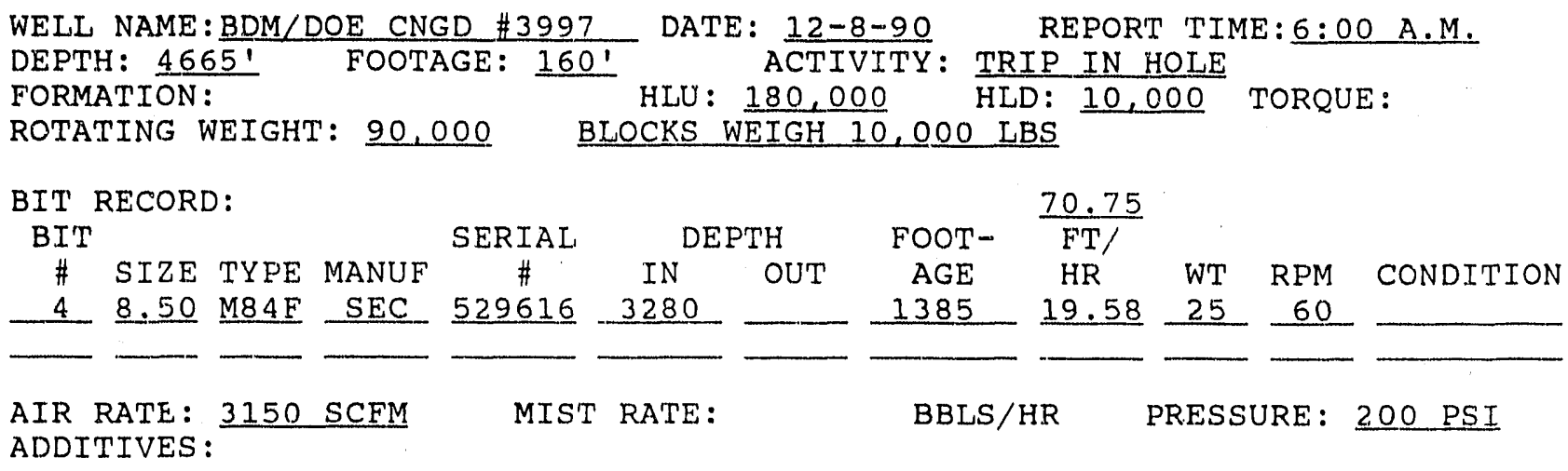

BHA: BIT, FLOAT SUB, MONEL, 37 STANDS DRILI PIPE, 18 DRILL COLLARS TOTAL 591.58

SURVEYS: SEE SURVEY SHEET

GAS: C1: , C2: , C3:, C4:, C5:, C5+: , TOT: 21400 PPM SHOWS : $4660^{\prime}-8000$ PPM

TIME BREAKDOWN AND COMMENTS:

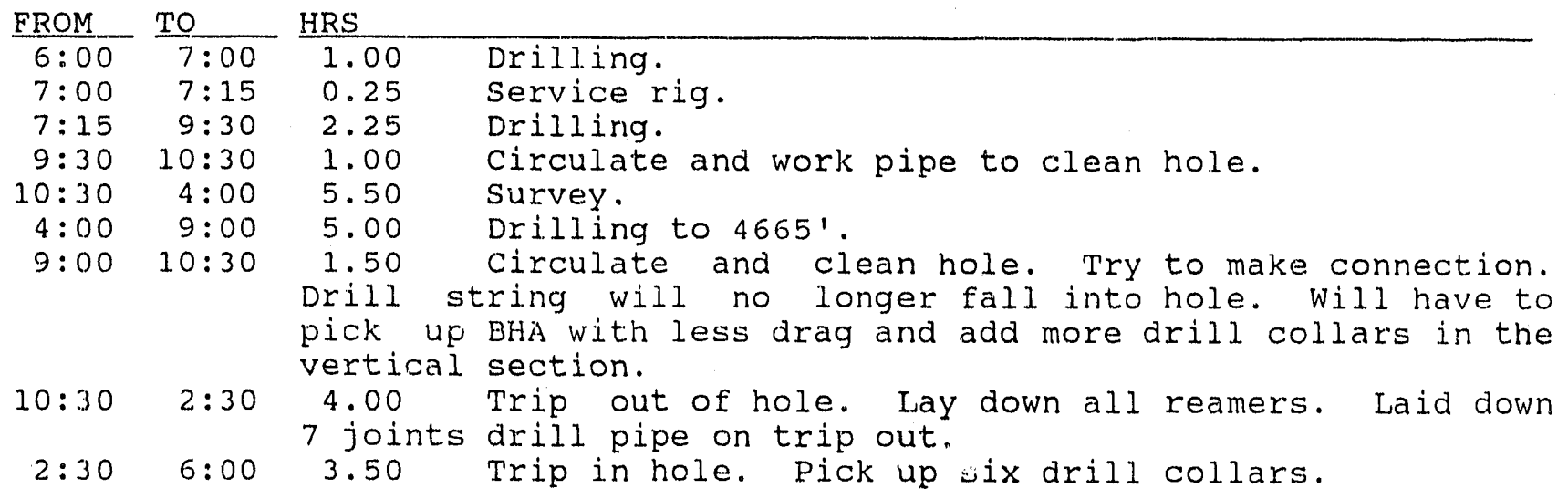




\section{BDM DAILY REPORT}

WELL NAME : BDM/DOE CNGD \#3997 DEPTH : 50131 FOOTAGE: 3481 FORMATION: SILT AND SHALE

DATE : $12-9-90$ ACTIVITY: TRIP OUT OF HOLE

ROTATING WEIGHT: 105,000

BIT RECORD:
BIT
SIZE TYPE MANUF


BDM DAILY REPORT

WELL NAME: $\mathrm{BDM} / \mathrm{DOE}$ CNGD $\# 3997$
DEPTH: $\underline{5013}$ F'OOTAGE: $\underline{0}$

DATE: 12-10-90 REPOR'T TIME: 6:00 A.M.

FORMATI

ROTATING WEIGHT:

HLU :

ACTIVITY: LOG WITH TLC LOGS

BIT RECORD:

BIT

SERIAL DEPTH FOOT- $\frac{91.50}{\text { FT/ }}$

\# SIZE TYPE MANUF \# IN OUT AGE HR WT RPM CONDITION

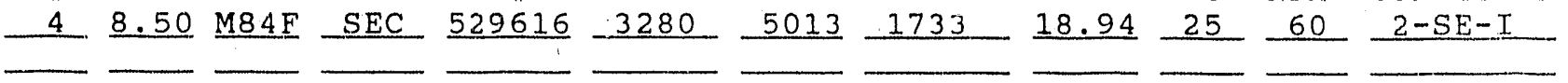

AIR RATE:

MIST RATE:

BBLS/HR PRESSURE:

ADDITIVES :

BHA :

SURVEYS :

GAS: C1: , C2:, C3:, C4:, C5:, C5+:, TOT:

SHOWS :

TIME BREAKDOWN AND COMMENTS:

\begin{tabular}{|c|c|c|}
\hline & ro & \\
\hline $6: 00$ & $7: 00$ & $\begin{array}{l}\text { 1.00 Trip out of hole. Drill string had parted on the } \\
15 \text { th drill collar down. Box had twisted off. }\end{array}$ \\
\hline $7: 00$ & $11: 00$ & Wait on fishing tools to arrive on location. \\
\hline $11: 00$ & $1: 00$ & Make up overshot and cross over sub. \\
\hline $1: 00$ & $1: 30$ & Fish. \\
\hline $1: 30$ & $3: 30$ & Trip out of hole with fish. \\
\hline $3: 30$ & $4: 30$ & Laid down fish and fishing tools. \\
\hline 30 & $6: 00$ & Trip \\
\hline & & $\begin{array}{l}\text { mutltishot st } \\
\text { location. }\end{array}$ \\
\hline $6: 00$ & $10: 0$ & Wait on Schl \\
\hline 10: & $1 .: 45$ & 3.75 \\
\hline & & , Temperature, and Compensated Density. \\
\hline $1: 45$ & $6: 00$ & $\begin{array}{cl}4.25 & \text { Rig down free fall logs. Rig up to run drill pipe } \\
\text { conveyed logs and trip in hole with drill pipe and logs. }\end{array}$ \\
\hline
\end{tabular}


BDM DAILY REPORT

WELL NAME: BDM/DOE CNGD \#3997
DEPTH: $\frac{50131}{\text { FOOTAGE: } \underline{0}}$ DORMATION:
ROTATING WEIGHT:

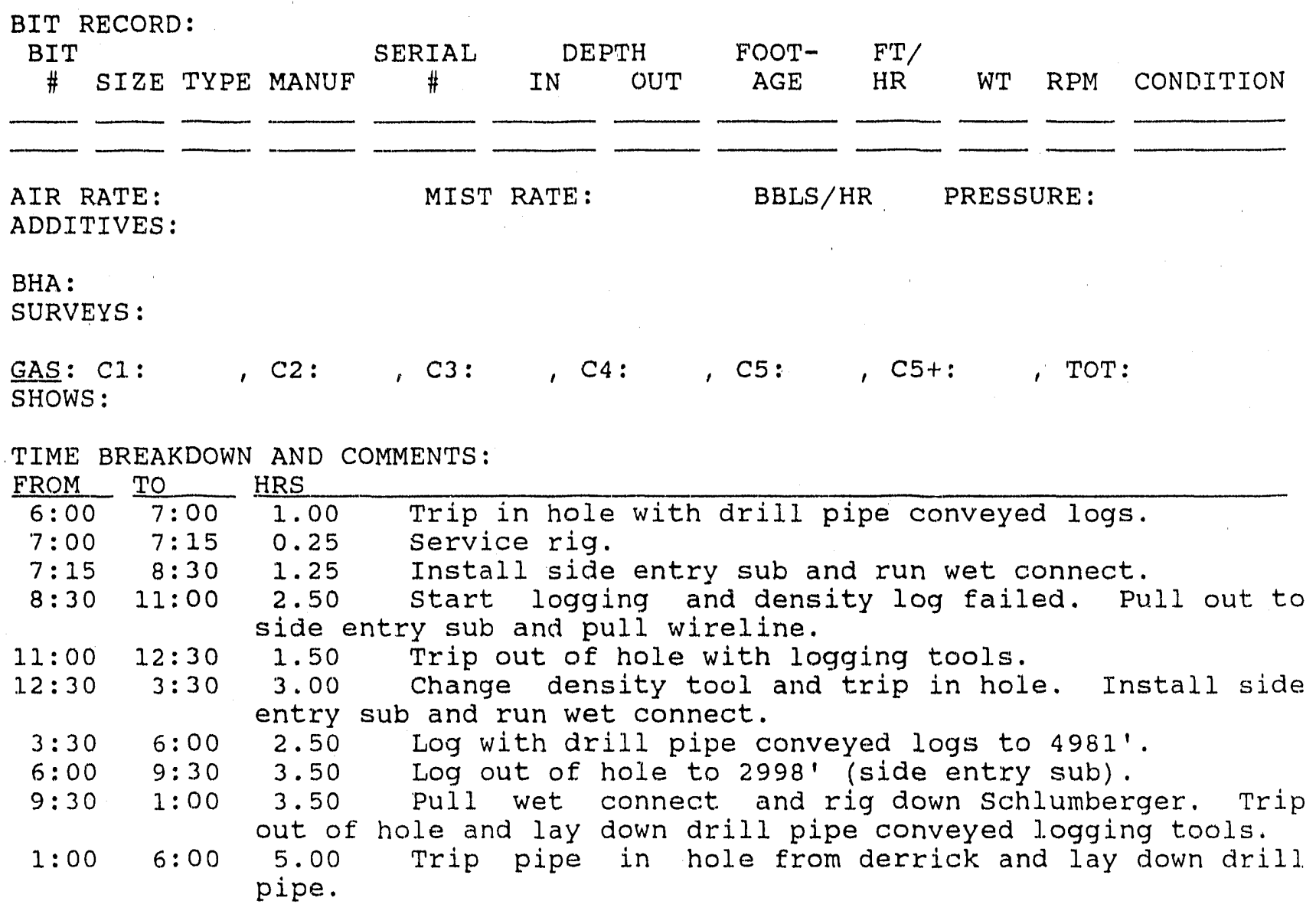


BDM DAILY REPORT

WELL NAME: BDM/DOE CNGD \#3997 DEPTH: 50131 FOOTAGE: 01 FORMATION: ROTATING WEIGHT:
DATE: $12-12-90$ REPORT TIME: 6:00 A.M. ACTIVITY: TRIP OUT OF HOLE HLU : HLD:

BIT RECORD:

BIT
$\#$ SIZE TYPE MANUF

BHA :

SURVEYS: SEE SURVEY SHEET

GAS: C1: , C2: C $23:, \mathrm{C} 4:, \mathrm{C} 5:, \mathrm{C} 5+:, \mathrm{TOT}:$ SHOWS :

TIME BREAKDOWN AND COMMENTS:

\begin{tabular}{|c|c|c|}
\hline & & \\
\hline $6: 00$ & $9: 30$ & Lay down drill pipe and collars. \\
\hline $9: 30$ & $10: 30$ & Nipple down. \\
\hline $10: 30$ & $12: 00$ & Rig up power tongs and rig up to run casing. \\
\hline $12: 00$ & $5: 15$ & Run 11 joints of $51 / 2 ", 17 \# / f t, J-55$, ST\&C casing \\
\hline & & $\begin{array}{l}\text { with six external casing packers and nine port collars. } \\
\text { casing at } 4755^{\prime} \mathrm{KB} \text {. }\end{array}$ \\
\hline $5: 15$ & $7: 00$ & $\begin{array}{l}1.75 \text { Set wellhead in slips with } 40,000 \text { lbs tension. Rig } \\
\text { down casing tools and wait on tubing. }\end{array}$ \\
\hline $7: 00$ & $12: 00$ & Unload $23 / 8 "$ tubing and wait on tubing slips. \\
\hline $12: 00$ & $5: 15$ & $\begin{array}{l}\text { Pick up tubing off of rack and trip in hole with } \\
\text { ble bridge plug. set bridge plug at } 4618^{\prime} \text {. }\end{array}$ \\
\hline $\begin{array}{l}5: 15 \\
5: 45\end{array}$ & $\begin{array}{l}5: 45 \\
6: 00\end{array}$ & $\begin{array}{l}\text { Spot } 35 \text { bbls of } 2 \% \mathrm{KCl} \text { water in casing. } \\
\text { Trip out }\end{array}$ \\
\hline & & LUDLIII. \\
\hline
\end{tabular}




\section{BDM DAILY REPORT}

WELL NAME: BDM/DOE/CNGD \#3997 DATE: 12-13-1990

REPORT TIME: 6:00 A.M.

DEPTH: 5013 FOOTAGE: 0 ACTIVITY: Setting ECPs and cement $51 / 2$ FORMATION: HLU: HLD: TORQUE:

ROTATING WEIGHT:

BIT RECORD:

BIT SERIAL DEPTH FOOT- FT/

\# SIZE TYPE MANUF \# IN OUT AGE HR WT RPM CONDITION

AIR RATE: MIST RATE: BBLS/HR PRESSURE:

ADDITIVES:

BHA:

SURVEYS: NONE

GAS: $\quad$ C1: , C2: , C3: , C4: , C5: , C5+: , TOT:

SHOWS:

TIME BREAKDOWN AND COMMENTS:
FROM TO HRS
6:00 8:00 2.00 Trip out of hole w/tubing.
8:00 $11.00 \quad 3.00$ Trip in hole w/RTTS assembly to test Bridge Plug and ECPs.
11:00 11:30 $\quad 0.50$ Test BP by pressuring up $w / n i t r o g e n$. Leak detected.
11:30 1:30 2.00 Trip out of hole for BP setting tool.
$\begin{array}{ccc}1: 30 & 4: 00 & 2.50 \text { Trip in hole } w / B P \text { setting tool and RTTS. Re } \\ 4: 00 & 5: 00 & 1.00 \text { Set RTTS and pressure up on BP. Test was a } \\ \text { success. }\end{array}$
5:00 9:00 4:00 Inflate and test ECPs.
9:00 11:30 2.50 Trip out w/tubing and RTTS assembly.
11:30 12:30 1.00 Trip in w/tubing and opening and closing tool for port collars.
12:30 1:00 $\quad 0.5$ Nipple up wellhead.
1:00 4:00 3.0 Rig up Nowsco. and open PC for cement job.
4:00 6:00 2.0 Circulate casing and batch mix cement. 


\section{BDM DAILY REPORT}

WELL NAME: BDM/DOE/CNGD \#3997 DATE: $12-14-90$

REPORT TIME: 6:00 A.M.

DEPTH: 5013 FOOTAGE: 0 ACTIVITY: CEMENTING 5 1/2" CSG

FORMATION: HLU: HLD: TORQUE:

ROTATING WEIGHT:

BIT RECORD:

BIT SERIAL DEPTH FOOT. FTI

\# SIZE TYPE MANUF \# IN OUT AGE HR WT RPM CONDITION

AIR RATE: MISTRATE: BBLS/HR PRESSURE:

ADDITIVES:

BHA:

SURVEYS: NONE

GAS: $\quad$ C1: , C2: , C3: , C4: , C5: , C5+: , TOT:

SHOWS:

TIME BREAKDOWNS AND COMMENTS:

$\begin{array}{cccl}\text { FAOM } & \text { TO } & \text { HRS } & \\ 6: 00 & 7: 00 & 1.0 & \text { PUMP 6\% GEL MIX AHEAD OF 3\% CaCI SPACER. } \\ & & & \text { FOLLOWED BY 235 SACKS 50/50 POZMIX DOWN } 2 \\ & & 3 / 8 " \text { TUBING. } \\ 7: 00 & 7: 30 & 0.5 & \text { REVERSE OUT. } \\ 7: 30 & 12: 00 & 3.5 & \text { SHUT IN FOR INITIAL SET. } \\ 12: 00 & 2: 40 & 2.6 & \text { PUMP ACID SWEEP TO CLEAN OUT ANY CEMENT LEFT } \\ & & & \text { IN TUBING ICASING. CLEAN UP SHUTDOWN. } \\ 2: 40 & 7: 00 & 4.2 & \text { WOC. } \\ 7: 00 & & & \text { RELEASE RIG. }\end{array}$




\section{APPENDIX G}

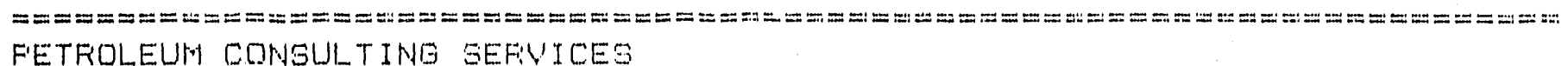

P.D. EOX ISEDS

CANTON, OH 44735

(216). 499-382.

DAIL ' CEIST SUMMAFIY

\begin{tabular}{|c|c|c|c|c|}
\hline WELL.: & HUNTEF EENNETT & $\# \div 957$ & DEFTH: & 2091 \\
\hline TAFIGET: & DEVDNIAN SHALE & & TODFYS COST: & 7.787 \\
\hline WATEFISHED & CFIUMMIS CFIEEH: & & TO DATE: & 94526 \\
\hline QUAD:DIGT & MILLSTONE/LEE & & FIEMAINING: & \\
\hline CNTY/ST: & C,FLLHOUN/WV & & DATE: FFEFAFED: & $11 / 14: 90$ \\
\hline
\end{tabular}

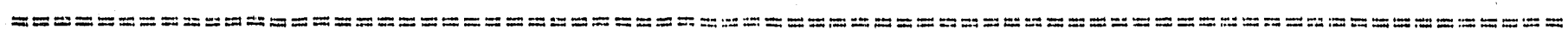

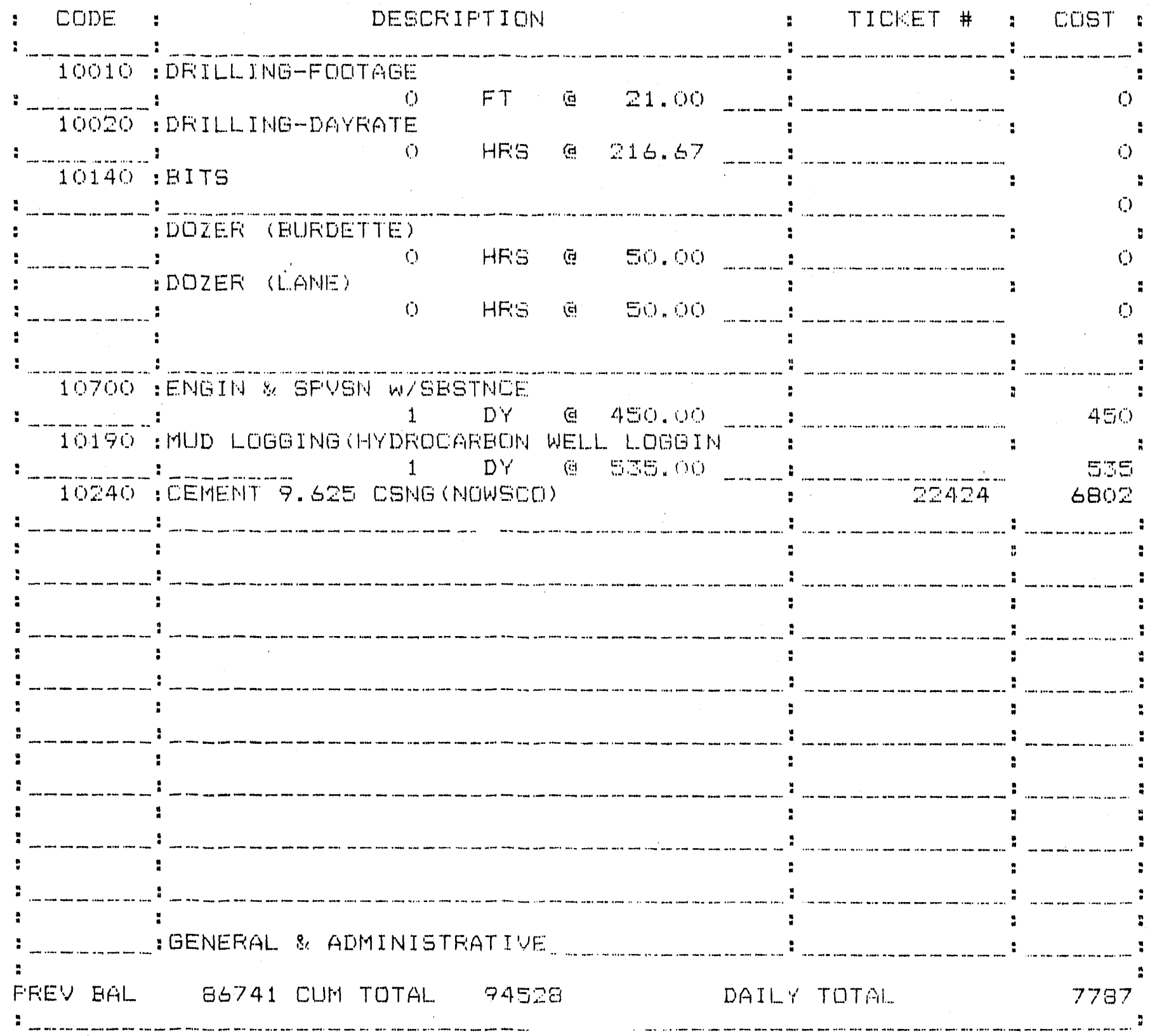

- COMMENTS:

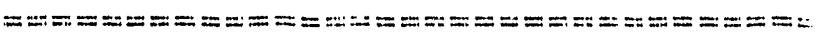

102

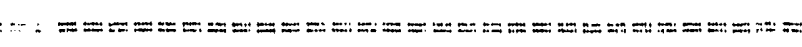




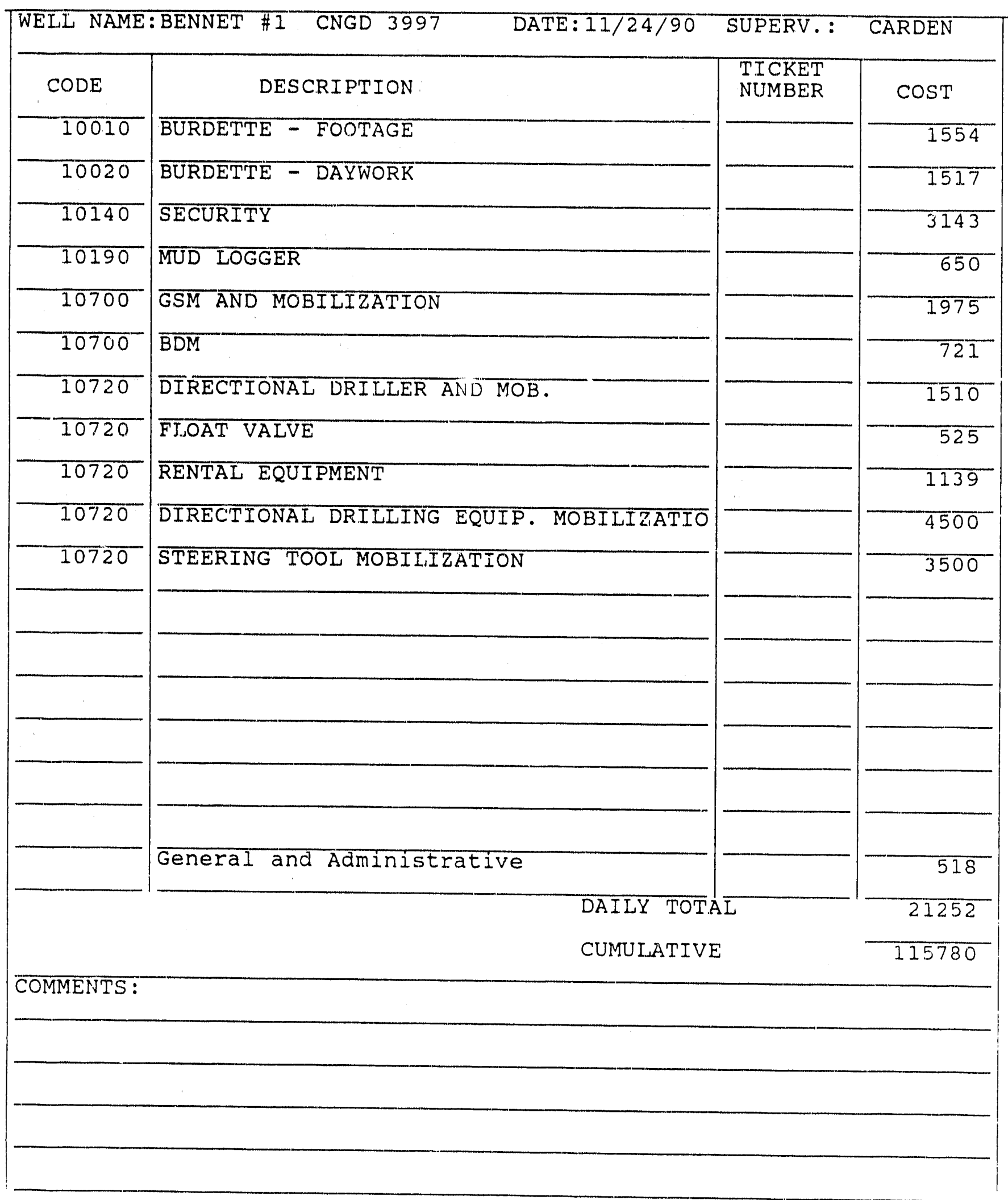




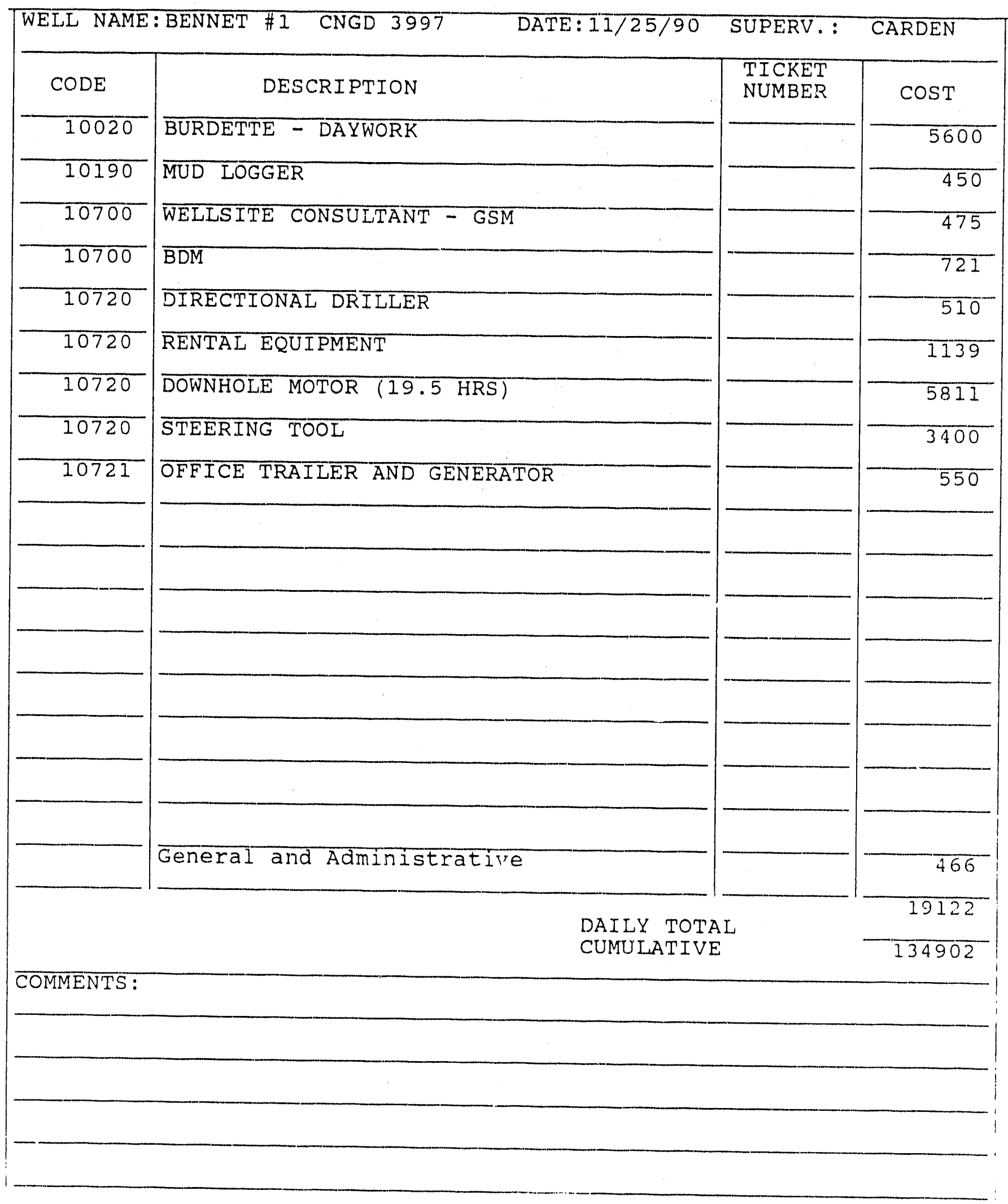




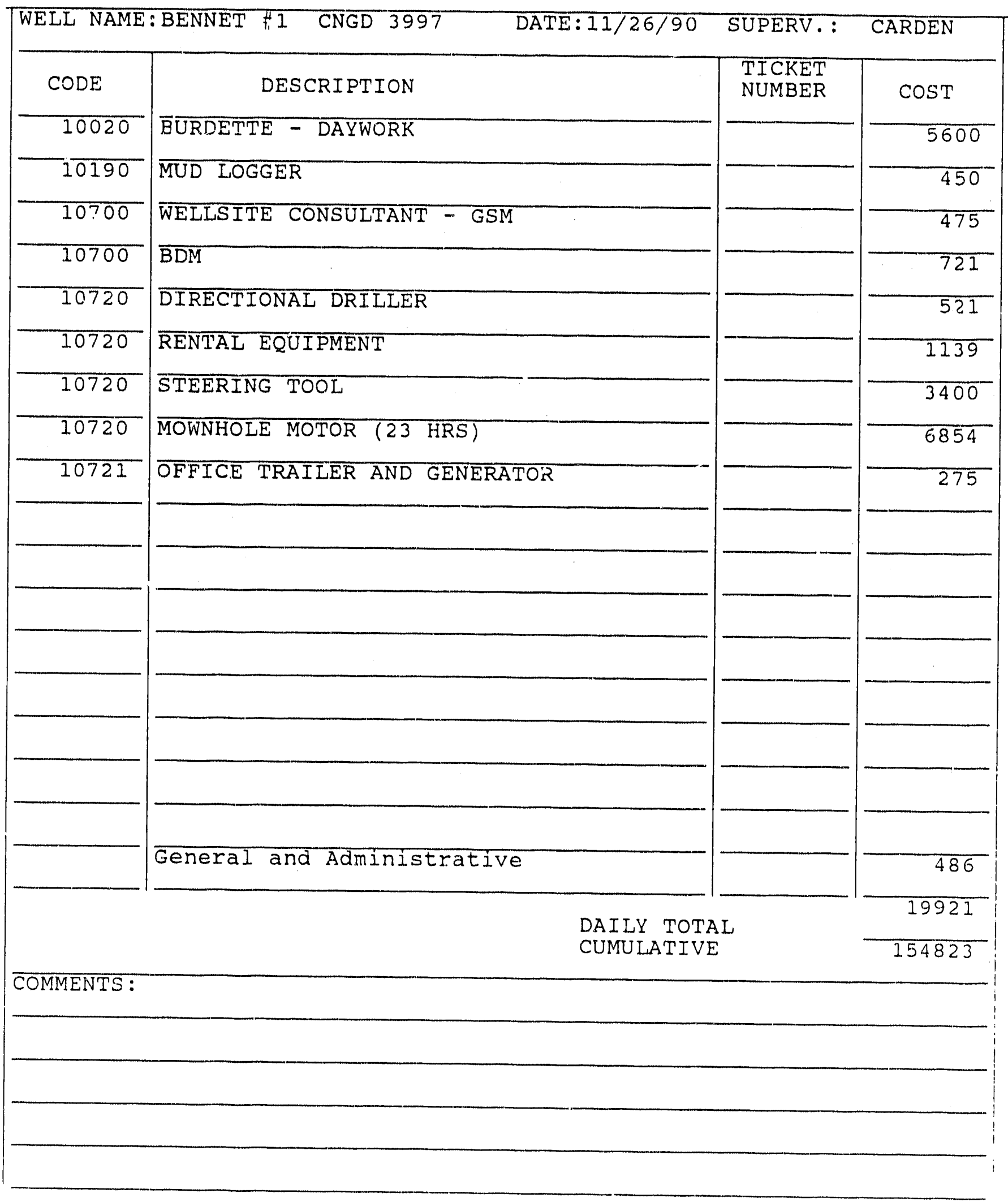




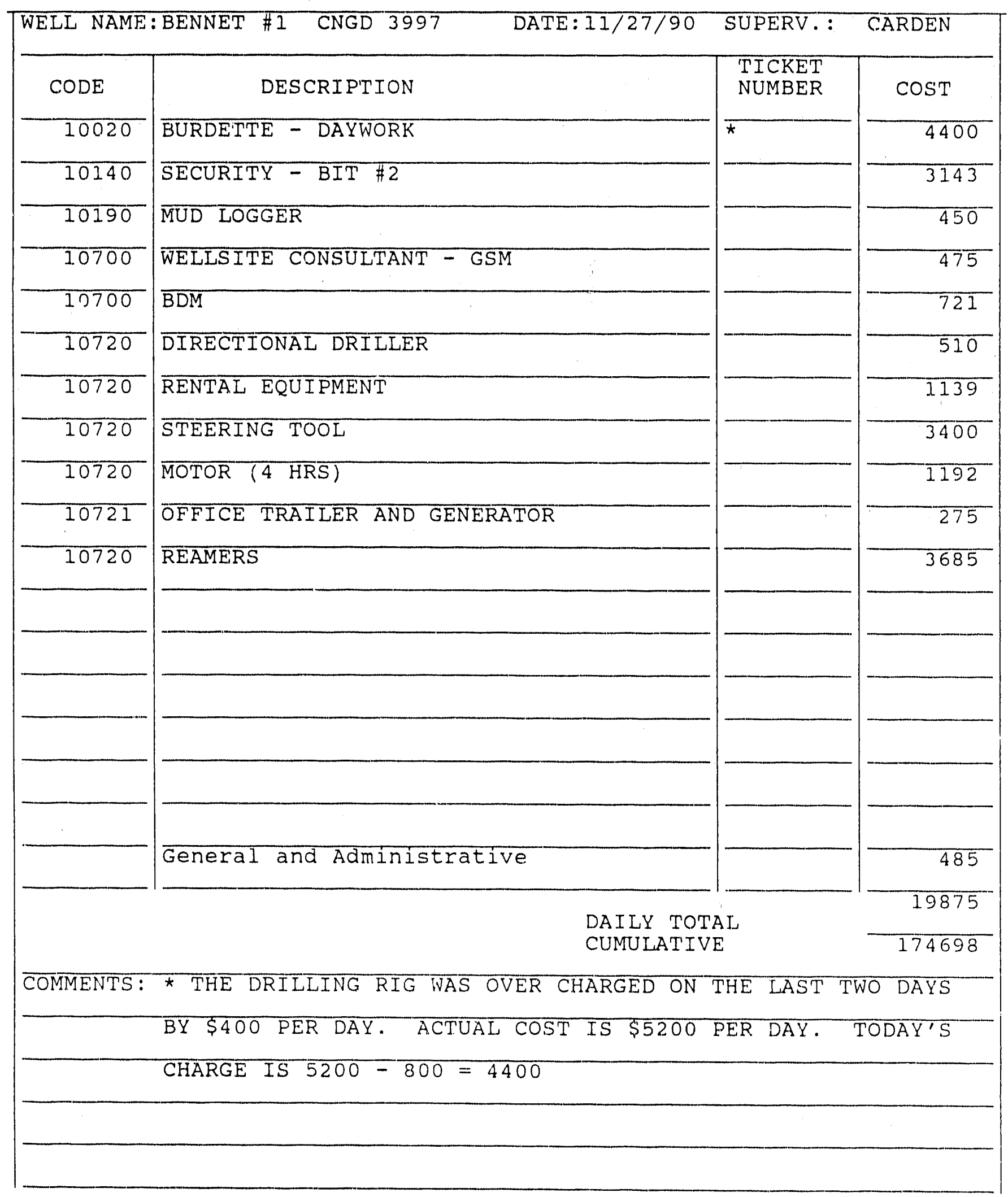




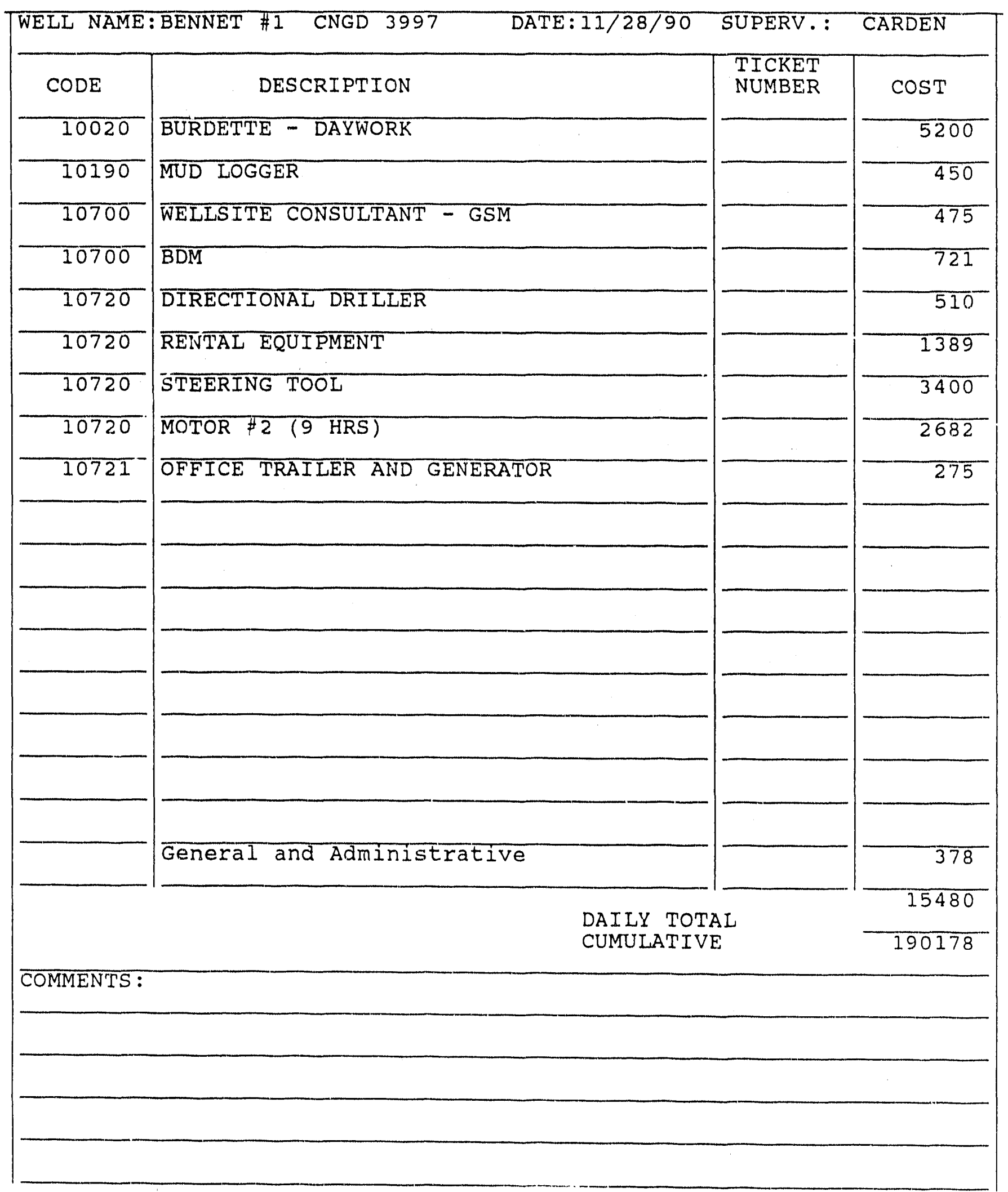




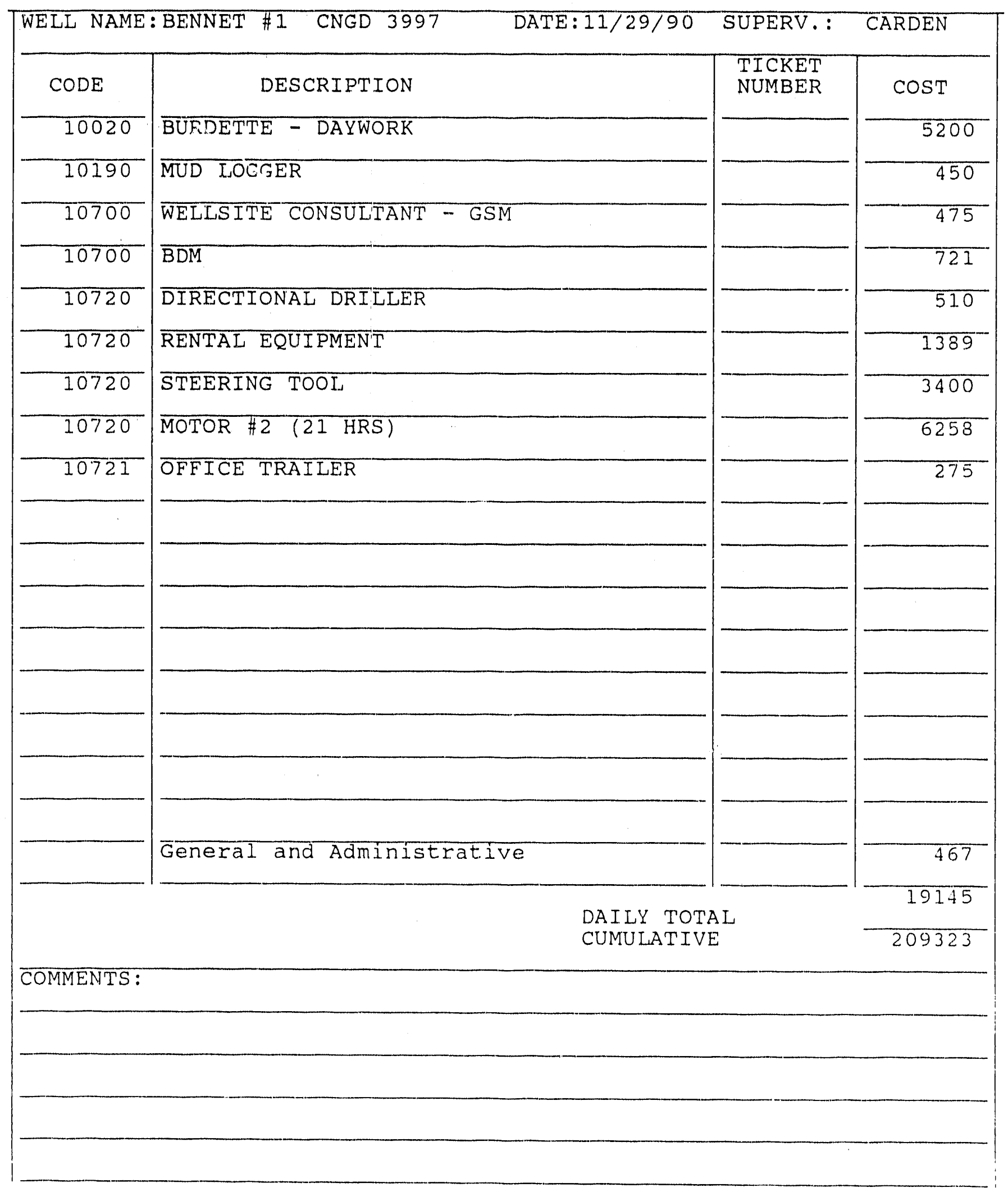




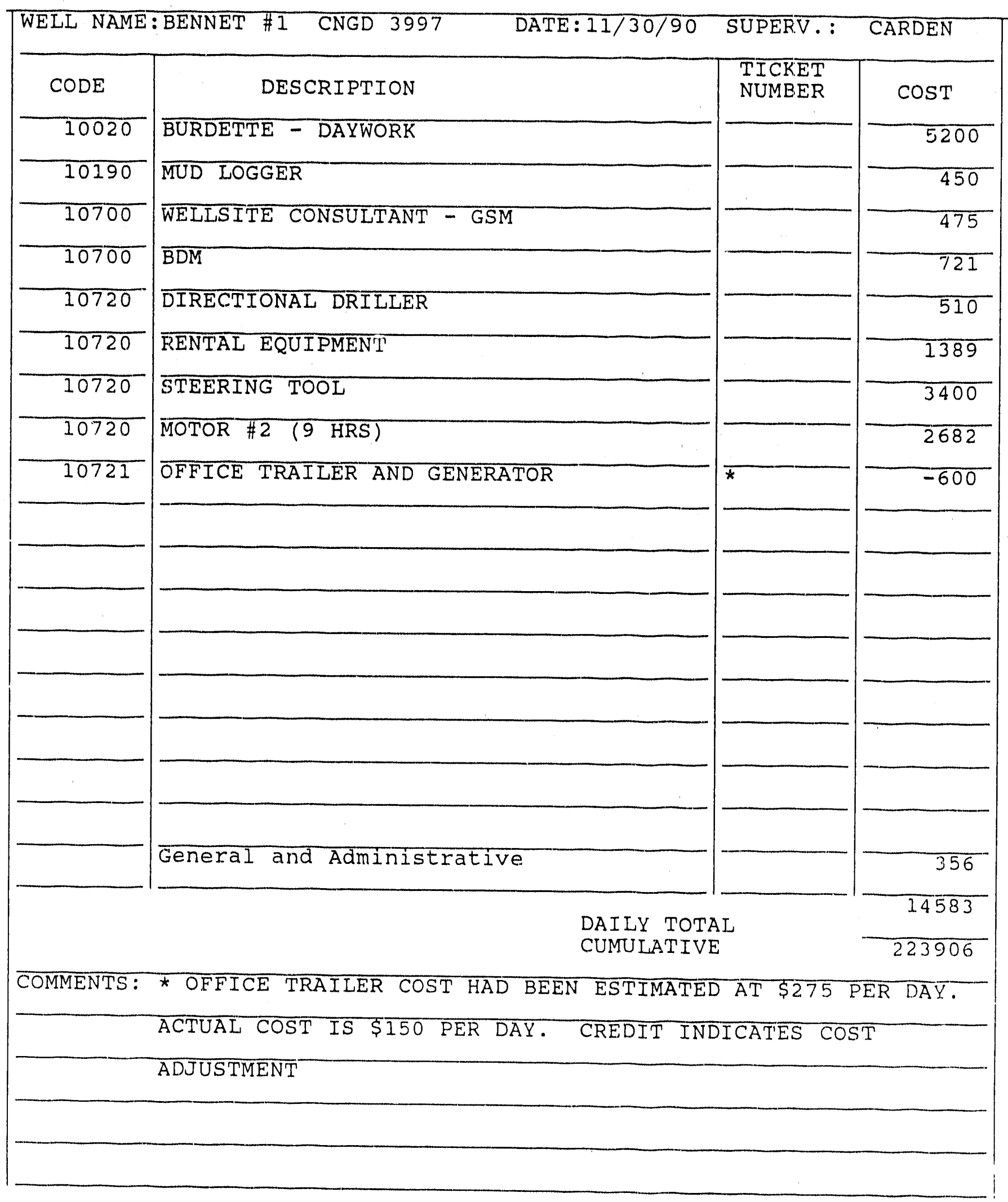




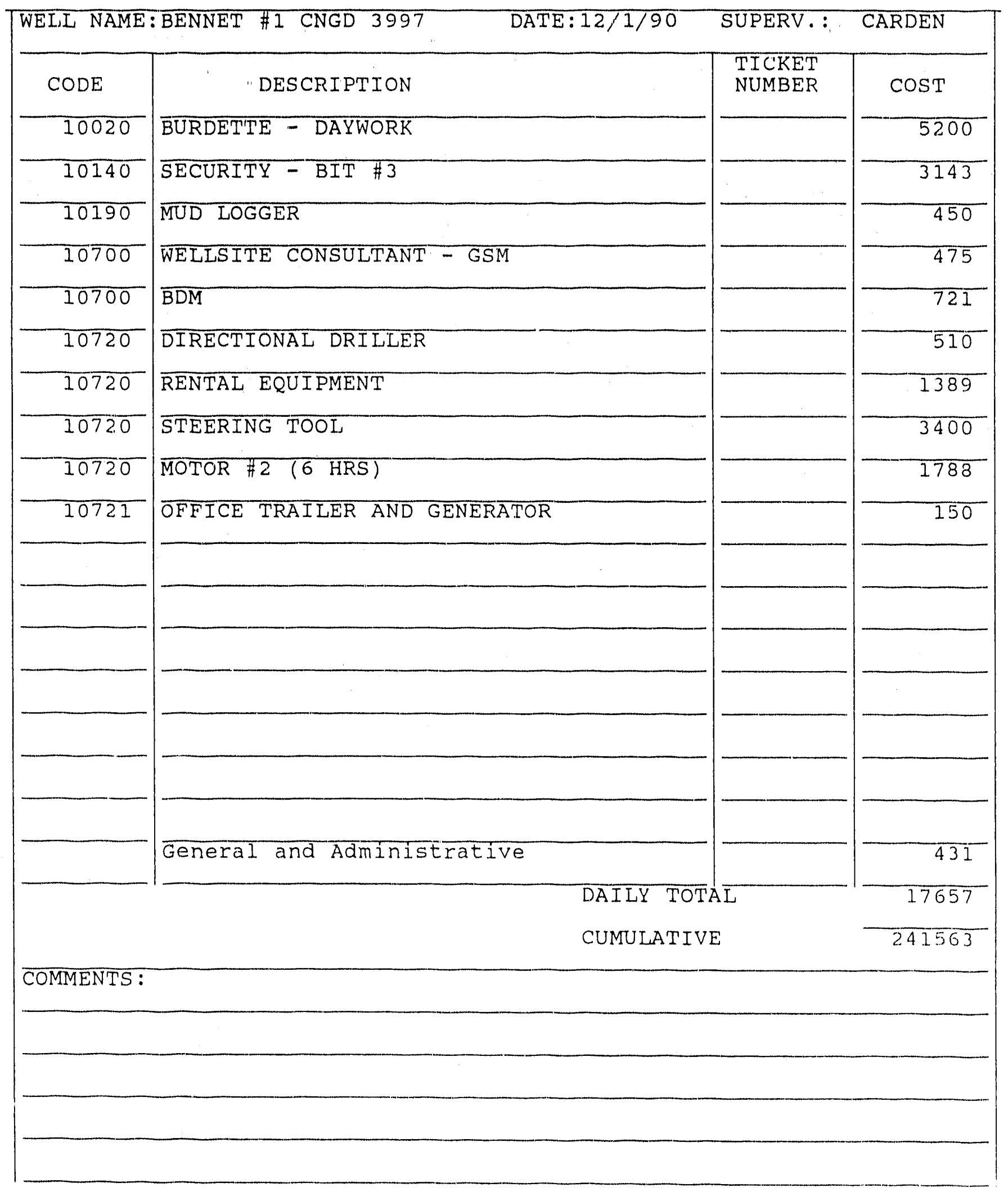




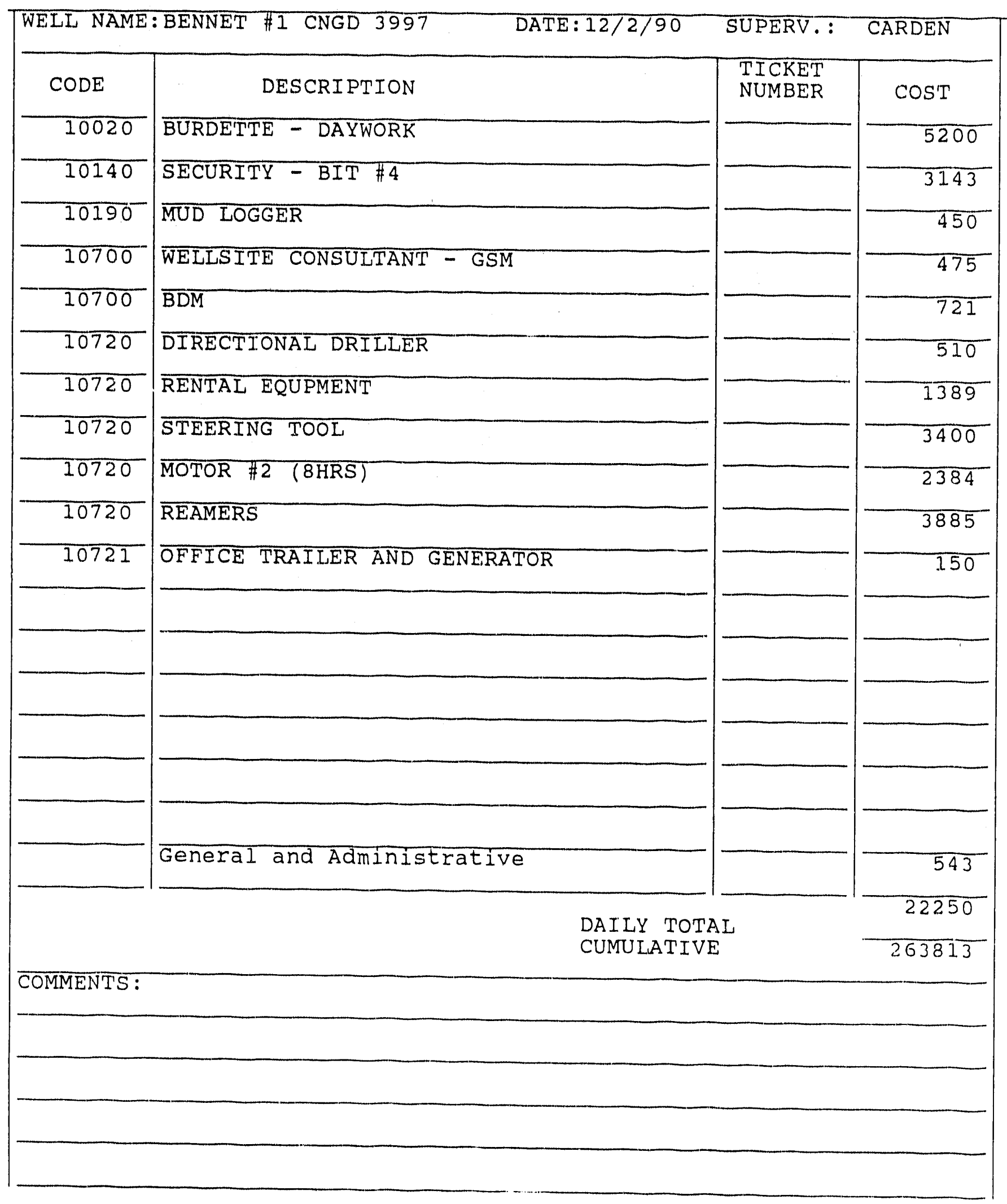




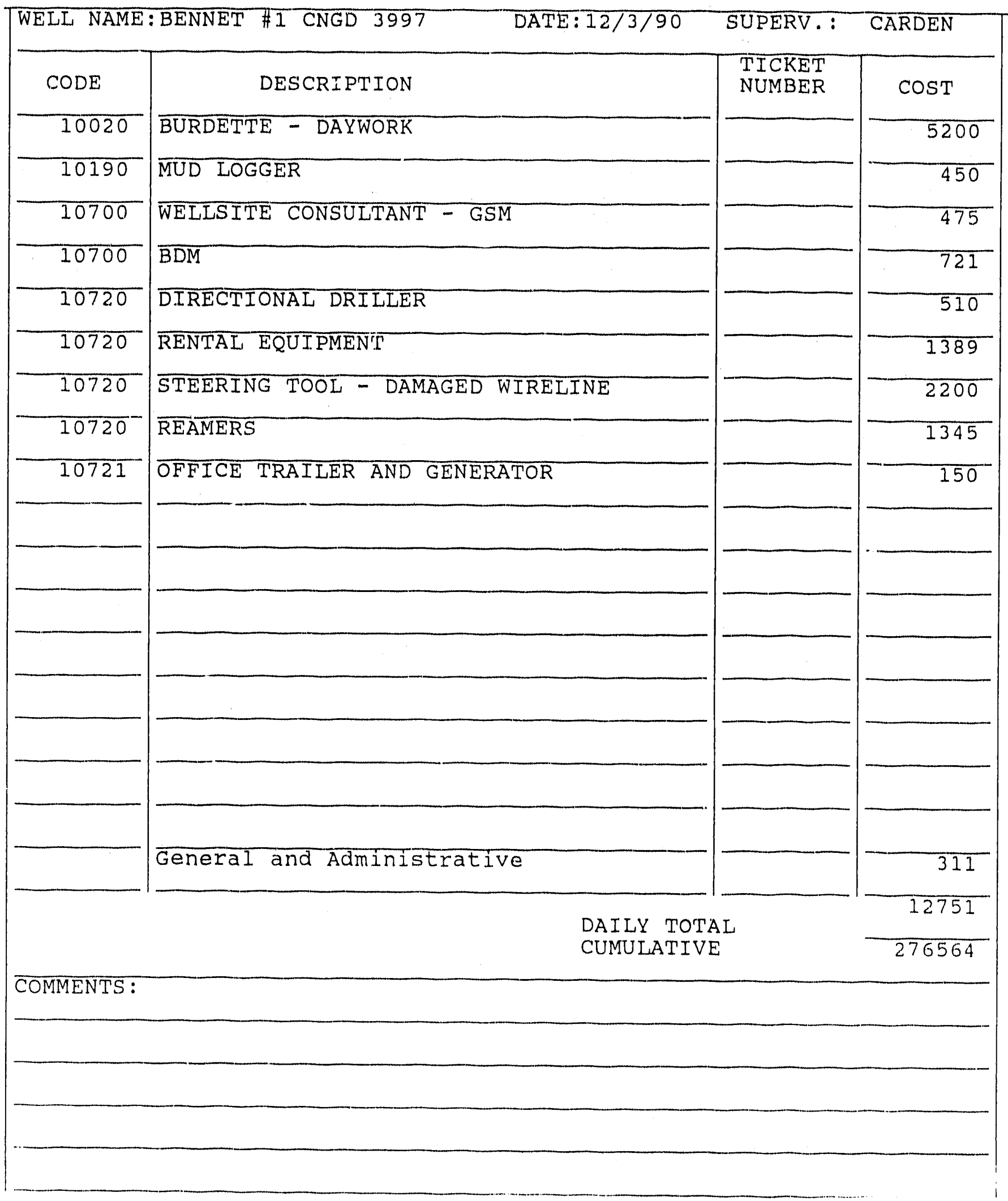




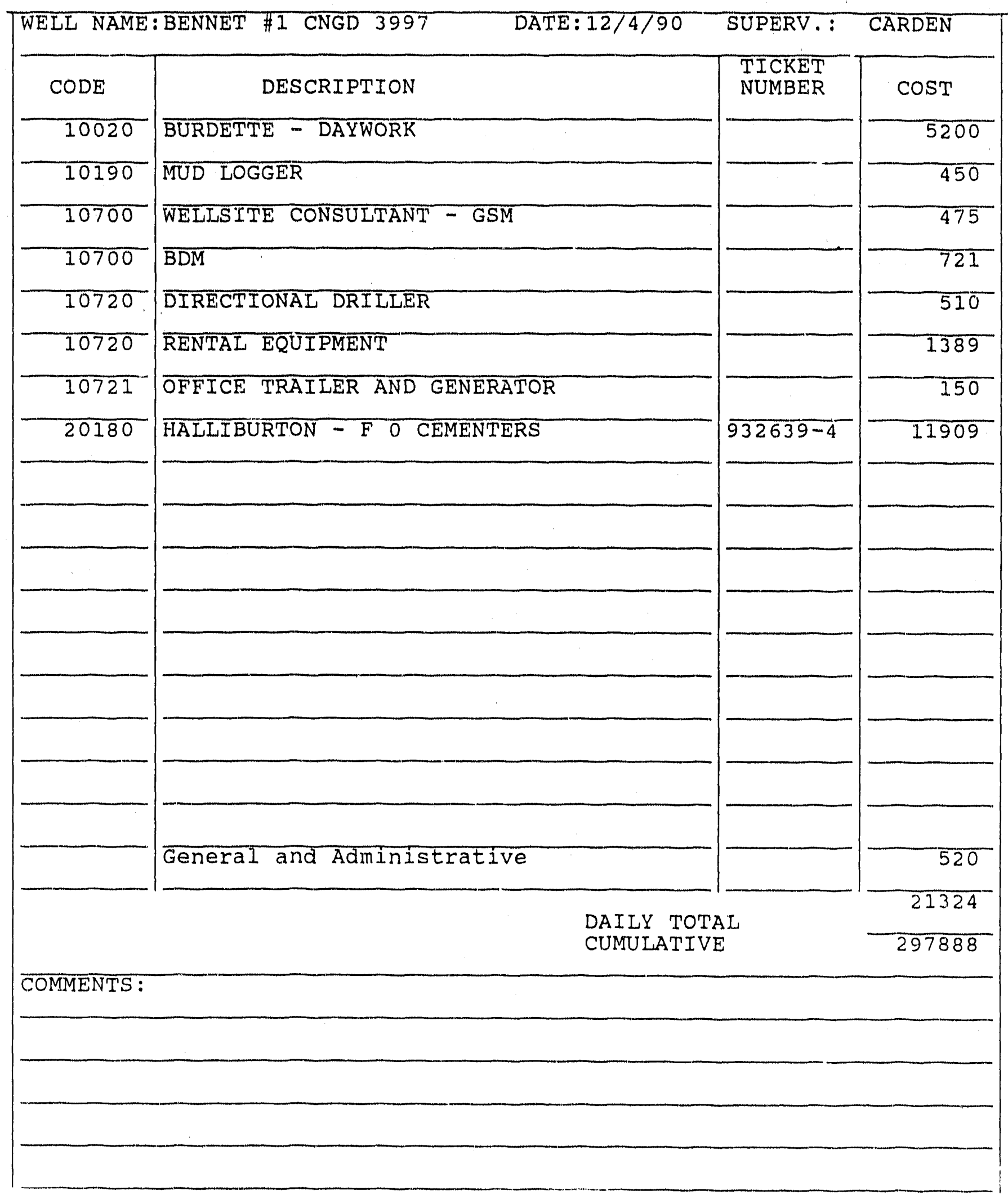




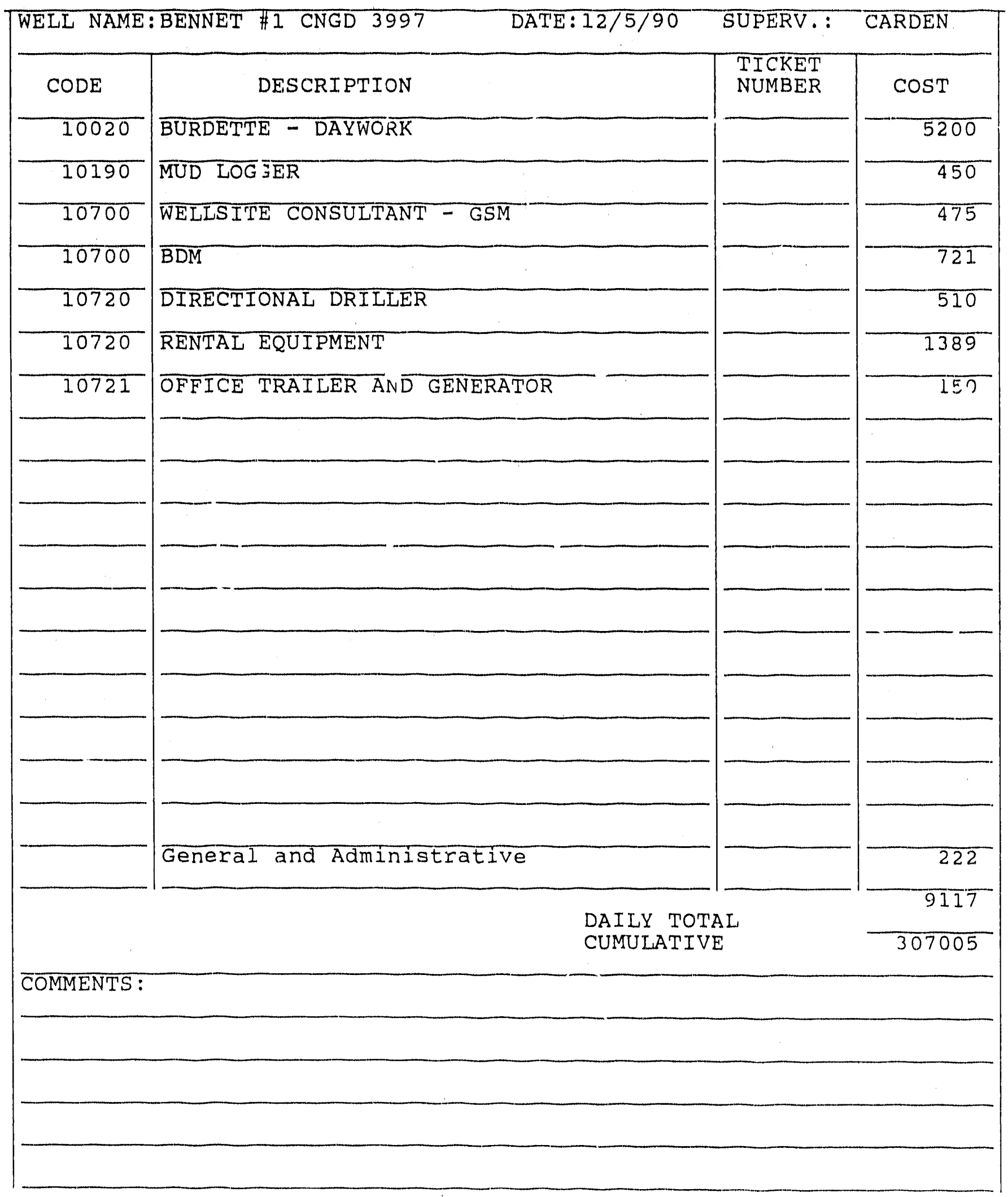




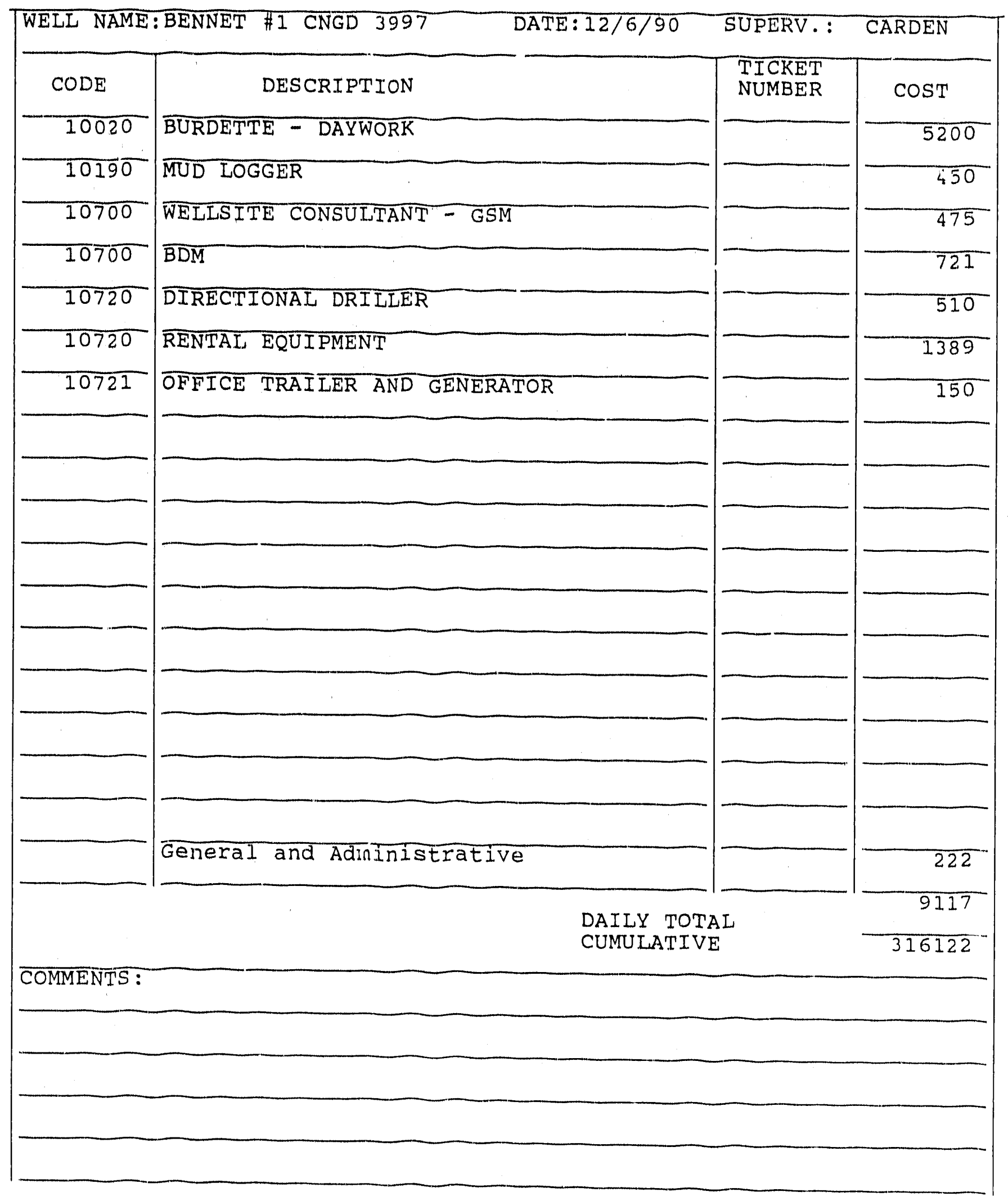




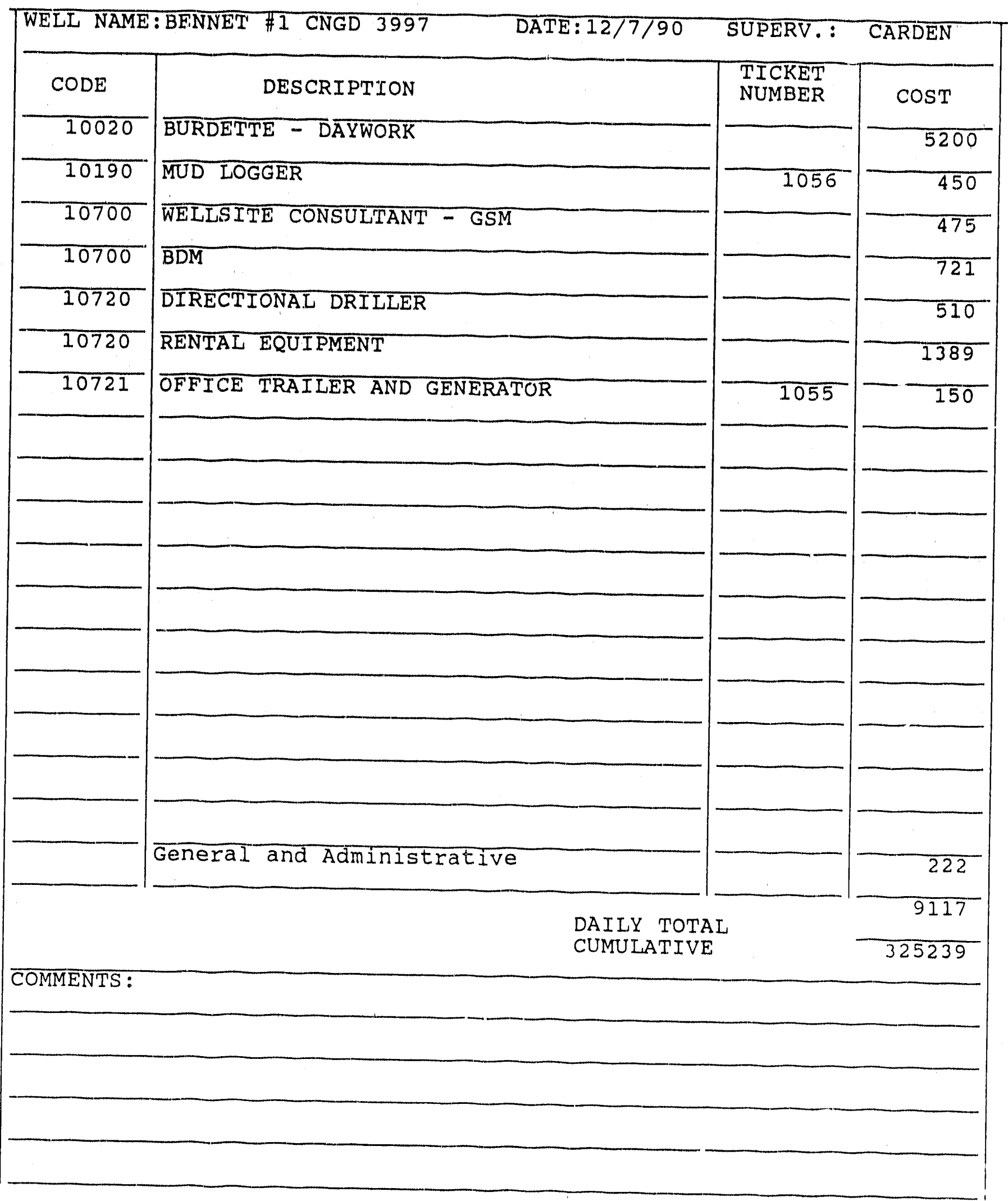




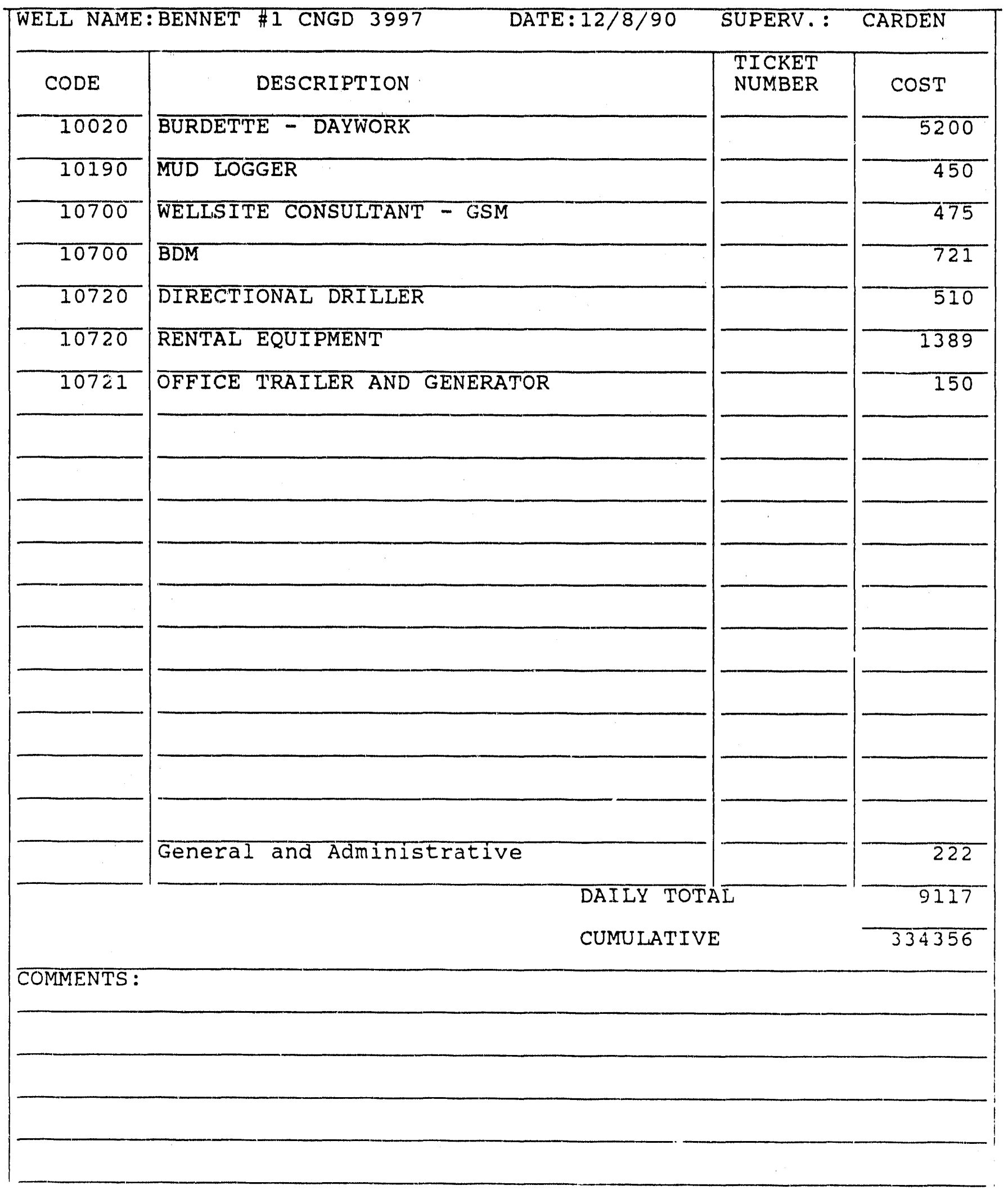




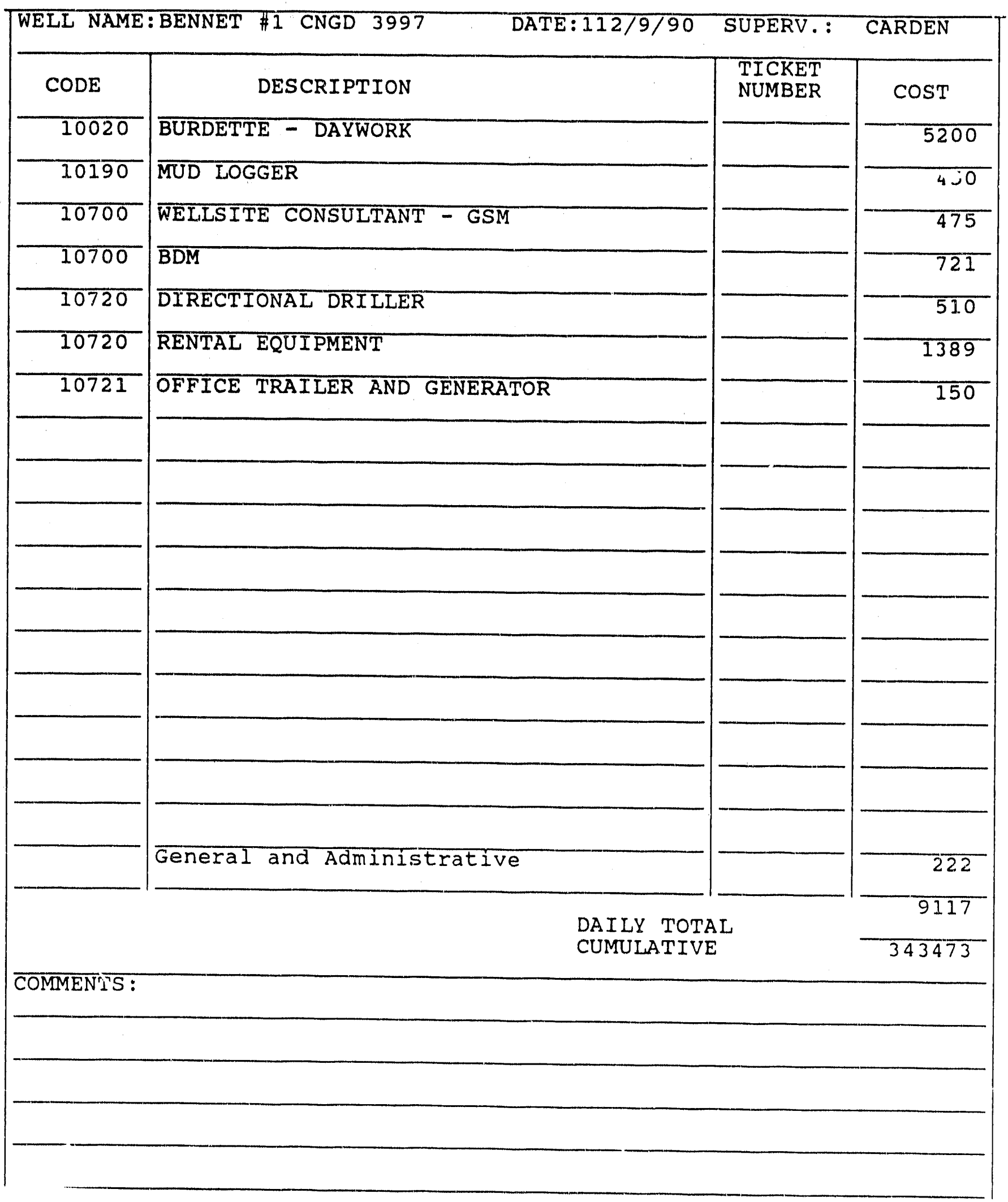




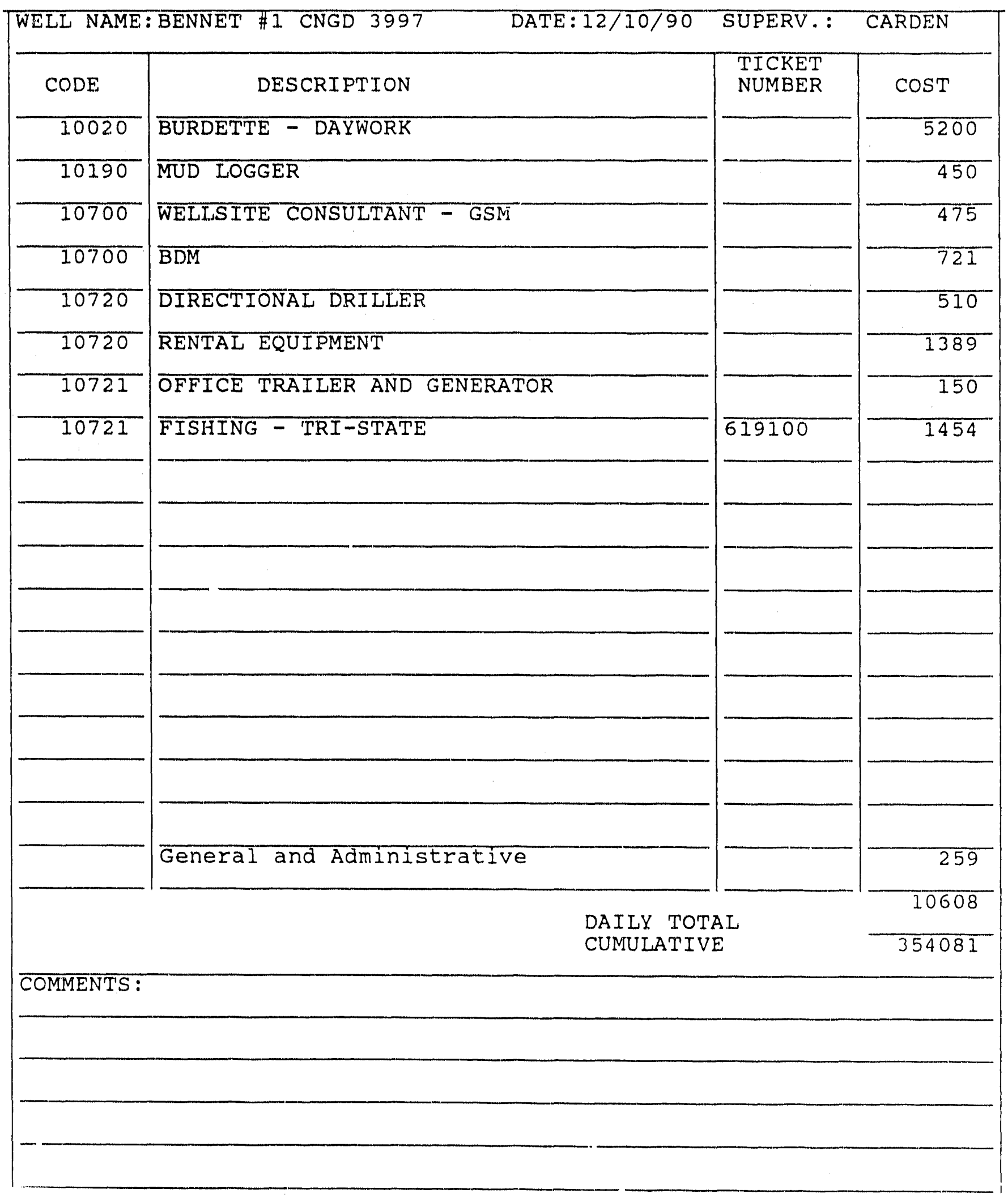




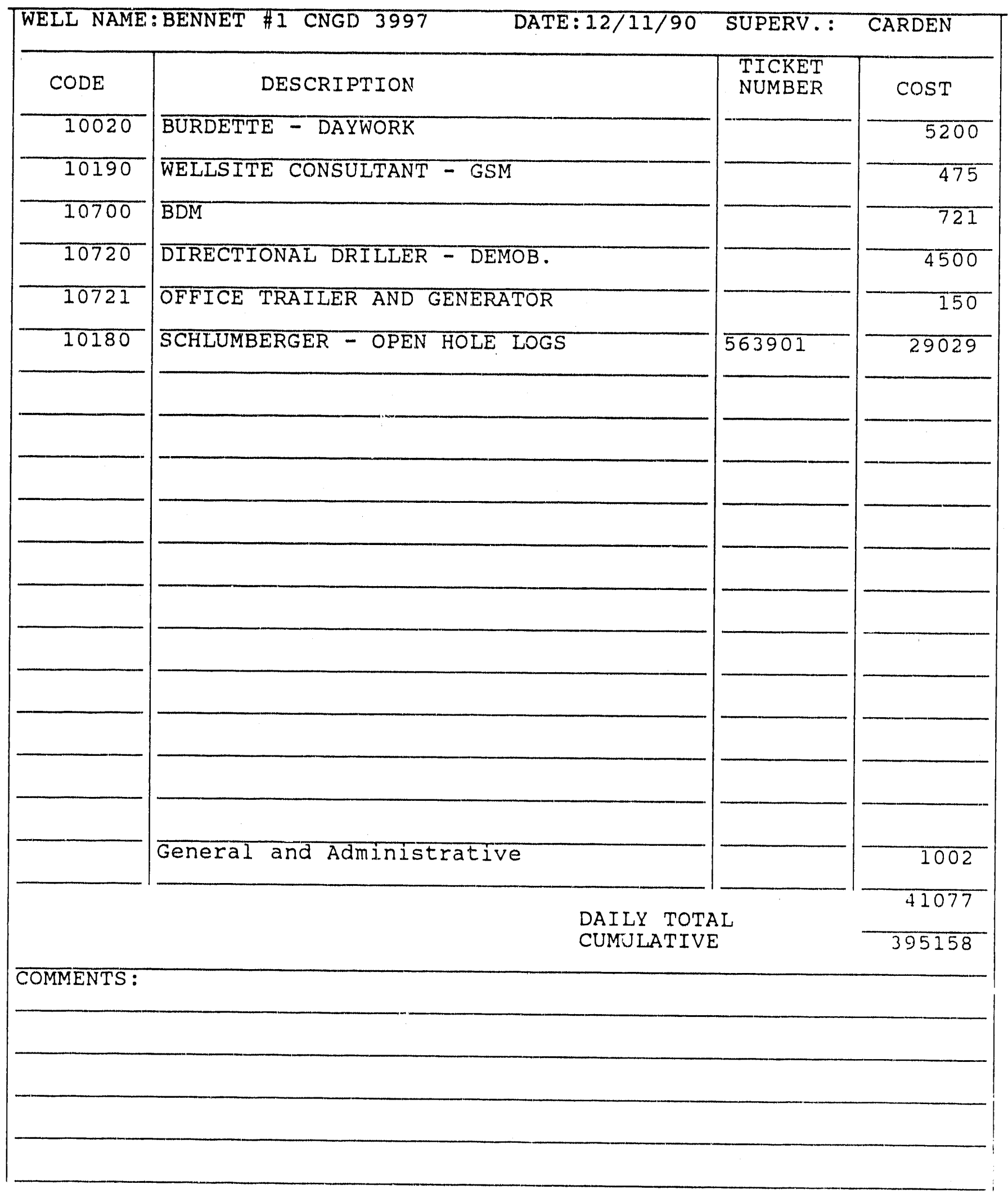




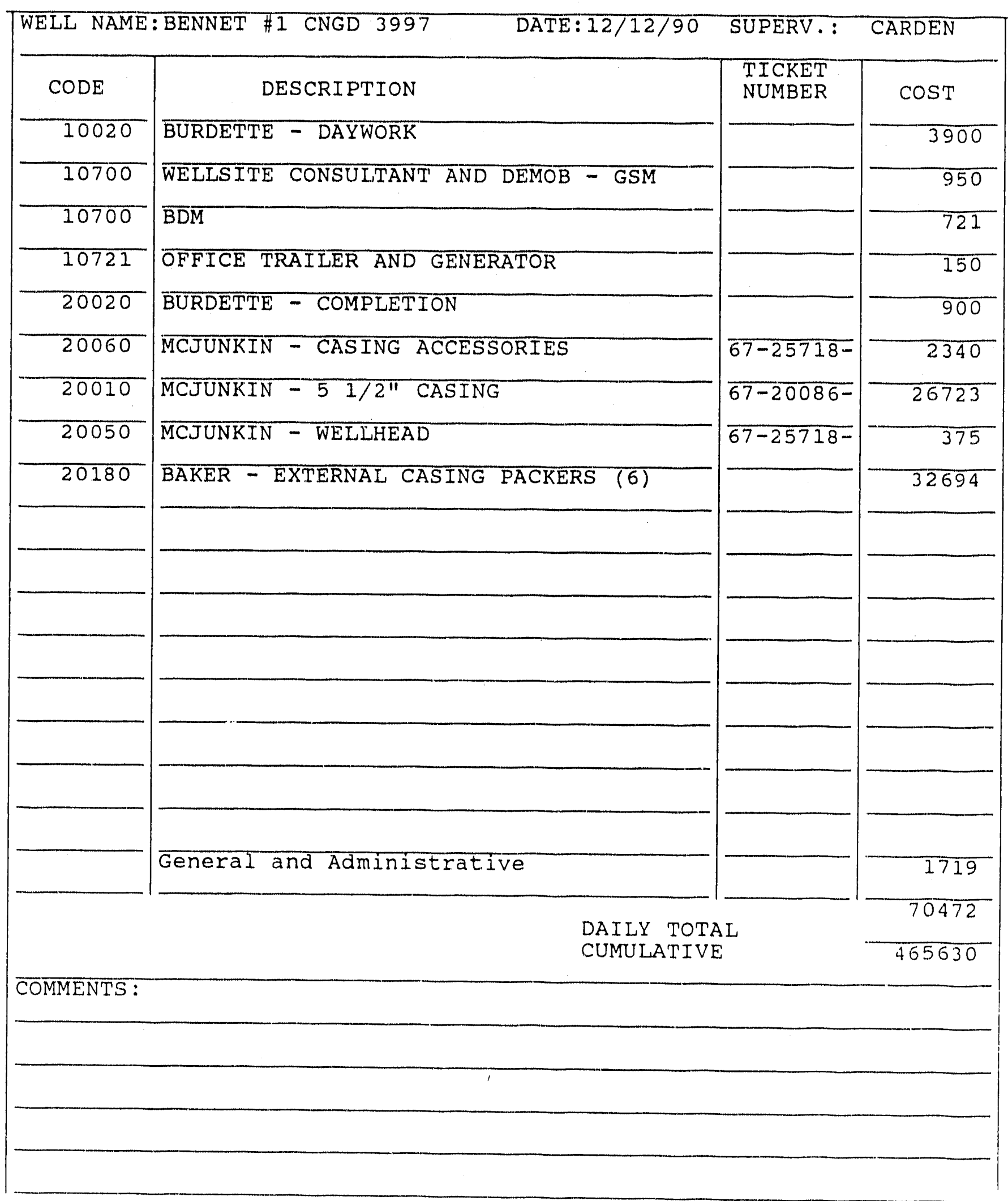




\section{APPENDIXH}

\section{DAILY LOG OF OPERATIONS BDM/DOE/CNGD \\ BENNETT \#1-3997}

$11 / 23 / 90$ Arrived on location at 1700 hours. The rig had taken Thanksgiving off and had commenced operations at 0700 hours. From 0700 to 1100 , the rig crew rigged up the air compressors, unloaded the Wilson reamers and stabilizers, and placed drill pipe on the rack to be cleaned prior to drilling with a downhole motor. Tomko later cleaned the pipe with the high pressure jet. From 1100 to 1230 hours, the shoe joint was drilled out. Then the hole was dried out by circulating for $1 / 2$ hour. From 1300 to 1415 hours, the hole was drilled from $2091^{\prime}$ to 2165 '. Then the hole was circulated for 15 minutes and the drill pipe was tripped out of the hole. At 1530 hours, the rig started laying down the drill collars. At 1700, the collars were laid down.

Otto with Wilson Downhole was on location and started picking up the Baker motor at 1700 hours. The motors had come to the location with $85 / 8^{\prime \prime}$ stabilizers below the adjustable bend which was unexpected. The bends were set at 1.5 degrees. The stabilizers are likely to make the motor build faster but without a second tangency point it is not possible to determine the build rate. Should be greater than 9 degrees per 100 with a 2 degree bend in motor. Set bend in motor to 2 degrees. Placed a float sub on top of the motor and picked up the kelly. Motor runs fine. The bit is an M84F (Security) and has 3 14/32nd jets. The surface pressure should be 290 psia with two 1050 scfm compressors running (estimated actual rate $1800 \mathrm{scfm}$ ). Picked up one monel and placed it on top of the motor.

At 2000 hours, shut down and wait on steering tool. The steering tool had some problems and Well Nav went to Young's yard in Charleston to fix it along with the wireline truck. Need to wait for Well Nav to check the mule shoe stinger on the 
steering tool for compatibility with Wilson's mule shoe sleeve. At 2115 hours, the tool arrived back on location and the test was performed. Make up a second monel collar and align tool face.

At 2230 hours, started in the hole. The motor is a tight fit and does not fall continuously even with two collars. Will have to go in the hole slowly. Poured 5 gals of oil in drill pipe half way in to coat the inside of the pipe. Running all the pipe in the derrick.

$11 / 24 / 90$ Finished running the pipe out of the derrick at 0015 hours. Started picking up pipe off the rack. Should have to pick up 14 joints to get bottom. Started rigging up the steering tool at 0115 hours with 12 joints in the hole. Installed side entry sub and run steering tool. Placed string float 1 joint above the side entry sub.

On bottom at 0430 hours. Oriented the motor and started drilling. The motor was running very rough with two 1050 compressors. The pressure was 300 psi. (Note: had dumped 5 more gals of oil in drill pipe prior to starting air). Took one compressor off the hole. The pressure dropped to $210 \mathrm{psi}$ and the motor ran with less vibration. The steering tool was also functioning much better. Oil is being injected in the standpipe at a rate of 5 to 10 gals per hour. It is difficult to adjust the injection pump to a specific amount. Oriented the motor and started drilling. Drilling slow like the Sterling well. Running 6-8000 lbs on bit. Putting as much weight on the bit as possible without stalling it. Still stalling periodically because of too much weight. The estimated flow rate through the motor is $1000 \mathrm{scfm}$ (that rate calculates a surface pressure of $210 \mathrm{psi}$ ). The equivalent flow rate through the motor is $600 \mathrm{gpm}$.

Made the first connection at 0830 hours and a depth of 2204'. Survey was $2160^{\prime}, 2.0,249$. Finished making the connection at 0900 hours. Drilled slow at first, then the ROP picked up at 
2224'. The first 20' drilled in 1.5 hours. The next 40 feet drilled in 1.75 hours. Able to run $4-8000$ lbs on the bit depending upon how hard the formation is. The harder the formation is the more weight that can be run in the bit.

Made a connection at 1115 hours and 2266'. The survey was $2222,5.4,313$. The average dogleg severity was 7.85 degrees per 100 feet. In actuality, the dogleg severity will be slightly higher because the hole lost a little inclination while turning to the right. Expect it should be 9 to 10 degrees per 100 . Finished connection at 1145 hours. Continued drilling. The ROP dropped off significantly sometimes drilling only 3 to 4 feet per hour. Still running as much bit weight as possible. Have one compressor on the hole with 220 psi standpipe pressure. Injecting 5-10 gals per hour oil.

Made a connection again at 1815 hours and 2328'. The average ROP was 9.54 feet per hour. Very similar to the Sterling well. The survey was 2284', 11.8, 317. The average build rate is 10.3 per 100 . Finished making the connection at 1845 hours. The standpipe pressure is 260 psi. Calculations show one jet may be plugged. The calculated pressure with one jet plugged is 271 psi. Tried running tow compressors to make the motor drill faster but the standpipe pressure increased to 350 psi which is too high for the compressor system. Had to go back to one compressor. The second compressor made the motor run very rough and did not seem to increase the ROP for the short period of time it was on the hole. The readings from the steering tool also started jumping around considerably.

At 2030 hours, drilling at $2343^{\prime}$ and very slowly. Only 3 feet per hour. The standpipe pressure is now 230 psi. At 2200, drilling at 2349'. Drilled 2 ' in last hour. At 2300', the pressure is back down to 220 psi. There is no fill on connections.

$11 / 25 / 90$ At 0530 , started running two compressors. The hole was not unloading cuttings. The pressure with two compressors (1050 
each) is $360 \mathrm{psi}$. The air going down the hole is hot. (Drill pipe is too hot to touch). May not be able to continue running both compressors all the time because of the temperature on the booster. If it gets too hot, one compressor can be run for a while. The motor is drilling better since the well is cleaning. The oil injection rate is about 5 gals per hour.

Made connection at 2452'. Survey was $2408^{\prime}, 26,313$. The build rate is 12.1 degrees per 100'. At 1350, shut down to take a survey. 2439', 29.6, 313. The build rate is 11.6 degrees per $100^{\prime}$. Eleven to twelve degrees per $100^{\prime}$ will be a pretty good average for the motor. The oil injection pump quit working. Had to repair it. Back to drilling at 1420 hours. At 1700 , make a connection at 2544'. Survey 2470", 33, 314. Build rate is 11 degrees per 100'. The tool face has been set at 10-15 degrees to the right for most of the drilling. The tool face was set 40 right for most of the last connection. The well does not seem to be turning to the right.

At 2000 , the depth is $2555^{\prime}$. Still can't see any right hand turn in the well even though the tool face had been set 40 right. The tool face is not set at 50 to 60 right. At 2200, connection and survey. The survey is 2532', 39.6, 317. Now starting to see right hand turn.

At 2315, the pressure is up to 380 to 390 psi. Both compressors have been running all the time. The pressure increase may be due to the fact that the hole is getting dirty. The well is not unloading any dust and the penetration rate is very low. Pulled two joints from the well. No excess drag. Worked the pipe while circulating but the well did not unload many cuttings. Trip back to bottom. The motor still has 390 psi off bottom. The pressure increase may be due to the motor.

$11 / 26 / 90$ Back to drilling at 0015 hours. At 0100 , the pressure had dropped to $365 \mathrm{psi}$ off bottom and $375 \mathrm{psi}$ on bottom. Still drilling slow. No dust in the returns. May not be generating enough cuttings to soak up all the oil. At 0215, start out of the hole. The motor won't drill and it sticks on bottom. The 
depth is 2598'. The pipe pulled tight one stand off bottom. Circulated out 4 joints. Removed steering tool and continued to trip out of the hole.

At 0800 , out of the hole. Motor and bottom hole collars are covered with dirt and oll. The oil injection rate has been less than 5 gallons per hour. That should be enough for the cutting to get wet but with the very low penetration rates it could be. Either that or the well is making some oil or water. The bit looks to be in gauge but there is no gauge ring to check it. Decided to go back in the hole and drill a tangent section since the inclination if ahead of schedule. It will also allow the hole to be cleaned up and dried out. The build up of cuttings in the well probably kept the slacked off weight from reaching the motor.

Will run a bit, float sub, six point reamer (button cutters on bottom and flat on top), monel collar, three point and six drill collars. At 1145, started reaming. The bit took weight in the vertical portion of the hole at 2090'. The build section reamed quick and easy. Got a lot of cuttings out of the hole. Started drilling at 1545 hours. At 1750, stopped to take a survey. The survey was 2625', 46.25, 327. The last part of the motor run had turned the well to the right significantly. Finished the survey and started back to drilling at 1830. Calculations indicated approximately $175^{\prime}$ of tangent section would be required to hit the top of the target with an anticipated build rate of 9.5 degrees per $100^{\prime}$ below the tangent. Next survey $2687^{\prime}, 46.0,325$. Assembly is dropping 0.5 degrees per 100'.

$11 / 27 / 90$ Drilled to the end of the tangent section at 2773'. Surveyed again: $2737^{\prime}, 45.75,325$. Still dropping the same. Tripped out of the hole with the rotary assembly and picked up the second Baker motor. Based upon the 2 degree bend building 11 degrees per 100', the bend in the second motor was placed at 1.75 degrees which should yield a build rate of 9.5 degrees per 100'. Left the six collars on top of the motor. Tripped in the hole and ran the steering tool through the side entry sub. At 0800 , 
the steering tool would not go past $2270^{\prime}$ which is above the drill collars. Put the air on the hole and then the steering tool went to bottom. Don't know what was in the pipe. Installed float sub and started to drill.

At 0930, the steering tool failed almost immediately after starting to drill, Pulled steering tool and found that the connector between the rope socket and steering tool had falled. Replaced same and run steering tool back in hole. At 1200, started drilling with the second motor. The drill pipe pressure is 310 psi. Now going to limit the amount of oil run in the pipe to approximately $1 \mathrm{gal}$ per hour because of the problems with hole cleaning before. Just running the injection pump for a little at each tool joint. The inside of the drill pipe stays coated for a long time so continual lubrication should not be a problem. At 1530 , made a connection at $2823^{\prime}$. Picks up at 98,000 and slacks off at 60,000 .

At 1600, the steering tool failed again. Will drill some rat hole and turn the oil off for 30 minutes prior to pulling steering tool. The motor has stayed oriented well so there should be no problem. At 1645, started out of the hole to fix steering tool. The problem was the same. The connector between the tool and rope socket failed again. Modified the connector and ran steering tool in the hole. Started drilling again at 2100 hours. AT 2330, had drilled over two hours with no oil pumped into pipe. Pumped 3 gallons, the stand pipe pressure fell from 340 psi to 320 psi after pumping the oil. The pressure increase to 340 psi after 20 minutes. Hole is dusting good.

$11 / 28 / 90$ The rotating head rubber started leaking badly. Will change it on the first connection. Kelly down at 0245. Pull to side entry sub and pull steering tool. Change rotating head rubber. Run steering tool and started drilling again at 0600 hours. Depth is $2887^{\prime}$. A survey at $2842^{\prime}$ was $52.4,324$. The build rate is 
9.37 degrees per $100^{\circ}$ which is close to the calculated build rate. At 1200, made a connection at 2948'. Pulled tight a couple times while making the connection. (Up to 140,000 lbs). Nurmal drag is 100,000 . Survey was 2904, 60.1, 325. Now the build rate is 12.42 degrees per 100'. More than the first motor with a 2 degree bend. Projecting the present build rate, the well will be a $t 90$ degrees at a TVD of $2815^{\prime}$ which is $30^{\prime}$ too high. The top of the target is at 2846'. Will check the rate of build after drilling 30'. If the rate is still near 12 degrees per 100 feet, we will have to make a change. A build rate of only 6 degrees per 100 will be needed to hit the target. There are several options available:

Option 1 Pull the motor and reset the bend to 1 degree which should yield a build rate of 6 degrees per 100'. Will have to drill more hole and make a trip.

Option 2 Rotate the motor for 100'. Will have to pull the steering tool to do it and it probably would not be good for the motor.

Option 3 Turn the motor left and right reducing the rate of build until the desired inclination is reached. Then point the motor straight up to finish the build. Will require less hole to be drilled and will not require a trip. Will increase the overall dogleg severity in the well.

Opted for the third option. Started at a depth of 2962'. Started the turn to the left because the well is already 5 degrees right of the desire direction. Calculations indicated that by turning the tool face 60 to 70 degrees to the left until $3042^{\prime}$ and then 60 to 70 right until 3072'. At 3072', the tool face would be turned straight up to achieve 88 degrees at TVD of $2843^{\prime}$ with an azimuth of 320 . The well was assumed to be 67 degrees at 2962 ' with the 12.42 per 100 build rate.

At 1900, made a connection at 3010'. The survey was 2966', $66.4,323$ which is start of the turn section. The tool face had 
averaged 70 left to this depth. The build rate is 10.59 degrees per 100'. Adjusted the calculations accordingly. Started turning the motor up at $3025^{\prime}$. Some indication that the inclination may have dropped.

11/29/90 Made a connection at 3041'. At 2997', the inclination had dropped to 64.6'. Not a good signl Have left the motor turned straight up since 3025'. Will have to worry about turning the well back to the right later. At 0600, drilling at 3098'. The motor has been drilling slow for some time now. Working to make it drill faster. At 1200, the motor won't drill any more. The pressure is up on the stand pipe to 360 psi both on bottom and off bottom. Can't seem to get any weight on the bit or make the motor stall. The motor is not sticking on bottom. May be a hole cleaning problem again but the well is dusting though not many cuttings are coming out. Will have to pull out of the hole. The steering tool is also not working. The total depth is 3117'. Pulled 110' of pipe from the hole and the pipe pulled tight. Had to circulate with air to get the rest of the pipe out of the hole to the side entry sub. Had kinked the wireline pretty bad at the side entry sub which is the second time it has been kinked. That may be the problem with the steering tool. After inspection of the steering tool, the Well Nav hand said the wire was all right. He suspected the problem was with the transmitter section of the steering tool and changed out the same.

At 1630 , out of the hole with the motor. Motor appears to be OK on the surface. (Did not test it with air). Decision time! Don't know exactly why the motor would not drill. There were several potential problems offered by people on location. They are: The collars won't allow the weight to get to the bit. (I don't like that one. The pipe doesn't drag excessively). Too many cuttings in the hole last time. (Possible but the well is still dusting). The bit may be under gauge. (Don't have a gauge ring to check it. Estimated to be $1 / 8$ the $1 / 4$ under gauge. Stabilizer on motor is $85 / 8^{\prime \prime}$ ). There is something wrong with the motor and no pressure increase is seen when it stalls. 
(Doesn't seem so at surface).

THE PLAN! Run a bit and six point reamer. "Ream the hole for possible under gauge problem and clean the hole at the same time. Use three 1050 compressors while reaming. At 1800, started in the hole with the reaming assembly. Started reaming at 2000 hours. The hole is reaming hard. It is taking approximately 45 minutes per joint to ream it. Will have to be careful not to sidetrack the hole. A bit gauge arrived on location and the bit pulled from the hole was $1 / 4^{\prime \prime}$ under gauge. That was probably the reason the bit would not drill.

$11 / 30 / 90$ Continued reaming. At 0600 , reaming at $3080^{\prime}$. This joint has taken 2 hours to ream so far. It acts like the well is trying to sidetrack. Stop reaming and run a survey. The survey is 65.5 degrees at 320 which is what it should be. The well has not been sidetracked at the survey point. Otto worked the bit down the hole without drilling much. Reamed through that spot quickly several times. Still preity tight. Made a connection. Bit would not go past the tight spot at 3081 '. Had to put the slips in and rotate the pipe to get it to fall through. Reamed the rest of the hole to TD without much difficulty. Could not pull back up through the tight spot. Had to rotate to get out of it! Run back to bottom to survey. Survey shows 3086, 69.75, 311. A lot of left hand turn even though the tool face was to the right 20 degrees since $3025^{\prime}$.

At 1100, tripped out of the hole and laid down the reamer and bit. There were $1 / 8^{\text {n }}$ under gauge. Picked up the second motor with the 1.75 bend. (The last surveys showed high dogleg severities. Better to run the smaller bend). Test motor. Runs good at the surface. At 1515, started in the hole. Installed side entry sub and ran steering tool with a latch down. (Marks on the orienting sub indicated that the steering tool may have come unseated while drilling showing a tool face more to the right than it should have been. That would explain why the well had turned so far to the left and dropped iriclination and why it would not turn back to the right. Run motor to bottom. 
Had to turn the air on to get through the tight spot at $3081^{\prime}$.

Started drilling at 1900 hours. Motor is strong and drilling good. The pressure is 300 to 320 psi. (Bit contains three $16 / 32$ jets as in previous run with second motor). Running approximately $1 \mathrm{gal}$ per hour of oil. Survey 3153', 75.4, 308. Need to turn to the right. Set tool face 45 right at 3197'. Had been 10 to 20 right.

$12 / 1 / 90$ Survey at $3185^{\prime}, 79.0,309$. Not seeing much right turn yet. Survey at $32166^{\prime}, 81.9,310$. Still not seeing as much right turn as there should be. Survey at $3231^{\circ}, 83.6,312$. Drilled to $3280^{\prime}$ where the estimated inclination on bottom is 88 degrees. Finished drilling at 0700 . Circulated one hour to clean the hole.

Started out of the hole at 0815. Laid down 7 joints and pulled steering tool. Rig down the steering tool equipment. Finish trip out of the hole. Did not have to circulate any joints out of the hole. Out of the hole at 1230. Laid down the motors and picked up the bottom hole assemiviy. BHA consisted of a bit ( 8 $1 / 2^{n}$ M84F with no jets), float sub, six point (all flat cutters), pony monel, monel, three point (flat cutters), 20 stands drill pipe and six drill collars. Since the assembly in the tangent section had dropped 0.5 degrees per 100 feet, this assembly was modified. The button cutters in the bottom of the six point were changed to flat cutters and the distance between the reamers was increased by eight feet using the pony monel. Hopefully, the changes will keep the assembly from dropping too fast. At 90 degrees, it should drop faster than it did in the tangent section.

Finished tripping in the hole and started drilling at 1700 hours. Drilled to $3356^{\prime}$ and surveyed. The survey wa $3326,89.25$, 306. The inclination is a little more than expected but not out of line. The azimuth should have been around 314. Probably experiencing magnetic interference of that if just the difference between the singleshot and the steering tool. On 
the last motor run, the tool face had been set 45 right over this interval. Survey data with the steering tool showed that the well was indeed turning to the right. Very little had to be done to keep the tool face oriented which would indicate that the steering tool was still seated. An azimuth change of at least 6 degrees in assembly. The only way to correct it is to run a motor which is too costly.

$12 / 2 / 90$ Continued drilling to $3450^{\prime}$. Survey again. The hydraulic releasing tool is working good. This survey should indicate what the rotary assembly will do. Survey was 3420', 90.25, 304. The well is walking 2 degrees per 100 to the left and building 1 degree per 100' which is surprising. So much for the predictability of rotary assemblies! Will drill ahead another $90^{\prime}$ and survey again. If the inclination continues to build, we will run a packed assembly which should drop the inclination back down.

Started drilling again at 0800 hours. Drilled to $3544^{\prime}$ and surveyed again. HOLY BUILDING ASSEMBLY BATMAN! The survey wa 3514', 95, 306. Built at least 4.75 degrees in the last 93'. Are experiencing strong formation tendencies. Can't run the packed assembly; will have to run a dropping assembly to keep the well in the target. First of all, the angle unit was checked to make sure it was OK since the 120 degree unit was used for the first time on this survey. It compares favorably to the 90 degree unit we had been using before. Tripped out of the hole to change the rotary assembly. Changed to the aardvark which is a short pendulum assembly. This assembly dropped 2.5 degrees per 100 feet on the Cabot well.

On bottom and drilling again at 2130 hours. Have not seer the tight spot at 3081' on the last two trips. Will drill 200' and survey again. It usually take a finite amount of hole before the assembly breaks the build tendency and starts to drop inclination. Two hundred feet should be enough to see some drop. 
$12 / 3 / 90$ Drilled to 3753 . Survey again. This is getting boring. The survey said: $3727,95.5,302$. Walking fast to the left but not dropping inclination. Will drill three more joints. If the inclination hasn't dropped we will have to trip. Otto feels very confident the assembly will drop. Says it has never failed before. We will now be above the target zone of 2846'. Started drilling again at 1015 hours. Drilled to 3846 '.

Time to survey again. Who knows what kind of survey it will be: a good survey or a bad survey. The survey said: 3820', 95.75, 302. Still building $1 / 4$ degree per 100. We had bad surveys. At least it did not walk more to the left. Formation tendencies are very strong. The options are a longer pendulum or a motor. Consensus was to run the 30 foot pendulum, we will call it the elephant (longer snout than an aardvark). Money and time are definite considerations when running a motor. Trip out of hole and change to 30 foot pendulum. If this does not work, we will have no choice but to run a motor. Tripped in the hole and started drilling at 2345 hours.

12/4/90 Drilled to 3939'. Survey again. Finally got a good survey. Toto would be proud of us, don't you think Dorothy? Survey was 3927 ', 93.5, 307. Dropping inclination. Will drill 7 joints and survey again which will give us the ability to calculate drop rate. Will now have to drop to around 85 degrees to get into and stay in the target. Drilled to 4149'. Starting to get some appreciable down drag. Now running at 35,000 lbs down. Blocks weigh 10,000 lbs.

Survey again starting at 1930 hours. The survey tool did not release the first time. Had to run it a second time.

12/5/90 Finished taking survey shortly after midnight. Survey tool was moving when the picture was taken. Will have to do it again. Second time is the charm. Survey is 4136', 88.5, 308. Dropping at 2.39 degrees per 100'. Will drill until inclination is about 84 degrees which should be around 4325'. 
Started drilling again at 0415 hours. Having trouble getting the pipe in on the Ist three connection. Drilled to $4335^{\prime}$ and the pipe would no longer fall in the hole but will have to come out anyway. Estimating slightly less than 84 degrees at the bottom of the hole. Start out of the hole at 1700 hours. Decided to run a packed assembly. It is possible the assembly will continue to drop slightly. Want to run the pack to keep the hole from changing inclination very fast. Need to stay at 84 to 85 degrees to drill through the target interval. The assembly will consist of a bit, float sub, six point, pony monel, three point, monel, 34 stands drill pipe and 12 drill collars. Picked up an additional 6 collars to help push the pipe in the hole.

12/6/90 The pipe stopped at 3500' while tripping in. Had to pull 200,000 to get the pipe loose. Apparently, the packed assembly will not follow the other assemblies. Nill have to ream it to bottom. Not having fun now. The first few joints reamed hard but the rest went fairly easy. This BHA definitely drags more. Already having trouble getting it in the hole. Finished reaming at 1215 heurs. Will drill about 150' and take another survey. Hopefully, the drag won't prevent us from getting a survey.

Drilled to 4446'. Run survey. The hydraulic releasing tool did not release the first time. Had to run it twice. Survey was $4410^{\prime}, 84,308$. Pipe went in fairly easy. Still had 20 minutes on the timer when the pipe reached bottom. BHA seems to be holding inclination fairly well. Will run one more survey to determine what this assembly will do. Should be the last survey we have to run.

12/7/90 Got back to drilling at 0245 hours. Drilled to 4570 '. Take another survey. The packed assembly is not going in easy but it is still dropping. Survey was $4534^{\prime}, 85,309$. Assembly is building 0.81 degrees per $100^{\prime}$. Will have to trip at $4700^{\prime}$ and change back to 30 foot pendulum in order to fall through entire target by TD. Based upon the drag now, we probably will not be able to drill past about $5000^{\prime}$. Current calculations show that 
the casing will not go past $4700^{\prime}$ using the same friction coefficient as rotary drilling (0.48).

Started drilling again at 1600 hours. Now having trouble getting the pipe to go in the hole on next two connections. Drilled to $4665^{\prime}$ and could not make a connection even after circulating and cleaning the hole for 1.5 hours. Will have to trip and get the next assembly. Trip out of hole.

Overbey is changing the target again. The mud log data indicates that the target interval is getting shallower as we drill horizontally. Geologists, who'd a thunk it! Now says we need to drop less inclination, but might as well drop all the way through the target anyway. Instead of running the 30 foot pendulum (the elephant), we will run back in the hole with a slick assembly. It should still drop inclination but not as fast as the elephant.

12/8/90 Changed the BHA to bit, float sub, monel, 37 stands drill pipe, 18 drill collars. Had picked up six additional collars. Started drilling again at 0715 hours. Drill string is going down at 50,000 lbs. Computer calculates we will be able to drill a little past $5000^{\circ}$ before the pipe will no longer fall in the hole. Drilled all day.

$12 / 9 / 90$ Drilled to $5013^{\prime}$ and pipe would no longer fall in the hole. This is TD. We have finally arrived. Circulated and cleaned the hole for one hours when the drill string twisted off. DARN, DARN! String weight is 100,000 lbs which would indicated that the pipe twisted off just below the drill collars. Start out of the hole at 0530 hours. Called Tri-State for a fisherman. Out of the hole at 0700 hours. The box had twisted off on the 16th drill collar. $O D$ is $57 / 8^{n}$. Waiting for fisherman. Should be able to just go in hole and pick up the BHA. Bit is about $20^{\prime}$ off bottom.

Fisherman arrived at 1100 hours. Make up overshot and cross over sub. Trip in hole. Latch on to fish and pull out of hole. No 
sweat! Laid down the fish and the fishing tools. Finished trip out of the hole at 1800 hours. We were going to run a multishot survey but the necessary tools were no longer on location. Well Nav had assumed that the 120 degree angle units would still be on location. Unfortunately, we had sent them back to Casper yesterday since we no longer taking surveys. Now can't run multishot. I hate it when this happens. Called Schlumberger and told them to be on location earlier.

Schlumberger arrived on location at 2200 hours. Rigged up Schlumberger and ran free fall logs to $2969^{\prime}$ which is about 66 degrees.

12/10/90 Rig up to run the drill pipe conveyed logs. Trip in hole with logs. Will latch in at 55 degrees or 2850'. At 0700, installed side entry sub and latched into logging tools. Pack off side entry sub and start logging. Ran 1 stand drill pipe and 2 stands collars when the density tool quit. Pulled one stand of drill collars and the density tool started working again. Ran it back in the hole and it quit again. At 1100 hours, started out of the hole with the logs. Changed out density tool and trip back in hole. Started logging again at 1530 hours. No problems this time. Logged in the hole to $4981^{\prime}$. Schlumberger did not want to tag bottom. Logged out of the hole to 2998' (depths are bottom of logging tools). No problems with the wireline. Finished logging at 2130 hours. Rig down Schlumberger and pull side entry sub. Tripped out of the hole to lay down logging tools.

The drill string still weighted 25,000 lbs on bottom. Had 16 collars in the hole above the side entry sub. Without the BHA, the drill string drags less. New calculations show that we should be able to run casing to a little past $4900^{\prime}$. Decided to run casing to $4750^{\prime}$ to leave a little safety factor.

$12 / 11 / 90$ Finished laying down the logging tools at 0100 hours. Tripped the drill pipe and collars back in the hole. Lay down drill pipe and collars. Finished laying down drill collars at 0930 hours. 
Nippled down BOP's and rigged up to run casing. Got all the centralizers and port collars on the floor. Rigged up power tongs, elevators and slips. Started running casing at 1200 hours. Ran 111 joints $51 / 2^{\prime \prime}, 17 \# / \mathrm{ft}, \mathrm{J}-55$, ST\&C casing with six external casing packers (Baker), and 9 FO cementers. See casing detail for placement. Landed casing at $4755^{\prime} \mathrm{KB}$. Still had about 5000 lbs of string weight while running the casing. Did not have to force it in the hole. Set approximately 40,000 lbs of weight in the casing slips. Nippled up the well head. Drilling phase is complete. Now I can go home. 


\section{APPENDIX - 1 \\ Proposed Stimulation Operations Plan (August 22, 1991) HB \#3997 \\ Zones \#1 and \#2}

General Approach:

The purpose of stimulation operations on the well is to improve the productivity of the well to the point where production from the well will pay for drilling operations within a reasonable time period, say five years.

The general approach will be to frac Zone \#1, blow the well back immediately and go back in with the combination tool, open the first and second port collars and then frac Zone \#2.

Table 1 presents the general completion configuration of the well. separating it into five zones. Also presented is the length of the zone and size of the stimulation planned. Figure 1 illustrates the well schematic and completion configuration.

Stimulation Design Fluid:

Based on previous experience with stimulating the Fifth Sand in vertical wells in the area of interest, and because of the problems likely to be encountered during cleanup operations when sand laden foam is used, BDMESC recommends using straight nitrogen as the stimulating fluid. A nitrogen volume of $1.5 \mathrm{mmscf}$ will be pumped into each zone at a rate of $70 \mathrm{msct} / \mathrm{min}$. The anticipated maximum bottomhole pressure (BHP) is approximately 1100 psi.

Using available frac data from vertical wells, the average breakdown pressure and average instantaneous shut-in pressure (ISIP) are estimated at 2400 psi and 900 psi, respectively.

Procedures For Stimulation and Cleanup

1. Set $300 \mathrm{bbl}$ steel tank and lay lines to tank for flowback operations.

2. Move in workover rig and install 5000-psi working pressure frac valve on the well head. (Available at no cost). 
3. Frac Zone \#1 thru 5-1/2" casing with $1.5 \mathrm{mmscf}$ of nitragen at an injection rate of $70 \mathrm{msct} / \mathrm{min}$. Watch pressure after fracture for 40 minutes to be sure we van detect closure pressure.

4. Open well to flow back through $1 / 4^{\prime \prime}$ choke until pressure drops below closure pressure then open up to flow through 1" choke. Flow back into steel pit and measure fluid volume. Flow back until sate to go in with tools.

5. Trip in with PC opening and closing tools and isolation tool and a recrievable bridge plug on tubing to about 50' below PC\#1. Set bridge plug at $4580^{\prime}$.

Move back up the hole and open PC\#1 (4530') with the opening/closing/isolation tool (opening tool on top. closing tool on bottom). Straddle PC\#1 with isolation tool and gauge the pressure and measure the production rate through tubing. Move up the hole to PC\#2 at 4273' and open this port collar.

Move back down the hole with the opening/closing/isolation tool on bottom of $23 / 8^{\prime \prime}$ tubing. Pass PC\#1 it will close, then back up 6' to open again and stop near the retrievable bridge plug.

Stimulate Zone \#2 with 1.5 mmscf of nitrogen at a minimum injection rate of $70 \mathrm{msct} / \mathrm{minute}$. Nitrogen is injected through the annular space between the $23 / 8$ " tubing and the 5 1/2" casing.

- Friction pressure maybe too high to be comfortable, it so we will trip out with $23 / 8$ " making sure to close PC's $3-8$ and then frac down 5 1/2" casing. 1

6. Open well and flow back within 20 minutes to produce rapid closure of tracture. Flow back for a period of time (24 - 36 hours) till it is safe to retrieve the bridge plug set below PC\#1.

1 " Alternate Plan 
7. Retrieve bridge plug and trip out of the hole to the surface with the opening/closing/isolation tool. During this trip all the port collars will be closed by moving back down 6 feet after PC's are opened as the tools are pulled out of the hole.

" Trip in with $23 / 8$ " string and all tools to retrieve bridge plug. Open PC's \#1 and \#2 but close all others $(3-8)$.

8. Trip in hole below PC\#1 with opening/closing tool and start tripping out to open PC\#1 and \#2. Now Zone \#1 and Zone \#2 are in communication with wellbore. Set the tool below PC\#3 and continue the flowback of gas until nitrogen content is below 5 percent.

9. Trip out with the opening/closing tool to the surface and open port collars $5,6,7$, and 8 . Test open flow rates of combined Zones \#1 and $\# 2$ (stimulated) and $\# 4$ and \#5 (unstimulated).

10. Analyze results and prepare report and recommendations to CNGD and DOE.

TABLE 1 - COMPLETION CONFIGURATION OF HB \# 3997

\begin{tabular}{|c|c|c|c|c|c|}
\hline Zone & $\begin{array}{l}\text { Bottom } \\
\text { (ft) } \\
\end{array}$ & $\begin{array}{l}\text { Top } \\
(t) 1\end{array}$ & $\begin{array}{l}\text { Length } \\
\text { (ff) } \\
\end{array}$ & PC's at & $\begin{array}{c}\text { Grac Volume } \\
\text { mmsct }\end{array}$ \\
\hline 1 & 5014 & 4584 & 430 & -. & 1.5 \\
\hline 2 & 4575 & 4188 & 387 & $4530^{\prime}, 4273^{\prime}$ & 1.5 \\
\hline 3 & 4179 & 3835 & 344 & $4133^{\prime}, 3876^{\prime}$ & $N / A$ \\
\hline 4 & 3826 & 3483 & 343 & $3780^{\prime}, 3526^{\prime}$ & $N / A$ \\
\hline 5 & 3474 & 3170 & 304 & $3428^{\prime}, 3212^{\prime}$ & $N / A$ \\
\hline
\end{tabular}


Tentative Schedule

Sept 4. 7:00 am Move Norkover rig on location. Rig up. Run slick string $.4755^{\prime}$. Check to see that casing shoe is not plugged up. Trip out of hole.

Sept 4 - 3:00 pm Pump $1.5 \mathrm{mmcf}$ nitrogen frac job into Zone \#1 thru 5 1/2" casing.

Sept 4 - 5:00 pm Start flow back (Item 1 thru 4 of procedure).

Sept 5 - 8:00 am Flow well back.

Sept 6. 7:00 am Start implementation of Item 5 of procedure.

Sept 6 - 3:00 pm Implement Item 6 of procedure.

Sedt 7 - 8:00 am Implement Items $7 \& 8$ of procedure.

Sept 23 - 8:00 am Implement Items $9 \& 10$ of procedure. 


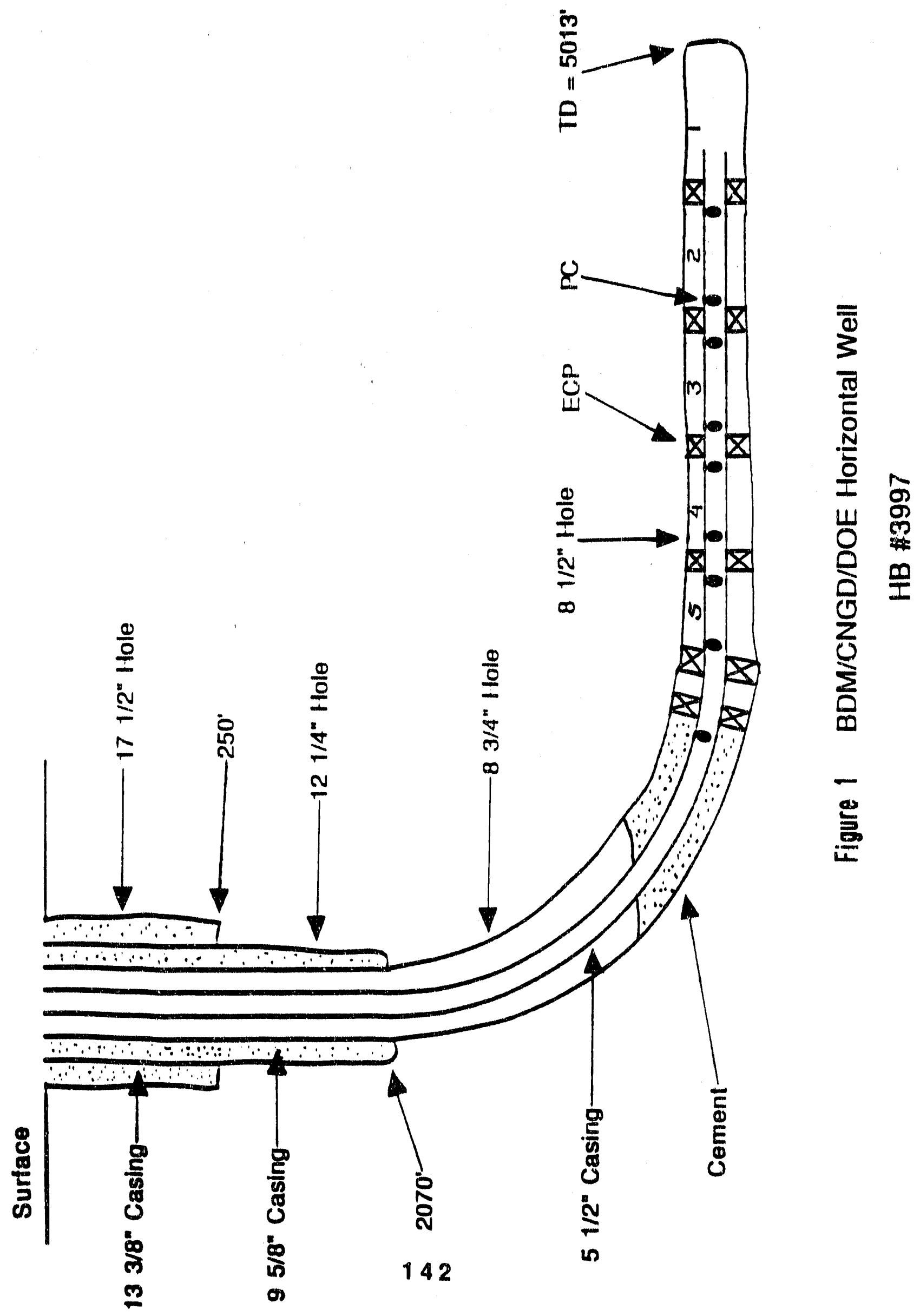




\section{APPENDIX - 1 \\ Zone \#1 Stimulation}

Hunter Bennett \#3997

$9 / 16 / 91$

Frac job started pumping at 10:55 a.m. and was completed at 11:27 a.m.

Started pumping slow to bring pressure up. Started at 20,000 scfm then went to $40,000 \mathrm{scfm}$ till break down. Shut down for five minutes to watch pressure fall off (leak off rate).

Started pumping again and pressure was possibly 100 psi higher when injection started. Continued to increase injection rate till pressure reached $3950 \mathrm{psi}$ (maximum reached). Top pressure was estimated as 4000 psig.

Reach programmed injection rate of $70,000 \mathrm{scfm}$ at a pressure of 3870 psi. Injection rate at top pressure was $74,700 \mathrm{scfm}$.

The job was completed in 32 minutes. ISIP was 2857 psi. Five, ten, fifteen, and twenty minute pressures were 1751, 1462, 1288, and 1185 psig, respectively. Average treating pressure was 3842 psi while average injection rate was 68,330 . 

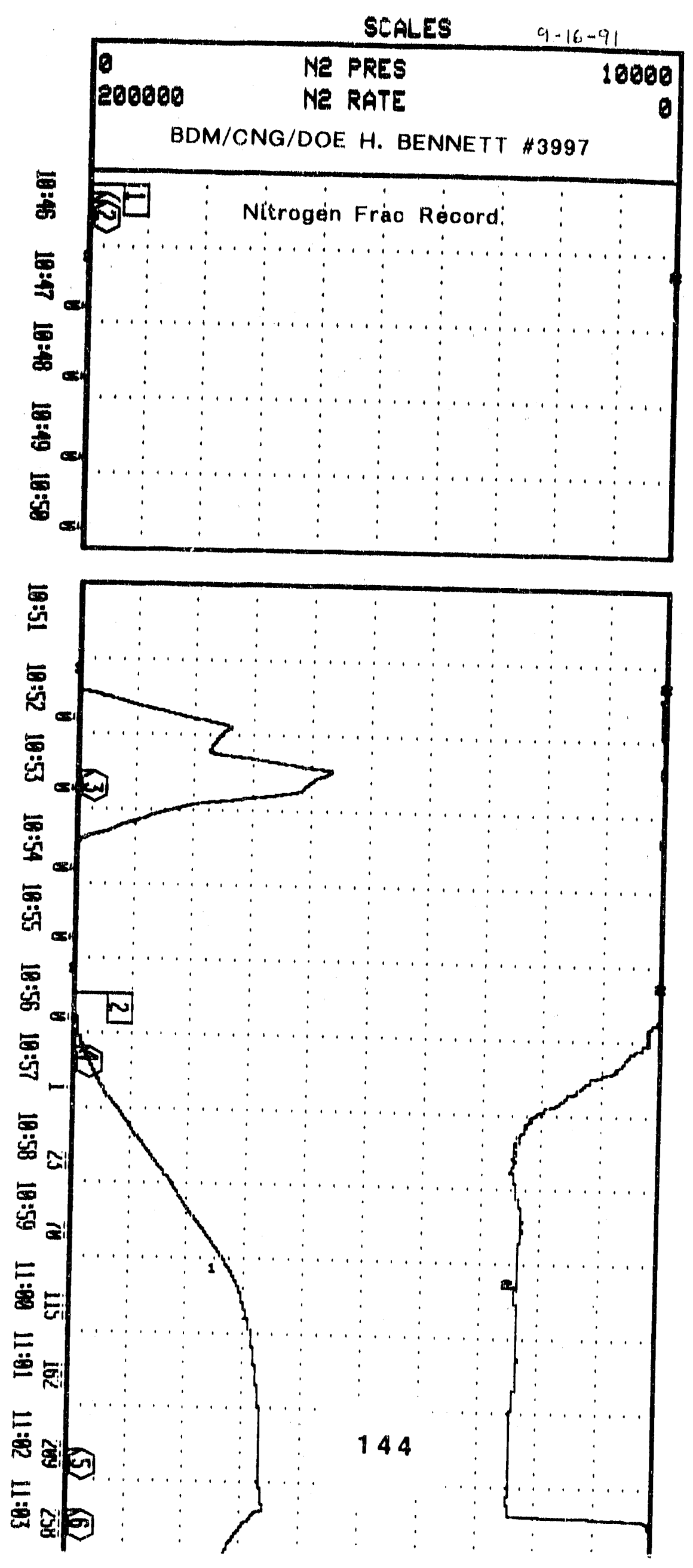


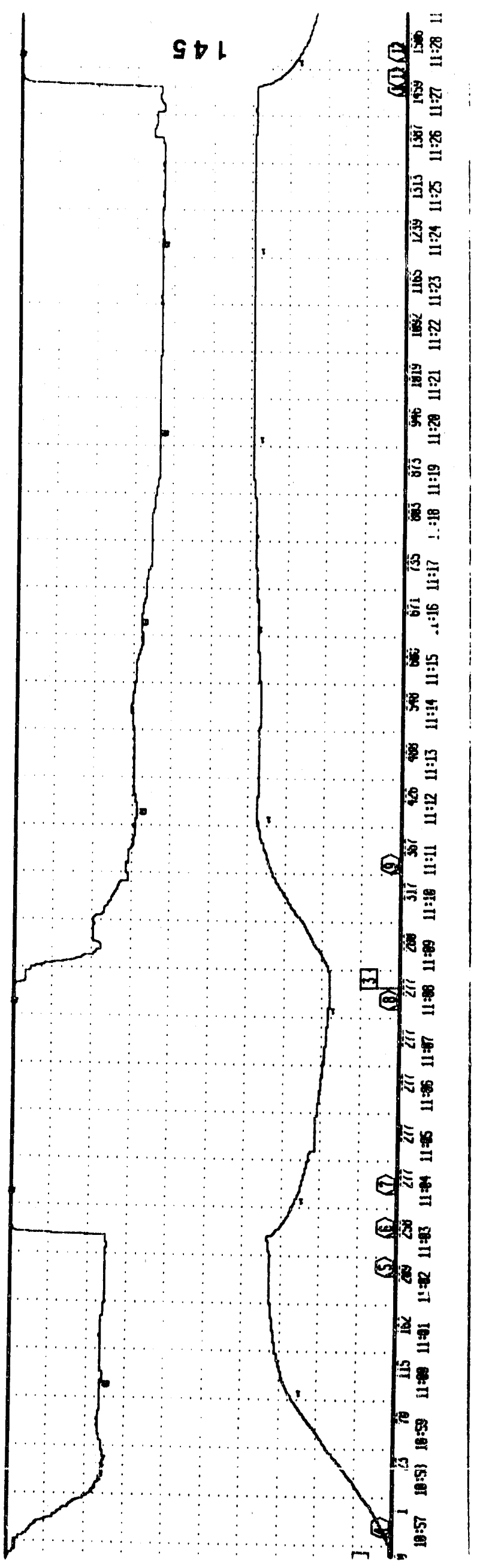




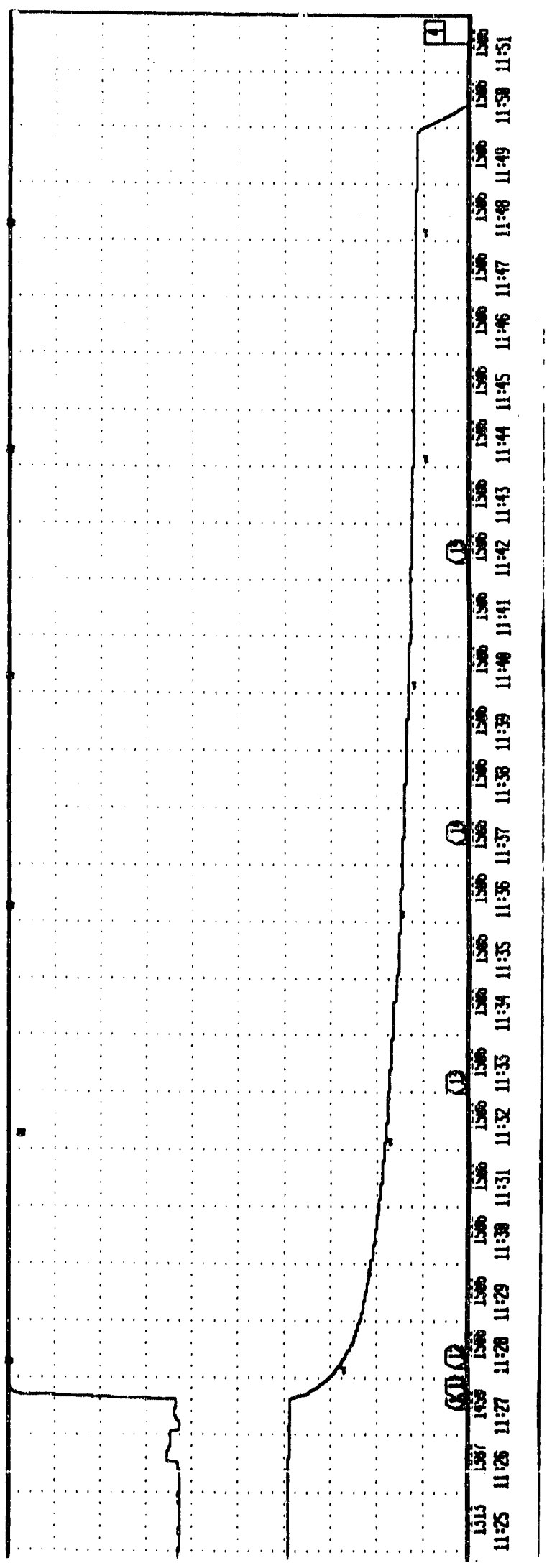




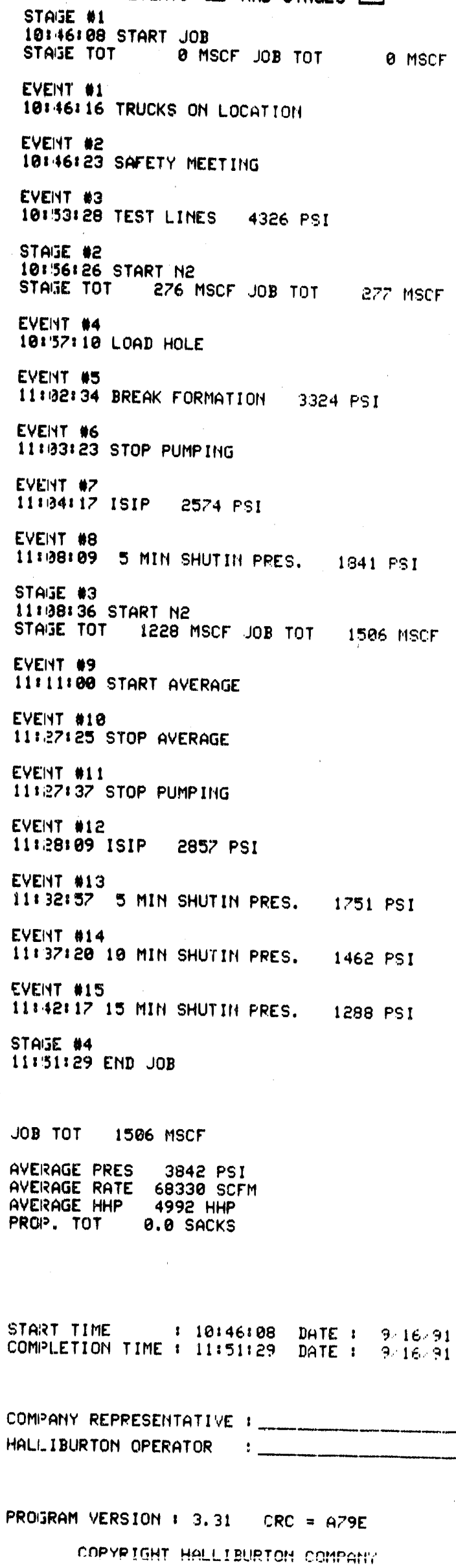


APPENDIX - I

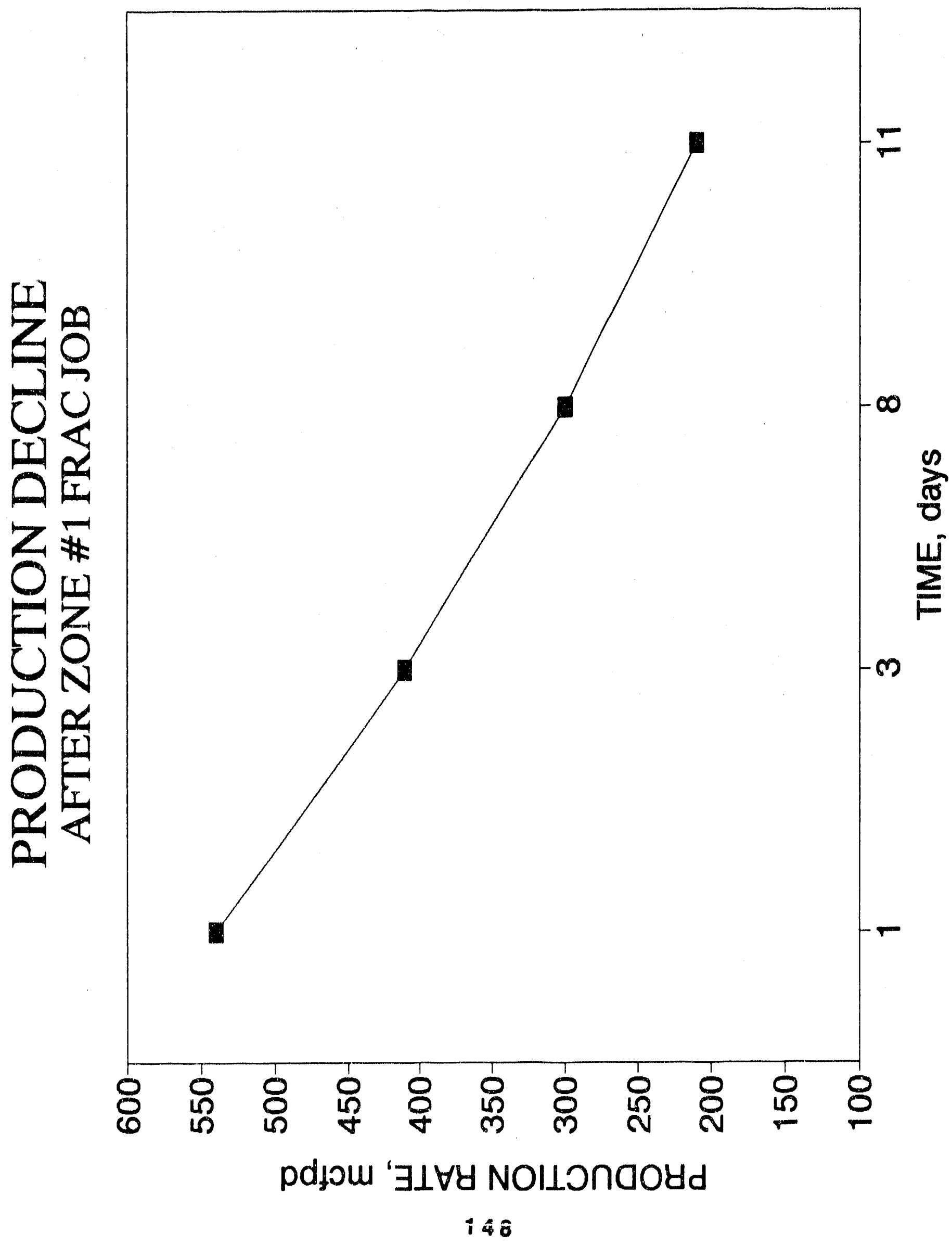




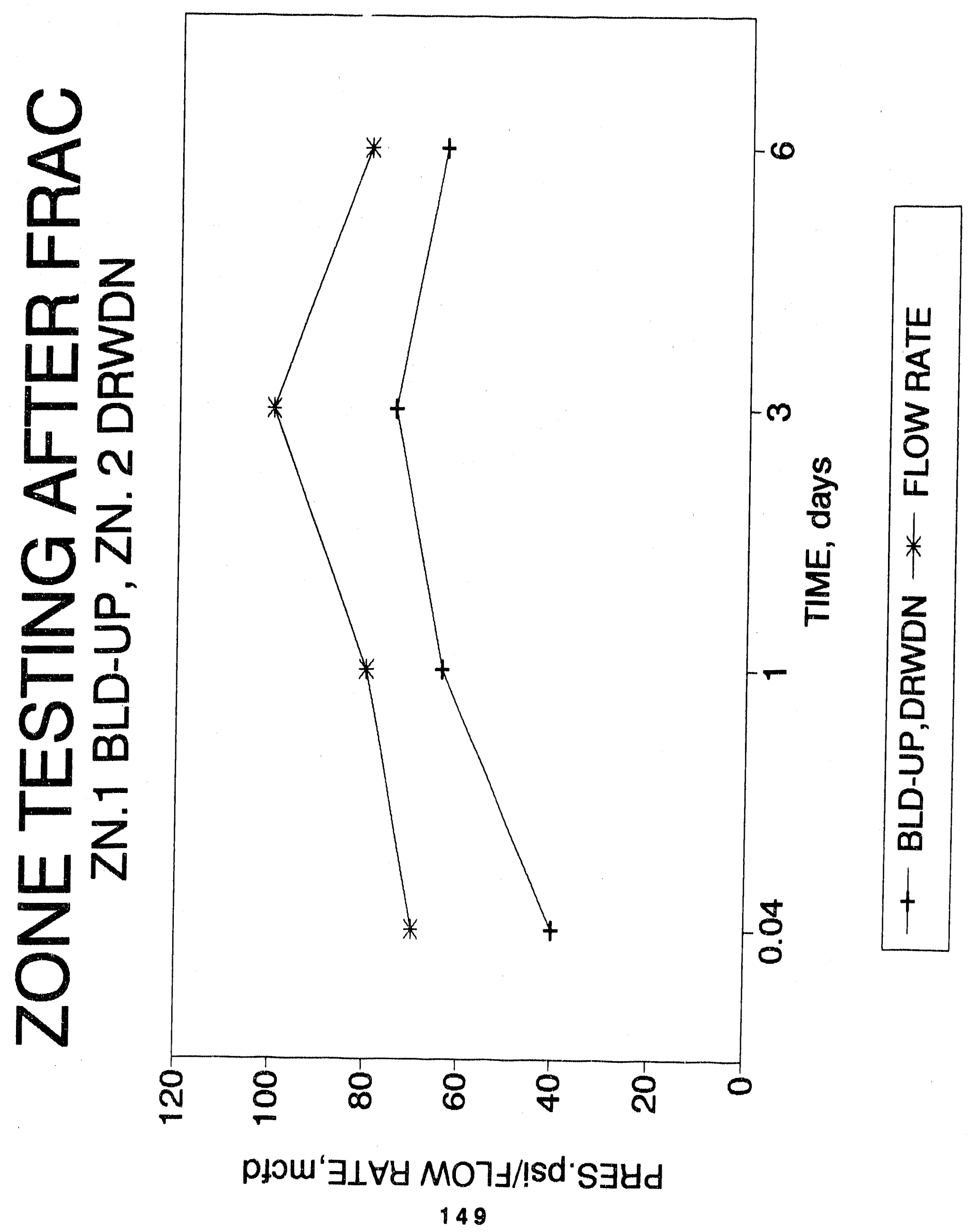




\author{
APPENDIX I \\ zone \# 2 stimulation \\ Hunter Bennett \#3997
}

$10 / 09 / 91$

started pumping the frac job $(1,500,000$ scf Nitrogen) at $9: 29$ a.m.

Started pumping at rate of $35,000 \mathrm{scf} / \mathrm{m}$, and increased slowly to $57,000 \mathrm{scf} / \mathrm{m}$ when formation broke at 9:33:31.

Pressure at breakdown was 2996 psig.

Rapidly increased rate to $72,000 \mathrm{scf} / \mathrm{m}$, pressure continued to climb also. Programmed injection rate of $90,000 \mathrm{scf} / \mathrm{m}$ met and exceeded at $9: 43: 30 \mathrm{a} . \mathrm{m}$.

Average injection rate for the job was $88,804 \mathrm{scfm}$, average treating pressure was 3608 psig, average hydraulic horsepower was 804 .

Job was completed at 9:48:29 a.m.taking 25 minutes to pump. ISIP was 2456 psig. Five minute shut in pressure was 1253 psig.

The well was immediately rigged-up to flow back, and flowback started at 10:30 a.m. with pressure already down to 920 psig. Opened to flow thru 1" choke, but pressure dropped to 500 psig within 5 minutes so well was opened to flow thru 2 " tubing. Flowing pressure down to 150 psig within 1 hour of starting flowback.

10/14/91 - Well still flowing to clean-up. Took gas sample and analyzed it. Well still had 7 percent Nitrogen so the well was flowed until 10/16/91 when the nitrogen was down to 1.5 percent and the pressure build-up test was started.

$10 / 24 / 91$ - Pressure built up to 560 psig in 8 days. Pressure stabilize after 5 days at 560 psig. Opened well to test flowrate. Initial rate was over $1,000,000$ cfd (after flowing 30 minutes) from zone $\# 2$. Zone \#2 is well stimulated. 


\section{APPENDIX -1}

HALL ITSURTDN DATA LDG

THIS REPORT IS EABED IJN GOUND ENGINEERING PRACTICEE, BUT BECAUEE OF VARIABLE WELL CONDITIONG AND OTHER INFORMAT:ON WHIOH MUST BE RELIED UPON, HALLIBURTON MAKES NO WAERANTY, EXPRESEED OR IMIFL:ED, AS TD THE MLCURAI'Y OF THE DATA OR ANY CALOULATIONS OR OPINIONS EXPREBBEE HEREIN, YOU ABREE THAT HALLIBURTON BHALL NOT BE LIABLE FOR ANY LUSB UR DAMAGE, WHETHEE DUE TO NEGLIGENCE OR OTHERWISE, ARIEING OUT OF IOR IN BONNECTION WITH BUCH DATA, GALOULATIONB DR DPINIONS.
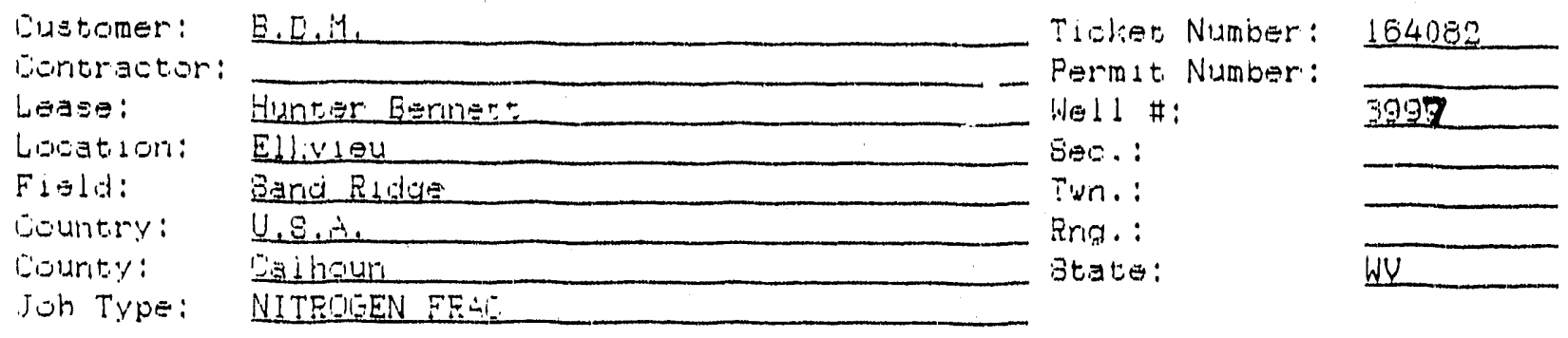

WELL DEBGIETPTIN

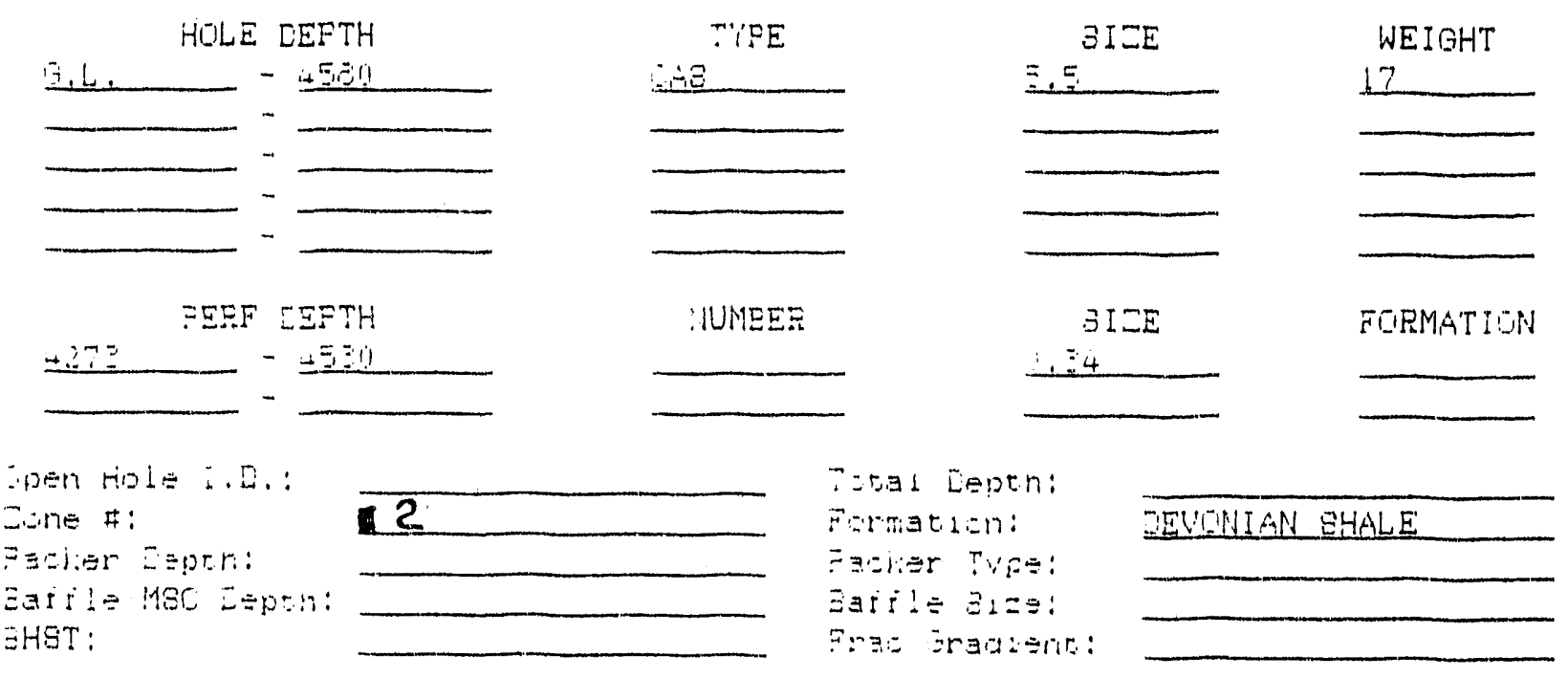

STIMULATIEN DATA

Frepad:

케:

ial:

arid Lacien:

Flusn:

Gertidan:

Tetai:

1:

$\therefore 2$ :

\section{$\because F E$}

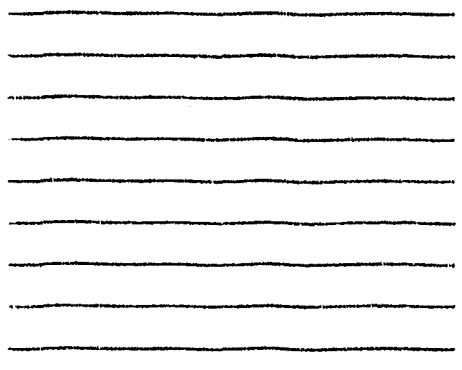

FETFANT ONE

NA

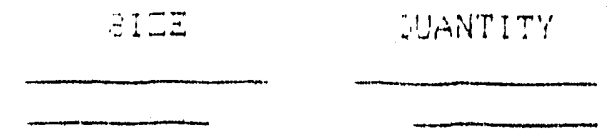

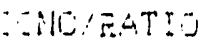

MULIME
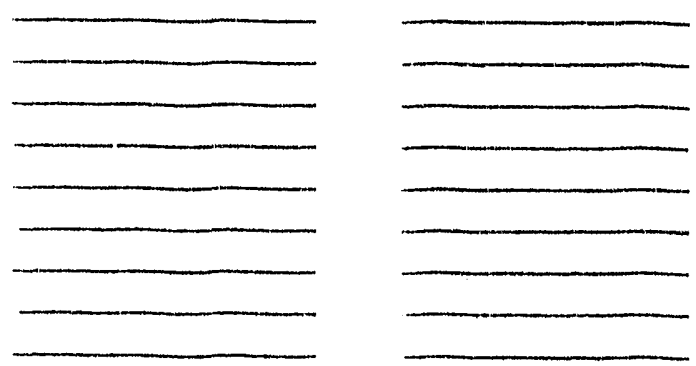

IAX BONO. 

1. Time
2. Caying_Press PGI
3. N2 Rate BCFM
4. 8tg N2 Totial BCF
5. N2 Total BCF

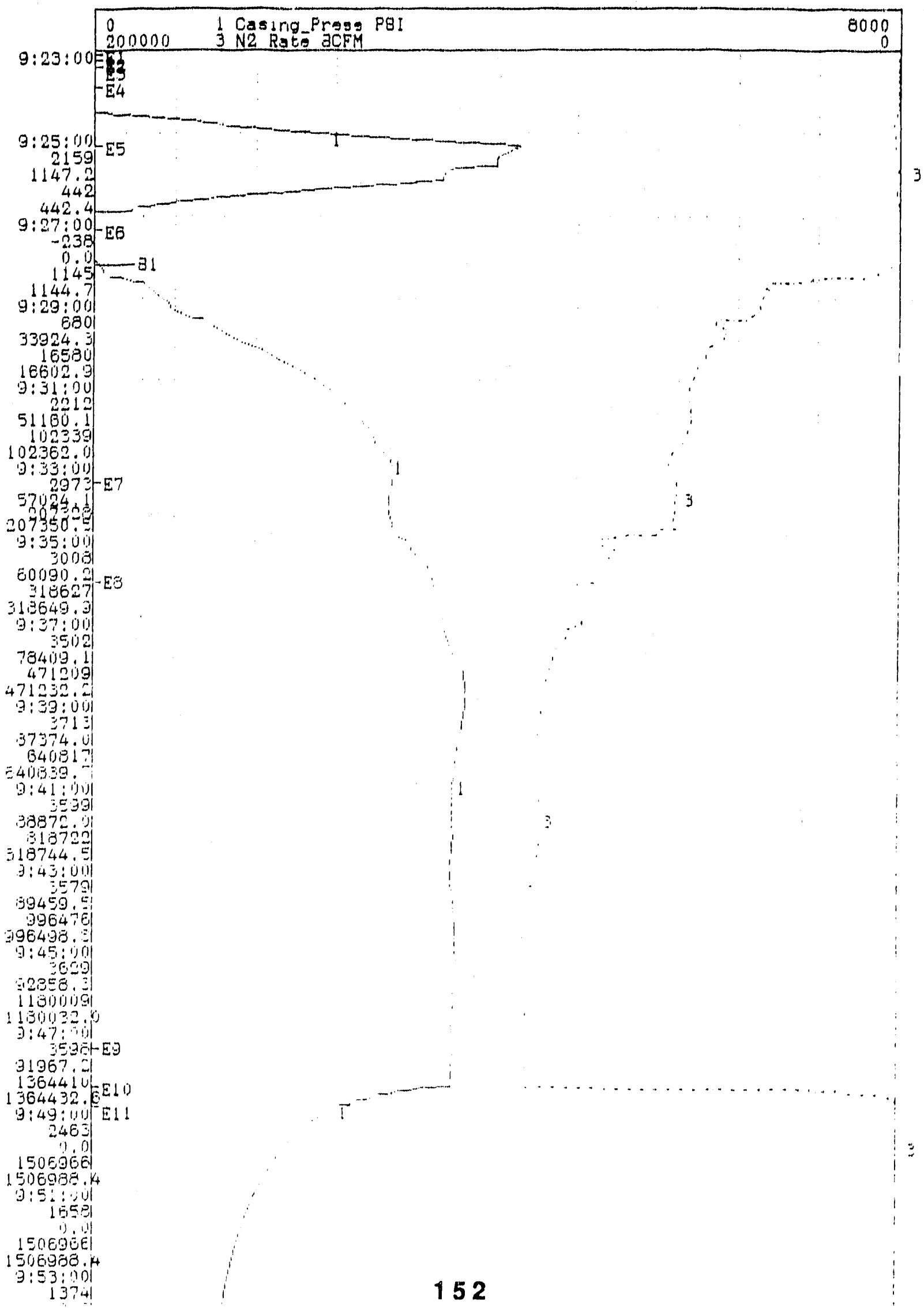




\section{BTAGE/EUENT BUMMARY}

Customer: B.D.M.

Job Type: NITROBEN FRAC
Date: $10 / 09 / 91$

Ticket \#! 104082

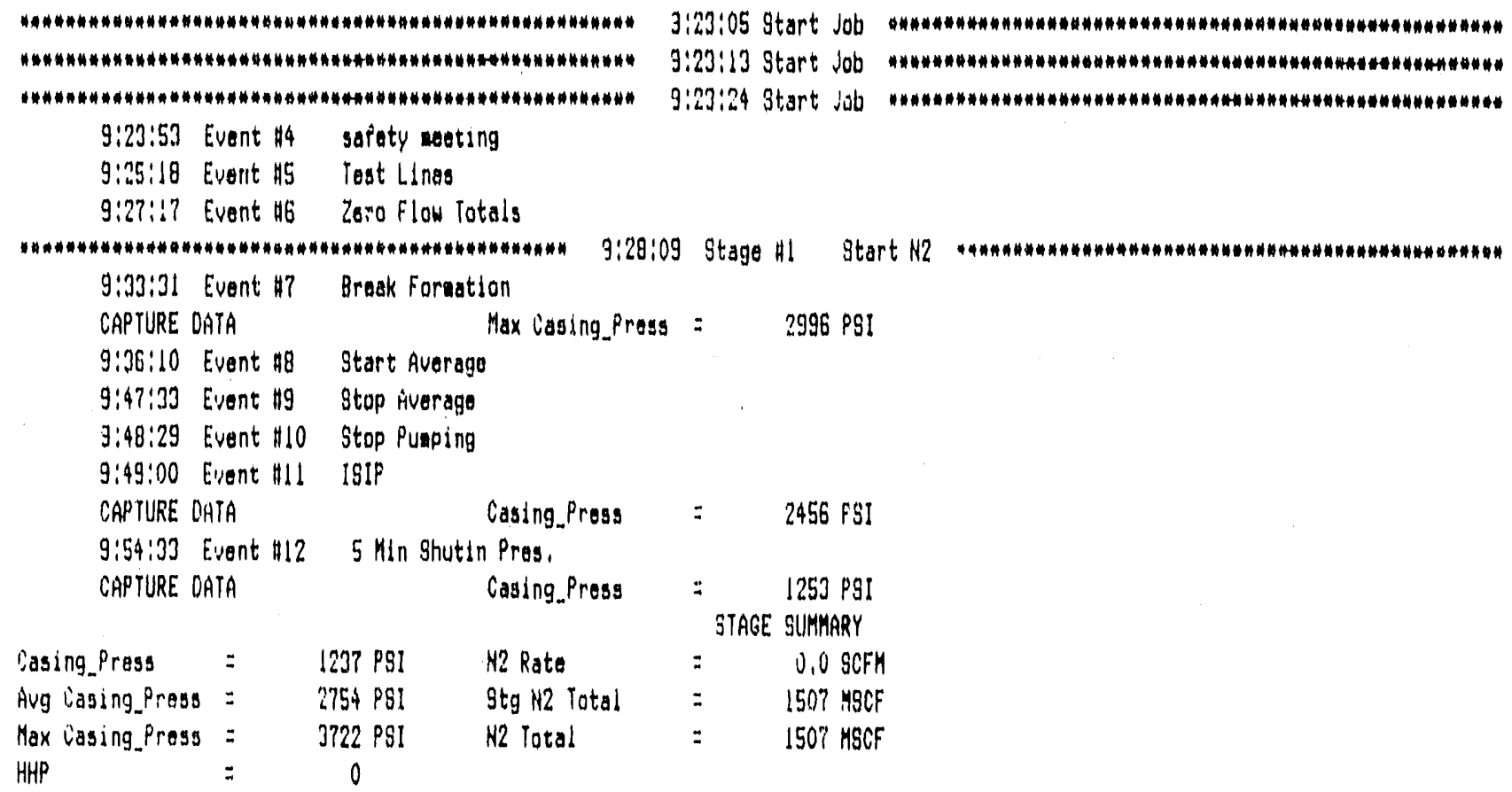

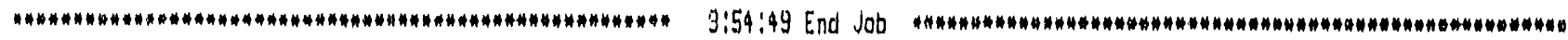
Aug N2,BH Pata = 38804.8 SCFH Aug Casing,Press $=3608$ PG! Hivg HHP $=804$ Job Comments: 
GAS ANALYTICAL SERVICES, INC

P.O. BOX 1028

BRIDGEEORT, WV 26330

\section{APPENDIX - 1}

CUSTOMER NAME:CNGP/BDM

STATION NO/NAME:BENNET 3997
CYLINDER NO.:142

SAMPLE DATE: 10/7/91

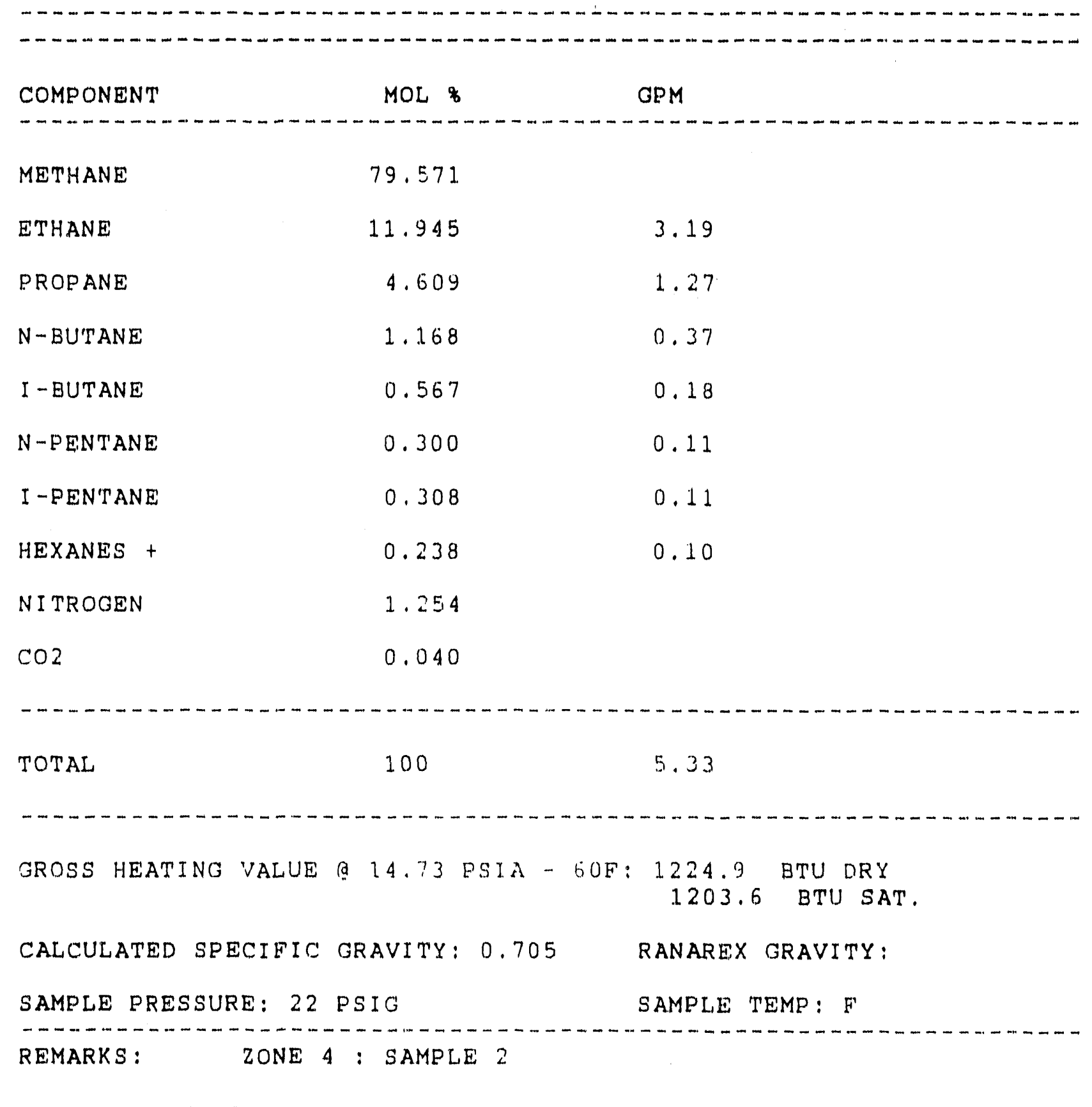


GAS ANALYTICAL SERVICES, INC

P.O. BOX 1028

BRIDGEPORT, WV 26330

$(304) \quad 623-0020$

FRACTIONAL ANALYSIS

CUSTOMER NAME:CNGP/BDM

CYLINDER NO.:48

STATION NO/NAME:BENNET 3997

SAMPLE DATE: $10 / 17 / 91$

$\begin{array}{lcl}\text { COMPONENT } & \text { MOL } & 3.19 \\ \text { ETHANE } & 79.919 & 1.21 \\ \text { PROPANE } & 11.944 & 0.34 \\ \text { N-EUTANE } & 4.415 & 0.18 \\ \text { I-BUTANE } & 1.089 & 0.09 \\ \text { N-PENTANE } & 0.548 & 0.12 \\ \text { I-PENTANE } & 0.240 & 0.10 \\ \text { HEXANES }+ & 0.227 & \\ \text { NITROGEN } & 1.266 & \\ \text { CO2 } & 0.030 & \end{array}$

TOTAL,

100

5.22

GROSS HEATING VALUE a 14.73 PGIA - 60F: 1218.0 BTU DRY

1196.8 BTU SAT.

CALCULATED SPECIFIC GRAVITY: 0.701 RANAREX GRAVITY:

SAMPLE PRESSURE: 22 PSIG

SAMPLE TEMP: F

\section{REMARKS :}




\section{APPENDIX J}

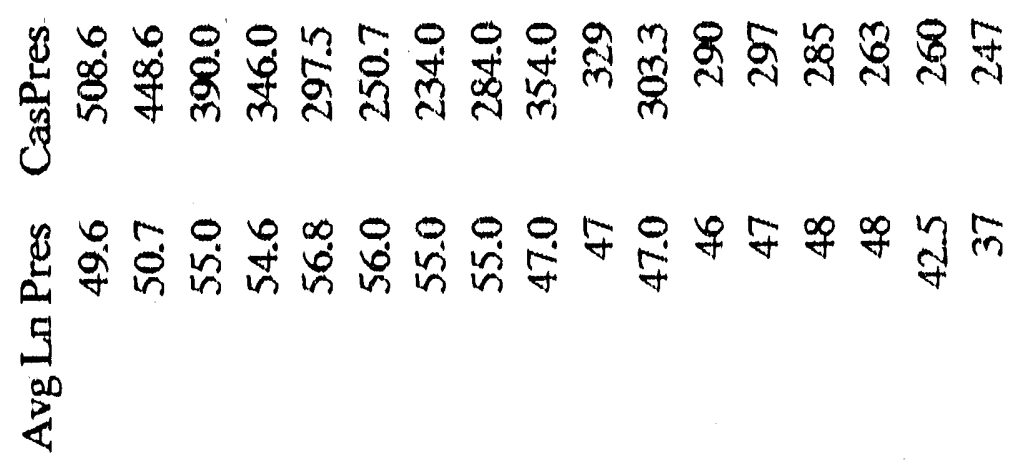

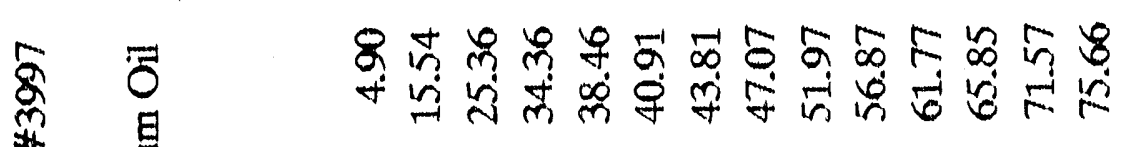

焉

$E$

$\sum_{[1}^{2}$

$\frac{11}{\infty} \frac{n}{0}$

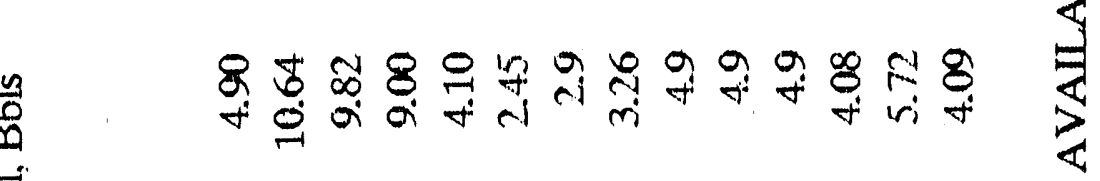

II

$\sum_{2}^{0}$

$\stackrel{\infty}{1} \quad 0$

$\$$

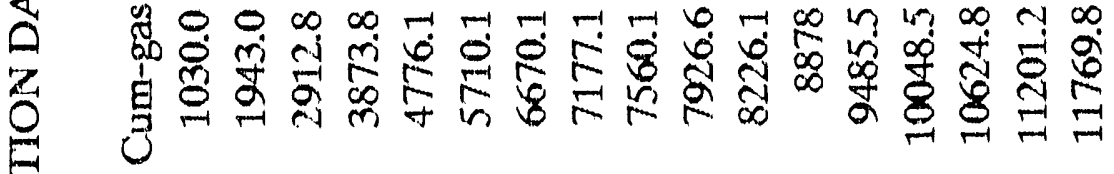

$\exists$ 年

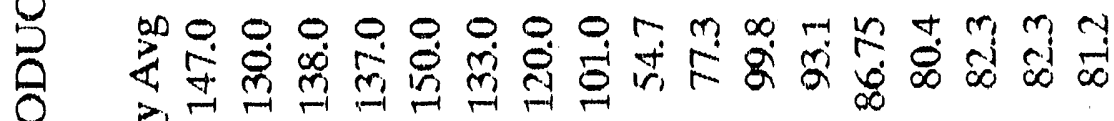
A

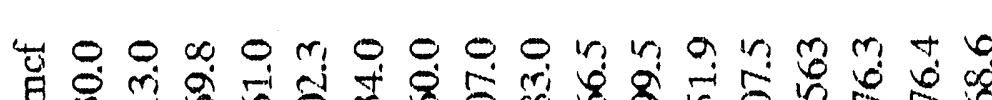

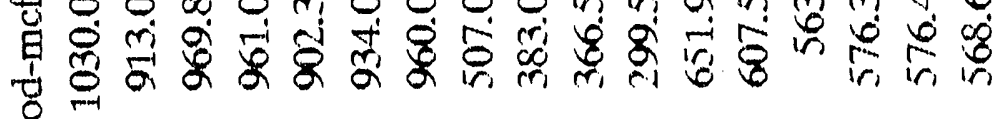

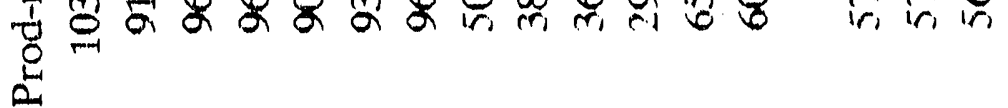

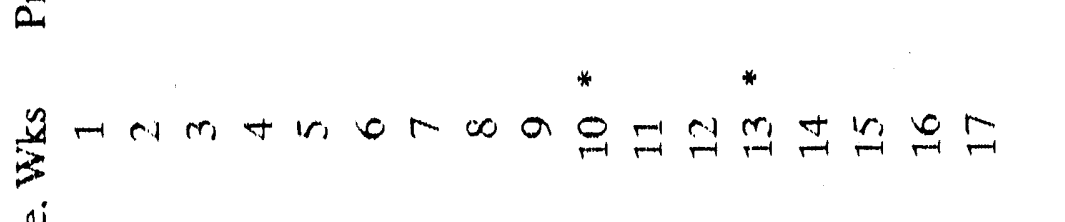




\section{Isd' $\exists$ IUSS $\exists y d$ פNIS $\forall 0$}

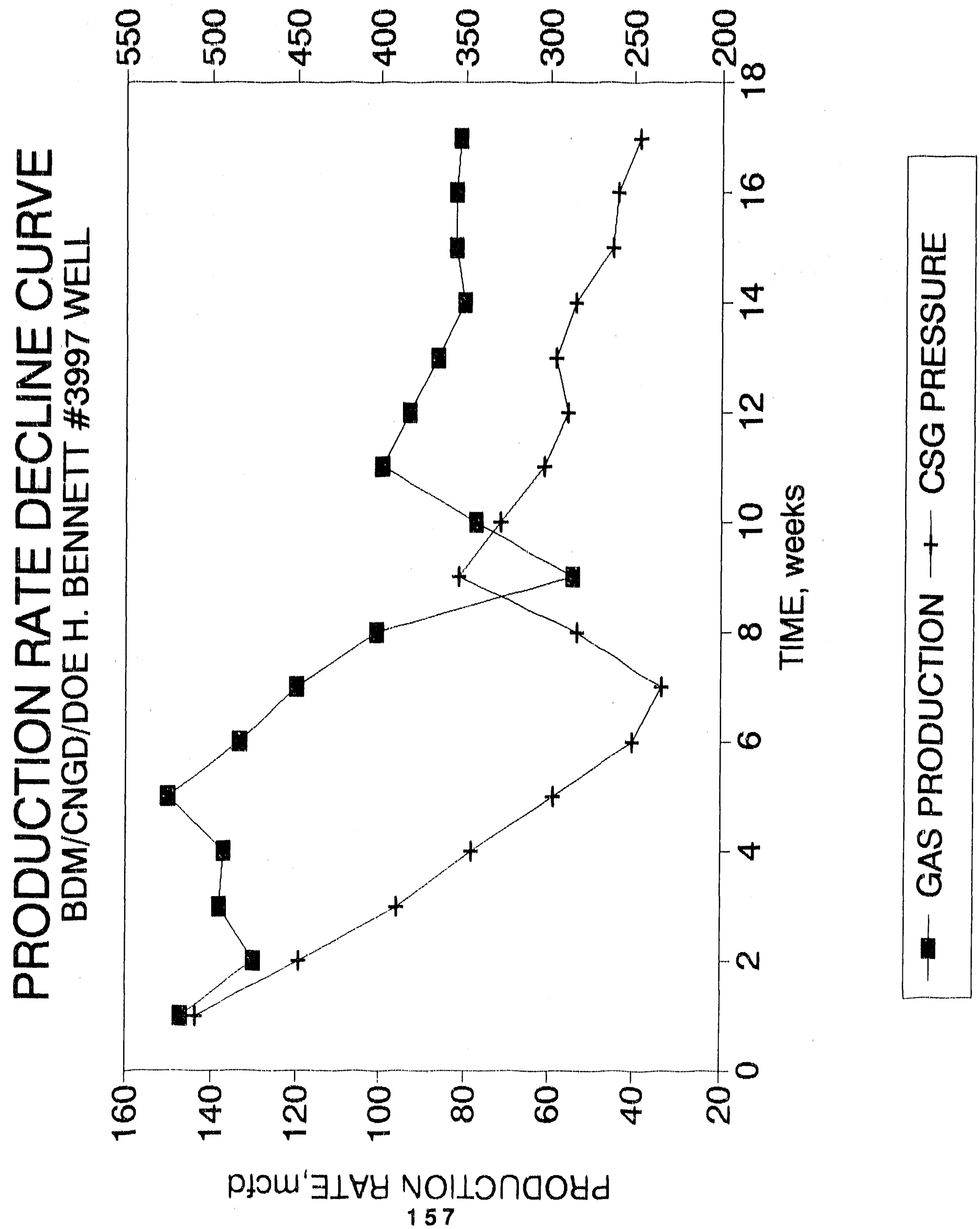




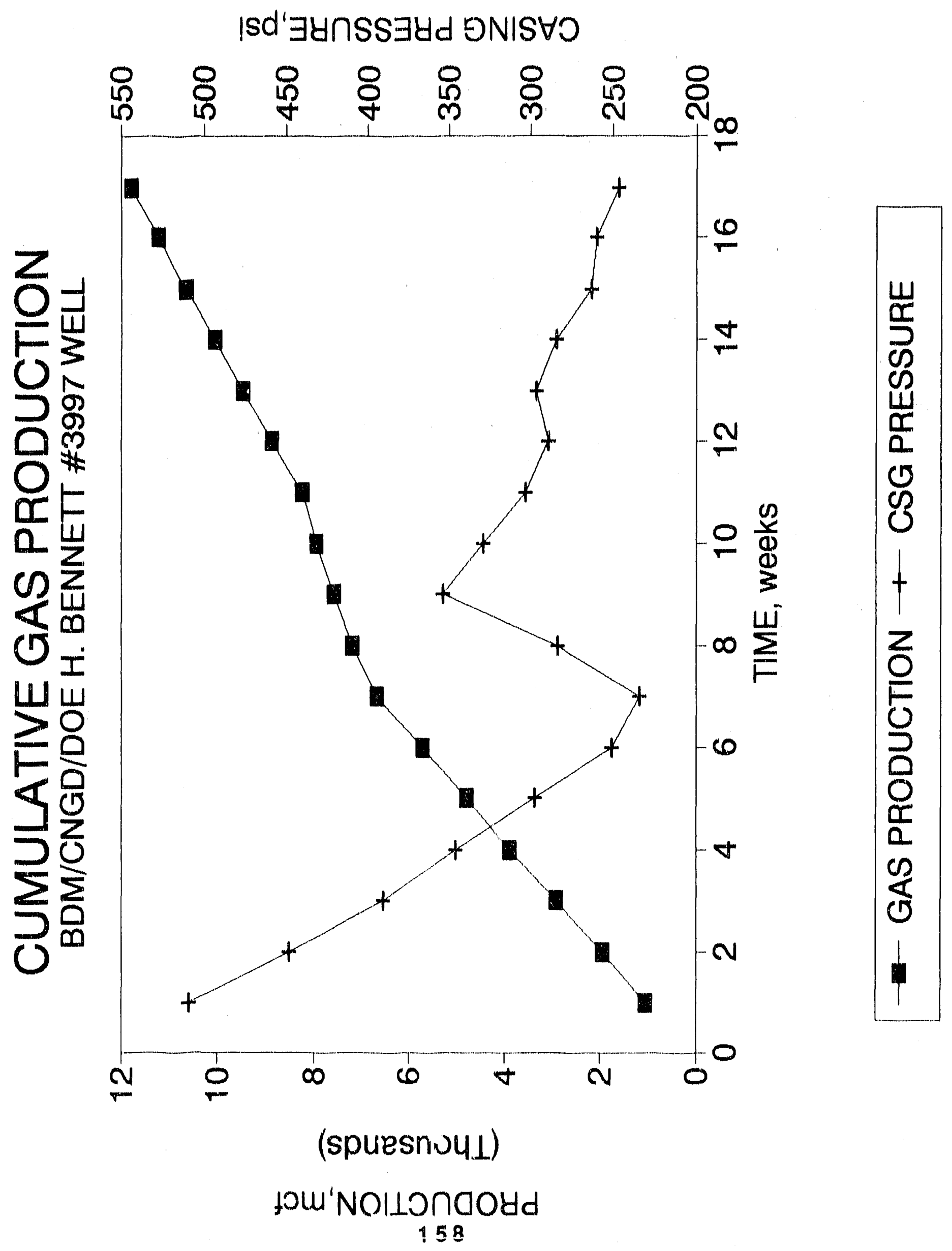




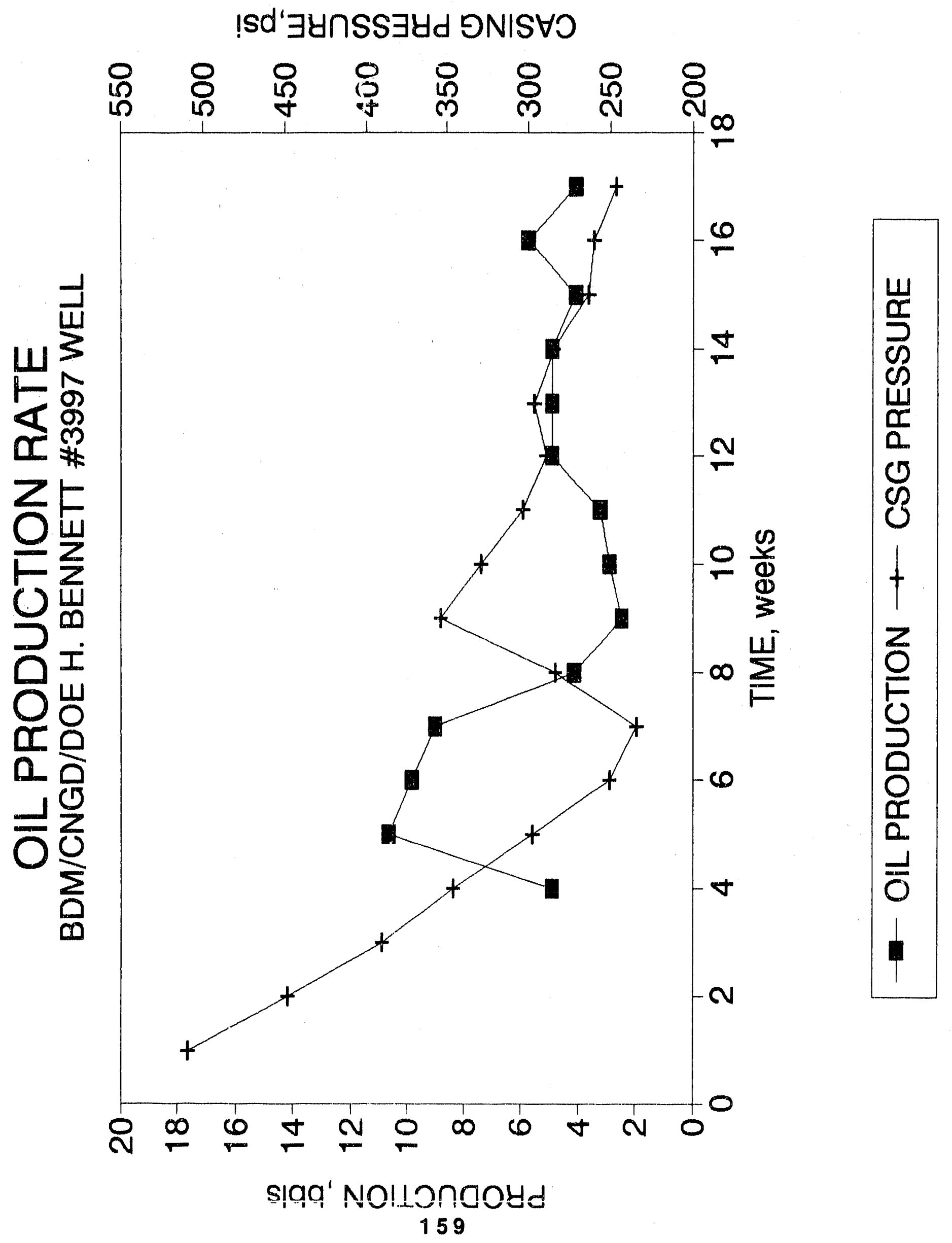


!sd' $\exists$ IUSS $\exists$ Y
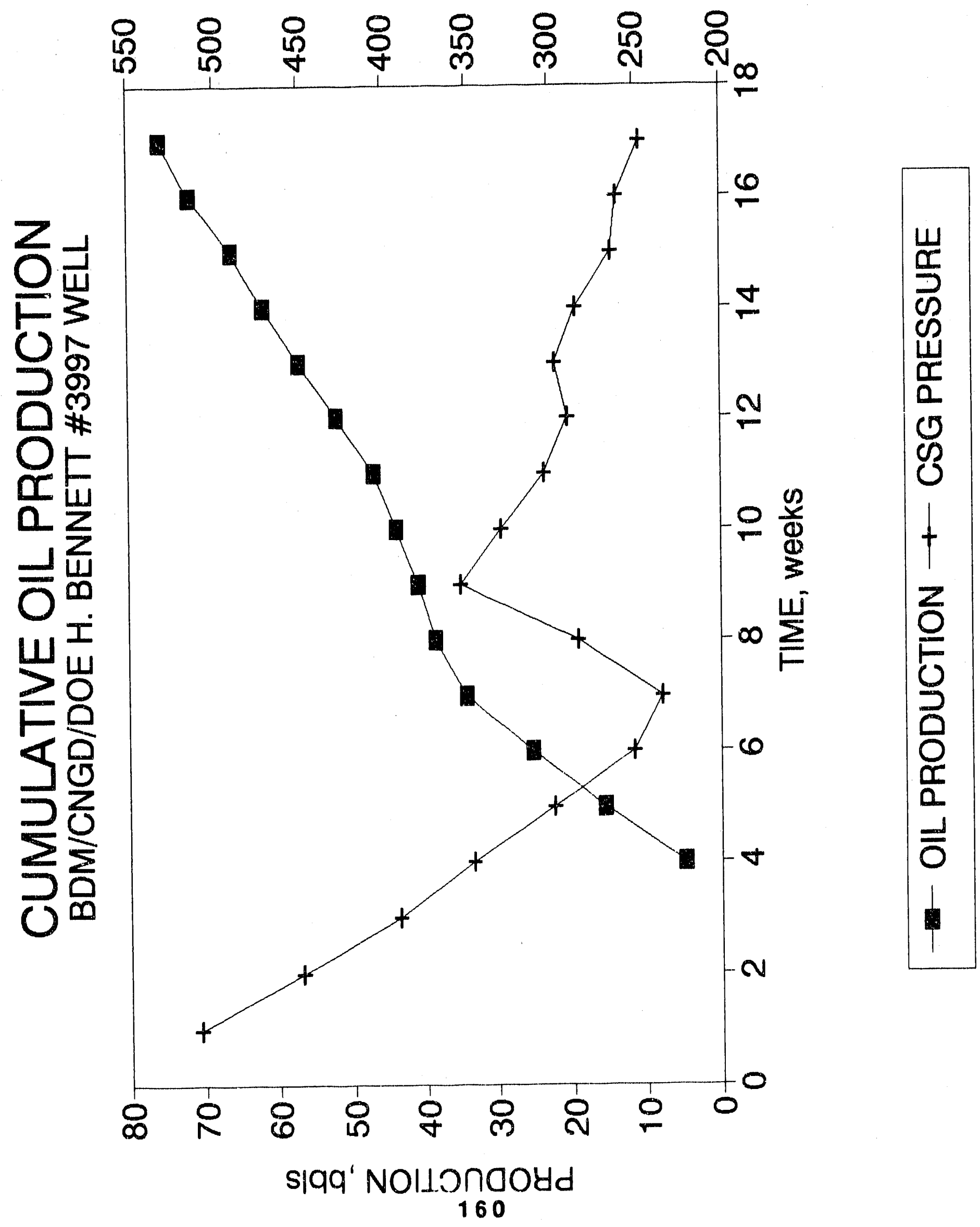

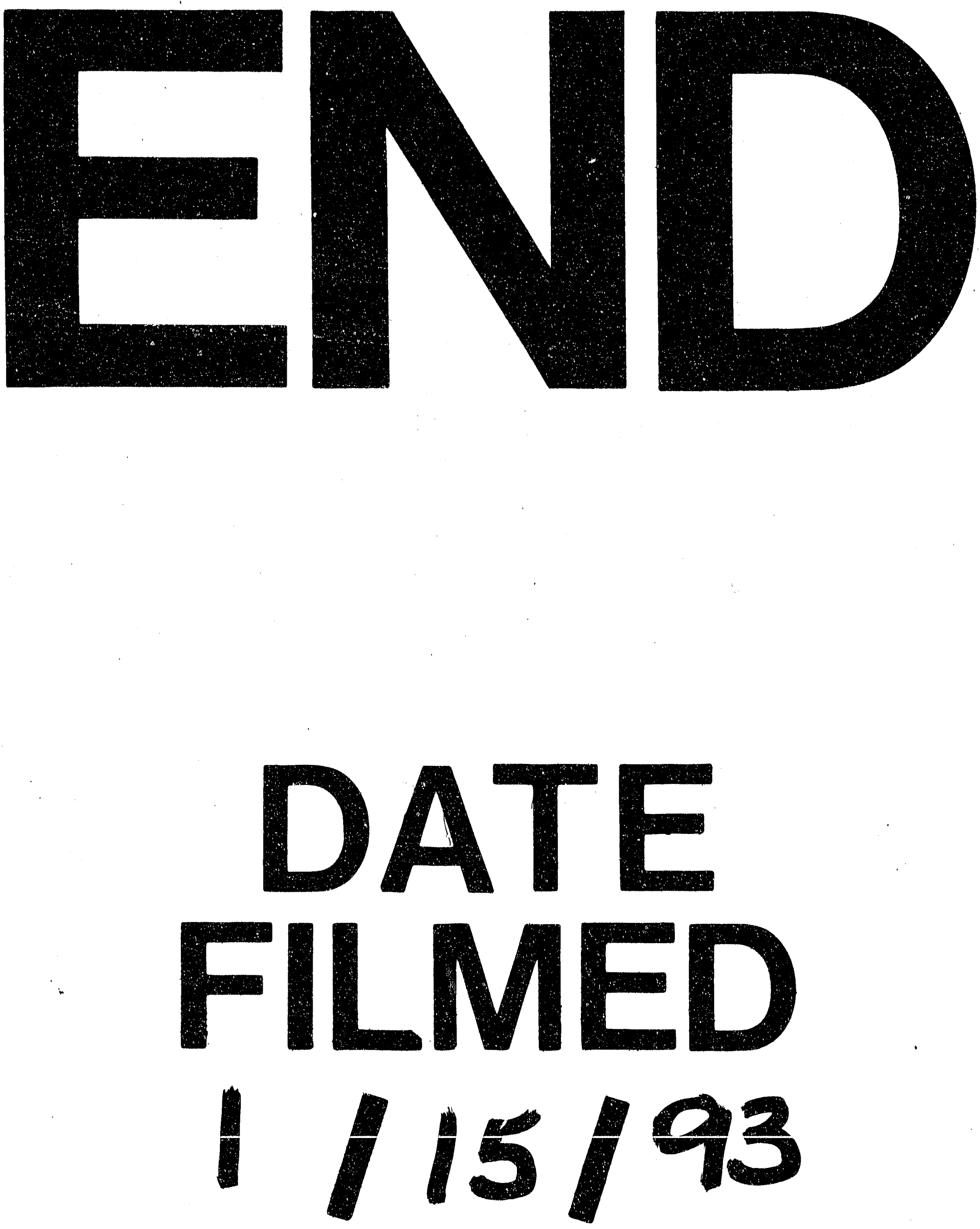

童 
产

$=$

言 